UNIVERSIDADE DE SÃO PAULO

INSTITUTO DE GEOCIÊNCIAS

\title{
APLICAÇÃO DE MÉTODOS GEOESTATÍSTICOS NO ESTUDO DAS DISTRIBUIÇÕES ESPACIAIS DE CONDUTIVIDADE HIDRÁULICA EM ÁREAS DO SISTEMA AQUÍFERO GUARANI (SAG) E DO SISTEMA AQUÍFERO BAURU (SAB) NO ESTADO DE SÃO PAULO
}

Vitor Ribeiro de Sá

Orientadora: Prof. ${ }^{a}$ Dr. ${ }^{a}$ Alexandra Vieira Suhogusoff

DISSERTAÇÃO DE MESTRADO

Programa de Pós-Graduação em Recursos Minerais e Hidrogeologia

Versão Corrigida

São Paulo 
UNIVERSIDADE DE SÃO PAULO

INSTITUTO DE GEOCIÊNCIAS

\section{APLICAÇÃO DE MÉTODOS GEOESTATÍSTICOS NO ESTUDO DAS DISTRIBUIÇÕES ESPACIAIS DE CONDUTIVIDADE HIDRÁULICA EM ÁREAS DO SISTEMA AQUÍFERO GUARANI (SAG) E DO SISTEMA AQUÍFERO BAURU (SAB) NO ESTADO DE SÃO PAULO}

Vitor Ribeiro de Sá

Orientadora: Prof. ${ }^{a}$ Dr. ${ }^{a}$ Alexandra Vieira Suhogusoff

$$
\text { DISSERTAÇÃO DE MESTRADO }
$$

Programa de Pós-Graduação em Recursos Minerais e Hidrogeologia

Versão Corrigida

São Paulo

2016 
Autorizo a reprodução e divulgação total ou parcial deste trabalho, por qualquer meio convencional ou eletrônico, para fins de estudo e pesquisa, desde que citada a fonte.

Ficha catalográfica preparada pelo Serviço de Biblioteca e Documentação do Instituto de Geociências da Universidade de São Paulo

Sá, Vitor Ribeiro de

Aplicação de métodos geoestatísticos no estudo das distribuições espaciais de condutividade hidráulica em áreas do Sistema Aquífero Guarani (SAG) e do Sistema Aquífero Bauru (SAB) no estado de São Paulo, Brasil. / Vitor Ribeiro de Sá. - São Paulo, 2016. 197 p.: il.

Dissertação (Mestrado) : IGc/USP

Orient.: Suhogusoff, Alexandra Vieira

1. Condutividade hidráulica 2. Geoestatística 3. Sistema Aquífero Guarani 4. Sistema Aquífero Bauru I. Título 
Dedico às mulheres da minha vida

Cidinha (minha mãe), Tia Anastácia, Vó Maria e Carol (Namorada) 
"In a dark place we find ourselves, and a little more knowledge lights our way."

("Em um lugar escuro encontramos nós mesmos, e um pouco mais de conhecimento ilumina nosso caminho.") 


\section{AGRADECIMENTOS}

À Prof. a Dr. ${ }^{a}$ Alexandra Vieira Suhogusoff, pela colaboração, presteza, amizade e paciência na orientação desse trabalho.

À CAPES, pelo apoio financeiro.

Ao físico e consultor Luiz Ferrari, por todo imprescindível suporte dado ao longo de todo o mestrado.

Ao DAEE-São Paulo e DAEE- Araraquara, em especial ao Eng. ${ }^{\circ}$ Reinaldo de Jesus Passerini, aos Geo. José Luiz Galvão de Mendonça, Gustavo Lopes. Paula Spinelli, Sérgio Torres, Luiz Aragaki, Regina Bragança e Leila de Carvalho Gomes pela inestimável colaboração no acesso e levantamento de dados.

À Cláudia Varnier do Instituto Geológico (IG-SMA), por fornecer valioso dados.

À empresa UNIPER, em espacial Julia Iriyama, Ricardo Konishi e André Aragoni, por cederem informações de poços nas áreas de interesse.

À Ingo Wahnfried da UFAM, pelas dicas prestadas no início desse mestrado.

Aos funcionários do Instituto de Geociências da universidade de São Paulo, que sempre foram muito solícitos.

Aos colegas e amigos da sala 105-LIG do Instituto de Geociências-USP, em especial Sidney, Eduardo (Consolo), Gustavo (Bolovo), Antônio, Marcelo (Dadinho), Carlos Carrasco e Santiago (Doideira), pelo apoio, conhecimento e amizade prestado durante esse tempo de convívio.

Aos professores e amigos Marcelo Rocha e Jorge Kazuo Yamamoto, pela ajuda em todos os momentos e por cederem um pouco do conhecimento. Grande parte desse trabalho não seria possível sem a ajuda de vocês.

Aos familiares e amigos que sempre me apoiaram, incentivaram ou simplesmente me ouviram. Agradeço em especial, minha mãe (Sandra, carinhosamente chamada de Cidinha), Tia Anastácia, Vó Maria, meu pai (Joel, carinhosamente chamado de Jô) e Carol (namorada, amiga e companheira de todas as horas). 


\section{RESUMO}

SÁ, Vitor Ribeiro de. (2016). Aplicação de Métodos Geoestatísticos no Estudo das Distribuições Espaciais de Condutividade Hidráulica em Áreas do Sistema Aquífero Guarani (SAG) e do Sistema Aquífero Bauru (SAB) no Estado de São Paulo, Brasil. Dissertação (mestrado). Instituto de Geociências, Universidade de São Paulo, São Paulo.

A condutividade hidráulica $(\mathrm{K})$ é um dos parâmetros controladores da magnitude da velocidade da água subterrânea, e consequentemente, é um dos mais importantes parâmetros que afetam o fluxo subterrâneo e o transporte de solutos, sendo de suma importância o conhecimento da distribuição de K. Esse trabalho visa estimar valores de condutividade hidráulica em duas áreas distintas, uma no Sistema Aquífero Guarani (SAG) e outra no Sistema Aquífero Bauru (SAB) por meio de três técnicas geoestatísticas: krigagem ordinária, cokrigagem e simulação condicional por bandas rotativas. Para aumentar a base de dados de valores de K, há um tratamento estatístico dos dados conhecidos. O método de interpolação matemática (krigagem ordinária) e o estocástico (simulação condicional por bandas rotativas) são aplicados para estimar os valores de $\mathrm{K}$ diretamente, enquanto que os métodos de krigagem ordinária combinada com regressão linear e cokrigagem permitem incorporar valores de capacidade específica $(\mathrm{Q} / \mathrm{s})$ como variável secundária. Adicionalmente, a cada método geoestatístico foi aplicada a técnica de desagrupamento por célula para comparar a sua capacidade de melhorar a performance dos métodos, o que pode ser avaliado por meio da validação cruzada. Os resultados dessas abordagens geoestatísticas indicam que os métodos de simulação condicional por bandas rotativas com a técnica de desagrupamento e de krigagem ordinária combinada com regressão linear sem a técnica de desagrupamento são os mais adequados para as áreas do SAG (rho=0.55) e do SAB (rho=0.44), respectivamente. O tratamento estatístico e a técnica de desagrupamento usados nesse trabalho revelaram-se úteis ferramentas auxiliares para os métodos geoestatísticos.

Palavras-chave: Condutividade hidráulica; Geoestatística; Sistema Aquífero Guarani; Sistema Aquífero Bauru 


\section{ABSTRACT}

SÁ, Vitor Ribeiro de. (2016). Application of Geostatistical Methods in the Study of Spatial Distribution of Hydraulic Conductivity at Areas of Guarani Aquifer System (GAS) and Bauru Aquifer System (BAS) in State of São Paulo, Brazil. Master's Thesis. Instituto de Geociências, Universidade de São Paulo, São Paulo.

Hydraulic conductivity $(\mathrm{K})$ is one of the parameters controlling magnitude of the groundwater velocity, and consequently, is one of the most important parameters affecting groundwater flow and solute transport. This study aims to estimate hydraulic conductivity values for two distinct areas, one in the Guarani Aquifer System (GAS) and the other in Bauru Aquifer System (BAS) through three geostatistical methods: ordinary kriging, cokriging and conditional simulation by turning bands. Carrying out statistic treatment of the available data in order to increase the database. The mathematical interpolation method (ordinary kriging) and the stochastic one (conditional simulation by turning bands) are applied to estimate directly the K values, while the methods of ordinary kriging combined with linear regression and cokriging allow to incorporate specific capacity $(\mathrm{Q} / \mathrm{s})$ values as a secondary variable. Moreover, the declustering by cells technique is applied for each geostatistical method to evaluate if there is improvement in their performance, which can be accessed by cross validation. The results of these geostatistical approaches indicate that the method of conditional simulation by turning bands with declustering technique is more suitable for GAS area (rho=0.55), whereas the ordinary kriging combined with linear regression method without this technique is for BAS area (rho=0.44). The statistical treatment and declustering technique undertaken in this study revealed to be useful tools for the application of geostatistical methods.

Key words: Hydraulic Conductivity; Geostatistics; Guarani Aquifer System; Bauru Aquifer System 


\section{LISTA DE FIGURAS}

Figura 1: Mapa de localização das áreas de estudo, com seus respectivos poços, representados pelos pontos. 26

Figura 2: Área do Sistema Aquífero Guarani (SAG). Modificado de Oliveira e Vieira (2010).

Figura 3: Mapa de Localização do Aquífero Bauru no Estado de São Paulo. Fonte: DAEE (2005).

Figura 4: Representação sobre o uso de coordenadas polares para descrever a posição de um ponto no plano, mostrando a distância $r$ da origem e o ângulo $\theta$ entre o eixo polar e a linha conectando o ponto e a origem. Adaptado de Fetter (1988).

Figura 5: Perfil ilustrativo do rebaixamento do nível d'água provocado por um poço que está bombeando. Adaptado de Waterloo Hydrogeologic (2015).

Figura 6: Método gráfico de superposição para a determinação da transmissividade (T) e do coeficiente de armazenamento (S) utilizando a metodologia de Theis. Adaptado de Fetter (1988).

Figura 7: Curvas teóricas de $\mathrm{W}(\mathrm{uA}, \mathrm{uB}, \Gamma)$ versus $1 / \mathrm{uA}$ e $1 / \mathrm{uB}$ para um aquífero livre. Fonte: Freeze e Cherry (1979).

Figura 8: Procedimento de Kolmogorov-Smirnov para testar a qualidade do ajuste da distribuição da amostra (linha tracejada) e modelo hipotético da população (linha contínua). Ambos são plotados de forma acumulativa de 0 a 1 . K-S representa a máxima diferença entre as distribuições.

Figura 9: Distribuição de t Student. Uma distribuição de probabilidade baseada nos números de observações.

Figura 10: Relações entre as funções variograma e covariograma, sendo $\gamma(\mathrm{h})$, o semivariograma e C(h), o covariograma. Fonte: Yamamoto e Rocha (2001).

Figura 11: Ilustração mostrando a direção do variograma, os passos, a tolerância angular, a largura máxima e a tolerância do passo. Fonte: Yamamoto, 2001 (modificado de Pannatier, 1994) 65

Figura 12: Variograma típico e seus elementos. Fonte: Yamamoto, 2001 66

Figura 13: Comportamento linear próximo à origem. 67

Figura 14: Localização de oito pontos mais próximos para arranjo aleatório (A) e semi-regular (B). Fonte: Yamamoto (2001). 
Figura 15: Representação de uma validação cruzada e sua reta de regressão. Fonte: Yamamoto (2001).

Figura 16: Exemplo de desagrupamento por células com 122 poços e 33 células para desagrupamento. Fonte: Deutsch, Frykman and Xie, (1999).

Figura 17: Ilustração do método de bandas rotativas em duas dimensões. Cada ponto simulado no plano é a média de todos os valores de linhas simuladas as quais as bandas de influência contém o ponto. Para simplificação, somente quatro linhas são usadas na figura. 87

Figura 18: Malha urbana e rural de São Carlos, onde estão inseridos os poços....................... 95

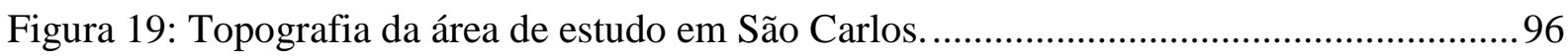

Figura 20: Mapa potenciométrico da área de estudo na cidade de São Carlos. ....................... 97

Figura 21: Mapa geológico da área de estudo na cidade de São Carlos, segundo a CPRM. Adaptado do mapa geológico do Estado de São Paulo, escala 1: 750.000, CPRM (2006)......98 Figura 22: Modelo geológico em três dimensões da área de interesse na cidade de São Carlos. Modelo desenvolvido com base nas informações das amostras descritas na construção dos poços

Figura 23: Mapa geológico da área de estudo na cidade de São Carlos baseado nas descrições litológicas dos poços de bombeamento estudados. As linhas representam os locais escolhidos para a confecção das seções geológicas.

Figura 24: Seções geológicas baseadas nas descrições litológicas dos poços de bombeamento estudados na cidade de São Carlos. As linhas tracejadas representam os limites inferidos...100 Figura 25: Malha urbana e rural de Bauru, onde estão inseridos os poços. ............................ 102 Figura 26: Topografia da área de estudo em Bauru. ............................................................... 103 Figura 27: Mapa potenciométrico da área de estudo na cidade de Bauru ............................... 104 Figura 28: Mapa geológico da área de estudo na cidade de Bauru. Adaptado do mapa geológico do Estado de São Paulo, escala 1: 750.000, CPRM (2006). 105

Figura 29: Modelo geológico em três dimensões da área de interesse na cidade de Bauru. Modelo desenvolvido com base nas informações das amostras descritas na construção dos poços. 106

Figura 30: Mapa geológico da área de estudo na cidade de Bauru baseado nas descrições litológicas dos poços de bombeamento estudados. As linhas representam os locais escolhidos para a confecção das seções geológicas.

Figura 31: Seções geológicas baseadas nas descrições litológicas dos poços de bombeamento estudados na cidade de São Carlos. As linhas tracejadas representam os limites inferidos... 107 
Figura 32: Histogramas dos valores de capacidade específica $(\mathrm{Q} / \mathrm{s})$ e condutividade hidráulica dos poços instalados no Sistema Aquífero Guarani (SAG) e Sistema Aquífero Bauru (SAB).

Figura 33: Representação gráfica da relação empírica ente $\log (\mathrm{Q} / \mathrm{s})$ e $\log (\mathrm{K})$ com a reta ajustada por regressão linear de primeira ordem no SAG.

Figura 34: Representação gráfica da relação empírica ente $\log (\mathrm{Q} / \mathrm{s})$ e $\log (\mathrm{K})$ com a reta ajustada por regressão linear de primeira ordem no SAB.

Figura 35: Representação gráfica da relação empírica ente $\log (\mathrm{Q} / \mathrm{s})$ e $\log (\mathrm{K})$ com a reta ajustada por regressão linear de primeira ordem no SAB.

Figura 36: Krigagem ordinária: variogramas modelados sem e com aplicação da técnica de desagrupamento por célula da área de estudo de São Carlos (SAG). A linha tracejada representa a variância amostral.

Figura 37: Krigagem ordinária: validação cruzada e histogramas de erros padronizados sem e com aplicação da técnica de desagrupamento por célula da área de estudo de São Carlos (SAG).

Figura 38: Krigagem ordinária: mapas das estimativas e da incerteza das estimativas de $\log \mathrm{K}$ associados ao método sem e com aplicação da técnica de desagrupamento por célula da área de estudo de São Carlos (SAG).

Figura 39: Krigagem ordinária: histogramas das estimativas e da incerteza das estimativas de $\log \mathrm{K}$ associados ao método sem e com aplicação da técnica de desagrupamento por célula da área de estudo de São Carlos (SAG).

Figura 40: Krigagem ordinária: mapas e histogramas das estimativas de K sem e com aplicação da técnica de desagrupamento por célula da área de estudo de São Carlos (SAG).

Figura 41: Krigagem ordinária combinada com regressão linear: Distribuição dos poços que apresentam valores de condutividade hidráulica $(K)$ e capacidade específica $(Q / s)$, em São Carlos (SAG). 122

Figura 42: Krigagem ordinária combinada com regressão linear: variogramas modelados sem e com aplicação da técnica de desagrupamento por célula da área de estudo de São Carlos (SAG). A linha tracejada representa a variância amostral.

Figura 43: Krigagem ordinária combinada com regressão linear: validação cruzada e histograma de erros padronizados sem e com aplicação da técnica de desagrupamento por célula da área de estudo de São Carlos (SAG). 
Figura 44: Krigagem ordinária combinada com regressão linear: mapas das estimativas e de incerteza associados ao método sem e com aplicação da técnica de desagrupamento por célula da área de estudo de São Carlos (SAG).

Figura 45: Krigagem ordinária combinada com regressão linear: Histogramas das estimativas e de incerteza associada ao método sem e com aplicação da técnica de desagrupamento ou Decluster por célula da área de estudo de São Carlos, SAG. 126

Figura 46: Krigagem ordinária combinada com regressão linear: Mapas e histogramas das estimativas sem e com aplicação da técnica de desagrupamento ou Decluster por célula da área de estudo de São Carlos, SAG.

Figura 47: Cokrigagem: Distribuição dos poços que apresentam valores de condutividade hidráulica $(K)$ e capacidade específica $(\mathrm{Q} / \mathrm{s})$ (pontos em verde) e apenas valores de $\mathrm{Q} / \mathrm{s}$ (pontos em preto) na cidade de São Carlos (SAG). 128

Figura 48: Cokrigagem: variogramas cruzados modelados sem e com aplicação da técnica de desagrupamento por célula da área de estudo de São Carlos (SAG). A linha tracejada representa a variância amostral.

Figura 49: Cokrigagem: validação cruzada e histogramas de erros padronizados sem e com aplicação da técnica de desagrupamento por célula da área de estudo de São Carlos (SAG).

Figura 50: Cokrigagem: mapas das estimativas e de incerteza associada ao método sem e com aplicação da técnica de desagrupamento por célula da área de estudo de São Carlos, SAG. 131 Figura 51: Cokrigagem: histogramas das estimativas e de incerteza associada ao método sem e com aplicação da técnica de desagrupamento por célula da área de estudo de São Carlos, SAG.

Figura 52: Cokrigagem: mapas e histogramas das estimativas sem e com aplicação da técnica de desagrupamento por célula da área de estudo de São Carlos, SAG. 132

Figura 53: Bandas Rotativas: variogramas modelados, após a transformada normal score, sem e com aplicação da técnica de desagrupamento por célula da área de estudo de São Carlos (SAG). A linha tracejada representa a variância amostral.

Figura 54: : Bandas Rotativas: Validação cruzada e histogramas de erros padronizados sem e com aplicação da técnica de desagrupamento por célula da área de estudo de São Carlos, SAG.

Figura 55: Bandas rotativas: mapas das estimativas e de incerteza associada ao método sem e com aplicação da técnica de desagrupamento por célula da área de estudo de São Carlos, SAG. 
Figura 56: : Bandas Rotativas: histogramas das estimativas e de incerteza associada ao método sem e com aplicação da técnica de desagrupamento por célula da área de estudo de São Carlos, SAG.

Figura 57: Bandas rotativas: mapas e histogramas das estimativas sem e com aplicação da técnica de desagrupamento por célula da área de estudo de São Carlos (SAG). 136 Figura 58: Mapas comparativos entre a distribuição dos valores estimados de condutividade hidráulica (A), pelo método de bandas rotativas, a geologia inferida com base nas descrições dos poços (B), topografia (C) e potenciométrico na área de interesse de São Carlos. Figura 59: Distribuição dos poços que apresentam informações sobre os valores de condutividade hidráulica $(K)$ e capacidade específica $(\mathrm{Q} / \mathrm{s})$ na cidade de Bauru.

Figura 60: Krigagem ordinária: variogramas modelados sem e com aplicação da técnica de desagrupamento por célula da área de estudo de Bauru, SAB. A linha tracejada representa a variância amostral. 141

Figura 61: Krigagem Ordinária: Validação cruzada e histogramas de erros padronizados sem e com aplicação da técnica de desagrupamento ou decluster por célula da área de estudo de Bauru, $\mathrm{SAB}$

Figura 62: Krigagem Ordinária: Mapas das estimativas e de incerteza associada ao método sem e com aplicação da técnica de desagrupamento por célula da área de estudo de Bauru, SAB.

Figura 63: Krigagem Ordinária: Histogramas das estimativas e de incerteza associada ao método sem e com aplicação da técnica de desagrupamento ou Decluster por célula da área de estudo de Bauru, SAB.

Figura 64: Krigagem ordinária: Mapas e histogramas das estimativas sem e com aplicação da técnica de desagrupamento por célula da área de estudo de Bauru, SAB.

Figura 65: Krigagem ordinária combinada com regressão linear: Distribuição dos poços que apresentam informações sobre os valores de condutividade hidráulica $(K)$ e capacidade específica $(\mathrm{Q} / \mathrm{s})$ em Bauru. 146

Figura 66: Krigagem Ordinária combinada com regressão linear: variogramas modelados sem e com aplicação da técnica de desagrupamento por célula da área de estudo de Bauru, SAB. A linha tracejada representa a variância amostral.

Figura 67: Krigagem Ordinária combinada com regressão linear: Validação cruzada e histogramas de erros padronizados sem e com aplicação da técnica de desagrupamento ou decluster por célula da área de estudo de Bauru, SAB. 148 
Figura 68: Krigagem ordinária combinada com regressão linear: mapas das estimativas e de incerteza associada ao método sem e com aplicação da técnica de desagrupamento por célula da área de estudo de Bauru, SAB.

Figura 69: Krigagem ordinária combinada com regressão linear: histogramas das estimativas e de incerteza associada ao método sem e com aplicação da técnica de desagrupamento por célula da área de estudo de Bauru, SAB.

Figura 70: Krigagem ordinária combinada com regressão linear: mapas e histogramas das estimativas sem e com aplicação da técnica de desagrupamento por célula da área de estudo de Bauru, SAB.

Figura 71: Cokrigagem: Distribuição dos poços que apresentam informações sobre os valores de condutividade hidráulica $(K)$ e capacidade específica $(\mathrm{Q} / \mathrm{s})$ em Bauru. 151

Figura 72: Cokrigagem: Variogramas cruzados modelados sem e com aplicação da técnica de desagrupamento ou Decluster por célula da área de estudo de Bauru, SAB. A linha tracejada representa a variância amostral.

Figura 73: Cokrigagem: Validação cruzada e histogramas de erros padronizados sem e com aplicação da técnica de desagrupamento ou decluster por célula da área de estudo de Bauru, SAB.

Figura 74: Cokrigagem: Mapas das estimativas e de incerteza associada ao método sem e com aplicação da técnica de desagrupamento ou Decluster por célula da área de estudo de Bauru, SAB.

Figura 75: Cokrigagem: Histogramas das estimativas e de incerteza associada ao método sem e com aplicação da técnica de desagrupamento ou Decluster por célula da área de estudo de Bauru, SAB.

Figura 76: Cokrigagem: Mapas e histogramas das estimativas sem e com aplicação da técnica de desagrupamento ou Decluster por célula da área de estudo de Bauru, SAB. 156

Figura 77: Bandas Rotativas: Variogramas modelados, após a transformada normal score, sem e com aplicação da técnica de desagrupamento por célula da área de estudo de Bauru, SAB. A linha tracejada representa a variância amostral.

Figura 78: Bandas Rotativas: Variogramas modelados, após a transformada normal score, sem e com aplicação da técnica de desagrupamento por célula da área de estudo de Bauru, SAB. A linha tracejada representa a variância amostral.

Figura 79: Bandas rotativas: mapas das estimativas e de incerteza associada ao método sem e com aplicação da técnica de desagrupamento por célula da área de estudo de Bauru, SAB. 159 
Figura 80: Bandas rotativas: histogramas das estimativas e de incerteza associada ao método sem e com aplicação da técnica de desagrupamento por célula da área de estudo de Bauru, SAB.

Figura 81: Bandas Rotativas: Mapas e histogramas das estimativas sem e com aplicação da técnica de desagrupamento por célula da área de estudo de Bauru, SAB. 160 Figura 82: Mapas comparativos entre a distribuição dos valores estimados de condutividade hidráulica (A), pelo método de bandas rotativas, a geologia inferida com base nas descrições dos poços (B), topografia (C) e potenciométrico na área de interesse de Bauru. 162 


\section{LISTA DE TABELAS}

Tabela 1: Propriedades geométricas e hidráulicas das Fms. Botucatu e Pirambóia. Fonte: Araújo et al. (1999).

Tabela 2: Descrição da coluna estratigráfica da Bacia do Paraná para as unidades de estudo. Adaptada de IPT (1981) e IPT (2003).

Tabela 3: Estatística descritiva e comparativa da profundidade, nível estático (NE), nível dinâmico (ND) dos poços que apresentam dados de Condutividade hidráulica e capacidade específica em São Carlos e Bauru.

Tabela 4: Estatística descritiva das capacidades específicas $(\mathrm{Q} / \mathrm{s})$ e condutividades hidráulicas (K) referentes aos poços estudados no SAG em geral, e mais especificamente São Carlos, e Bauru, que por sua vez representa o SAB 108

Tabela 5: Resultados dos testes de normalidade aferidos pelos métodos de KolmogorovSmirnov e Shapiro-Wilk para os poços estudados instalados em aquíferos livres no SAG. Para o método de Kolmogorov-Smirnov, adota-se o nível de significância p=0.05. 111

Tabela 6 Resultados dos testes de normalidade aferidos pelos métodos de Kolmogorov-Smirnov e Shapiro-Wilk para os poços estudados instalados em aquíferos semiconfinado no SAG. Para o método de Kolmogorov-Smirnov, adota-se o nível de significância $\mathrm{p}=0.05$.

Tabela 7: Resultados dos testes de normalidade aferidos pelos métodos de KolmogorovSmirnov e Shapiro-Wilk para os poços estudados instalados em aquíferos confinado no SAG. Para o método de Kolmogorov-Smirnov, adota-se o nível de significância $\mathrm{p}=0.05$.

Tabela 8: Resultados do teste de independência para os poços estudados instalados em aquíferos livre e semiconfinado no SAG.

Tabela 9: Valores dos elementos da equação da reta da regressão linear de primeira ordem para o SAG.

Tabela 10: Resultados dos testes de normalidade aferidos pelos métodos de KolmogorovSmirnov e Shapiro-Wilk para os poços estudados instalados em aquíferos semiconfinado no SAB. Para o método de Kolmogorov-Smirnov, adota-se o nível de significância $\mathrm{p}=0.05 \ldots 114$ Tabela 11: Valores dos elementos da equação da reta da regressão linear de primeira ordem para o SAB. 115

Tabela 12: Krigagem ordinária: estatística descritiva dos valores de log K sem e com decluster dos poços estudados na cidade de São Carlos (SAG). 
Tabela 13: Elementos do modelo do variograma para os dados sem e com o uso da técnica de desagrupamento.

Tabela 14: Krigagem ordinária combinada com regressão linear: estatística descritiva dos valores de $\log \mathrm{K}$ sem e com decluster dos poços estudados na cidade de São Carlos (SAG).

Tabela 15: Krigagem ordinária combinada com regressão linear: Elementos do modelo do variograma para os dados sem e com o uso da técnica de desagrupamento.

Tabela 16: Cokrigagem ordinária: estatística descritiva dos valores de log $\mathrm{K}$ sem e com decluster dos poços estudados na cidade de São Carlos (SAG)

Tabela 17: Cokrigagem: Elementos do modelo do variograma para os dados sem e com o uso de desagrupamento.

Tabela 18: Bandas rotativas: Elementos do modelo do variograma para os dados sem e com o uso de desagrupamento.

Tabela 19: Sumário dos resultados dos métodos geoestatísticos sem a aplicação da técnica de desagrupamento ou decluster por célula na área de interesse em São Carlos (SAG).

Tabela 20: Sumário dos resultados dos métodos geoestatísticos sem a aplicação da técnica de desagrupamento ou decluster por célula na área de interesse em São Carlos.

Tabela 21: Krigagem ordinária: estatística descritiva dos valores de log K sem e com decluster dos poços estudados na cidade de Bauru, SAB

Tabela 22: Krigagem ordinária: variogramas modelados sem e com aplicação da técnica de desagrupamento por célula da área de estudo de Bauru, SAB. A linha tracejada representa a variância amostral.

Tabela 23: Krigagem ordinária combinada com regressão linear: Estatística descritiva dos valores de $\log \mathrm{K}$ sem e com decluster dos poços estudados na cidade de Bauru, SAB. 146 Tabela 24: Elementos do modelo do variograma para os dados sem e com o uso da técnica de desagrupamento.

Tabela 25: Estatística descritiva dos valores de log $\mathrm{K}$ sem e com decluster dos poços estudados na cidade de Bauru, SAB.

Tabela 26: Elementos do modelo do variograma para os dados sem e com o uso da técnica de desagrupamento.

Tabela 27: Elementos do modelo do variograma para os dados sem e com o uso da técnica de desagrupamento.

Tabela 28: Informações dos poços instalado na área de interesse na cidade de Bauru. Na tabela são apresentadas as coordenadas em UTM (X e Y), a cota topográfica (Z), nível d'água estático 
(N.E.), nível d'água dinâmico (N.D.), capacidade específica e seu logaritmo $(\mathrm{Q} / \mathrm{s}$ e $\log \mathrm{Q} / \mathrm{s}$, respectivamente) e condutividade hidráulica e seu logaritmo ( $\mathrm{K}$ e $\log \mathrm{K}$, respectivamente) e o valor do logaritmo de condutividade hidráulica calculado pela equação 83 (log K calculado por regressão linear. “-“ significa que a informação não está disponível. 176 Tabela 29: Informações dos poços instalado na área de interesse na cidade de Bauru. Na tabela são apresentadas as coordenadas em UTM (X e Y), a cota topográfica (Z), nível d'água estático (N.E.), nível d'água dinâmico (N.D.), capacidade específica e seu logaritmo $(\mathrm{Q} / \mathrm{s}$ e $\log \mathrm{Q} / \mathrm{s}$, respectivamente) e condutividade hidráulica e seu logaritmo ( $\mathrm{K}$ e $\log \mathrm{K}$, respectivamente) e o valor do logaritmo de condutividade hidráulica calculado pela equação 85 (log K calculado por regressão linear. “_“" significa que a informação não está disponível. 


\section{SUMÁRIO}

RESUMO

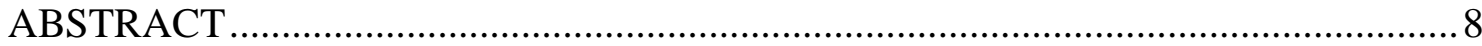

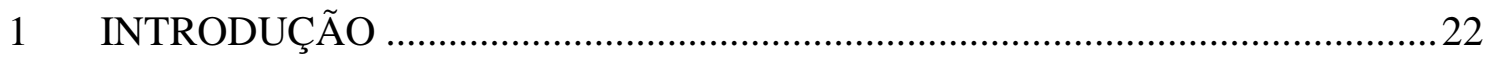

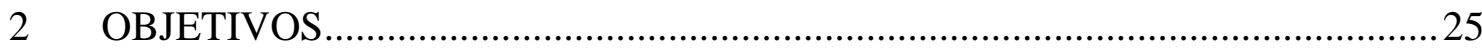

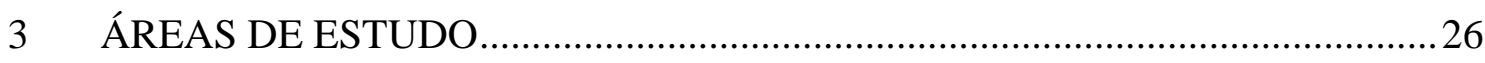

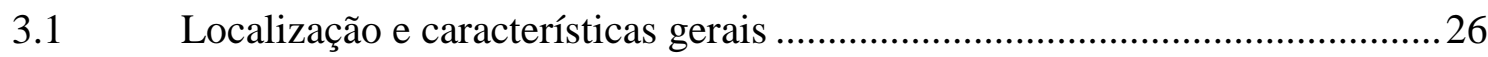

3.1.1 Sistemas Aquíferos do Estado de São Paulo..........................................2 27

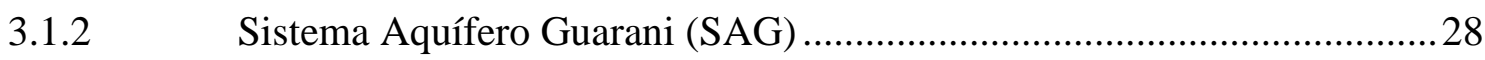

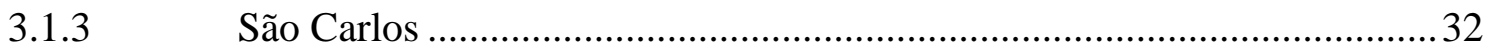

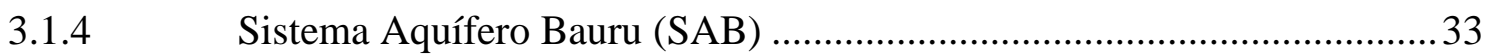

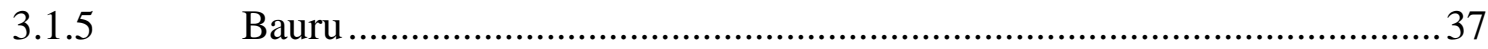

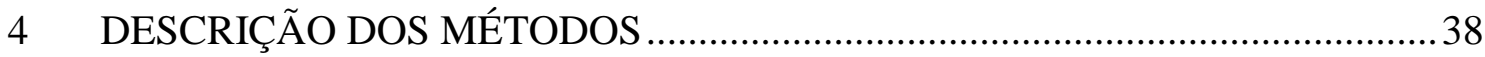

4.1 Métodos de Interpretação de Testes Hidráulicos em Aquíferos ......................38

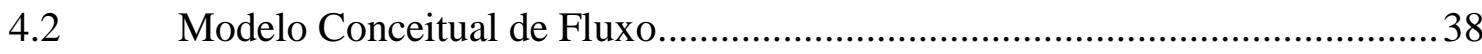

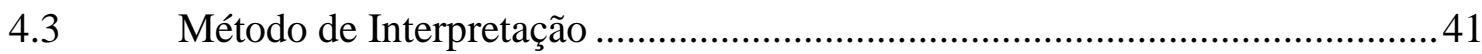

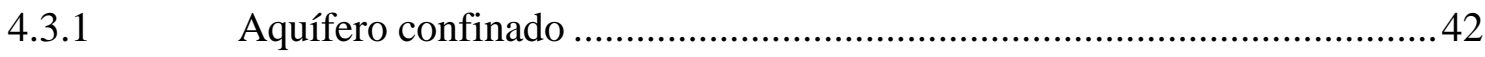

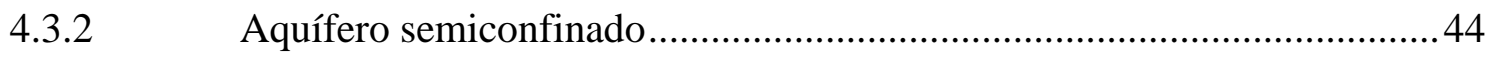

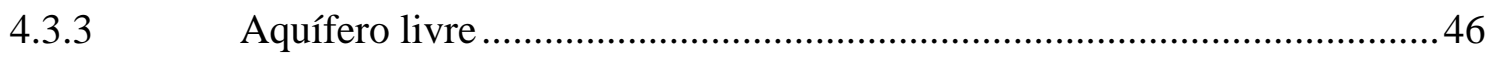

4.4 Parâmetros Hidráulicos e Erros Associados ................................................ 48

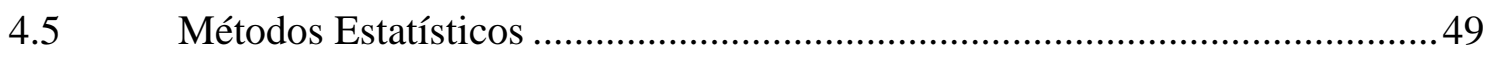

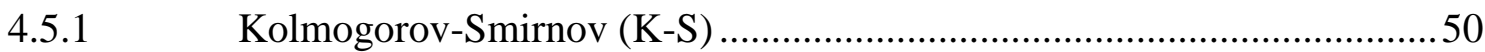

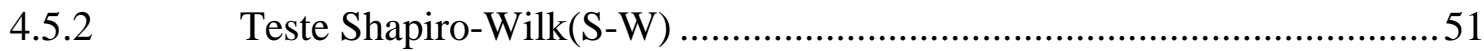

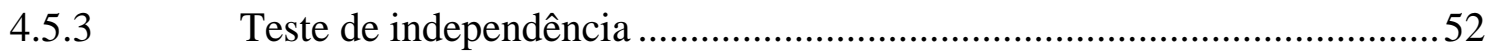

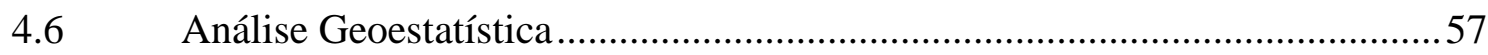

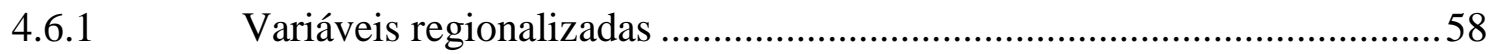

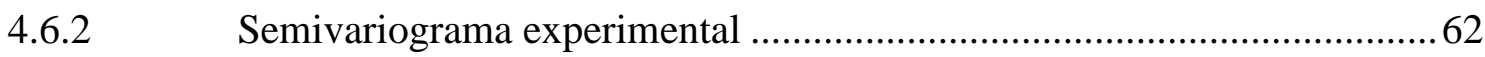




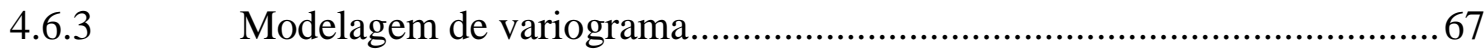

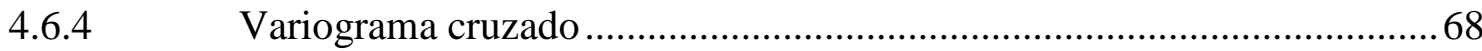

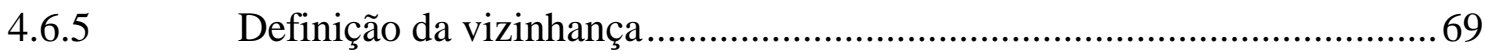

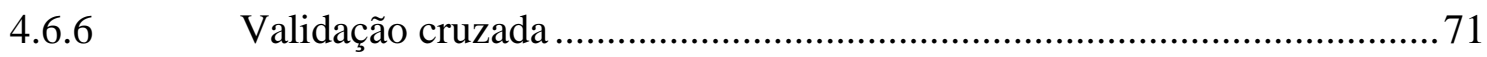

4.6.7 Desagrupamento ou Declustering …..................................................... 72

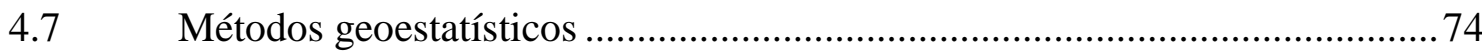

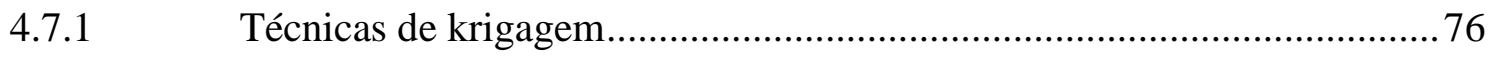

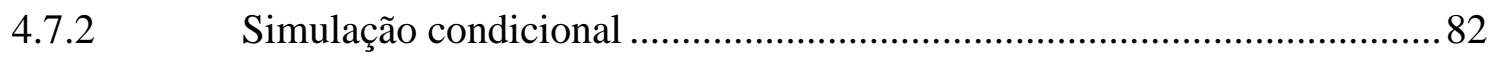

4.8 Outros métodos de interpolação utilizados ................................................ 88

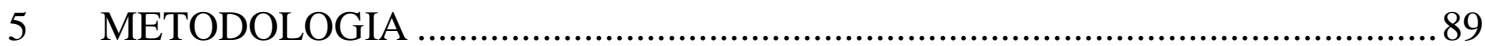

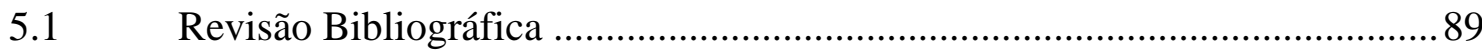

5.2 Aquisição e Elaboração do Banco de Dados ................................................... 89

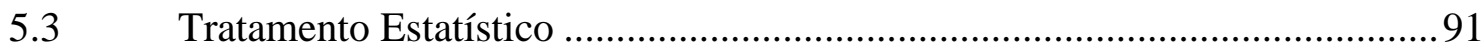

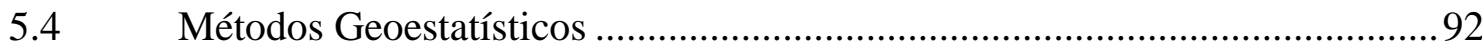

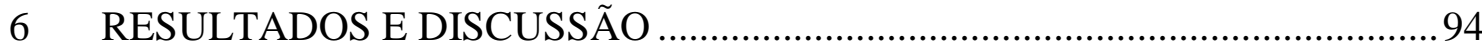

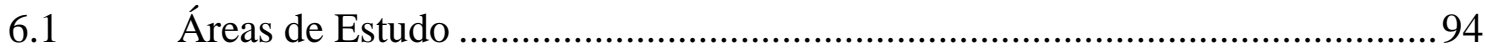

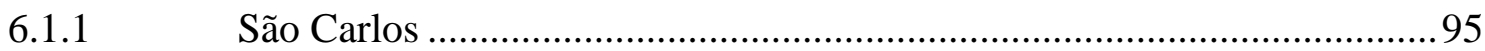

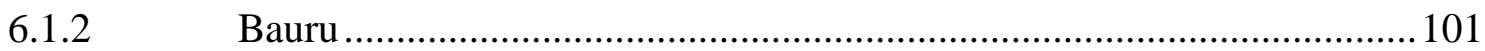

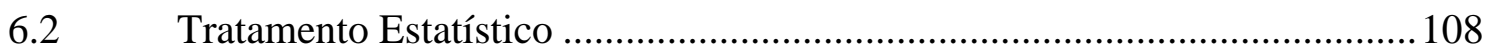

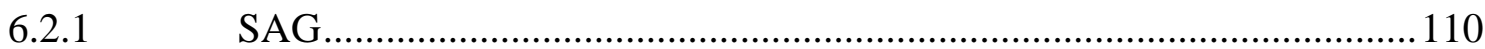

6.2.2 $\quad$ SAB

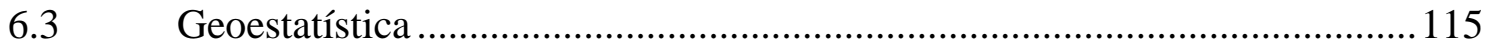

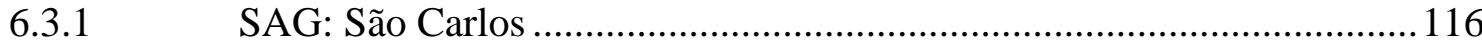

6.3.2 Estudos comparativo dos métodos geoestatísticos aplicados em São Carlos (SAG) $\quad 136$

6.3.3 SAB: Bauru 140

6.3.4 Estudo Comparativo dos métodos geoestatísticos aplicados em Bauru $(\mathrm{SAB}) \quad 160$ 


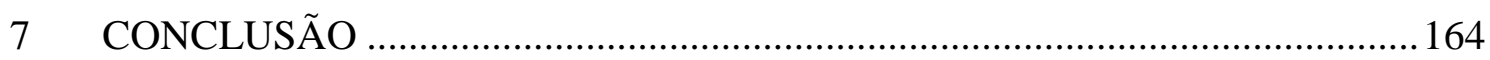

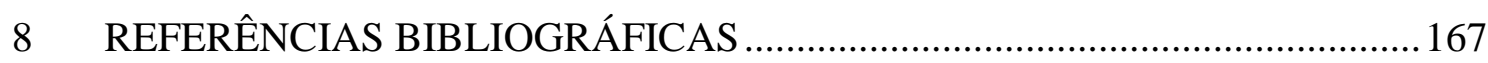

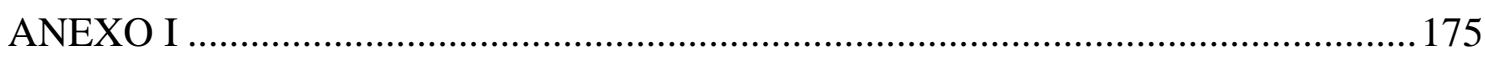

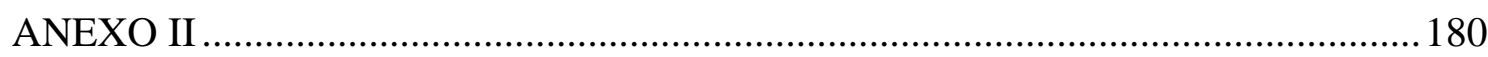




\section{INTRODUÇÃO}

O Sistema Aquífero Guarani (SAG) e o Sistema Aquífero Bauru (SAB) são responsáveis pelo abastecimento total ou parcial de aproximadamente seis milhões de pessoas no Estado de São Paulo (Brasil) através de poços públicos e privados de bombeamento (DAEE, 2005). Na maioria dos casos, os registros disponibilizados sobre os poços apresentam ausência de informações sobre os parâmetros hidráulicos dos aquíferos explorados. Um desses parâmetros muitas vezes negligenciado é a condutividade hidráulica (K) que pode ser entendida como o parâmetro hidráulico que quantifica a facilidade com que a água passa pelo meio poroso, sendo um dos parâmetros que controlam a magnitude da velocidade da água subterrânea. Ainda, é um dos mais importantes parâmetros que afetam o fluxo subterrâneo e o transporte de contaminantes. O seu entendimento é crucial para qualquer estudo que anseie abordar a hidrogeologia de uma área ou região de interesse, desde tomadas de decisões quando se deseja instalar poços com maior produtividade a fornecer dados para o desenvolvimento de modelos hidrogeológicos. Técnicas estatísticas e geoestatísticas são aplicadas nesse trabalho para estimar valores de condutividade hidráulica em porções do aquífero onde esse parâmetro é desconhecido. A capacidade específica $(\mathrm{Q} / \mathrm{s})$ é um parâmetro hidráulico abundante nos bancos de dados dos poços e é usado nesse trabalho para aumentar os valores conhecidos de $\mathrm{K}$ por meio dessas técnicas, através da relação empírica ou por cokrigagem desses parâmetros. A krigagem ordinária e a simulação condicional por bandas rotativas também são empregadas no presente trabalho para estimar os valores de $\mathrm{K}$ nas duas áreas de interesse, São Carlos, representando o SAG, e Bauru, que representa o SAB.

O estudo feito no SAG é realizado com base em um banco de dados composto de 85 poços que apresentam os valores $\mathrm{K}$ e Q/s distribuídos em oito cidades: São Carlos, Araquara,

Américo Brasiliense, Boa Esperança do Sul, Ibaté, Itirapina, Luiz Antônio e Ribeirão Bonito. Esses dados são provenientes de poços instalados em aquíferos livres, semiconfinados e confinados. A cidade de São Carlos é o objeto de estudo geoestatístico no SAG por, após a seleção das amostras e o tratamento estatístico, apresentar um maior número de informações de poços disponíveis. Sendo esses representados por 28 poços com valores de K e Q/s e 67 com apenas os valores de $\mathrm{Q} / \mathrm{s}$.

O banco de dados do SAB está concentrado na cidade de Bauru, sendo esse constituído por 69 poços com valores de $\mathrm{K}$ e Q/s e 243 com apenas os valores de Q/s, todos instalados em aquífero semiconfinado. 
Com base na descrição das amostras dos poços e da literatura disponível sobre a geologia e hidrogeologia das áreas de estudo, dois modelos geológicos são desenvolvidos. Um modelo referente a área de estudo na cidade de São Carlos e outro em Bauru. Uma das premissas dos estudos geoestatísticos é o conhecimento da geologia das áreas de estudo para subsidiar a interpretação dos produtos gerados pelos métodos geoestatísticos aplicados.

Para trabalhar os dados disponíveis de ambos os sistemas aquíferos, técnicas estatísticas são aplicadas. No SAG são utilizados testes de normalidade e o teste $t$ de Student. Todos os poços no SAB tratados no trabalho são considerados semiconfinados e o teste $\mathrm{t}$ de Student não é requerido, pois esse só é aplicado, nesse trabalho, no SAG devido aos poços nele serem de diferentes configurações, como confinados, semiconfinados e livres. O teste de normalidade é um método formal e envolve testar se um determinado dado segue a distribuição normal, no caso abordado, as distribuições de $\log \mathrm{K}$ e $\log \mathrm{Q} / \mathrm{s}$. Dentre os diversos testes de normalidade na literatura são utilizados os de Kolmogorov-Smirnov (K-S) e Shapiro-Wilk (S-W). O teste $t$ de Student é um teste estatístico de hipóteses sobre os parâmetros das distribuições de probabilidade. Nele são testadas as hipóteses de os poços que satisfizeram as condições nos testes de normalidade, inseridos em aquíferos livres e semiconfinados, serem provenientes de uma mesma população. A relação empírica é uma regressão linear de primeira ordem entre $\log \mathrm{K}$ e $\log \mathrm{Q} / \mathrm{s}$, como a relação logarítmica dá melhor coeficiente de correlação e o logaritmo desses parâmetros apresentam melhor distribuição, as técnicas estatísticas e geoestatísticas lidam com valores de $\log \mathrm{K}$ e $\log \mathrm{Q} / \mathrm{s}$.

São aplicadas três técnicas geoestatísticas nessa dissertação para gerar uma distribuição de valores de condutividade em todo domínio das duas áreas estudadas (São Carlos e Bauru). Duas correspondem a métodos matemáticos de interpolação: krigagem ordinária (KO) e cokrigagem (CoK). A krigagem ordinária é aplicada para duas situações para cada área, pois são krigados os valores de $\mathrm{K}$ aferidos a partir dos testes de bombeamento e os valores de $\mathrm{K}$ baseados na equação de regressão linear proveniente da relação empírica entre $K$ e Q/s, nesse caso, são adicionados valores calculados por essa relação aos valores de condutividades hidráulicas conhecidas. O outro método é chamado de estocástico, sendo esse a simulação condicional por bandas rotativas (BT). Segundo Yamamoto e Landim (2013), um mapa confeccionado pelos dois primeiros métodos é mais apropriado quando se almeja observar a tendência local, enquanto os métodos de simulação, como BT, são mais indicados quando se decide observar padrões de tendências globais, como nas simulações de fluxo. Todo método geoestatístico nesse trabalho é aplicado sem e com a técnica de desagrupamento ou 
declustering por células, para avaliar se essa técnica é capaz de melhorar o desempenho dos métodos.

O produto desse trabalho é o preenchimento das áreas de interesse, São Carlos e Bauru, com valores de condutividade hidráulica, baseando-se em um pequeno conjunto de dados por meio de métodos geoestatísticos. Esses valores geram um mapa de $\mathrm{K}$ que podem auxiliar na escolha da locação de novos poços ou servir como dados de entrada para modelos hidrogeológicos. 


\section{OBJETIVOS}

O objetivo principal desse trabalho é gerar um mapa de valores de condutividade hidráulica $(\mathrm{K})$ para uma área em São Carlos e outra em Bauru via métodos geoestatísticos. Secundariamente, busca-se verificando a validade de técnicas estatística para o aumento da base de dados do parâmetro hidráulico de interesse, condutividade hidráulica $(\mathrm{K})$, com o auxílio dos valores de capacidade específica $(\mathrm{Q} / \mathrm{s})$ de forma qualitativa. Ainda, a técnica de desagrupamento ou declustering por célula também é aplicada visando testar a sua capacidade de melhorar o desempenho dos métodos geoestatísticos. 


\section{3 ÁREAS DE ESTUDO}

\subsection{Localização e características gerais}

O presente trabalho estuda os parâmetros hidráulicos do Sistema Aquífero Guarani (SAG) e do Sistema Aquífero Bauru (SAB) através de poços neles instalados. No tratamento estatístico, 85 poços inseridos no SAG foram selecionados, sendo: 38 localizados em São Carlos, 26 em Araraquara, dois em Américo Brasiliense, três em Boa Esperança do Sul, três em Ibaté, nove em Itirapina, um em Luiz Antônio e três em Ribeirão Bonito. No caso do SAB, selecionaram-se 69 poços, todos instalados na cidade de Bauru. Na figura 1 é apresentada a distribuição espacial dos poços utilizados nessa dissertação.
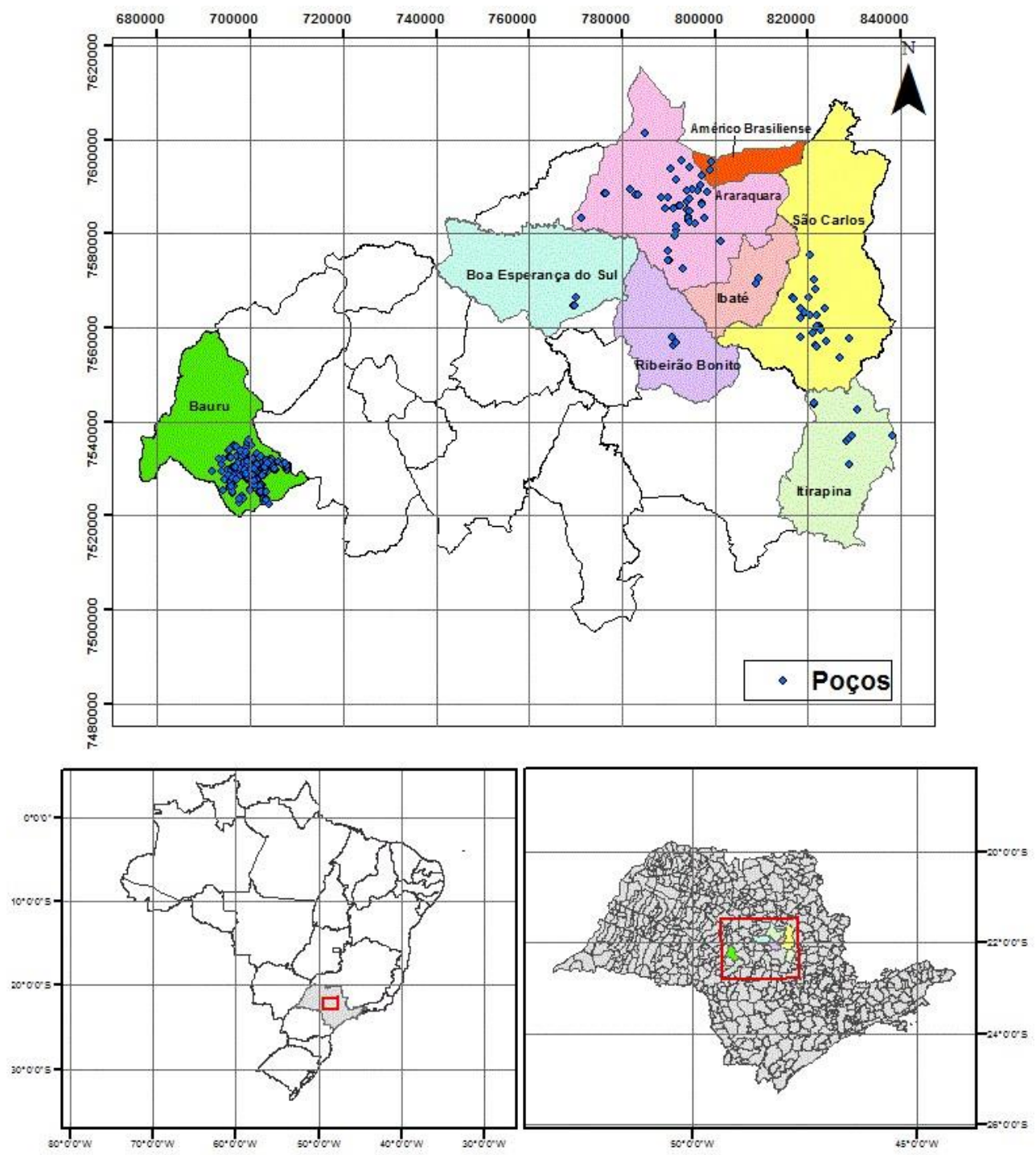

Figura 1: Mapa de localização das áreas de estudo, com seus respectivos poços, representados pelos pontos. 
Dentre os poços do SAG, 37 encontram-se em aquífero de comportamento hidráulico confinado, 26 semiconfinado e 22 livre. Já todos os poços instalados no SAB encontram-se em condições de semiconfinamento hidráulico.

Os poços do SAG exploram águas do aquífero a profundidades maiores que as dos poços do SAB. Na cidade de São Carlos, as profundidades dos poços estão compreendidas entre $47 \mathrm{~m}$ e $484 \mathrm{~m}$, ao passo que no município de Bauru, os poços apresentam profundidades entre 28 e $160 \mathrm{~m}$.

O município de São Carlos está localizado na região centro-leste do Estado de São Paulo, a 230 km da capital paulista. É composto por uma população de 241.389 habitantes, distribuídos em uma área total de 1.136,907 km² (IBGE, 2015).

A área de estudo em São Carlos é compreendida pelas bacias hidrográficas contíguas dos rios Jacaré-Guaçu e Jacaré-Pepira. Esses rios pertencem à bacia Hidrográfica Tietê/Jacaré e deságuam na região do curso médio do rio Tietê. Atualmente, a área em que os poços estão inseridos pertence à Unidade de Gerenciamento de Recursos Hídricos 13 do sistema de bacias Tietê- Jacaré, UGRHI-TJ.

O clima de São Carlos pode ser definido como temperado úmido com inverno seco e verão quente, recebendo a nomenclatura Cwa na classificação climática de Köppen-Geiger. A temperatura média anual corresponde a $21,2^{\circ} \mathrm{C}$ e a precipitação média anual $118.6 \mathrm{~mm}$ (CEPAGRI, 2015).

O município de Bauru encontra-se na região centro-oeste do Estado de São Paulo, a uma distância de $326 \mathrm{~km}$ da capital paulista e a $150 \mathrm{~km}$ de São Carlos. De acordo com IBGE

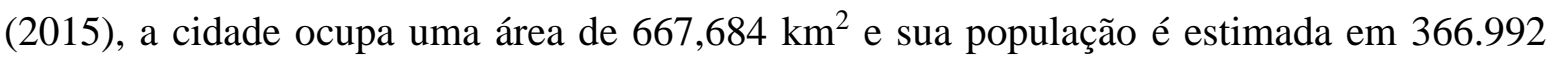
habitantes.

De acordo com CEPAGRI (2015), o clima de Bauru pode ser definido como tropical com estação seca de inverno, recebendo a nomenclatura Aw na classificação climática de Köppen-Geiger. A temperatura média anual corresponde a $22,6^{\circ} \mathrm{C}$ e a precipitação média anual a $110.9 \mathrm{~mm}$.

\subsubsection{Sistemas Aquíferos do Estado de São Paulo}

O Estado de São Paulo é caracterizado por dois tipos de aquíferos: os sedimentares e os fraturados. Dentre os aquíferos sedimentares, destacam-se os aquíferos Guarani, Bauru, 
Taubaté, São Paulo e Tubarão. Como aquíferos fraturados, distinguem-se o aquífero Serra Geral e os Aquíferos Cristalinos.

Como as áreas de estudo referem-se ao Sistema Aquífero Guarani e ao Sistema Aquífero Bauru, esses são descritos e discutidos detalhadamente para dar suporte aos resultados e conclusões presentes nessa dissertação.

\subsubsection{Sistema Aquífero Guarani (SAG)}

O Sistema Aquífero Guarani (SAG) é um dos maiores aquíferos transfronteiriços do mundo, constituído por rochas de idade Triássica e do Jurássica confinadas pelo derrame basáltico cretácico, e que se estende por uma área superior a $1.194 .00 \mathrm{~km}^{2}$, desde a Bacia do Paraná até a Bacia do Chaco-Paraná, (Figura 2) (Araújo et al., 1995). Em território brasileiro, o SAG abrange áreas dos estados de Goiás, Mato Grosso do Sul, Minas Gerais, Paraná, Santa Catarina, Rio Grande do Sul e São Paulo. Neste último, ocupa cerca de 60\% de seu território $\left(155.800 \mathrm{~km}^{2}\right)$; é confinado por derrames de rochas basálticas em $90 \%$ de sua área de ocorrência, o que lhe confere condições de artesianismo em $80 \%$ da área confinada. 


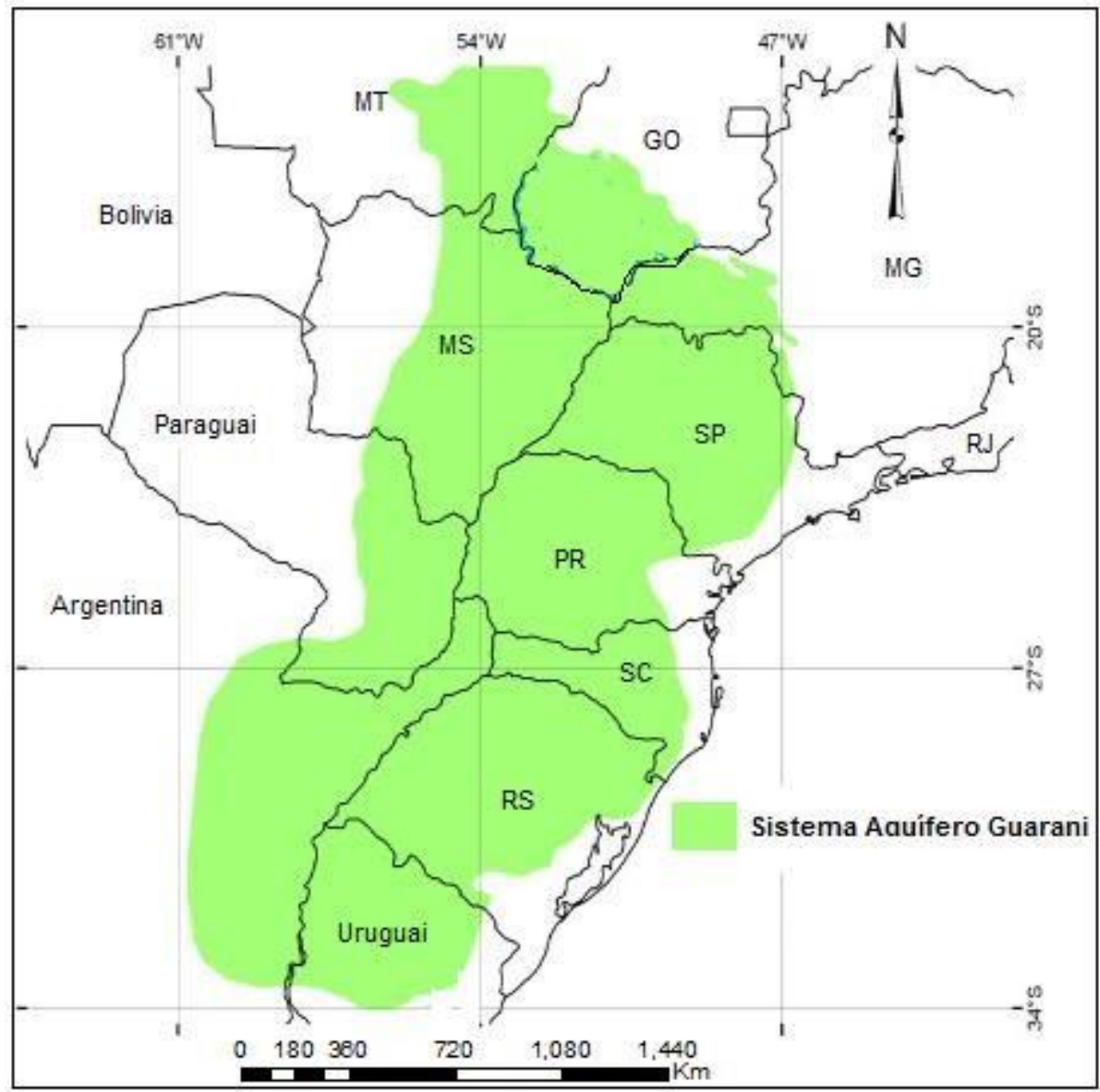

Figura 2: Área do Sistema Aquífero Guarani (SAG). Modificado de Oliveira e Vieira (2010).

No Estado de São Paulo, o SAG ocorre na porção oeste do Estado, ocupando cerca de $76 \%$ do seu território. A leste está localizada a faixa aflorante, que se estende desde o município de Rifaina, a norte, até Fartura, ao sul. Esta faixa, com área de $16.000 \mathrm{~km}^{2}$, está inserida na Depressão Periférica e apresenta largura irregular que se amplia ao longo das grandes drenagens, como é o caso do rio Jacaré-Pepira, quando atinge o máximo de $175 \mathrm{~km}$. Para oeste daquela faixa, o aquífero encontra-se confinado pelos basaltos da Formação Serra Geral, numa extensão de cerca de $174.000 \mathrm{~km}^{2}$. Nesta região, as águas do SAG abastecem cidades importantes como São José do Rio Preto, Presidente Prudente, Marília e Araçatuba (DAEE, 2005).

O SAG no Estado de São Paulo é representado pelas Formações Botucatu e Pirambóia. Essas e a Formação Serra Geral constituem o Grupo São Bento.

Os arenitos datados do período Jurássico pertencem à Formação Botucatu. Esses são de origem eólica e de maior capacidade hídrica, sendo considerados melhores reservatórios subterrâneos e, consequentemente, o principal sistema aquífero do SAG Quanto aos arenitos datados do período Triássico, esses são da Formação Pirambóia e são de origem flúviolacustre/ eólica, possuindo elevado nível de argila, comprometendo a sua eficiência hidráulica 
(Rocha, 1997). A unidade subjacente ao SAG compreende uma formação de baixa permeabilidade e caracteriza-se por um aquiclude (Permo-Triássico). Sobrepostas ao SAG, há sucessivas camadas de derrames basálticos, devido à atividade vulcânica, que formam rochas consolidadas, descontínuas, caracterizadas em parte como aquitardes e em parte como aquíferos. Esses derrames são oriundos do Cretáceo e conhecidos como Formação Serra Geral. Essa formação ígnea está sotoposta, em partes da Bacia do Paraná, por arenitos caracterizados como aquífero superior da sequência, em uma unidade geológica conhecida como Grupo Bauru, que data do Cretáceo (Rocha, 1997).

Como salientado por Campos (1999), o SAG é caracterizado como uma unidade confinada de arenitos com valores elevados de condutividade hidráulica (K). No entanto, os valores de K diminuem com o aumento da profundidade, onde há maior proporção de argila.

A Tabela 1 apresenta os valores médios das geometrias e parâmetros hidráulicos que constam no trabalho de Araújo et al. (1999). Segundo Borghetti et al. (2004), no SAG, a condutividade hidráulica tem valores entre 0,2 e $4,6 \mathrm{~m} / \mathrm{dia}$, com média de $3 \mathrm{~m} / \mathrm{dia}$, e os valores mais comuns de transmissividade estão entre 150 e $800 \mathrm{~m}^{2} /$ dia.

Tabela 1: Propriedades geométricas e hidráulicas das Fms. Botucatu e Pirambóia. Fonte: Araújo et al. (1999).

\begin{tabular}{|l|c|c|}
\hline \multicolumn{1}{|c|}{ Parâmetro } & Formação Botucatu & Formação Pirambóia \\
\hline Variação de espessura & $4-484(\mathrm{~m})$ & $25-770(\mathrm{~m})$ \\
\hline Espessura média & $138(\mathrm{~m})$ & $139(\mathrm{~m})$ \\
\hline Variação de porosidade & $17-30(\%)$ & $14-24(\%)$ \\
\hline Condutividade Hidráulica média $(K)$ & $8.7(\mathrm{~m} / \mathrm{d})$ & $1,9(\mathrm{~m} / \mathrm{d})$ \\
\hline Variação de transmissividade $(\mathrm{T})$ & $2,4-552\left(\mathrm{~m}^{2} / \mathrm{d}\right)$ & não confiáveis \\
\hline
\end{tabular}

Para Rosa Filho et al. (2003), o SAG recebe recarga por dois prováveis mecanismos: por infiltração direta, onde o aquífero aflora nos estados brasileiros, como São Paulo, Goiás, Mato Grosso do Sul, Paraná e Santa Catarina e no leste do Paraguai e norte do Uruguai; e por recarga indireta, através de fraturas nos basaltos da Formação Serra Geral.

Segundo Wahnfried (2010), os basaltos da Formação Serra Geral, diretamente sobrepostos ao SAG, podem confinar ou permitir a recarga deste, dependendo de suas características físicas, como espessura, grau e tipo de fraturamento. De acordo com os estudos desse autor, aferidos em basaltos na região de Ribeirão Preto, o fluxo de água se concentra até $50 \mathrm{~m}$ de profundidade no Sistema Aquífero Serra Geral (SASG), com um forte predomínio 
de circulação horizontal. Em profundidades maiores, o basalto e, principalmente, suas camadas vesiculares de topo atuam como barreira hidráulica notadamente para o fluxo vertical.

O SAG é confinado e saturado, delimitado por uma discordância na base, em contato com diferentes unidades, desde o embasamento pré-cambriano até sobre rochas do final do Permiano ou início do Triássico. No topo é delimitado pelos derrames basálticos da Formação Serra Geral. Em São Paulo, em Goiás e Mato Grosso, raramente a Formação Serra Geral está ausente e os arenitos fluviais do Grupo Bauru assentam-se diretamente sobre o SAG (Soares et al., 2008).

De acordo com Piuci e Diniz (1985), o aquitarde da base do SAG é representado, do topo para a base, por arenitos argilosos, siltitos arenosos, argilitos, folhelhos, bancos de calcário e eventuais intercalações de lentes arenosas de diferentes níveis. Segundo Corrêa (1995), esse aquitarde funciona hidraulicamente como camada semiconfinante da base do SAG, e depende das cargas hidráulicas entre este e o SAG por entrada ou saída de água por drenança. Pela inexistência de valores calculados de condutividade hidráulica vertical e pelas características das rochas, indicativas de uma condutividade baixa, esta camada é comumente considerada como limite de impermeabilidade da base do aquífero. Nas áreas de estudo a Formação Cotumbataí, membro do Grupo Passa Dois, atua como aquitarde do SAG.

De acordo com França et al. (1999), o fluxo do SAG é condicionado pela presença de lineamentos estruturais. Esses lineamentos ora são condutos preferenciais de fluxo e ora se manifestam como uma anisitropia na permeabilidade. A determinação da geometria destas zonas é baseada no grau de fraturamento secundário e alguns lineamentos principais. Montaño et al. (1998, apud Oliveira e Vieira, 2010) propõem a divisão do SAG de acordo com o comportamento hidráulico nas zonas aflorante e confinada. Segundo Gilboa et al. (1977), no Brasil, o fluxo é direcionado das áreas de recarga, caracterizada de cotas mais elevadas, para o eixo central da Bacia do Paraná.

Conforme Araújo et al. (1999), o sistema de fluxo principal, bem como a inclinação preferencial e as variações de espessura do SAG são condicionados por três arcos estruturais principais: Arco Assunção, Arco Ponta Grossa e Arco Rio Grande. Esses constituem soerguimentos basais, juntamente com a localização das zonas de recarga. O fluxo é preferencialmente direcionado ao Rio Paraná que percorre a Bacia de NE-SW e configura o principal destino da descarga de base do SAG, enquanto que a principal área de descarga subterrânea ocorre entre os rios Paraná e Uruguai, na Argentina, a oeste do Rio Arco Grande. 
Como conclui Soares et al. (2008), o SAG é bastante complexo, heterogêneo, com diferentes espessuras e comportamentos hidráulicos. A delimitação e caracterização de compartimentos estratigráficos revelam uma grande influência destas nas propriedades do aquífero. A homogeneidade característica do SAG é restrita às fácies dunares da formação Botucatu.

\subsubsection{São Carlos}

O Grupo São Bento está presente em quase a totalidade do munícipio de São Carlos, sendo representado pelas formações Serra Geral, Botucatu e Pirambóia. De acordo com Schneider et al. (1974), os sedimentos arenosos da Formação Pirambóia afloram na área em duas manchas principais, ao longo das sub-bacias do Médio Jacaré-Guaçu e Médio Jacaré Pepira. Geralmente, junto aos vales das drenagens são observadas manchas menores, a leste e sudeste, onde já foram erodidas as unidades superiores. Essa formação é composta por uma sucessão de camadas arenosas de coloração avermelhada a esbranquiçada. Conforme Soares (1975), a espessura atinge no máximo em torno de $350 \mathrm{~m}$ na Bacia do Tietê, e dados de perfuração de poços obtiveram espessura máxima de $146 \mathrm{~m}$. Dentre os poços estudados na presente dissertação, as suas profundidades variam entre 47.9 e 484 metros.

De acordo com o trabalho de Rabelo (2006), os arenitos da Formação Botucatu afloram em uma expressiva área que se estende desde a região de Itirapina, a leste, até as proximidades da Barragem de Ibitinga, a oeste. Dali para oeste, os arenitos encontram-se recobertos pelos basaltos da Formação Serra Geral e pelos sedimentos do Grupo Bauru. Segundo esse mesmo autor, a Formação Botucatu é constituída por arenitos avermelhados com estratificação cruzada tangencial de médio a grande porte, de granulação fina a média. Conforme estudo desenvolvido por DAEE (1998), sondagens indicam que a espessura dessa formação no Estado de São Paulo excede os $200 \mathrm{~m}$ e dados de perfuração de poços indicam espessura máxima de 192 metros em Ibaté.

As Formações Botucatu e Pirambóia encontram-se disseminadas na área do município de São Carlos, sendo, em sua maior parte, confinadas pelos derrames basálticos da Formação Serra Geral (Rabelo, 2006). De acordo com DAEE (1998), as rochas eruptivas da Formação Serra Geral constituem um conjunto de derrames toleíticos de espessura individual bastante variável. Em São Carlos, a espessura total varia desde poucos metros a $350 \mathrm{~m}$. 
Entre as unidades sedimentares existentes acima dos derrames basálticos da Formação Serra Geral, integrantes do Grupo Bauru, a Formação Adamantina é a unidade geológica que ocupa uma das maiores áreas de exposição na Bacia do Jacaré, estendendo-se desde as proximidades da Barragem de Ibitinga, de onde segue para leste-nordeste, até a região de Araraquara (Rabelo, 2006). Segundo IPT (2003), essa Formação é composta por arenitos finos, podendo apresentar cimentação e nódulos carbonáticos com lentes de siltito arenosos e argilitos ocorrendo em bancos maciços, estratificação plano-paralela e cruzada de pequeno a médio porte. De acordo com Fernandes (1998), geralmente, essa formação apresenta espessura preservada e bastante regular de aproximadamente $100 \mathrm{~m}$. Na área de São Carlos, a espessura da Formação Adamantina é menor, possivelmente por se tratar de uma área de borda das Formações do Grupo Bauru (IPT, 2003).

\subsubsection{Sistema Aquífero Bauru (SAB)}

O Sistema Aquífero Bauru (SAB) ocupa aproximadamente a metade oeste do território do Estado de São Paulo, possuindo uma área aproximada de $96.880 \mathrm{~km}^{2}$. Seus limites no Estado compreendem a oeste e noroeste o rio Paraná, a norte o rio Grande, a sul o rio Paranapanema e áreas de afloramento da Formação Serra Geral, que delimitam também o aquífero na região leste (Figura 3). 


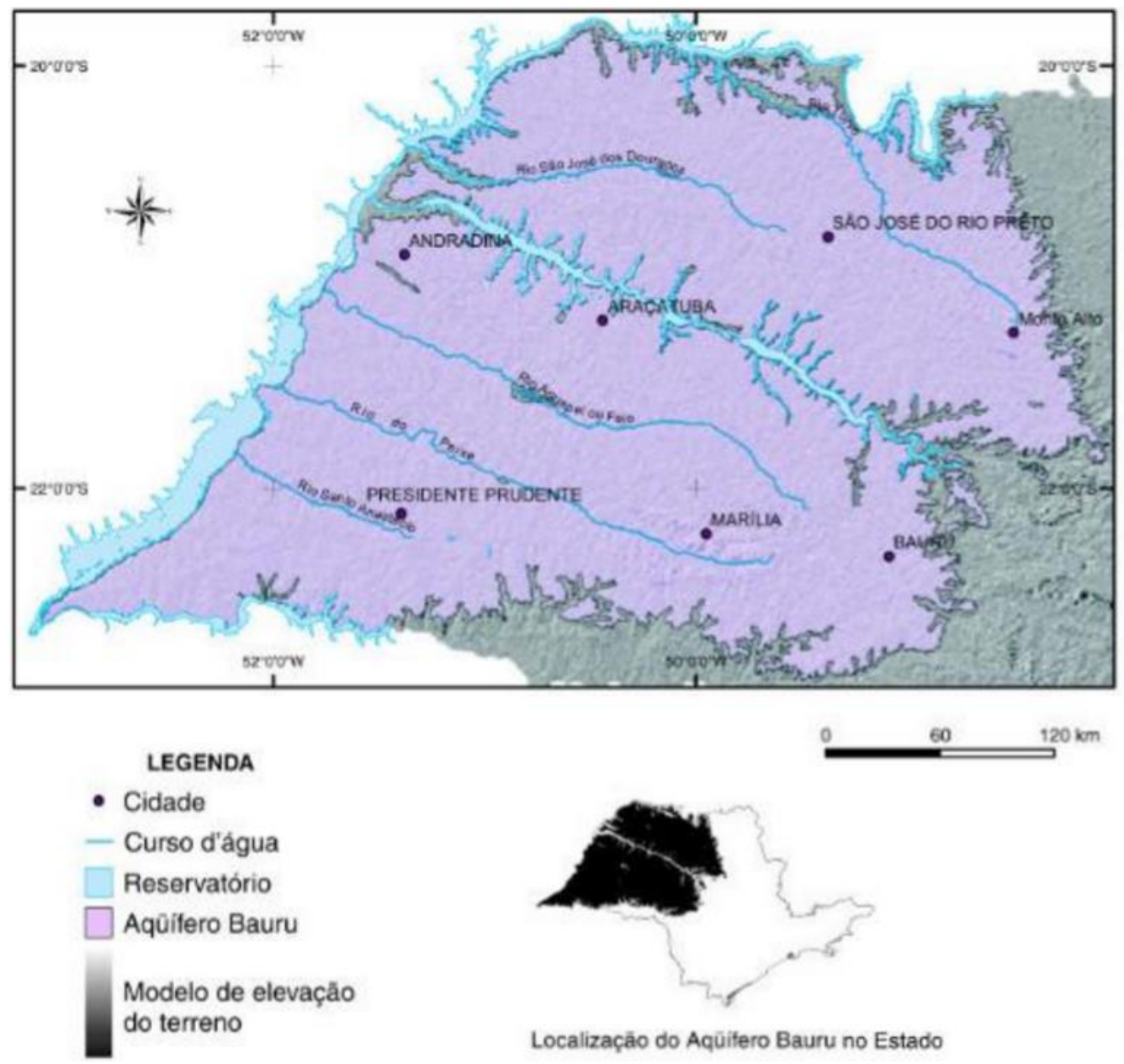

Figura 3: Mapa de Localização do Aquífero Bauru no Estado de São Paulo. Fonte: DAEE (2005).

As rochas sedimentares que compõem o SAB estão dispostas sobre os derrames basálticos da Formação Serra Geral. As cotas topográficas da base do aquífero são de aproximadamente $600 \mathrm{~m}$ de altitude nas áreas próximas às cuestas basálticas, com tendência de diminuição no sentido oeste da área de ocorrência, atingindo $100 \mathrm{~m}$ acima do nível do mar, na região de Presidente Epitácio (DAEE, 2005).

Conforme Fernandes e Coimbra (1992), o SAB é constituído por rochas sedimentares do Grupo Bauru, depositados na Bacia Bauru. Segundo Fernandes (1998), a deposição dos sedimentos que compõem o SAB é dividida em duas fases principais: a primeira em condições essencialmente desérticas e; a segunda, em clima semiárido, com maior presença de água. Estas fases compreendem, respectivamente, depósitos de lençóis secos de areias com dunas eólicas e com interdunas úmidas, e depósitos de sistemas fluviais e leques aluviais com pantanal interior bem definido.

De acordo com Almeida et al. (1981), a bacia de deposição do Grupo Bauru iniciou-se com a sedimentação do arenito Caiuá, na área do Pontal do Parapanema, estendendo-se depois 
no sentido norte e nordeste com a sedimentação Santo Anastácio e Adamantina e, por fim, apresentou embaciamento localizado, quando se depositou a Formação Marília.

Segundo Paula e Silva (2003), a Formação Caiuá é caracterizada por uma deposição cíclica de fácies psamíticas e pelíticas, retratadas respectivamente por pacotes arenosos depositados em ambientes fluviais, com eventuais interações eólicas mais proeminentes em direção ao topo da sucessão, e pacotes argilo-siltosos, depositados em ambiente lacustre. Essa formação aflora em pequena extensão na região do Pontal do Parapanema e nas proximidades do Rio Paraná.

Em subsuperfície, a Formação Santo Anastácio é caracterizada pelo predomínio dos termos arenosos em detrimento dos constituintes pelíticos. A litologia predominante é composta por arenitos de cor marrom avermelhada, de granulação muito fina a média, recoberto por película limonítica, com frequentes nódulos e cimentação calcíferos. Intercalam-se arenitos, lentes descontínuas de lamito, siltito e argilito marrom avermelhados, cuja frequência se torna mais pronunciada nas porções basais da unidade (Paula e Silva, 2003). O padrão de variação granulométrica da formação sugere que essa seja produto de deposição de ambiente fluvial. Inicialmente, eram depósitos de canal evoluindo para um modelo com escassez de fácies pelíticas do tipo entrelaçado. Essa formação aflora em área que se estende em estreita faixa paralela ao Rio Paraná, mas em subsuperfície avança na direção oriental até os limites do alto de Tanabi, e sobre as regiões que constituem o Alto de Paraguaçu Paulista e a Depressão do Rio Preto. A Formação Santo Anastácio é limitada pela Formação Caiuá na base e, no topo, pela Formação Adamantina (Paula e Silva, 2003).

A Formação Adamantina é caracterizada por arenitos avermelhados a acastanhados, finos a muito finos, argilosos, alguns carbonáticos, quartzitosos, intercalados por camadas de lamito marrom avermelhado, arenoso, carbonáticos. São depósitos arenosos em granodecrescente com terminação em pelitos, indicativos de sedimentação em canais fluviais meandrantes. Há alternância de fácies de canal e transbordamento, em repetições cíclicas, com fraco predomínio das fácies de planície de inundação. O sistema aquífero homônimo ocorre extensamente em superfície, estando coberto apenas localmente pela Formação Marília e ausente, por erosão, no extremo sudoeste paulista (Paula e Silva, 2003).

A Formação Marília aflora na área de estudo e tem ocorrência restrita às demais formações do Grupo Bauru. A abundância de cimento calcífero em suas litologias propiciou um arcabouço resistente à erosão, responsável pela sustentação das escarpas dos planaltos de Marília, Garça e Echaporã. Esta sucessão sobrepõe-se à Formação Adamantina através de contatos interdigitados e seu limite superior é marcado pela superfície topográfica atual. É 
constituída dominantemente por arenitos grossos a conglomeráticos, com teor de matriz variável maciços ou com acamamento incipiente subparalelo e descontínuo, raras estratificações cruzadas de médio porte e raras camadas descontínuas de lamitos vermelhos e calcários (Paula e Silva, 2003).

Todas as formações supracitadas têm sistemas aquíferos homônimos.

Conforme DAEE (2005), a espessura média do SAB é da ordem de $75 \mathrm{~m}$. No Planalto Residual de Marília encontram-se espessuras máximas de 300 m e nas regiões de São José do Rio Preto e Presidente Prudente ocorrem espessuras máximas de 150 e 200 m, respectivamente. A forma irregular do topo dos basaltos também favorece a presença de maiores espessuras ao longo do rio Santo Anastácio, até o rio Paraná, com valores máximos entre 150 e 230 m; já nos divisores dos rios Aguapeí e Peixe ocorrem espessuras médias de $100 \mathrm{~m}$. As menores espessuras são observadas nas proximidades dos afloramentos dos basaltos da Formação Serra Geral nos limites sul, leste e norte do aquífero Bauru.

Paula e Silva (2003) ressalta que as variações de espessura deste sistema aquífero refletem a maior ou menor resistência das litologias presentes aos processos erosivos diferenciais, e a configuração do embasamento basáltico receptor dos sedimentos.

Esse mesmo autor analisou perfis geofísicos para avaliar a permeabilidade das formações e seus respectivos sistemas aquíferos homônimos que compõem o SAB. A classificação foi subdividida em muito permeáveis, moderadamente permeáveis e impermeáveis, os dois primeiros correspondendo a unidades aquíferas e o último a aquitardes.

Paula e Silva (2003) concluiu que, o sistema aquífero Caiuá é de extensão regional, livre a confinado e contínuo. Pode-se considerar esse sistema um aquitarde em algumas localidades, pois apresenta permeabilidade moderada a impermeabilidade. Sobrejacente ao aquífero Caiuá, o aquífero Santo Anastácio é considerado de extensão regional, livre a semiconfinado e contínuo. Esse aquífero apresenta muita permeabilidade a moderada, tendendo a apresentar mais a segunda categoria. O aquífero Adamantina é considerado de extensão regional, livre a semiconfinado e contínuo. O semiconfinamento é decorrente principalmente das variações de permeabilidade dos sedimentos em função do maior ou menor teor de argila da matriz, ou das camadas pelíticas que se intercalam aos corpos arenosos. Predominam sedimentos de permeabilidade aparente. Quanto ao aquífero Marília, pode-se considerá-lo de extensão regional, livre a semiconfinado e contínuo. A intensidade variável da cimentação de seu arcabouço litológico conduz a variações de permeabilidade que o tornam heterogêneo e anisotrópico, o que pode dar origem a situações de confinamento hidráulico. Também é comum, nesta sucessão, a formação de aquíferos suspensos nas zonas 
de alteração superficiais de unidade, devido à presença de estratos subjacentes, relativamente impermeáveis, isolando o corpo d'água principal.

As águas do SAB ocorrem regionalmente de forma livre podendo, localmente, se apresentar de forma semiconfinada ou confinada. No contato com o SASG, a leste, as cotas potenciométricas variam de 600 até $300 \mathrm{~m}$. O sentido de escoamento regional das águas subterrâneas se dá em direção às drenagens principais, como os rios Turvo, Preto, São José dos Dourados, Tietê, Aguapeí, Peixe e Santo Anastácio, Paraná e Parapanema (DAEE, 2005).

\subsubsection{Bauru}

Segundo Silva e Chang (2010), a área urbana da cidade Bauru encontra-se sobre os sedimentos do Grupo Bauru. Sotoposto a esse grupo, encontra-se, em contato discordante, as formações Serra Geral, Botucatu ou Pirambóia do Grupo São Bento, com topo e profundidades que variam de 58 a $193 \mathrm{~m}$. Na região, o SAG é coberto pelas formações Adamantina e Marília do Grupo Bauru.

Conforme Cavaguti e Paula e Silva (1994), na cidade de Bauru afloram as formações Marília e Adamantina, sendo que a primeira recobre a segunda por contato interdigitado e abrupto. Segundo esses autores, a Formação Adamantina é predominante na região. Localmente, a Formação Marília é composta por arenitos grossos a conglomeráticos, com teor de matriz variável, rico em feldspatos e raras camadas de lamitos vermelhos e calcários (Soares et al., 1980). Em subsuperfície, a Formação Marília tem composição predominantemente arenosa, com intercalações de material pelítico (Paula e Silva, 2003).

De acordo com Soares et al. (1980), a Formação Adamantina é composta por um conjunto de fácies cuja principal característica é a presença de bancos de arenitos com espessuras que variam de 2 a 20 m, granulação fina a muito fina, com variabilidade regional,

e conjuntos litológicos distintos mais ou menos localizados. Esses arenitos exibem estratificação cruzada e se alternam com camadas de lamitos, siltitos e arenitos lamíticos com acamamento plano-paralelo e frequentes marcas onduladas e microestratificações cruzadas. 


\section{DESCRIÇÃO DOS MÉTODOS}

\subsection{Métodos de Interpretação de Testes Hidráulicos em Aquíferos}

A determinação das propriedades hidráulicas de aquíferos é de fundamental importância para o entendimento e caracterização do fluxo de água subterrânea, e consequentemente para desenvolvimento de modelos que descrevam este fluxo e forneçam subsídios a uma compreensão condizente a este recurso.

Os valores dos parâmetros hidrodinâmicos de sedimentos, rochas e solos, tais como transmissividade, coeficiente de armazenamento e condutividade hidráulica, podem ser determinados por diferentes métodos. No presente trabalho, aplicam-se três métodos diferentes para interpretar as medições realizadas em testes de bombeamento: método de Theis (1935) para aquíferos confinados, Hantush-Jacob (1988) para aquíferos semiconfinados, e Neuman (1975) para aquíferos livres.

Antes de apresentar os métodos de interpretação utilizados nessa dissertação, há uma breve explanação do modelo conceitual do fluxo para os poços, o que dará suporte para o entendimento dos métodos.

\subsection{Modelo Conceitual de Fluxo}

Segundo Bressan et al. (2002), os métodos de interpretação de aquíferos são determinados em função das condições físicas de cada aquífero (confinado não drenante, ou simplesmente confinado, confinado drenante ou semiconfinado e livre) associadas à evolução dos rebaixamentos em função do bombeamento do poço (regime permanente ou transitório) para um dado intervalo de tempo. As equações hidráulicas para os testes de aquíferos foram desenvolvidas para um aquífero idealizado, enquanto os dados coletados em campo são representações da realidade do aquífero em estudo. Conforme Fetter (1988), Freeze e Cherry (1979) e Feitosa et al. (2008), os modelos são simplificações da realidade e, para fazer uso dessas equações, é preciso assumir algumas condições para a determinação dos modelos, tais como:

O aquífero é homogêneo e isotrópico e a água possui viscosidade e densidade constantes; A espessura do aquífero é constante e sua base é horizontal; 
Não existe fluxo natural, ou seja, a superfície potenciométrica do aquífero não muda antes do início do bombeamento;

O escoamento é laminar, ou seja, a lei de Darcy é válida em qualquer momento;

O coeficiente de armazenamento é constante no espaço e no tempo. Para os aquíferos confinados, supõe-se que em nenhum lugar, os rebaixamentos produzidos pelo bombeamento diminuam o nível da água abaixo do topo do aquífero;

A água retirada do armazenamento do aquífero é liberada instantaneamente e proporcionalmente à diminuição do nível piezométrico;

Supõe-se que o aquífero tenha extensão infinita e que não existam outras captações;

O poço bombeado e os de observação são totalmente penetrantes, sendo assim eles atravessam toda a espessura do aquífero;

O raio do poço é suficientemente pequeno e a variação do volume de água armazenada no mesmo não influi na vazão de bombeamento;

Não existem perdas de carga no poço;

A vazão de bombeamento é constante.

O bombeamento induz o gradiente horizontal para o poço, com uma diminuição da carga hidráulica no aquífero ao redor de onde o poço está inserido, apresentando um fluxo simétrico e radial (Freeze e Cherry, 1979).

O fluxo bidimensional em um aquífero confinado é dado pela seguinte equação diferencial parcial:

$$
\frac{\partial^{2} h}{\partial x^{2}}+\frac{\partial^{2} h}{\partial y^{2}}=\frac{S}{T} \frac{\partial h}{\partial t}
$$

Onde:

h= Carga hidráulica $(\mathrm{L})$;

$\mathrm{T}=$ Transmissividade $(\mathrm{L} 2 / \mathrm{T})$;

$\mathrm{S}=$ Coeficiente de armazenamento (adimensional);

$\mathrm{t}=$ Tempo a partir do início do bombeamento $(\mathrm{T})$;

Para lidar com esse fluxo radial é empregado o sistema de coordenadas polares. A posição de um ponto em um plano é especificada de acordo com a sua distância e direção de um ponto fixo ou um polo. A distância é medida diretamente do polo para o ponto no plano. A direção é determinada pelo ângulo entre a linha do polo com o ponto no plano e uma linha de referência fixa, o eixo polar. Esse eixo é normalmente desenhado horizontalmente e para a direita do polo e o ângulo é mensurado pela rotação no sentido horário do eixo polar, conforme a figura 4. Somente o valor do ângulo $(\theta)$ e a distância radial (r) precisam ser especificados. 


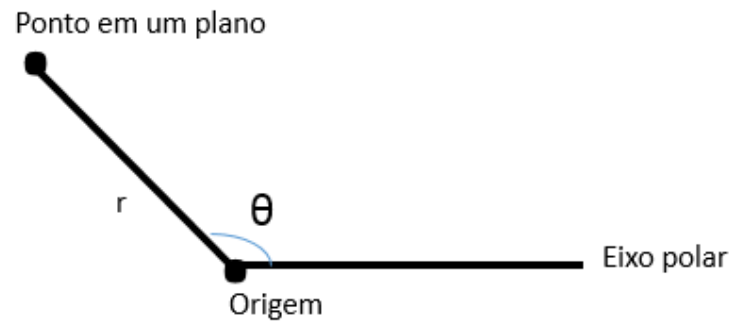

Figura 4: Representação sobre o uso de coordenadas polares para descrever a posição de um ponto no plano, mostrando a distância $r$ da origem e o ângulo $\theta$ entre $o$ eixo polar e a linha conectando o ponto e a origem. Adaptado de Fetter (1988).

A equação 1 está no contexto de um plano cartesiano. Em um aquífero isotrópico e homogêneo com simetria radial, pode-se transformar a equação usando a seguinte relação que vem do Teorema de Pitágoras:

$$
r^{2}=x^{2}+y^{2}
$$

Se o aquífero é isotrópico em um plano horizontal, o fluxo apresentará simetria radial e $\theta$ é irrelevante (Fetter, 1988). Sendo assim, tem-se a equação em coordenadas radiais:

$$
\frac{\partial^{2} h}{\partial r^{2}}+\frac{1}{r} \frac{\partial h}{\partial r}=\frac{S}{T} \frac{\partial h}{\partial t}
$$

onde r é a distância radial do poço de bombeamento (L)

O fluxo bidimensional em um aquífero confinado que recebe recarga é dado pela equação 4 (Fetter, 1988):

$$
\frac{\partial^{2} h}{\partial x^{2}}+\frac{\partial^{2} h}{\partial y^{2}}+\frac{w}{T}=\frac{S}{T} \frac{\partial h}{\partial t}
$$

onde $w$ representa a razão de drenança vertical (L/T), mais comumente metros por dia).

Transformando a equação acima em coordenadas radiais, obtém-se a equação (5):

$$
\frac{\partial^{2} h}{\partial r^{2}}+\frac{1}{r} \frac{\partial h}{\partial r}+\frac{w}{T}=\frac{S}{T} \frac{\partial h}{\partial t}
$$

Na Figura 5, a região matemática do fluxo é uma linha horizontal unidirecional no aquífero de $r=0$ no poço para um $r$ na extremidade infinita. 


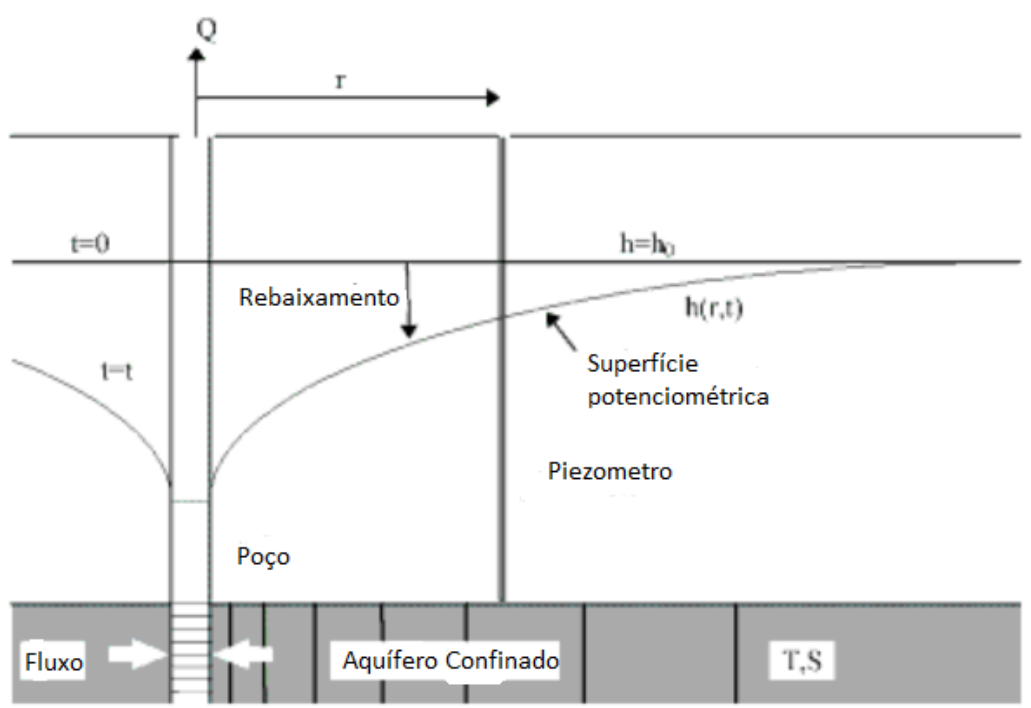

Figura 5: Perfil ilustrativo do rebaixamento do nível d'água provocado por um poço que está bombeando. Adaptado de Waterloo Hydrogeologic (2015).

Segundo Fetter (1988), a solução da equação (3) para um fluxo radial gerado por um poço e aplicada a diferentes contextos, como, por exemplo confinado ou livre, produz algumas equações extremamente úteis. Essas soluções são importantes para determinar o rebaixamento da superfície potenciométrica ou nível d'água nas proximidades de um poço que está sendo bombeado, quando as características hidráulicas da formação são sabidas. Se as características hidráulicas de um aquífero não são conhecidas, um teste de bombeamento pode ser realizado para sua obtenção. Para esse teste, uma vazão conhecida é bombeada e a resposta da superfície potenciométrica é mensurada.

\subsection{Método de Interpretação}

No presente trabalho são sumarizados os métodos de interpretação de aquíferos utilizados para calcular os valores de condutividade hidráulica $(\mathrm{K})$ para cada contexto hidrogeológico considerado (aquífero confinado drenante, confinado não drenante e livre). Os valores de $\mathrm{K}$ foram calculados usando o software AquiferTest. 


\subsubsection{Aquífero confinado}

\subsubsection{Método de Theis}

Segundo Feitosa et al. (2008), o método de Theis deve ser aplicado especificamente quando o aquífero em estudo é do tipo confinado não drenante e de regime transiente. Fetter (1988) relata que a primeira análise matemática dos efeitos do rebaixamento em um aquífero confinado foi publicada por Theis (1935). Além das condições básicas de fluxo determinadas previamente, ele adicionou outras quatro:

O aquífero é confinado no topo e na base;

Não há fonte de recarga no aquífero e;

O aquífero é compressivo e a água é instantaneamente liberada do aquífero quando a carga é diminuída.

Tendo a seguinte equação diferencial do fluxo subterrâneo:

$$
\mathrm{h}_{\mathrm{o}}-\mathrm{h}=\frac{\mathrm{Q}}{4 \pi \mathrm{T}} \int_{\mathrm{u}}^{\infty} \frac{-\mathrm{e}^{\mathrm{u}}}{\mathrm{u}} \mathrm{du}
$$

Onde:

$$
\mathrm{u}=\frac{\mathrm{r}^{2} S}{4 \mathrm{Tt}}
$$

Como a integral da expressão não tem solução exata, a resolução foi proposta por Theis (1935) através da série convergente:

$$
0,5772-\ln u+u-\frac{u^{2}}{2.2 !}+\frac{u^{3}}{3.3 !}-\frac{u^{4}}{4.4 !}
$$

Como ho $-\mathrm{h}=\mathrm{s}$ (rebaixamento), tem-se:

$$
\mathrm{s}=\frac{\mathrm{Q}}{4 \pi \mathrm{T}} \mathrm{W}(\mathrm{u})
$$

Tirando-se o valor de T e Sc, teremos:

$$
\begin{aligned}
& \mathrm{s}=\frac{\mathrm{Q}}{4 \pi \mathrm{T}} \mathrm{W}(\mathrm{u}) \\
& \mathrm{s}=\frac{4 \mathrm{Ttu}}{\mathrm{r}^{2}}
\end{aligned}
$$

Onde:

$\mathrm{Q}=\operatorname{vazão}\left(\mathrm{L}^{3} / \mathrm{T}\right)$;

$h_{0}=$ nível estático $(\mathrm{L})$; 
$h$ = nível dinâmico $(\mathrm{L})$;

$\mathrm{T}=$ transmissividade $\left(\mathrm{L}^{2} / \mathrm{T}\right) ;$

$\mathrm{Q}=$ vazão de bombeamento $\left(\mathrm{L}^{3} / \mathrm{T}\right)$;

$\mathrm{s}=$ rebaixamento a uma distância $\mathrm{r}$ do poço bombeado $(\mathrm{L})$;

$\mathrm{S}=$ coeficiente de armazenamento (adimensional);

$\mathrm{t}=$ tempo a partir do início do bombeamento $(\mathrm{T})$;

$\mathrm{r}=$ distância do poço de bombeamento ao ponto de rebaixamento s (L);

$\mathrm{W}(\mathrm{u})=$ função de poço para aquífero confinado não drenante.

Feitosa et al. (2008) sumaria a metodologia de aplicação desse método em uma lista:

- Realização de um teste de aquífero com acompanhamento de, no mínimo, um poço de observação, no caso desse trabalho, o ponto de observação é o próprio poço;

- Construção da curva padrão $\log \mathrm{W}(\mathrm{u}) \mathrm{X} \log 1 / \mathrm{u}$ ou $\log \mathrm{u}$, através de valores apresentados em livros texto, ou utilizando a série convergente de Theis, na equação 6, programada em computador;

- Construção da curva de campo plotando-se os valores de rebaixamento (s) X tempo (t), em papel log-log. Deve-se utilizar o mesmo módulo logarítmico da curva teórica;

- Superposição da curva de campo sobre a curva padrão até a obtenção do melhor ajuste e escolha de um ponto qualquer, denominado ponto de superposição como ilustrado na Figura 13. Na medida do possível deve-se escolher um ponto de superposição para valores inteiros de $\mathrm{W}(\mathrm{u})$ e 1/u para facilitar os cálculos, como por exemplo $\mathrm{W}(\mathrm{u})=1$ e 1/u =1.

- Mantendo a superposição, efetuar o registro dos valores de W(u) e 1/u, na curva padrão, e s e t, na curva de campo, correspondentes ao ponto de superposição escolhido, tal como mostrado na figura 6.

- Cálculo de transmissividade $(\mathrm{T})$ e de coeficiente de armazenamento $\left(\mathrm{S}_{\mathrm{c}}\right)$ através das equações 10 e 11, respectivamente;

- Conhecendo-se a espessura do aquífero (b), calcula-se a condutividade hidráulica (K) através da equação:

$$
\mathrm{K}=\frac{\mathrm{T}}{\mathrm{b}}
$$




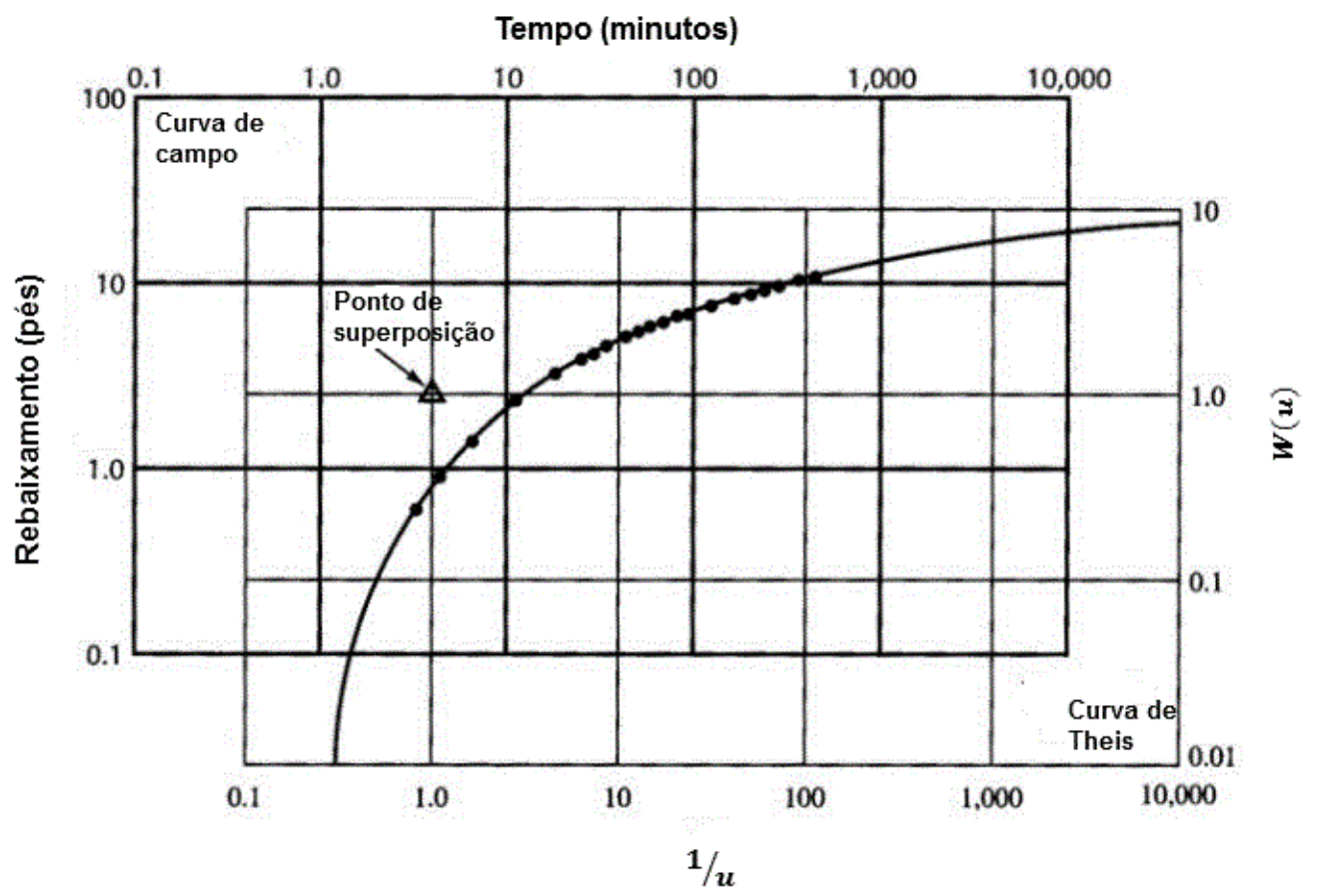

Figura 6: Método gráfico de superposição para a determinação da transmissividade (T) e do coeficiente de armazenamento (S) utilizando a metodologia de Theis. Adaptado de Fetter (1988).

\subsubsection{Aquífero semiconfinado}

A maioria dos aquíferos confinados não é totalmente isolada de fontes de recarga vertical. Aquitardes, acima ou abaixo do aquífero, podem drenar água para o aquífero, caso a direção de gradiente hidráulico seja favorável (Fetter, 1988).

Quando há drenança vertical para o aquífero confinado o fluxo bidimensional é representado pela equação 5 (Fetter, 1988). A razão da drenança, w, pode ser aferida pela lei de Darcy. Nesse caso o valor de condutividade hidráulica da cada semiconfinante é $\mathrm{K}^{\prime}$. O gradiente hidráulico é a carga na camada semiconfinante, que é o rebaixamento, $h_{0}-h$, dividido pela espessura da camada confinante, $\mathrm{b}^{\prime}$. Sendo assim a razão de drenança é calculada pela equação:

$$
\mathrm{w}=\mathrm{K}^{\prime} \frac{\mathrm{h}_{0}-\mathrm{h}}{\mathrm{b}^{\prime}}
$$

Aplicando a substituição de w na equação 5, a mesma é apresentada da seguinte forma:

$$
\frac{\partial^{2} \mathrm{~h}}{\partial \mathrm{r}^{2}}+\frac{1}{\mathrm{r}} \frac{\partial^{2} \mathrm{~h}}{\partial \mathrm{r}^{2}}+\mathrm{K}^{\prime} \frac{\left(\mathrm{h}_{0}-\mathrm{h}\right)}{\mathrm{Tb}^{\prime}}=\frac{\mathrm{S}}{\mathrm{T}} \frac{\partial \mathrm{h}}{\partial \mathrm{t}}
$$

onde $\mathrm{r}$ é a distância radial do poço bombeado, dado em metro, $\mathrm{t}$ é o tempo, $\mathrm{S}$ é o armazenamento, adimensional, e $\mathrm{T}$ é a transmissividade, $\mathrm{L}^{2} / \mathrm{T}$. 


\subsubsection{Método de Hantush-Jacob}

Segundo Fetter (1988), o método apresentado por Hantush e Jacob (1954) é adequado para poços instalados em aquíferos semiconfinados onde a água drenada não é proveniente do armazenamento elástico da camada confinante. Nesse caso o método assume que toda água que flui para o poço de bombeamento tem como origem o armazenamento elástico do aquífero confinado ou é proveniente de uma camada superior à que confina o aquífero e abastece o poço por drenança.

A solução para a equação 14 dada Por Hantush e Jacob (1954) é conhecida como a fórmula de Hantush-Jacob e é definida como:

$$
\begin{aligned}
& h_{0}-h=\frac{Q}{4 \pi T} W(u, r / B) \\
& u=\frac{r^{2} S}{4 T t} \\
& B=\left(T b^{\prime} / K^{\prime}\right)
\end{aligned}
$$

Onde:

Q é vazão $\left(\mathrm{L}^{3} / \mathrm{T}\right)$;

$h_{0}-h$ é o rebaixamento no aquífero confinado (L);

$\mathrm{T}$ é transmissividade no aquífero confiando $\left(\mathrm{L}^{2} / \mathrm{T}\right)$;

$W(u, r / B)$ é a função de drenança do poço, disponível em Fetter (1988);

t é o tempo a partir do início do bombeamento (T);

r é a distância do poço de bombeamento ao ponto de rebaixamento s (L);

$\mathrm{S}$ é o coeficiente de armazenamento (adimensional);

B é o fator de drenança (L);

b' é a espessura do aquitardo (L);

$\mathrm{K}$ ' é a condutividade hidráulica do aquitardo $(\mathrm{L} / \mathrm{T})$. 


\subsubsection{Aquífero livre}

\subsubsection{Método de Neuman}

Freeze e Cherry (1979) consideram que a abordagem mais comum dada para a interpretação de testes de bombeamento em aquíferos livres é o método desenvolvido por Neuman (1972), com base no conceito de atraso de resposta do nível freático. Neuman (1972) observou que o rebaixamento dos níveis d'água nos poços de observação adjacentes aos poços bombeados em aquíferos livres tende a declinar a uma taxa mais lenta que a prevista pela solução proposta por Theis. De fato, são observados três distintos segmentos na curva do gráfico tempo-rebaixamento. O primeiro segmento, um curto período no início do bombeamento, corresponde a um momento em que o aquífero livre reage da mesma maneira que um aquífero confinado. A água é liberada instantaneamente do armazenamento pela compactação do aquífero e expansão da água. No segundo segmento, há diminuição da inclinação da curva tempo-rebaixamento em relação à curva de Theis devido a água fornecida ao poço pelo rebaixamento do nível d'água ser maior do que seria no caso de um igual declínio da superfície potenciométrica em aquífero confinado. Quanto ao terceiro segmento, que ocorre em um momento mais tardio, novamente a curva tende a seguir uma curva padrão de Theis (Freeze e Cherry, 1979).

Segundo esses mesmos autores, a solução de Neuman é capaz de reconhecer a existência de componentes de fluxo vertical, e a solução geral para o rebaixamento, h0-h, é uma função de $\mathrm{r}$ e z. Essa solução pode ser reduzida a uma que é uma função somente de r, caso um rebaixamento médio seja considerado. A solução de Neuman pode ser representada de forma simplificada pela expressão:

$$
\mathrm{h}_{0}-\mathrm{h}=\frac{\mathrm{Q}}{4 \pi \mathrm{T}} \mathrm{W}\left(\mathrm{u}_{\mathrm{A}}, \mathrm{u}_{\mathrm{B}}, \Gamma\right)
$$

onde $\mathrm{W}(\mathrm{uA}, \mathrm{uB}, \Gamma)$ é conhecido como função de poço livre e $\Gamma=\mathrm{r}^{2} / \mathrm{b}^{2}$.

A figura 7 é um gráfico dessa função para vários valores de $\Gamma$. As curvas do tipo A que são como a curva à esquerda na curva de Theis (Figura 6) e que ocorrem no tempo inicial, são dadas pela expressão:

$$
\mathrm{h}_{0}-\mathrm{h}=\frac{\mathrm{Q}}{4 \pi \mathrm{T}} \mathrm{W}\left(\mathrm{u}_{\mathrm{a}}, \Gamma\right)
$$


onde

$$
u_{\mathrm{A}}=\mathrm{r} \frac{\mathrm{r}^{2} \mathrm{~S}}{4 \mathrm{Tt}}
$$

e S é o armazenamento elástico responsável pela liberação instantânea de água para o poço.

As curvas do tipo B, similares à curva de Theis mais à direita, e que ocorrem em tempo tardio, são dadas pela expressão:

$$
\mathrm{h}_{\mathrm{o}}-\mathrm{h}=\frac{\mathrm{Q}}{4 \pi \mathrm{T}} \mathrm{W}\left(\mathrm{u}_{\mathrm{B}}, \Gamma\right)
$$

onde

$$
u_{B}=r \frac{r^{2} S_{y}}{4 T t}
$$

e $S_{y}$ é o rendimento específico que é responsável pela liberação da água tardiamente para o poço.

Para um aquífero anisotrópico com condutividade hidráulica horizontal, $\mathrm{K}_{\mathrm{r}}$, e vertical, $\mathrm{K}_{\mathrm{z}}$, o parâmetro $\Gamma$ é dado por:

$$
\Gamma=\frac{\mathrm{r}^{2} \mathrm{~K}_{\mathrm{z}}}{\mathrm{b}^{2} \mathrm{~K}_{\mathrm{r}}}
$$

Se o aquífero é isotrópico, $K_{z}=K_{r}$, e $\Gamma=r^{2} / b^{2}$. Sendo a transmissividade definida como $\mathrm{T}=\mathrm{K}_{\mathrm{r}} \mathrm{b}$.

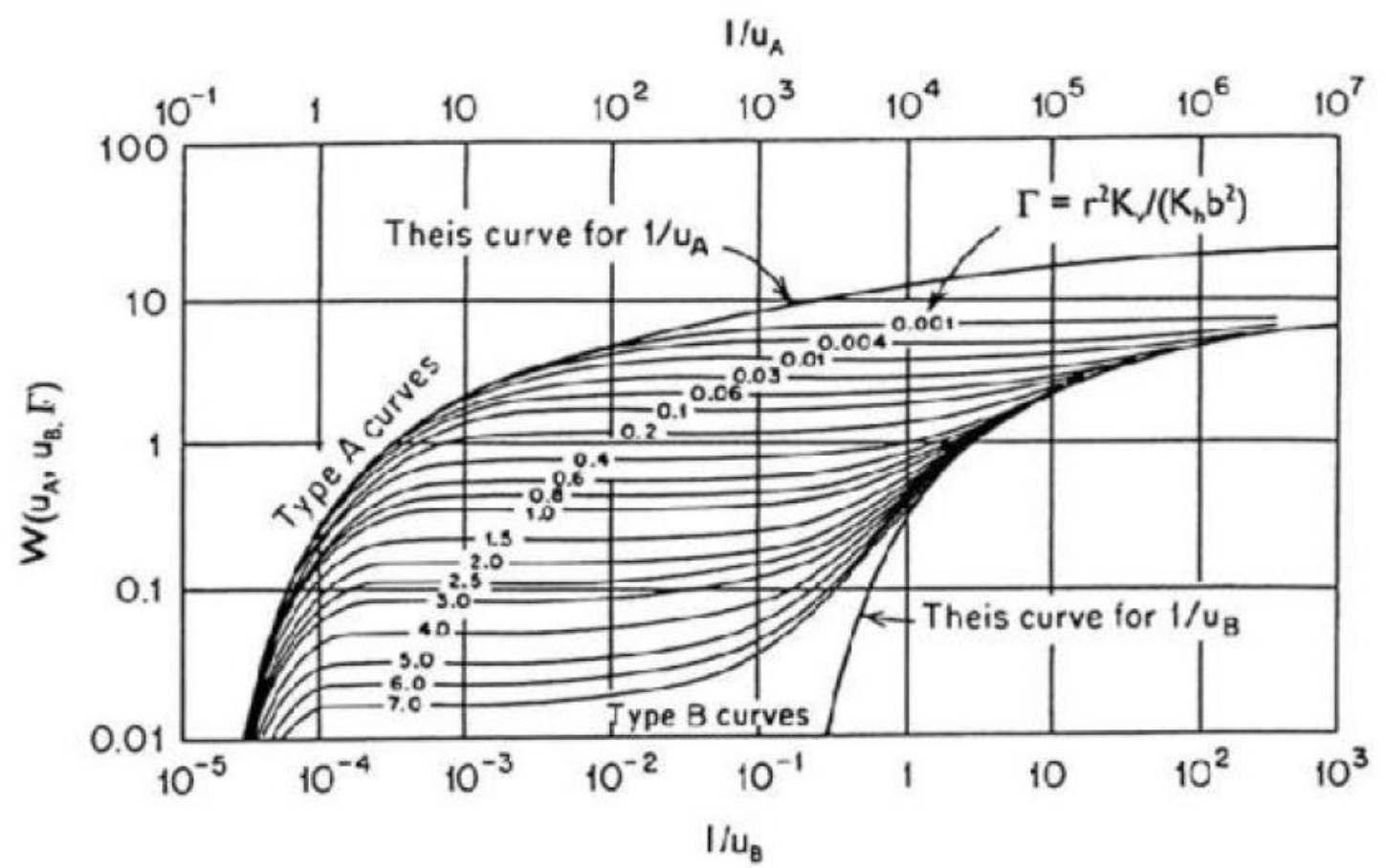

Figura 7: Curvas teóricas de $W(u A, u B, \Gamma)$ versus 1/uA e 1/uB para um aquífero livre. Fonte: Freeze e Cherry (1979). 


\subsection{Parâmetros Hidráulicos e Erros Associados}

Testes de bombeamento e recuperação são normalmente empregados para a obtenção dos parâmetros hidráulicos, condutividade hidráulica $(\mathrm{K})$, transmissividade $(\mathrm{T})$ e coeficiente de armazenamento (S) e os métodos descritos nas seções anteriores são utilizados para a interpretação desses testes. O coeficiente de armazenamento é importante e aplicado para modelos de aquíferos transientes, que não está no escopo desse trabalho.

De acordo com Cey et al. (1998), devido à heterogeneidade do solo, as medições de valores de $\mathrm{K}$ podem, com frequência, ser aferidas com grandes variações na ordem de grandezas, mesmo em medições em poços a curta distância. Meier et al. (1998) ressaltam também que a medição de valores de transmissividade local são susceptíveis a erros, pois são assumidas a homogeneidade e isotropia na transmissividade em campo, e há erros na medição do rebaixamento ou ascensão do nível d'água no poço durante a execução dos testes. Pelo fato da interpretação dos testes ser baseada em modelos teóricos que muitas vezes não representam adequadamente as características do aquífero, valores não acurados podem ser aferidos. Esses mesmos autores salientam que, na maioria dos casos, os valores de K são obtidos indiretamente da relação $T=b . K$, sendo $b$ a espessura do aquífero. Um dos maiores problemas é dimensionar o espaço em que o aquífero está sob influência do teste. Esse aspecto é diretamente relacionado com o tempo de duração do teste. Quando esse é de curta duração, o espaço de influência pode ser da ordem de metros. Caso contrário, em testes de longa duração, o espaço de influência pode atingir um raio de quilômetros. Mesmo conhecendo a duração do teste, esse está sujeito a outras incertezas associadas a outros parâmetros inerentes ao meio, como, por exemplo, o coeficiente de armazenamento que também é associado a incertezas, no entanto, frequentemente, sujeito a variações menores que $\mathrm{T}$.

De acordo com Rabelo (2006), o tratamento dos dados experimentais é necessário antes de iniciar qualquer modelo. Segundo ele, valores de T são disponíveis localmente em apenas alguns pontos do aquífero, formando, por exemplo, um conjunto de algumas dezenas em uma área de 1000 km². Independentemente dos erros associados à mediação dos parâmetros de T, não é incomum os seus valores variarem em até cinco ordens de grandeza em aquíferos regionais.

Montenegro et al. (1999) observam que os valores de T, observados experimentalmente, seguem os padrões de uma distribuição log-normal, por apresentar uma distribuição assimétrica 
desses valores. Sendo assim, o uso de $y=\log (T)$ passa a ser permitido como variável, tratando o problema de sua variação por uma abordagem gaussiana.

Essas mesmas observações são estendida para os valores de condutividade hidráulica e capacidade específica $(\mathrm{Q} / \mathrm{s})$ na presente dissertação. Ou seja, adotam-se $\log (K)$ e $\log (Q / s)$ como variáveis.

A necessidade de se completar o conjunto de informações, em especial os valores de parâmetros hidráulicos a serem alocados em todos os pontos requeridos pelo modelo, bem como, a necessidade de avaliar sua incerteza associada, têm levado ao uso da geoestatística, promovendo um melhor ajuste entre os resultados observados em campo e gerados pelo modelo (Rabelo, 2006).

\subsection{Métodos Estatísticos}

O tratamento estatístico dos dados nesse trabalho consiste nos testes de normalidade e o cálculo da correlação entre dois parâmetros hidráulicos, condutividade hidráulica $(\mathrm{K})$ e capacidade específica $(\mathrm{Q} / \mathrm{s})$, tendo como produto desse tratamento uma relação empírica entre esses.

Basicamente, são três as maneiras mais comuns de verificar a hipótese de normalidade: métodos gráficos, numéricos e os formais testes de normalidade. Os métodos gráficos são os métodos mais fáceis de verificação da normalidade. O gráfico quantil-quantil ou Q-Q plot destaca-se como a ferramenta mais usada e efetiva para a verificação de normalidade da distribuição dos dados (Razali e Wah, 2011). Outros métodos gráficos comuns para essa verificação são o histograma e o diagrama de caixa ou box plot. Apesar dos métodos gráficos configurarem uma ferramenta útil para constatação da normalidade para uma amostra de $n$ observações independentes, eles ainda não são suficientes para fornecer evidências conclusivas da normalidade esperada. Sendo assim, métodos numéricos e testes formais de normalidades devem ser aplicados antes de uma conclusão final quanto à normalidade dos dados.

Os métodos numéricos incluem coeficientes de assimetria e de curtose. O teste de normalidade, por sua vez, é mais formal e envolve testar se um determinado dado segue a distribuição normal. Há diversos testes de normalidade na literatura, no entanto, os mais comuns em trabalhos científicos são Shapiro-Wilk (S-W), Kolmogorov-Smirnov (K-S), AndersonDarling e Lilleiefords (Razali e Wah, 2011). 
Dentre os testes de normalidade citados, o teste Kolmogorov-Smirnov destaca-se como o mais utilizado nos estudos de parâmetros hidrogeológicos (Yoon et al., 2013; Verbovšek, 2008; Dogan et al., 2011; Razack e Lasm, 2006). Gleeson et al. (2011) e Verbovšek (2009) aplicam o teste Shapiro-Wilk juntamente com o teste K-S com o objetivo de dar mais credibilidade para os resultados de seus trabalhos. De acordo com Swan e Sandilands (1995), a forma da distribuição pode fornecer pistas da natureza do processo geológico.

Os dois testes de normalidade aplicados nesse trabalho, Kolmogorov-Smirnov e ShapiroWilk, utilizam métodos não paramétricos. Diferentemente dos paramétricos, esses métodos são baseados em testes de distribuição em que os parâmetros são desconhecidos (Davis, 1986). De acordo com Swan e Sandilands (1995), os parâmetros da distribuição normal que os métodos não paramétricos não usam especificamente são: média e desvio padrão.

Pela média não ter relevância nos cálculos não paramétricos, os testes são baseados na mediana. Ao contrário da média, a mediana é encontrada sem cálculos e é baseada somente nas posições relativas. Os testes estatísticos não paramétricos univariados comumente apresentam uma hipótese nula de igualdade das medianas das populações (Swan e Sandilands, 1995).

$\mathrm{Na}$ busca por trabalhos de referência no que concerne a relação empírica entre dois parâmetros hidráulicos, observa-se que esse tipo de abordagem é majoritariamente dado à relação entre transmissividade $(\mathrm{T})$ e $(\mathrm{Q} / \mathrm{s})$. No entanto, como são necessários dados de K para alimentar os modelos hidrogeológicos, nesse trabalho a variável T é substituída pela condutividade hidráulica. Os trabalhos consultados para tal abordagem foram os de Razack e Huntley (1991), Mace (1997), Mace et al (2000), Hamm et al. (2005) e Srivastav et al. (2007).

\subsubsection{Kolmogorov-Smirnov (K-S)}

Razali e Wah (2011) classificam o teste K-S como um teste de função de distribuição empírica (FDE). Sucintamente, os testes FDE são baseados na medição da discrepância entre distribuições empíricas e hipotéticas. No teste K-S, a distribuição hipotética aplicada no presente trabalho é a função de distribuição acumulada (FDA).

A figura 8 ilustra como o teste K-S funciona. Segundo Davis (1986), seleciona-se uma amostra de uma população desconhecida e é testada a conformidade de um modelo hipotético para tal população. Tanto a amostra como o modelo hipotético são plotados juntos de forma acumulada. Então é verificada a maior diferença entre as distribuições empírica e hipotética, T. Com os $n$ dados ordenados, $\mathrm{x}_{1}<\mathrm{x}_{2}<\ldots<\mathrm{x}_{n}$, Conover (1999) define o teste K-S como: 


$$
\mathrm{T}=\sup _{\mathrm{x}}\left|\mathrm{F}^{*}(\mathrm{x})-\mathrm{F}_{n}(\mathrm{x})\right|
$$

onde 'sup' é uma abreviação de supremum que é a máxima diferença entre as distribuições. $\mathrm{F}^{*}(\mathrm{x})$ representa a função de distribuição hipotética, enquanto $\mathrm{F}_{\mathrm{n}}(\mathrm{x})$ é a FDE estimada com base na amostra aleatória. No teste de normalidade $\mathrm{K}-\mathrm{S}, \mathrm{F}^{*}(\mathrm{x})$ é tomada como uma distribuição normal com média, $\mu$, conhecido.

O teste estatístico K-S é construído para testar:

$\mathrm{H}_{\mathrm{o}}: \mathrm{F}(\mathrm{x})=\mathrm{F}^{*}(\mathrm{x})$ para todo $\mathrm{x}$ de $-\infty$ a $\infty$ (os dados seguem uma distribuição específica)

$\mathrm{H}_{\mathrm{a}}: \mathrm{F}(\mathrm{x}) \neq \mathrm{F}^{*}(\mathrm{x})$ para pelo menos um valor de $\mathrm{x}$ (os dados não seguem a distribuição específica).

No caso do presente trabalho, a hipótese nula é a de normalidade.

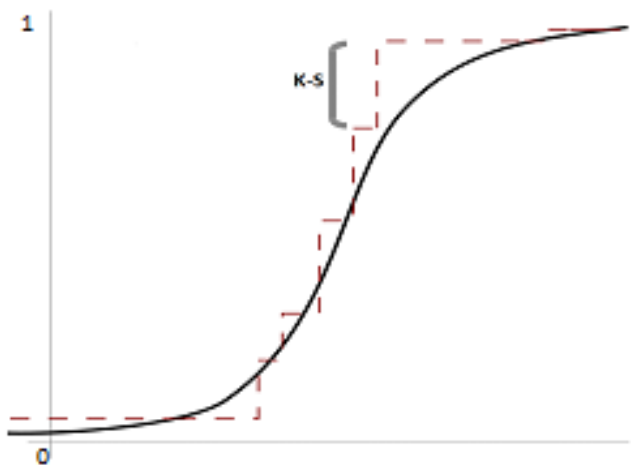

Figura 8: Procedimento de Kolmogorov-Smirnov para testar a qualidade do ajuste da distribuição da amostra (linha tracejada) e modelo hipotético da população (linha contínua). Ambos são plotados de forma acumulativa de 0 a 1 . $K-S$ representa a máxima diferença entre as distribuições.

Segundo Razali e Wah (2011), se T excede o quantil 1- $\alpha$ como dado pela tabela de quantis do teste K-S a hipótese nula, $\mathrm{H}_{\mathrm{o}}$, é rejeitada no nível de significância, $\alpha$.

\subsubsection{Teste Shapiro-Wilk(S-W)}

De acordo com Razali e Wah (2011), o teste S-W foi o primeiro capaz de detectar a diferença de normalidade pela assimetria e/ou curtose. Devido às suas propriedades, o teste SW é preferido na verificação da normalidade na distribuição das amostras.

Para esses autores, dada uma amostra aleatória ordenada, $\mathrm{y}_{1}<\mathrm{y}_{2}<\cdots<\mathrm{y}_{\mathrm{n}}$, o teste SW é definido como:

$$
\mathrm{W}=\frac{\left(\sum_{\mathrm{i}=1}^{\mathrm{n}} \mathrm{a}_{\mathrm{i}} \mathrm{y}_{\mathrm{i}}\right)^{2}}{\sum_{\mathrm{i}=1}^{\mathrm{n}}\left(\mathrm{y}_{\mathrm{i}}-\overline{\mathrm{y}}\right)^{2}}
$$


onde $y_{\mathrm{i}}$ é o valor de cada elemento da amostra; $\bar{y}$ é a média da amostra e $\mathrm{a}_{\mathrm{i}}=\left(\mathrm{a}_{1}, \ldots, \mathrm{a}_{\mathrm{n}}\right)=$ $\frac{\mathrm{m}^{\mathrm{T}} \mathrm{V}^{-1}}{\left(\mathrm{~m}^{\mathrm{T}} \mathrm{V}^{-1} \mathrm{~V}^{-1} \mathrm{~m}\right)^{1 / 2}}$ e $\mathrm{m}=\left(\mathrm{m}_{1}, \ldots, \mathrm{m}_{\mathrm{n}}\right)^{\mathrm{T}}$ são valores esperados das estatísticas ordinais de distribuições independentes e idênticas de variáveis aleatórias amostradas de uma distribuição normal padrão; e $\mathrm{V}$ é a matriz de covariância dessas ordens estatísticas.

$\mathrm{O}$ valor obtido de $\mathrm{W}$ está entre zero e um. Valores pequenos indicam a rejeição da hipótese de normalidade, enquanto o valor de um mostra a normalidade dos dados (Razali e Wah, 2011).

Razali e Wah (2011) concluíram em seu trabalho que o teste Shapiro-Wilk se mostrou o teste mais poderoso para todos os tipos de distribuições e tamanhos de amostras, comparativamente com o teste Kolmogorov-Smirnov. No entanto, o poder do teste $\mathrm{S}$-W é baixo para pequenas amostras $(<50)$.

\subsubsection{Teste de independência}

Antes de prosseguir na apresentação do teste de independência, teste de $t$, é importante discutir a escolha do nível de significância $(\alpha)$ que será utilizado e o critério para sua escolha. Segundo Davis (1986), o nível de significância é de responsabilidade do pesquisador, cabendo a ele decidir qual é o risco de rejeitar a hipótese verdadeira. Caso um nível de significância seja demasiadamente restrito, a hipótese nula pode nunca ser rejeitada, sendo necessário um número elevado de dados, que em muitos casos não estão disponíveis para a pesquisa. Por outro lado, a aplicação de níveis de confiança mais modestos possibilita que conclusões satisfatórias sejam alcançadas com mais frequência.

Em trabalhos que associam duas propriedades hidrogeológicas é comum verificar que os autores optam por usar um nível de significância de 5\% $(\alpha=0.05)$, como Mace (1997), Mace et al. (2000), Hamm et al. (2005), Srivastav et al. (2007), que empregam diferentes tamanhos de amostras em extensas áreas. Seguindo essa tendência, no presente trabalho é usado um nível de significância de $5 \%$.

\subsubsection{Teste $t$ de Student}

O teste $t$ é um teste estatístico de hipóteses sobre os parâmetros distribuições de probabilidade. De acordo com Swan e Sandilands (1995), de forma genérica um teste estatístico deve ter as seguintes componentes: 
a) Duas hipóteses sobre o parâmetro ou parâmetros de interesses;

b) Dados de duas populações;

c) Estatísticas que forneçam informações sobre os parâmetros;

d) Uma função, chamada de teste estatístico, das estatísticas que apresentam uma distribuição de probabilidade conhecida quando o parâmetro de interesse é conhecido;

e) Um nível de significância para distinção entre eventos raros e comuns;

f) Usar o nível de significância para identificar séries de valores do teste estatístico que gerariam dúvida nas hipóteses e;

g) Um reconhecimento da possibilidade de rejeitar uma hipótese verdadeira ou aceitar uma falsa.

Como explicado por Davis (1986), o teste $t$ é útil para estabelecer a probabilidade de uma dada amostra ser membro de uma população com características específicas, ou para testar a hipótese sobre a equivalência de duas amostras.

Em testes como o teste $\mathrm{t}$, duas hipóteses são consideradas. A hipótese nula, comumente denotada por $\mathrm{H}_{\mathrm{o}}$, e a hipótese alternativa, $\mathrm{H}_{1}$. É a afirmação de $\mathrm{H}_{\mathrm{o}}$, que é utilizada na estatística de teste. A hipótese alternativa é a afirmação cuja veracidade se deseja estabelecer, sendo uma hipótese que contrasta com a hipótese nula (Swan e Sandilands, 1995).

O teste $t$ usa uma distribuição chamada de $t$, sendo essa similar à distribuição normal (Figura 9). No entanto, a forma da curva muda de acordo com o número de observações na amostra que se usa para estimar a população. Quanto maior for o número de observações na amostra, mais a curva da distribuição $t$ vai parecer com uma distribuição normal. Quando esse número de observações é infinito, as duas distribuições são idênticas (Davis, 1986). 


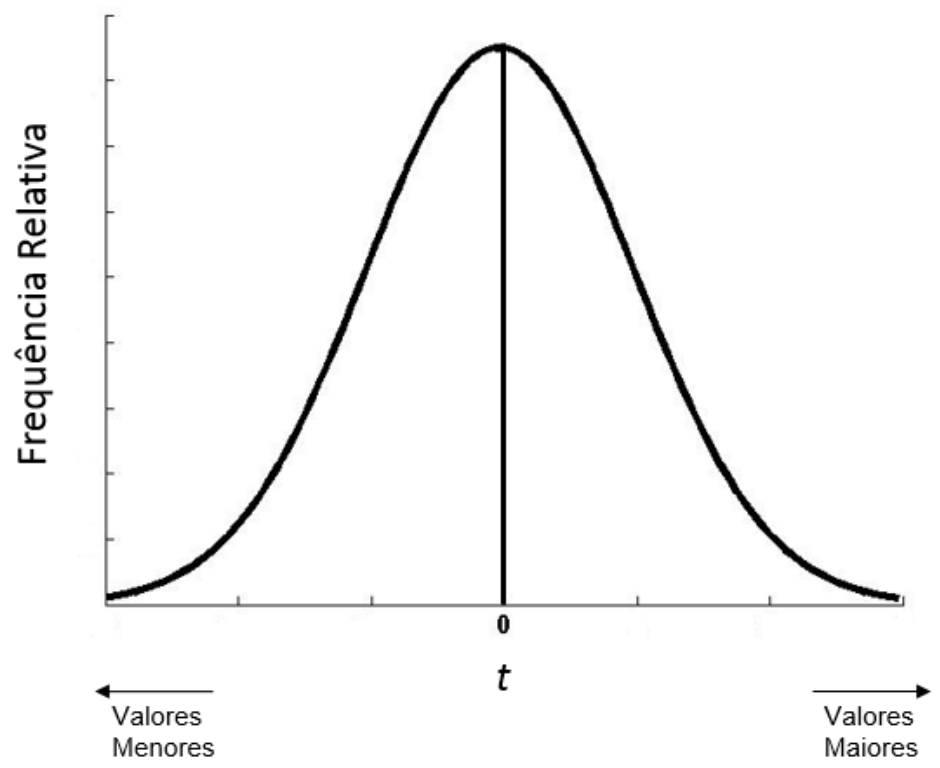

Figura 9: Distribuição de t Student. Uma distribuição de probabilidade baseada nos números de observações.

No test $t$ assume-se que as amostras são coletadas aleatoriamente da distribuição normal e a estatística t pode ser computada pela expressão (26):

$$
t=\frac{\bar{x}-\mu_{o}}{s_{e}}=\frac{\bar{X}-\mu_{o}}{s \sqrt{\left(\frac{1}{n}\right)}}
$$

onde $\overline{\mathrm{X}}$ é a média das amostras, $\mu_{\mathrm{o}}$ representa a média da população hipotética, $\mathrm{n}$ é o número de observações, s o desvio padrão das observações e $\mathrm{s}_{\mathrm{e}} \mathrm{o}$ erro padrão das médias.

Conforme Davis (1986), para se obter o valor crítico de $t$ é necessário especificar o nível de significância e os graus de liberdade, sendo o último definido como o número de observações em uma amostra menos o número de parâmetros estimados da amostra. Definidos $\alpha$ e os graus de liberdade, consulta-se uma tabela de valores críticos. Caso o valor de $t$ seja maior que o $\mathrm{t}$ crítico, a hipótese nula é aceita. Caso contrário, $\mathrm{H}_{\mathrm{o}}$ é rejeitada. Lembrando que com o uso de um nível de significância igual a 0.05 , há $5 \%$ de se rejeitar uma hipótese verdadeira.

Esse mesmo teste pode ser aplicado quando se deseja comparar estatísticas de duas populações. Esse trabalho usa essa abordagem, comparando as estatísticas dos diferentes aquíferos e verificando se esses pertencem a uma mesma população. Nesse caso, verifica-se a hipótese de ambas variáveis serem oriundas de uma mesma distribuição normal. No entanto, o cálculo é mais elaborado.

O processo para associar o teste da diferença entre duas médias é similar ao utilizado no teste de um valor hipotético da média populacional, exceto que se utiliza o erro padrão da 
diferença entre médias como base para se determinar o valor da estatística de teste associada com os resultados das amostras. A hipótese nula usualmente testada é a de que as duas amostras tenham sido obtidas de populações com médias iguais (Davis, 1986).

Segundo Davis (1986), nesse caso, o uso da distribuição normal está baseado nas mesmas condições que o caso de uma média (ou uma amostra), exceto que estão envolvidas duas amostras independentes. Na prática, a distribuição normal pode ser utilizada quando o desviopadrão da população for conhecido ou as variâncias forem conhecidas.

O uso da distribuição de Student $(t)$ leva em conta se as variâncias populacionais são equivalentes ou diferentes. Na prática, utiliza-se a distribuição $t$ quando o desvio-padrão da população for desconhecido ou as variâncias forem desconhecidas, empregando-se o desviopadrão da amostra, s.

Considerando duas populações normais independentes com médias $\mu_{1}$ e $\mu_{2}$ e variâncias $\sigma_{1}^{2}$ e $\sigma_{2}^{2}$, sendo $n_{1}$ e $n_{2}$ duas amostras independentes obtidas, respectivamente, dessas populações, e $\overline{\mathrm{x}}_{1}$ e $\overline{\mathrm{x}}_{2}$ suas médias. A estatística de teste a ser usada é:

$$
z_{t}=\frac{\left(\bar{x}_{1}-\bar{x}_{2}\right)}{\sqrt{\left(\frac{\sigma_{1}^{2}}{n_{1}}+\frac{\sigma_{2}^{2}}{n_{2}}\right)}}
$$

Swan e Sandilands (1995) acrescentam que quando as variâncias populacionais forem desconhecidas, mas $\left(n_{1}+n_{2}\right) \geq 30$, usam-se as suas estimativas não tendenciosas (variâncias amostrais $\mathrm{s}_{1}^{2}$ e $\mathrm{s}_{2}^{2}$ ), no cálculo da estatística de teste $\mathrm{z}_{\mathrm{t}}$ :

$$
z_{t}=\frac{\left(\bar{x}_{1}-\bar{x}_{2}\right)}{\sqrt{\left(\frac{s_{1}^{2}}{n_{1}}+\frac{s_{2}^{2}}{n_{2}}\right)}}
$$

\subsubsection{Teste de correlação linear}

Em alguns casos é necessário estudar a relação mútua entre duas variáveis aleatória (X e Y) para assegurar se elas são correlacionáveis ou não, para o cálculo de co-estimativas. Para isso necessita-se das estatísticas que correlacionem duas variáveis aleatórias (Yamamoto, 2001).

A hipótese de que X e Y são variáveis independentes por análise de regressão linear é normalmente difícil de provar em dados nas ciências da Terra. Poucas variáveis na natureza são verdadeiramente independentes fisicamente ou geologicamente (Size, 1987). 
Conforme Landim (1998), se x e y representam duas variáveis medidas em um certo número de indivíduos, um diagrama de dispersão mostrará a localização dos pontos $\left(\mathrm{x}_{\mathrm{i}}, \mathrm{y}_{\mathrm{i}}\right)$ em um sistema de eixos cartesianos. Se os pontos nesse diagrama se localizarem próximos de uma reta, a relação é dita linear e uma equação torna-se apropriada para os fins de análise de correlação entre duas variáveis, ou seja, de estimativa do comportamento de uma variável em relação a outra.

De acordo com Davis (1986), pode-se estender os procedimentos usados para o cálculo da variância de uma única propriedade para o cálculo da medida de variabilidade mútua entre as duas variáveis. Sendo assim, a covariância mede a distribuição de valores de duas variáveis em torno de uma média comum. A covariância pode ser expressa por:

$$
\operatorname{Cov}(\mathrm{X}, \mathrm{Y})=\mathrm{E}[\mathrm{XY}]-\mathrm{E}[\mathrm{X}] \mathrm{E}[\mathrm{Y}]
$$

Para a estimativa do grau de correlação entre as variáveis pode ser utilizado o coeficiente de correlação linear Corr (X, Y) que representa a razão entre covariância e o produto dos desvios padrões das variáveis:

$$
\operatorname{Corr}(X, Y)=r=\frac{\operatorname{Cov}(X, Y)}{\sqrt{\operatorname{Var}(X) \operatorname{Var}(Y)}}=\frac{\frac{\sum\left(x_{i}-\bar{x}\right)\left(y_{i}-\bar{y}\right)}{n-1}}{\left[\frac{\sum\left(x_{i}-\bar{x}\right)^{2}}{n-1} \cdot \frac{\left(y_{i}-\bar{y}\right)^{2}}{n-1}\right]^{1 / 2}}
$$

onde $\mathrm{n}$ é o número de pares de valores para $\mathrm{x}_{\mathrm{i}}$ e $\mathrm{y}_{\mathrm{i}}$, variáveis com distribuição normal, e $\overline{\mathrm{x}}$ e $\overline{\mathrm{y}}$ são os valores médios para $\mathrm{x}_{\mathrm{i}} \mathrm{e} \mathrm{y}_{\mathrm{i}}$.

O coeficiente de correlação, r, que é adimensionais, assume valores entre -1 e 1. Quando ré igual a 1, significa que há completa relação entre as variáveis. Quando esse valor é -1, inferese que que há uma relação inversa, sendo assim, quando uma variável aumenta, a outra diminui. Se o coeficiente de correlação for 0 , as duas variáveis não apresentam qualquer relação. Portanto, o modelo linear simples pode ser utilizado quando se está interessado nas relações entre duas variáveis ou mesmo entre dois eventos, ou quando se quer predizer a ocorrência de uma delas ou de um deles em relação ao outro (Landim, 1998).

Nesse trabalho adotam-se dois métodos para avaliar o erro de ajuste da reta que relaciona a condutividade hidráulica e capacidade específica: gráfico de dispersão ou scatter plot e o erro da raiz da média ao quadrado ou root mean square error (RMSe).

O gráfico de dispersão é, segundo Spitz e Moreno (1996), juntamente com o coeficiente, indica onde as maiores discrepâncias ocorrem e se há discrepâncias localizadas ou generalizadas entre as previsões e as observações.

Quanto ao RMSE, pode-se calculá-lo usando a expressão: 


$$
R M S E=\left[\sum_{i=1}^{n} \frac{\left(P_{i}-O_{i}\right)^{2}}{n}\right]^{1 / 2}\left[\frac{100}{\bar{o}}\right]
$$

sendo $P_{i}$ o valor estimado, $O_{i}$ o valor observado, $\bar{o}$ a média dos valores observados e $n$ o números de valores. O valor do RMSE deve ser o mais próximo de zero (Spitz e Moreno, 1996).

\subsection{Análise Geoestatística}

Segundo Yamamoto e Landim (2013), a geoestatística tem por finalidade a caracterização espacial de uma variável de interesse por meio do estudo de sua distribuição e variabilidade espaciais, com determinação das incertezas associadas.

O uso dos métodos geoestatísticos tem sido amplamente utilizado em hidrogeologia. $\mathrm{O}$ artigo mais antigo em língua inglesa encontrado na revisão bibliográfica tratando sobre geoestatística aplicada a aquíferos foi escrito por Delhomme (1978). Outros artigos que datam desse período são os trabalhos desenvolvidos por Myers (1984) e Aboufirassi e Marino (1984).

Como observado por Patriarche et al.(2005), os estudos geoestatísticos que visam estimar parâmetros hidráulicos em escala regional, abrangendo quilômetros, são escassos, sendo alguns exemplos de trabalhos nessa escala desenvolvidos por Castro et al. (1998), Castro e Goblet (2003) e Patriarche et al. (2004).

Alguns estudos como os desenvolvidos por Ahmed e Marsily (1987), Christensen (1997), Delhomme (1974, 1979), Hughson et al. (1996) e Wladis e gustafson (1999) fazem análises comparativas entre diversos métodos geoestatísticos visando estimar parâmetros hidráulico com dados esparsos (variável primária) com o uso de um outro parâmetro mais densamente amostrado (variável secundária). Em comum a todos esses trabalhos, é o uso dos métodos de krigagem ordinária e cokrigagem. A variável primária é a transmissividade (T) e a secundária é a capacidade específica (Q/s). Ahmed e Marsily (1987) e Christensen (1997) aplicam o método de krigagem ordinária combinada com regressão linear usando a relação empírica entre T e Q/s. Na busca por literatura referente ao tema, o artigo de Pucci e Murashige (1988) mostrase como um dos pioneiros no uso da krigagem ordinária combinada com a regressão linear relacionando $\mathrm{K}$ e $\mathrm{Q} / \mathrm{s}$.

O presente trabalho consiste na aplicação de três métodos geoestatísticos de estimativa, a krigagem ordinária e cokrigagem, e o método estocástico, a Simulação por bandas rotativas. O método de krigagem ordinária é usado duas vezes em cada área de interesse, sendo uma usando apenas os valores de condutividade hidráulica $(\mathrm{K})$ mensurados pelos métodos de interpretação 
dos testes de bombeamento e outra usando os mesmos valores de K da primeira aplicação e, adicionalmente, valores calculados com base na equação da reta que associa esse parâmetro hidráulico com a capacidade específica $(\mathrm{Q} / \mathrm{s})$, ou seja, uma krigagem ordinária combinada com regressão linear.

Primeiramente, são abordados os fundamentos geoestatísticos inerentes a todos os métodos aplicados no trabalho. Sequencialmente, são descritos os métodos individualmente.

\subsubsection{Variáveis regionalizadas}

De acordo com Olea (2003) e Armstrong (1998), a geoestatística trata da caracterização de atributos espaciais, também conhecidos como variáveis regionalizadas, termo esse criado por Matheron (1963). Normalmente, os atributos são parcialmente conhecidos em um número limitado de pontos amostrados. Pesquisas sempre incluem a localização geográfica para cada medição de atributo.

As técnicas geoestatísticas depende de variáveis aleatórias para modelar a incerteza associada com dada avaliação. A ideia de usar variáveis aleatórias para caracterizar eventos determinísticos incertos pode não ser intuitivo, mas ela não é a única forma para geoestatística. Frequentemente, em geoestatística, usam-se modelos que compreendem uma variável por atributo por local para modelar uma área parcialmente conhecida. Esse é um ponto de partida radical, para a estatística clássica multivariada. Uma vez que a localização geográfica varia continuamente, o número de variáveis tratadas em geoestatística é infinito mesmo para áreas de interesse de tamanho finito (Olea, 2003).

De acordo com Yamamoto (2001), as características das variáveis regionalizadas que os métodos estatísticos convencionais não conseguem reconhecer são:

- Localização: a posição relativa das amostras e a sua distribuição espacial exercem influência sobre a correlação espacial da variável regionalizada;

- Suporte: corresponde à unidade amostral, seja ela pontual, volumétrica, etc.;

- Continuidade: para uma variável ser considerada regionalizada, deve existir uma variação espacial ponto a ponto, que pode ser expressa matematicamente por meio do semivariograma;

- Anisotropia: corresponde à diferença de variações entre as diferentes direções estudadas. 
Como abordado por Olea (2003) e usando notações utilizadas por Deutsch (2002), uma função aleatória (FA) é uma coleção de variáveis aleatórias (VA) $\{\mathrm{Z}(\mathrm{u}): \mathrm{u} \in$ área de estudo A $\}$, sendo A o domínio espacial em um espaço Euclidiano n-dimensional. Normalmente, a definição de FA é restrita a variáveis aleatórias relacionadas ao mesmo atributo, dito como $z$, então, outra VA seria definida para modelar a variabilidade espacial do segundo atributo, dito como $\{\mathrm{Y}(\mathrm{u})$, $\mathrm{u} \in$ área de estudo A\}. No presente trabalho, aplica-se o método de cokrigagem para dois atributos distintos, porém estatisticamente relacionados.

A incerteza sobre um valor não amostrado $z$ é modelado através da distribuição de probabilidade de uma função aleatória $Z$. Na notação Z(u), u é o vetor da coordenada de localização das amostras. A distribuição de probabilidade de $\mathrm{Z}$ após o condicionamento dos dados é usualmente dependente da localização (Deutsch, 2002).

Segundo Armstrong (1998) o valor observado em cada ponto u é considerado como um resultado, z(u), de uma variável aleatória, Z(u). Em pontos onde não há medição, os valores z(u) são definidos, mesmo sendo desconhecidos. Eles podem ser considerados realizações da variável aleatória correspondente $\mathrm{Z}(\mathrm{u})$. Em termos matemáticos, a família de todas essas variáveis aleatórias é chamada de função aleatória.

De acordo com Deutsch (2002), assim como uma VA, Z(u) é caracterizada por sua função de densidade acumulada (FDA), uma FA, Z(u), é caracterizada pela série de todas as suas FDA $\mathrm{N}$-variáveis para qualquer número $\mathrm{N}$ e qualquer escolha $\mathrm{N}$ locais $u_{i}, i=1, \ldots, N$ dentro da área de estudo A:

$$
F\left(u_{1}, \ldots, u_{N} ; z_{1}, \ldots, z_{N}\right)=\operatorname{Prob}\left\{Z\left(u_{1}\right) \leq z_{1}, \ldots, Z\left(u_{N}\right) \leq z_{N}\right\}
$$

Assim como a função de densidade acumulada univariada da variável aleatória, Z(u) é caracterizada por demonstrar a incerteza sobre o valor z(u), a FDA multivariada é utilizada para caracterizar conjunto de incerteza sobre os $\mathrm{N}$ valores $\mathrm{z}\left(u_{1}\right), \ldots, \mathrm{z}\left(u_{N}\right)$.

A FDA bivariada $(\mathrm{N}=2)$ de quaisquer duas variáveis aleatórias $\mathrm{Z}\left(u_{1}\right), \mathrm{Y}\left(u_{2}\right)$ é particularmente importante devido aos métodos geoestatísticos convencionais serem restritos à univariável (F(u; z)) e bivariável:

$$
F\left(u_{1}, u_{2} ; y, z\right)=\operatorname{Prob}\left\{Z\left(u_{1}\right) \leq z, Y\left(u_{2}\right) \leq y\right\}
$$

A função de covariância resume a FDA bivariável $\mathrm{F}\left(u_{1}, u_{2} ; z, y\right)$, sendo definida como:

$$
C\left(u_{1}, u_{2}\right)=E\left\{Z\left(u_{1}\right) Y\left(u_{2}\right)\right\}-E\left\{Z\left(u_{1}\right)\right\} E\left\{Y\left(u_{2}\right)\right\}
$$

Como ressaltado por Isaaks e Srivastava (1989), tanto a distribuição de probabilidade da variável aleatória univariada quanto a bivariada independem da localização de u. Em todas a localização, 0 e 1 têm ocorrência equiprovável. Independentemente da localização, todos os 
pares de variáveis aleatórias separados por uma particular distância $h$ têm o mesmo conjunto de distribuição de probabilidade. Essa independência da localização é conhecida como estacionariedade.

A distância que separa um par de pontos representada pela letra $h$ é chamada de passo ou lag na geoestatística.

Chilès e Delfiner (1999) explicam que, fisicamente, a estacionariedade significa que o fenômeno é homogêneo no espaço e se repete em todo domínio. Sendo assim, quando uma função aleatória é estacionária, seus momentos estatísticos são obviamente invariáveis se transladados. Se apenas os dois primeiros momentos forem considerados, tem-se para pontos $u$ e $u+h$ de $\mathbb{R}^{n}$

$$
\begin{aligned}
& \left\{\begin{array}{c}
E Z(u)=m \\
E[Z(u)-m][Z(u+h)-m]=C(h)
\end{array}\right. \\
& \forall u, u+h \in A
\end{aligned}
$$

A média é constante e a função de covariância depende somente da separação $h$. Por definição, uma FA que satisfaz ambas condições é considerada estacionária de segunda ordem (Chilès e Delfiner, 1999).

Segundo Olea (2003), a estacionariedade de segunda ordem diz que apesar da função aleatória variar de local para local, o semivariograma é independente da localização e depende somente da distância de pares h de variáveis a serem consideradas.

Deutsch (2002) explica que para inferências estatísticas são necessárias repetitivas amostragens. No entanto, na maioria das aplicações, tem-se no máximo uma amostra para cada localização u em cada caso que z(u) é conhecido, ignorando os erros de amostragem. Sendo assim, a necessidade de considerar um modelo de VA desaparece. Para lidar com o paradigma embutido no processo de inferência estatística, a replicação indisponível na locação u é substituída por uma disponível em algum lugar no espaço e/ou tempo. Por exemplo, a FDA $\mathrm{F}(\mathrm{u} ; \mathrm{z})$ pode ser inferida da distribuição de amostragem de z-amostras coletadas de outras localizações, $u_{\alpha} \neq u$, dentro do mesmo campo A. Essa substituição de replicação corresponde à decisão de estacionariedade.

A decisão de estacionariedade também permite a inferência da estacionariedade de covariância $C(h)$, em que a covariância na amostra de todos os pares de dados é separada pelo vetor $h$. Quando $h=0$, a covariância estacionária $C(0)$ iguala à estacionariedade de variância $\sigma^{2}$, ou seja, 


$$
\begin{aligned}
C(0) & =E[Z(u)-m][Z(u+h)-m] \\
& =E[Z(u)-m][Z(u)-m]
\end{aligned}
$$

$=\operatorname{Var} Z(u)=\sigma^{2}$

A notação $C(0)$ é frequentemente usada como variância.

Segundo Deutsch (2002), em alguns casos o correlograma de estacionariedade padronizado é preferido:

$$
\rho(h)=\frac{C(h)}{C(0)}
$$

Em outros casos, um outro momento de segunda ordem chamado de variograma é considerado:

$$
\begin{array}{r}
2 \gamma(h)=\operatorname{Var}\left\{[Z(u)-Z(u+h)]^{2}\right\} \\
\forall u, u+h \in A
\end{array}
$$

Considerando a decisão de estacionariedade, a covariância, correlograma e variograma são ferramentas equivalentes para caracterizar a correlação de dois pontos:

$$
C(h)=C(0) \cdot \rho(h)=C(0)-\gamma(h)
$$

Tanto o semivariograma quanto a covariância referem-se à taxa de variação espacial da função aleatória, no entanto, enquanto o semivariograma aumenta, a covariância diminui (Figura 10). Isso se dá pelo fato de a covariância medir similaridade, enquanto o semivariograma a dissimilaridade.

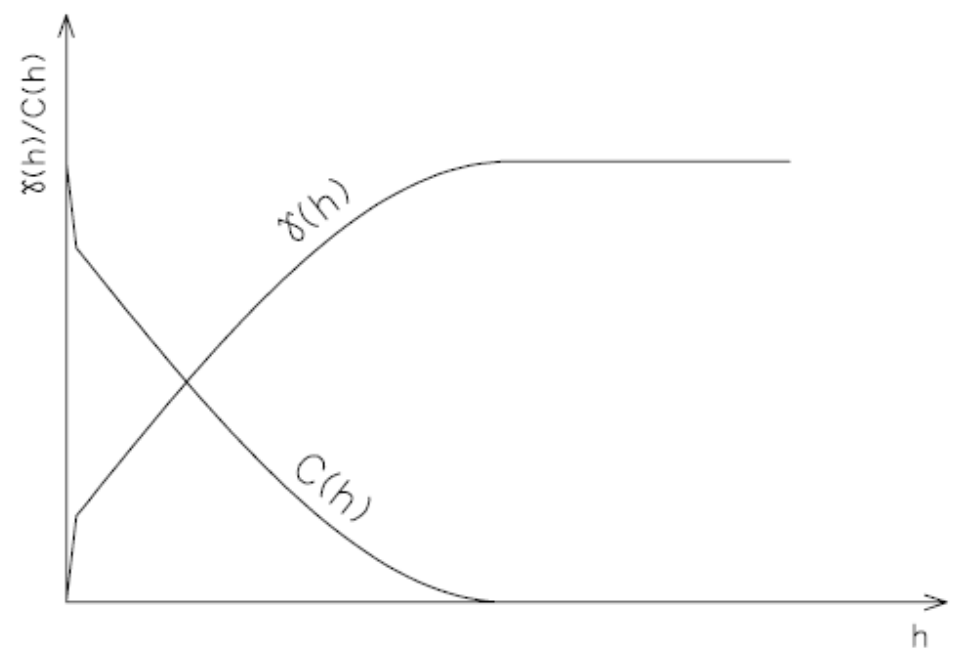

Figura 10: Relações entre as funções variograma e covariograma, sendo $x(h)$, o semivariograma e $C(h)$, o covariograma. Fonte: Yamamoto e Rocha (2001).

Relembrando que essa relação depende da estacionariedade indicada quando média e variância são constantes e independem da localização. Essas relações são fundamentais na interpretação do variograma (Deutsch, 2002). 


\subsubsection{Semivariograma experimental}

A utilização do semivariograma ou variograma é feita com o intuito de descrever o comportamento do fenômeno regionalizado, que corresponde à diferença entre valores amostrados, tomados em dois pontos, segundo uma determinada direção. De acordo com Kresic (2007), o variograma é usado como forma de determinar se há correlação espacial entre os dados medidos em campo. Esse mesmo autor sumariza a finalidade do semivariograma em três estágios:

1- Testar a correlação espacial entre as medições de uma mesma variável aferida em campo (correlação espacial);

2- Computar a covariância espacial entre os dados, incluindo cálculo da semivariância para cada par de observações;

3- Apresentar as semivariâncias calculadas graficamente como um variograma ou um semivariograma.

Nota-se que os termos variograma e semivariograma são permutavelmente usados na literatura e a real diferença entre os termos é o fator dois: o semivariograma é a metade do variograma amostrado, assim como semivariância é metade da variância amostrada.

Segundo Olea (2003), o semivariograma é uma estatística que avalia a diminuição média de similaridade entre duas variáveis aleatórias enquanto a distância entre as variáveis aumenta, fornecendo subsídios para tomadas de decisão. Uma estimativa do semivariograma é também chamada de variograma experimental.

Dadas duas localizações u e u+h em um campo de uma função aleatória $Z(u)$, se a média $E[Z(u)]$ é uma constante, então o semivariograma é:

$$
\gamma(h)=\frac{1}{2} E\left\{[Z(u)-Z(u+h)]^{2}\right\}
$$

ou em termos computacionais:

$$
\hat{\gamma}(h)=\frac{1}{2 N(h)} \sum_{N(h)}^{n}[Z(u+h)-Z(u)]^{2}
$$

onde $\hat{\gamma}(h)$ é a função semivariograma, $N(h)$ é o número de pares de pontos separados por uma distância $h ; Z(u+h)$ é o valor da variável regionalizada no ponto $(u+h) ; Z(u)$ é o valor da variável regionalizada no ponto $u$, que é ao mesmo tempo um pressuposto e uma definição de estacionariedade de segunda ordem de incrementos. 
Como salientado por Kresic (2007), o variograma é calculado para todo número de pares possível, que normalmente é representado por um número alto e pode ser estimado por:

$$
\text { Total de número de pares }=\frac{n(n-1)}{2}
$$

onde $n$ é o número de pontos de dados calculados.

A teoria por trás da krigagem e simulações condicionais requer o uso do variograma ou covariograma.

Pode-se notar que diferentemente de outros momentos estatísticos como a média, o semivariograma não é um simples número, mas uma função contínua de uma que depende da variável $h$. O passo é um vetor, sendo assim, não envolve somente magnitude de uma separação, mas também o azimute da linha entre os pares. O semivariograma é em geral uma função vetorial contínua de $h$. Uma amostragem descontínua impede que o variograma experimental seja estimado para todos os possíveis valores $h$. Pode-se definir o passo como a média dos espaçamentos mais próximos em determinada direção. Na prática, a estimativa pode ser limitada não somente pela distância de poucos pontos e direções após o arranjo dos pares de locais de amostragem, mas também pela orientação espacial (Olea, 2003).

De acordo com Deutch (2002), a variável de interesse é selecionada antes do cálculo do variograma. Sendo essa escolha evidente para aplicações convencionais de krigagem, no entanto, a transformação dos dados é comumente usada na moderna geoestatística. O uso de técnicas gaussianas requer uma prévia transformação normal score dos dados e o variograma desses dados transformados.

Nos métodos estocásticos no escopo desse trabalho, simulação sequencial gaussiana e bandas rotativas, os dados selecionados, no caso os referentes à condutividade hidráulica, são previamente transformados por normal score e, após isso, o variograma é calculado.

A função semivariograma é direcional, pois o semivariograma é calculado em uma direção predefinida. Na prática, é utilizada a chamada análise estrutural, onde são construídos semivariogramas segundo várias direções no campo amostral. A partir da interpretação do semivariograma, obtêm-se parâmetros que descrevem o comportamento espacial das variáveis regionalizadas. Semivariogramas em diferentes direções podem fornecer valiosas informações sobre a continuidade ou ausência de variação ao longo do campo amostral (Barros, 2001).

Segundo Yamamoto (2001), uma análise geoestatística inicia-se com o cálculo do semivariograma para diferentes direções. Comumente os variogramas são construídos em intervalos de $45^{\circ}$, iniciando-se na direção N-S. No caso de malhas regulares, pode-se especificar as direções segundo a orientação da linha base $\left(0^{\circ}, 45^{\circ}, 90^{\circ}\right.$ e $135^{\circ}$, em sentido anti-horário). 
De acordo com Deutch (2002), há dependência entre a direção de continuidade do variograma e a continuidade geológica. No entanto, direções de continuidade são melhor inferidas quando se considera a interpretação geológica dos dados. Sendo assim, a busca das principais direções de continuidade é raramente satisfatória avaliando somente o cálculo do variograma em várias direções.

Quando as amostragens apresentam uma distribuição irregular, a distância máxima em que se pode calcular o variograma experimental é chamada de campo geométrico e é igual à metade do comprimento da linha na direção considerada (Journel e Huijbregts,1978 apud Yamamoto e Landim, 2013).

A pior configuração em termos de estimativa de semivariograma é quando se trabalha com uma malha com amostragem irregular. Esse também é o cenário mais comum. Olea (2003) sugere que em casos como esse, para uma prática mais segura, deve-se usar passos com valores iguais à média da distância para os pontos vizinhos mais próximos nos limites laterais. Segundo Deutch (2002), o passo e a direção devem permitir que haja número suficiente de dados, ou seja, $N(h)$ expresso na equação (41) deveria ser grande suficiente para permitir um cálculo confiável de variograma. Nas diagonais, deve-se usar duas vezes esse intervalo e uma tolerância angular de $22,5^{\circ}$.

A figura 11 ilustra a explicação dada por Yamamoto e Landim (2013) de que, para cada ponto dado, define-se uma janela, dentro da qual pode haver um ou mais pontos, ou nenhum. Essa janela é definida pela direção, tolerância angular e largura máxima, bem como o tamanho do passo e tolerância do passo. Quanto ao parâmetro largura máxima, objetiva-se limitar a abertura indefinida da janela de pesquisa dada pela tolerância angular. 


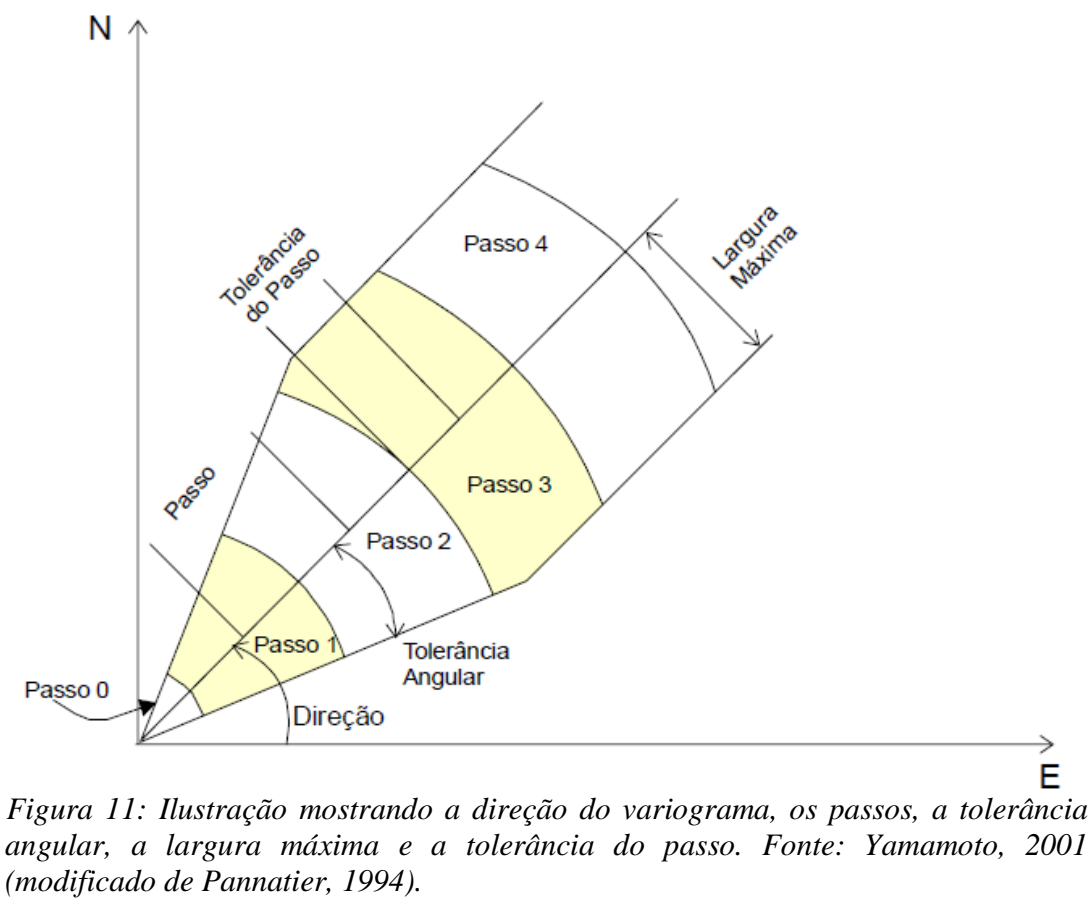

Como abordado por Deutch (2002), quando a anisotropia não é identificada, o parâmetro de tolerância angular deve ser ajustado para o ângulo de $90^{\circ}$ ou mais, o que equivale a unir todas as direções horizontais. O resultado desse ajuste é um variograma omnidirecional. Isso ocorre no presente trabalho, pois as direções de maiores continuidades não se mostram evidentes.

O parâmetro de "largura máxima" ou bandwidth, como é mais encontrado na literatura, é usado para limitar o desvio máximo das direções. No caso do cálculo do variograma omnidirecional ou quando não se dispõe de uma grande base de dados, o bandwith é ajustado para um valor grande (Deutch, 2002).

Segundo Kresic (2007), para uma estimativa de semivariograma mais confiável, é requerido um número mínimo de 30 pares para cada lag. No entanto, muitas vezes esse não é o caso dos estudos referentes às águas subterrâneas. O pesquisador deve conhecer seu banco de dados e avaliar um limite razoável para considerar o número de pares por passo.

Na aplicação de semivariograma para krigagem e simulação, a porção próxima da origem requer uma estimativa mais acurada, devido à alta influência que esses pontos exercem no resultado final. Quanto maior o tamanho do passo e menor o número de pares para uma distância dada, menor será a confiabilidade na estimativa (Olea, 2003).

Definidos a direção, a tolerância angular, o passo, sua tolerância e o número de passos, pode-se calcular a nuvem de semivariograma usando a equação (40) para cada par de pontos. 
Na Figura 12, observam-se os principais elementos que compõem um semivariograma típico:

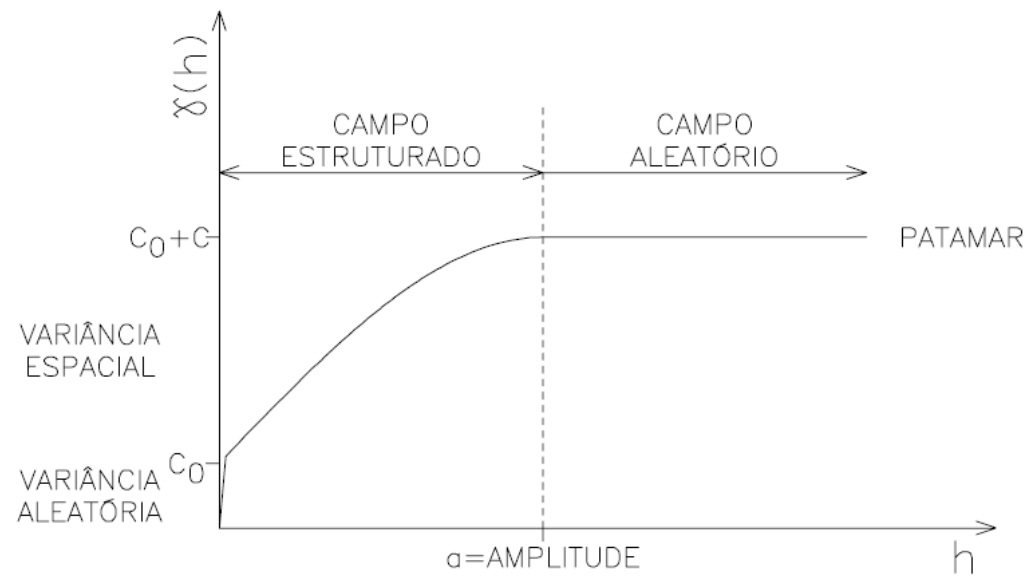

Figura 12: Variograma típico e seus elementos. Fonte: Yamamoto, 2001.

As descrições dos elementos do semivariograma, segundo Yamamoto (2001) e Yamamoto e Landim (2013), são:

- Amplitude: é a distância a partir da qual as amostras passam a não possuir correlação espacial entre si;

- Patamar: valor da variância correspondente ao início do campo aleatório. Corresponde à variância regionalizada. Ao aumentar a distância, os valores dos pontos tornam-se mais diferentes, sendo assim, a variância aumenta;

- Efeito pepita: é o valor da função semivariograma na origem $(\mathrm{h}=0)$, também chamado de variância aleatória;

- Variância Espacial: diferença entre a variância regionalizada (patamar) e a variância aleatória (efeito pepita).

A anisotropia corresponde a variações de comportamentos espaciais ao longo de diferentes direções na área de interesse. Como esse trabalho aborda casos em que direções de maior continuidade não são encontradas, os diferentes tipos de anisotropia não são descritos. Caso o leitor se interesse por essa informação, recomenda-se a leitura de Yamamoto (2001).

De acordo com Journel e Huijbregts (1978, apud Yamamoto e Landim, 2013), as variáveis regionalizadas podem apresentar comportamentos, ou graus de continuidade, distintos quando próximo à origem de variograma, normalmente apresentados por um destes quatro tipos básicos: parabólico, linear, efeito pepita e efeito pepita puro. Os variogramas abordados nesse trabalho apresentam o comportamento linear próximo à origem, figura 13. Em outras palavras, esse comportamento é caracterizado por uma tangente à origem, representando uma 
continuidade média das amostras. Segundo Yamamoto (2001), a continuidade média das amostras pode ser entendida como uma grande homogeneidade destas em pequenas distâncias e uma progressiva perda de homogeneidade com o aumento da distância.

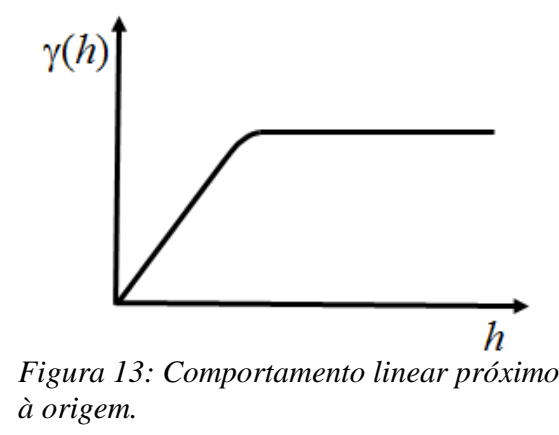

\subsubsection{Modelagem de variograma}

Os pontos calculados que compõem um variograma não são usados diretamente nas etapas estatísticas como krigagem e simulação estocástica. Para utilizá-los, uma função matemática deve ser ajustada ao semivariograma, que é o modelo teórico de variograma (Deutsch, 2002).

Isaaks e Srivastava (1989) dividem basicamente os variogramas em dois tipos: os que atingem um patamar e os que não atingem. Variogramas do primeiro tipo são comumente chamados de modelos de transição. Alguns desses modelos atingem o patamar assintoticamente. Para tais modelos, a amplitude é arbitrariamente definida para que seja a distância em que $95 \%$ do patamar seja atingido. Nos variogramas do segundo tipo, não se atinge um patamar, mas este continua crescendo com o aumento da magnitude de $h$. Por isso são necessários modelos matemáticos quando o conjunto de dados apresentam tendências.

No presente trabalho, apenas o modelo esférico é aplicado. Os outros principais modelos são explicados em Isaaks e Srivastava (1989) e Deutsch (2002).

Conforme Isaaks e Srivastava (1989), o modelo de variograma esférico é o mais utilizado, sua equação é padronizada pela expressão:

$$
\gamma(h)=\left\{\begin{array}{c}
1.5 \frac{h}{a}-0.5\left(\frac{h}{a}\right)^{3} \quad \begin{array}{c}
\quad \\
1
\end{array} \leq a
\end{array}\right.
$$

onde $a$ é a amplitude. Esse modelo apresenta um comportamento linear em pequenas distâncias de separação próximo da origem, mas achata em grandes distâncias e atinge o patamar em $a$. 
No ajuste do modelo ao variograma das amostras, é importante lembrar que a tangente na origem atinge o patamar em aproximadamente dois terços da amplitude. A figura 13 ilustra as características do modelo esférico.

\subsubsection{Variograma cruzado}

Quando há o interesse de inferir o valor de determinada variável correlacionando-a à outra, como o caso da cokrigagem, é necessário o cálculo do variograma cruzado. No caso dessa dissertação, objetiva-se inferir os valores da variável condutividade hidráulica (K), correlacionando-a com os valores de capacidade específica $(\mathrm{Q} / \mathrm{s})$, que são mais abundantes no domínio estudado.

De acordo com Deutch (2002), os modelos geoestatísticos foram desenvolvidos para qualquer número de variáveis, no entanto, na prática, torna-se difícil correlacionar mais de duas variáveis. Ou seja, considera-se apenas, a correlação de espacial duas variáveis X e Y.

A correlação entre as variáveis $\mathrm{X}$ e $\mathrm{Y}$ é a primeira avaliação nos trabalhos. Todavia, geralmente a avaliação desses pares de valores $z\left(u_{i}\right), y\left(u_{i}\right), i=1, \ldots, n$ não atende à total necessidade de correlaciona os pares espacialmente. Dessa forma, deve-se considerar a relação espacial cruzada entre os pares de valores separados por uma distância, $h, z\left(u_{i}\right), y\left(u_{i}+h\right), i=$ $1, \ldots, n(h)$. Essa dependência espacial entre as variáveis é demonstrada partindo-se da definição clássica de semivariograma para uma variável (Z) (Deutch, 2002):

$$
\begin{array}{r}
\gamma_{Z, Z}(h)=\frac{1}{2} E\left\{[Z(u)-Z(u+h)]^{2}\right\}= \\
=\frac{1}{2} E\{(Z(u)-Z(u+h))(Z(u)-Z(u+h))\}
\end{array}
$$

Essa associação é estendida para o semivariograma de duas variáveis (Z e Y):

$$
\gamma_{Z, Y}(h)=E\{(Z(u)-Z(u+h))(Y(u)-Y(u+h))\}
$$

Pode-se observar que o variograma é a média do produto da diferença $z(u)-z(u+h)$ ao quadrado. O variograma cruzado, por sua vez, é a média do produto da diferença de z, $z(u)-$ $z(u+h)$, e a diferença de y para o mesmo local e a uma mesma distância, $y(u)-y(u+h)$. O variograma cruzado é uma extensão simplificada do variograma. Todos princípios de interpretação aplicados no variograma são passíveis de serem usados para o variograma cruzado (Deutch, 2002). 
De acordo com Deutch (2002), para modelar os variogramas de duas ou mais variáveis, usa-se o Modelo Linear de Corregionalização (LMC). Sendo esse representado da seguinte forma:

$$
\begin{aligned}
& \gamma_{Z, Z}(h)=b_{Z, Z}^{0}+b_{Z, Z}^{1} \cdot \Gamma^{1}(h)+b_{Z, Z}^{2} \cdot \Gamma^{2}(h) \ldots \\
& \gamma_{Z, Y}(h)=b_{Z, Y}^{0}+b_{Z, Y}^{1} \cdot \Gamma^{1}(h)+b_{Z, Y}^{2} \cdot \Gamma^{2}(h) \ldots \\
& \gamma_{Y, Y}(h)=b_{Y, Y}^{0}+b_{Y, Y}^{1} \cdot \Gamma^{1}(h)+b_{Y, Y}^{2} \cdot \Gamma^{2}(h) \ldots
\end{aligned}
$$

onde $\Gamma^{i}, i=1, \ldots$, enésima são os modelos teóricos para os variogramas, tais como esférico, exponencial, gaussiano, etc.

Sendo assim, o LMC equivale a modelar cada direção e variograma cruzado com o mesmo modelo teórico. Os parâmetros de variância espacial, que o autor chama de $b$, podem ser ajustados contando que esses sigam tais condições como as mostradas abaixo:

$$
\forall i\left\{\begin{array}{c}
b_{Z, Z}^{i}>0 \\
b_{Y, Y}^{i}>0 \\
b_{Z, Z}^{i} \cdot b_{Y, Y}^{i} \geq b_{Z, Y}^{i} \cdot b_{Z, Y}^{i}
\end{array}\right.
$$

Deutch (2002) destaca que primeiramente deve-se decidir que modelo de variograma, $\Gamma^{i}$, $i=1, \ldots$, enésima, melhor se ajusta para as variáveis. Para isso algumas considerações devem ser seguidas:

1. Cada modelo de variograma deve ser definido com base no tipo de variograma e anisotropia;

2. O modelo de variograma deve ser escolhido de forma que todas feições significantes no variograma experimental possam ser modeladas.

O modelo linear de corregionalização não é o único usado para tratar a correlação espacial entre duas variáveis, no entanto, o software usado no processamento dos dados, ISATIS, usa o LMC preferencialmente.

\subsubsection{Definição da vizinhança}

Conforme Yamamoto (2001), a localização e busca de informações da variável de interesse em pontos vizinhos para a definição do subconjunto de amostras a ser utilizado na interpolação local é um passo importante na aplicação de métodos de estimativa. Portanto, dependendo do modo de pesquisa, diferentes subconjuntos de amostras poderão ser definidos e resultados distintos podem ser obtidos. A escolha de amostras de pontos vizinhos deve ser feita de tal modo que garanta uma boa amostragem espacial, que implica em evitar subconjuntos 
com agrupamento de amostras. Na figura 14, tanto na parte A quanto na B, observa-se a seleção de amostras sem um critério estabelecido. Sendo assim, não há uma boa amostragem espacial e, consequentemente, há um agrupamento dos pontos.
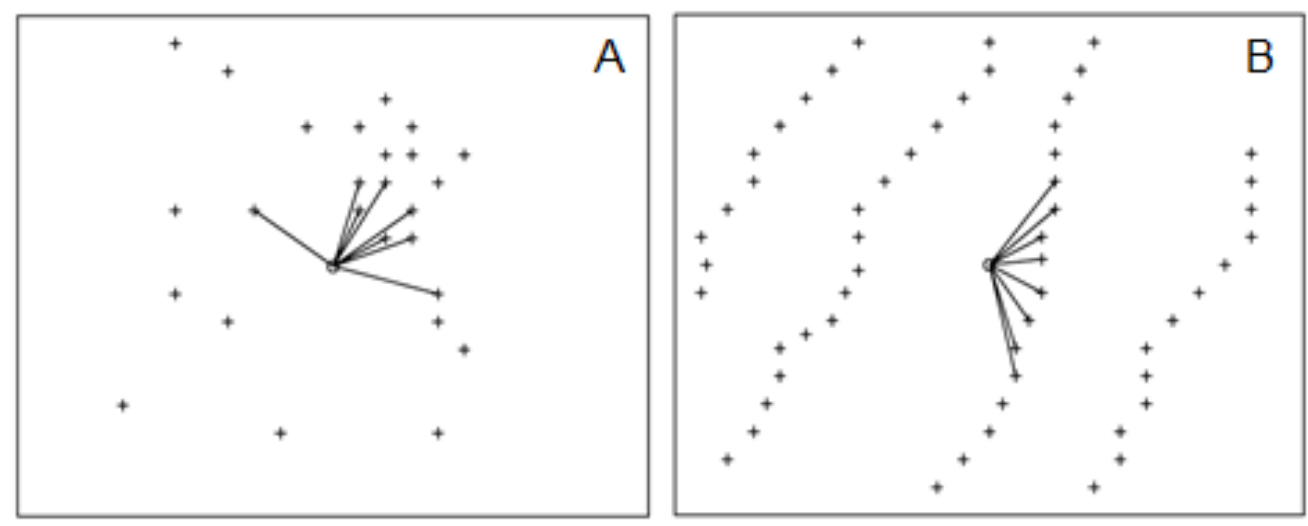

Figura 14: Localização de oito pontos mais próximos para arranjo aleatório $(A)$ e semi-regular (B). Fonte: Yamamoto (2001).

A busca na vizinhança é normalmente uma elipse centrada no ponto que se pretende estimar. A orientação dessa elipse é ditada pela anisotropia na continuidade espacial do modelo. Caso os valores das amostras sejam mais contínuos em uma direção do que em outra, o maior eixo da elipse será paralelo a direção de maior continuidade. Em casos em que a anisotropia não seja evidente, ao invés de usar uma elipse, usa-se um círculo centrado no ponto que se pretende estimar (Isaaks e Srivastava, 1989). Como a anisotropia não é evidente, nesse trabalho, o círculo é usado ao invés da elipse.

De acordo com Isaaks e Srivastava (1989), após a definição dos eixos da elipse ou, caso não haja anisotropia, o círculo, deve-se decidir o quão grandes serão os eixos. Para uma malha ou grid irregular de dados, sugere-se que a busca de pontos vizinhos atenda um raio maior que o passo ou lag, podendo ser uma distância próxima ao da amplitude do variograma, no caso de variograma sem anisotropia evidente. Sugere-se o uso do cálculo dessa distância com base na seguinte fórmula:

$$
\text { Média do espaçamento entre os dados }=\sqrt{\frac{\text { Área coberta pelos amostras }}{\text { Número de amostras }}}
$$

Yamamoto (2001) alerta que se deve ser cauteloso ao buscar pontos na vizinhança, pois se o número de amostras for excessivamente pequeno, o valor estimado corre o risco de ser semelhante ou igual ao vizinho mais próximo. No entanto, essa cautela deve ser estendida quando o número de amostras for excessivamente grande. Nesse caso, o ponto estimado pode apresentar um valor bastante suavizado, perdendo as características da interpolação local. 


\subsubsection{Validação cruzada}

Para aferir o ajuste do modelo teórico de semivariograma e definir a melhor vizinhança de busca a ser utilizada na estimativa ou simulação, deve-se realizar a validação cruzada dos dados. Esse procedimento compara, nos mesmos pontos, os valores amostrados e os valores estimados e essa comparação pode ser feita por meio de um gráfico de dispersão (Figura 15). Quanto menor a dispersão da nuvem de pontos, melhor terá sido a validação cruzada, ou seja, a reta de regressão ajustada à nuvem deve estar próxima à reta de $45^{\circ}$ (Yamamoto, 2001).

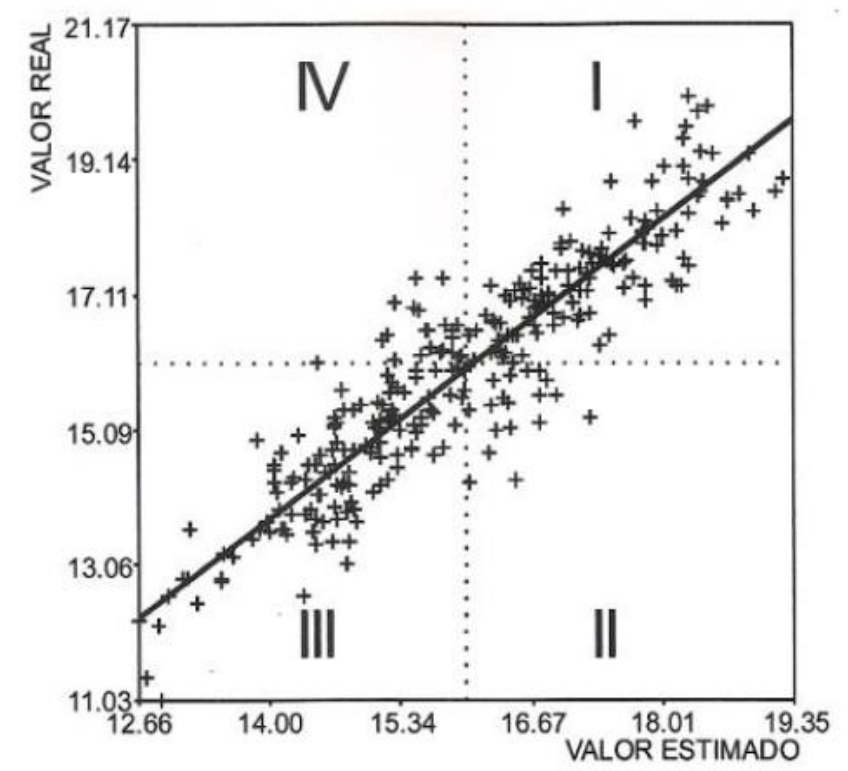

Figura 15: Representação de uma validação cruzada e sua reta de regressão. Fonte: Yamamoto (2001).

Conforme Ahmed e Marsily (1987), a validação cruzada do modelo variograma é feita pela reestimativa dos dados observados. Para isso cada ponto é removido do domínio, sendo um de cada vez, e estimado por meio de krigagem. O ponto removido é estimado com base nos dados remanescentes. A média $M_{e}$ dos erros estimados e a variância dos erros reduzidos $\sigma_{R e}^{2}$ são dados como:

$$
\begin{aligned}
& M_{e}=E\left(Z^{*}\left(u_{i}\right)-Z\left(u_{i}\right)\right) \\
& \sigma_{R e}^{2}=\left[\frac{\left(E\left(Z^{*}\left(u_{i}\right)-Z\left(u_{i}\right)\right)^{2}\right.}{S_{i}^{* 2}}\right]
\end{aligned}
$$

onde $Z^{*}\left(u_{i}\right)$ e $Z\left(u_{i}\right)$ são, respectivamente, os valores observados e estimados da variável, e $S_{i}^{*}$ representa o desvio padrão do erro estimado em cada ponto $i$. Se o modelo variograma usado é acurado suficiente para reproduzir os valores medidos, os valores de $M_{e} \mathrm{e} \sigma_{R e}^{2}$ devem ser perto de 0 e 1 , respectivamente. 
$\mathrm{O}$ erro experimental entre o valor estimado e o valor real $\left(Z(u)-Z^{*}(u)\right)$ pode ser medido pelo esperado desvio-padrão da estimativa $\left(\sigma^{*}\right)$ para produzir o erro padronizado. Esse valor, que deve ser uma distribuição normal, caracteriza a habilidade do variograma modelado re-estimar corretamente os dados somente com as informações da vizinhança dos pontos. Caso o valor não esteja dentro do intervalo dado, esse requer maior atenção. Esse valor deve estar dentro do intervalo $[-2.5 ; 2.5]$. Caso contrário, esse ponto será chamado de "outlier". O erro padronizado é aplicado como forma de avaliar a vizinhança dos dados.

Nesse trabalho, a validação cruzada é o critério para avaliar qual o método geoestatístico que melhor descreve os fenômenos espaciais nos dois aquíferos estudados.

\subsubsection{Desagrupamento ou Declustering}

Segundo Olea (2007), os mais eficientes padrões de amostragem são aqueles que cobrem a área ou volume de interesse uniformemente. Frequentemente, no entanto, as amostras são medições resultantes de atividades anteriores que visavam atender certa demanda, normalmente econômica.

De acordo com Deutsch (2002), raramente os dados são coletados com o intuito de representatividade estatística. Poços são comumente instalados em áreas com maior probabilidade de serem mais produtivos. Esses dados conduzem a uma melhor economia e maior número de informações nas porções de reservatório. No entanto, há a necessidade de ajustar os histogramas e os sumários estatísticos para representar a área de interesse. Para isso, foram desenvolvidos métodos de desagrupamento.

Os métodos de desagrupamento são, normalmente, aplicados de forma automatizada em

softwares. Questões como anisotropia entre as fácies e variáveis são analisadas. É essencial entender a aplicabilidade e as limitações dos algoritmos de desagrupamento, pois sua aplicação cega pode ser pior que o trabalho com os dados estatísticos sem tratamento (Pyrcz e Deutsch, 2003).

As técnicas de desagrupamento atribuem a cada dado um peso, $w_{i}, i=1, \ldots, n$ baseado em sua proximidade com os dados que o cercam (Deutsch, 2002). Sendo assim, o histograma e o sumário estatístico são calculados com esses pesos de desagrupamento. A média e o desviopadrão são calculados como, respectivamente: 
$\bar{z}=\sum_{i=1}^{n} w_{i} z_{i}$

$\mathrm{e}$

$$
s=\sqrt{\sum_{i=1}^{n} w_{i}\left(z_{i}-\bar{z}\right)^{2}}
$$

onde os pesos $w_{i}=1, \ldots, n$ são entre 0 e 1 . Uma abordagem mais intuitiva para o desagrupamento é basear os pesos no volume de influência de cada amostra.

A adequada inferência dos parâmetros da amostragem preferencial requer especial atenção para evitar a obtenção de resultados não realísticos. Os métodos são caracterizados para serem específicos para cada pretensão. Os principais métodos de desagrupamento são por polígonos e por células (Olea, 2007). No presente trabalho, apenas o método de desagrupamento por células é utilizado.

A técnica de desagrupamento por células é a abordagem mais comum. Ela não apresenta sensibilidade nas bordas e é de simples aplicação. Por isso, essa técnica é mais amplamente utilizada que o desagrupamento por polígonos (Pyrcz et al. 2006).

O desagrupamento por células segue os seguintes passos (Deutsch, 2002):

1. Divide-se o volume de interesse em um grid ou malha de células $l=1, \ldots, L$;

2. Contam-se as células ocupadas $L_{0}, L_{0} \leq L$, e o número de amostras em cada célula ocupada $n_{l o}, l_{0}=1, \ldots, L_{o}$ onde $\sum_{l_{0}=1}^{L_{0}} n_{l_{0}}=n$ igual ao número de amostras;

3. O peso $\mathrm{W}$ de cada dado é fornecido de acordo com o número de dados na mesma célula, por exemplo, para o dado $i$ em célula $l, l \in\left[0, L_{0}\right]$, o peso da célula desagrupada é:

$$
w_{i}^{(c)}=\frac{1}{n_{l} \cdot L_{0}}
$$

Os pesos $w_{i}^{(c)}, \mathrm{i}=1, \ldots, \mathrm{n}$ são entre $(0,1]$ e a soma de todos é igual a um, $\sum_{i_{1}}^{n} w_{i}^{(c)}=1$. Esses pesos são inversamente proporcionais ao número de dados em cada célula: dados em células com uma amostra recebem um peso de $1 / L_{0}$, dados em células com duas amostras recebem o peso de $1 /\left(2 \times L_{o}\right)$, assim por diante (Deutsch, 2002). A figura 16 ilustra os procedimentos de desagrupamento por células. 


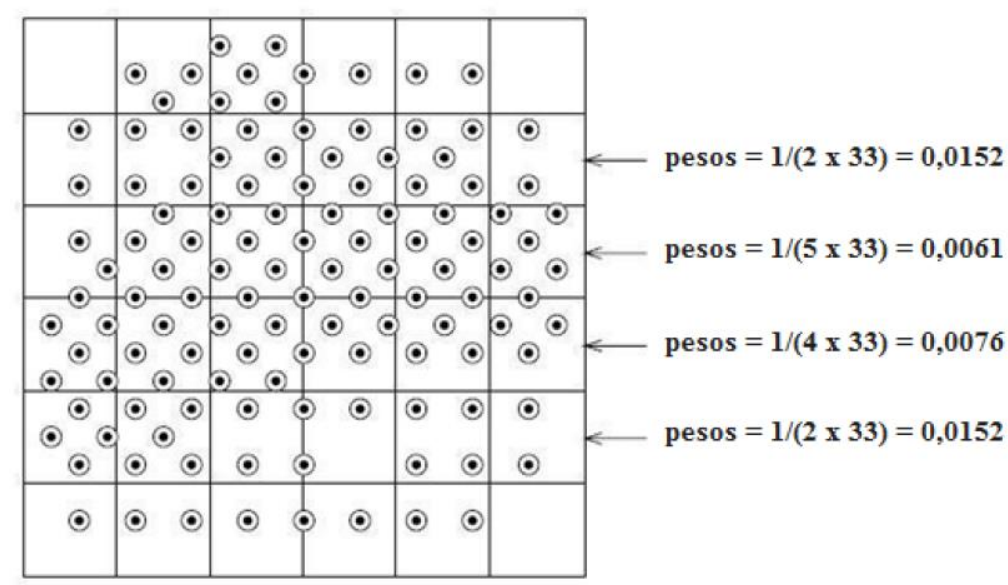

Figura 16: Exemplo de desagrupamento por células com 122 poços e 33 células para desagrupamento. Fonte: Deutsch, Frykman and Xie, (1999).

A técnica de desagrupamento por células é a escolhida para fins de comparação dos resultados da aplicação dos métodos geoestatísticos no presente trabalho. O objetivo dessa comparação é avaliar se a técnica é capaz de melhorar os resultados de cada método geoestatístico no que concerne a validação cruzada.

\subsection{Métodos geoestatísticos}

Os métodos geoestatísticos empregados nessa dissertação são duas técnicas de krigagem e uma estocástica. Os métodos de krigagem são a ordinária, cokrigagem e ordinária combinada com regressão linear. Quanto a técnica estocástica, a simulação condicional por bandas rotativas é aplicada. Todas essas objetivam estimar valores de condutividade hidráulica (K).

Armstrong (1998) sumariza assim as etapas dos métodos geoestatísticos tradicionais:

1. Coleta e validação dos dados. O profissional responsável pela geoestatística deve ter ciência dos detalhes das amostragens, tais como tipo de amostra e análises utilizadas. $\mathrm{O}$ conhecimento geológico da área é de suma importância. Ainda, deve-se definir os limites da área de estudo e o suporte das variáveis e se os dados são ou não estacionários;

2. Análise da estatística básica, tal como cálculo da média, variância, correlações, histogramas e diagramas de dispersão. Busca-se encontrar valores anômalos e/ou discrepantes e verificar a presença de dados não homogêneos que indica uma possível mistura de populações;

3. Cálculo do semivariograma experimental;

4. Ajuste do modelo teórico de semivariograma e;

5. Realização da krigagem ou simulação. 
A krigagem ordinária (KO) e cokrigagem (CoK) estão no escopo desse trabalho, no entanto, a técnica de krigagem simples (KS) também é descrita na dissertação por se tratar de uma parte importante nos métodos de simulação, que também são explorados nesse mestrado.

Embora ambos tipos de krigagem sejam discutidos mais profundamente nesse trabalho, é importante salientar o que difere essencialmente a krigagem simples da ordinária. Conforme Landim (2002), KS é utilizada quando a média é assumida como estatisticamente constante para toda a área, ao passo que em KO considera-se a média flutuante ou móvel por toda a área.

A KO é um dos métodos de interpolação estatística escolhido neste trabalho, a fim de inferir a condutividade hidráulica em pontos não amostrados, sendo esse método caracterizado por estimar o valor da variável utilizando a média dos pontos amostrados na vizinhança krigada. A KS, por sua, vez é feita com os resíduos dessa média estimada implicitamente (Deutsch, 2002, p. 154).

Yamamoto (2001) ressalta que, com base nos estudos geoestatísticos, deve-se avaliar se o uso da krigagem é passível de aplicação, pois, caso a variável regionalizada seja totalmente aleatória, esse método não se aplica. Os estudos geoestatísticos consistem na definição de um modelo de variograma que servirá para inferir os valores da função variograma ou covariograma que serão utilizados pelos métodos geoestatísticos de interpolação.

A amostragem fornece informações acuradas nos pontos amostrados, no entanto, não conta o que acontece entre esses pontos. Para isso é necessário encontrar um modo acurado de se estimar os valores em pontos intermediários. Armstrong (1998) lista quatro fatores que podem influenciar na acurácia da estimativa:

1. O número de amostras e a qualidade dos dados em cada ponto;

2. Posição das amostras na área de estudo. Amostras uniformemente espaçadas fornecem melhores informações do que as que apresentam agrupamento;

3. A influência da vizinhança na estimativa. Pontos mais próximos influenciam mais do que os que se encontram mais distantes;

4. Por fim, a continuidade espacial da variável considerada. É mais fácil a estimativa de um ponto não conhecido de uma variável com alta continuidade espacial do que um que apresenta ampla flutuação. 


\subsubsection{Técnicas de krigagem}

Como Armstrong (1998) explica, a krigagem é um método de estimativa que visa dar a melhor estimativa linear não enviesada de valores de pontos. O termo "a melhor", nesse contexto, significa que ela apresenta variância mínima. De acordo com Deutsch (2002), o preço desse não enviesamento é que os valores baixos são superestimados e os altos são subestimados. Essas estimativas apresentam o que o autor chama de enviesamento condicional.

Segundo Yamamoto (2001), a krigagem permite estimar o valor desconhecido $Z^{*}(u)$ associado a um ponto, área ou volume a partir de um conjunto de $n$ dados $\left\{Z\left(u_{\alpha}\right), \alpha=1, \ldots, n\right\}$ disponíveis.

Olea (2003) e Deutsch (2002) ressaltam que qualquer trabalho geoestatístico deve apresentar krigagem, sendo essa uma coleção de técnicas generalizadas de regressão linear. $\mathrm{O}$ valor não amostrado $z^{*}(u)$ poderá ser obtido como uma combinação linear dos dados disponíveis, ou seja:

$$
Z^{*}(u)-m(u)=\sum_{\alpha=1}^{n} \lambda_{\alpha}\left[Z\left(u_{\alpha}\right)-m\left(u_{\alpha}\right)\right]
$$

onde $\mathrm{Z}(u)$ é o valor da variável aleatória no local $u, m(u)=E\{Z(u)\}$ é a média inicial no local não amostrado $u, \lambda_{\alpha}, \alpha=1, \ldots, \mathrm{n}$ são os pesos aplicados para os $n$ dados amostrados, $m\left(u_{\alpha}\right), \alpha=1, \ldots, n$ são os as médias dos $n$ valores na localização dos dados e $Z^{*}(u)$ é o estimador da regressão linear, também chamado de estimador da krigagem simples. Caso a média inicial no ponto não amostrado não seja conhecida, $m(u)=M\left(u_{\alpha}\right)=m$, sendo essas médias constantes.

Um princípio da modelagem numérica é que limites geológicos devem ser representados deterministicamente. Devido a isso é necessário considerar sistematicamente resíduos que venham de tendências, esses resíduos podem ser determinados pela função:

$$
Y\left(u_{\alpha}\right)=Z\left(u_{\alpha}\right)-m\left(u_{\alpha}\right), \alpha=1, \ldots, n
$$

Quando não há tendências previsíveis em grandes escalas, a média $m\left(u_{\alpha}\right)$ pode ser considerada conhecida e fixada: $m\left(u_{\alpha}\right)=m$ para todo $u \in A$ (Deutsch, 2002).

Segundo Armstrong (1998) e Deutsch (2002) independentemente da decisão sobre a média $m$, a variável residual Y é considerada estacionária, ou seja, $E\{Y(u)\}=0, \forall u \in A$ com covariância estacionária $C(h)$ e variograma $2 \gamma_{Y}(h)$.

Seguindo o raciocínio desenvolvido por Deutsch (2002), considerando um estimador linear em uma localização onde não há dados de amostras disponíveis: 


$$
Y^{*}(u)=\sum_{\alpha=1}^{n} \lambda_{\alpha} \cdot Y\left(u_{\alpha}\right)
$$

onde $Y^{*}(u)$ é o valor estimado, $\lambda_{\alpha}, \alpha=1, \ldots, n$ são os pesos aplicados para os $n$ valores de dados $Y\left(u_{\alpha}\right), \alpha=1, \ldots, n$. O erro de variância para esse valor estimado é definido como:

$$
E\left\{\left[Y^{*}(u)-Y(u)\right]^{2}\right\}=\sigma_{u}^{2}(u)
$$

Apesar dos verdadeiros valores de $y(u)$ não serem conhecidos, é possível expandir o termo de erro de variância usando valores esperados, ou seja, a linearidade esperada dos operadores e da suposição de estacionariedade, sendo assim o erro de variância é expandido como:

$$
\begin{gathered}
E\left\{\left[Y^{*}(u)\right]^{2}\right\}-2 \cdot E\left\{Y^{*}(u) \cdot Y(u)\right\}+E\left\{[Y(u)]^{2}\right\} \\
=\sum_{\alpha=1}^{n} \sum_{\beta=1}^{n} \lambda_{\alpha} \lambda_{\beta} E\left\{Y\left(u_{\beta}\right) \cdot Y\left(u_{\alpha}\right)\right\}-2 \cdot \sum_{\alpha=1}^{n} \lambda_{\alpha} E\left\{Y(u) \cdot Y\left(u_{\alpha}\right)\right\}+C(0) \\
=\underbrace{\sum_{\alpha=1}^{n} \sum_{\beta=1}^{n} \lambda_{\alpha} \lambda_{\beta} C\left(u_{\beta}-u_{\alpha}\right)}_{\text {Termo I }}-\underbrace{2 \sum_{\alpha=1}^{n} \lambda_{\alpha} C\left(u-u_{\alpha}\right)+C(0)}_{\text {Termo II }}+\underbrace{C(0)}_{\text {Termo III }}
\end{gathered}
$$

Essa equação final mostra uma expressão matemática para erro de variância para qualquer série de pesos $\lambda_{\alpha}, \alpha=1, \ldots, n$. A estimativa de variância depende do modelo de covariância ou variograma. Os três termos da equação para estimativa de variância evidenciam características da expressão (58):

Termo 1: Quanto maior a covariância entre os dados, $C\left(u_{\beta}-u_{\alpha}\right)$, maior é a estimativa de variância.

Termo 2: Quanto mais próximos os dados do local a ser estimado, $C\left(u-u_{\alpha}\right)$, menor é a estimativa de variância.

Termo 3: A estimativa de variância é igual a variância ou $C(0)$ quando todos os dados estão muito distantes ou espaçados para receber qualquer peso, ou seja, $\lambda_{\alpha}=0, \alpha=1, \ldots, n \mathrm{e}$ a estimativa é a média local $Y^{*}(u)=m(u)$ assumida como conhecida.

\subsubsection{Krigagem simples}

Como já destacado anteriormente, tendo como fonte (Deutch, 2002), todas as versões de krigagem são baseadas em algoritmos de regressões lineares generalizadas e seus correspondentes estimadores, como visto na equação (52). Se a função aleatória é estacionária 
com média constante $m$, e função de covariância $C(h)=C(u, u+h), \forall u$, o estimador da krigagem simples é reduzido a sua versão estacionária:

$$
Z_{K S}^{*}=\sum_{\alpha=1}^{n} \lambda_{\alpha}(u) Z\left(u_{\alpha}\right)+\left[1-\sum_{\alpha=1}^{n} \lambda_{\alpha}(u)\right] m
$$

Os pesos, $\lambda_{\alpha}$, da krigagem simples são dados pelo sistema de equações normais escritas na suas formas não estacionárias mais gerais:

$$
\sum_{\beta=1}^{n} \lambda_{\beta} C\left(u_{\alpha}-u_{\beta}\right)=C\left(u-u_{\alpha}\right), \alpha=1, \ldots, n
$$

Essa expressão, conforme Deutsch (2002), minimiza a estimativa de variância. O sistema das $n$ equações com $n$ pesos desconhecido é chamado de sistema de krigagem simples e é representado tanto na forma de sistema quanto de matriz, como visto abaixo:

$$
\begin{aligned}
& C\left(u_{1}-u_{1}\right) \cdot \lambda_{1}+C\left(u_{1}-u_{2}\right) \cdot \lambda_{2}+C\left(u_{1}-u_{3}\right) \cdot \lambda_{3}=C\left(u-u_{1}\right) \\
& C\left(u_{2}-u_{1}\right) \cdot \lambda_{1}+C\left(u_{2}-u_{2}\right) \cdot \lambda_{2}+C\left(u_{2}-u_{3}\right) \cdot \lambda_{3}=C\left(u-u_{2}\right) \\
& C\left(u_{3}-u_{1}\right) \cdot \lambda_{1}+C\left(u_{3}-u_{2}\right) \cdot \lambda_{2}+C\left(u_{3}-u_{3}\right) \cdot \lambda_{3}=C\left(u-u_{3}\right)
\end{aligned}
$$

ou

$$
\begin{aligned}
& {\left[\begin{array}{lll}
C\left(u_{1}-u_{1}\right) & C\left(u_{1}-u_{2}\right) & C\left(u_{1}-u_{3}\right) \\
C\left(u_{2}-u_{1}\right) & C\left(u_{2}-u_{2}\right) & C\left(u_{2}-u_{3}\right) \\
C\left(u_{3}-u_{1}\right) & C\left(u_{3}-u_{2}\right) & C\left(u_{3}-u_{3}\right)
\end{array}\right] \cdot\left[\begin{array}{l}
\lambda_{1} \\
\lambda_{2} \\
\lambda_{3}
\end{array}\right]=\left[\begin{array}{l}
C\left(u-u_{1}\right) \\
C\left(u-u_{2}\right) \\
C\left(u-u_{3}\right)
\end{array}\right]} \\
& C \lambda=c \\
& \lambda=C^{-1} c
\end{aligned}
$$

Os pesos da krigagem são calculados invertendo o $\mathrm{C}$ e multiplicando-o pelo vetor c.

De acordo com Deutsch e Journel (1992), no sistema acima, os valores de covariância $C(h)$ não podem ser substituídos por valores do semivariograma $\gamma(h)=C(0)-C(h)$ caso $\sum_{\beta} \lambda_{\beta}(u)=1$ não seja verdadeiro, que é uma limitação da krigagem ordinária. Esses autores ainda enfatizam que de acordo com a teoria de estacionariedade, a krigagem simples deve ser aplicada na transformada normal score que é usada nas simulações condicionais, no caso do presente trabalho, o método de simulação condicional por bandas rotativas.

\subsubsection{Krigagem ordinária}

De acordo com Deutsch e Journel (1992) e Deutsch (2002), a krigagem ordinária filtra a média do estimador da krigagem simples (equação 59) exigindo que a soma dos pesos da krigagem seja igual a um. Sendo assim, o estimador da krigagem ordinária é dado pela expressão: 


$$
Z_{K O}^{*}(u)=\sum_{\alpha=1}^{n} \lambda_{\alpha}^{K O}(u) Z\left(u_{\alpha}\right)
$$

e o sistema estacionário da krigagem ordinária:

$$
\left\{\begin{array}{c}
\sum_{\beta}^{n} \lambda_{\beta}^{K O}(u) C\left(u_{\beta}-u_{\alpha}\right)+\mu(u)=C\left(u-u_{\alpha}\right), \alpha=1, \ldots, n \\
\sum_{\beta=1}^{n} \lambda_{\beta}^{K O}(u)=1
\end{array}\right.
$$

onde os $\lambda_{\beta}^{(K O)}(u)$ 's são os pesos da krigagem ordinária e $\mu(u)$ é o parâmetro de Lagrange associado com a condição $\sum_{\beta=1}^{n} \lambda_{\beta}^{(K O)}(u)=1$.

Comparando os sistemas (58) e (60), é possível observar os pesos aplicados nas krigagens simples e ordinária. A forma matricial do sistema de krigagem ordinária é expressa como:

$$
\left[\begin{array}{ccccc}
C\left(u_{1}-u_{1}\right) & C\left(u_{1}-u_{2}\right) & \cdots & C\left(u_{1}-u_{n}\right) & -1 \\
C\left(u_{2}-u_{1}\right) & C\left(u_{2}-u_{2}\right) & \cdots & C\left(u_{2}-u_{n}\right) & -1 \\
\vdots & \vdots & \cdots & \vdots & \vdots \\
C\left(u_{n}-u_{1}\right) & C\left(u_{n}-u_{2}\right) & \cdots & C\left(u_{n}-u_{n}\right) & -1 \\
1 & 1 & \cdots & 1 & 0
\end{array}\right] \cdot\left[\begin{array}{c}
\lambda_{1} \\
\lambda_{2} \\
\vdots \\
\lambda_{n} \\
\mu
\end{array}\right]=\left[\begin{array}{c}
C\left(u-u_{1}\right) \\
C\left(u-u_{2}\right) \\
\vdots \\
C\left(u-u_{n}\right) \\
1
\end{array}\right]
$$

Deutsch e Journel (1992) destacam que a krigagem ordinária consiste na reestimativa, em cada nova localização de $u$, da média $m$ como usada na expressão da krigagem simples. Desde que a krigagem ordinária seja aplicada de modo que os pontos vizinhos para estimar os locais $u$, a média reestimada, denotada de $m^{*}(u)$, dependam unicamente da localização de $u$. Nos jargões da geoestatística, esse comportamento é chamado de média flutuante. Então, o estimador da krigagem ordinária (eq. 59) é um tipo de krigagem simples, onde a média constante de valor $m$ é substituída por uma que é localmente dependente, $m^{*}(u)$ :

$$
\begin{array}{r}
Z_{K O}^{*}=\sum_{\alpha=1}^{n} \lambda_{\alpha}^{K O}(u) Z\left(u_{\alpha}\right) \\
=\sum_{\alpha=1}^{n} \lambda_{\alpha}^{K S}(u) Z(u)+\left[1-\sum_{\alpha=1}^{n} \lambda_{\alpha}^{(K S)}(u)\right] \cdot m^{*}(u)
\end{array}
$$

onde $\lambda_{\alpha}^{(K O)}$ são os pesos da krigagem ordinária dadas no sistema 62 e $\lambda_{\alpha}^{(K O)}$ são os pesos da krigagem simples dados no sistema 60.

O tipo de krigagem escolhido determina se uma média deve ser explicitamente mapeada. Os resultados são apropriados para visualizar tendências nos dados e, talvez, superfícies suavizadas (Deutsch, 2002). 


\subsubsection{Variância de krigagem ou incerteza}

De acordo com Deutsch e Journel (1992) e Deutsch (2002), a equação de estimativa de variância para a krigagem simples pode ser apresentada de forma simplificada como:

$$
\sigma_{E}^{2}(u)=C(0)-\sum_{\alpha=1}^{n} \lambda_{\alpha}\left(C\left(u-u_{\alpha}\right)\right.
$$

A krigagem pode ser considerada uma técnica de regressão espacial, sendo sua estimativa susceptível à suavização. A combinação de $n$ dados por uma soma linear ponderada é condicionada por estimativas altas ou baixas, sendo mais comumente próximas da média. A krigagem apresenta um modelo variograma em que os valores são afetados pela distância entre os pares.

Segundo Deutsch (2002), outra vantagem das técnicas de krigagem é a sua capacidade de quantificar o quanto as suas estimativas estão suavizadas, ou seja, a variância da estimativa de krigagem pode ser calculada como:

$$
\begin{aligned}
& \operatorname{Var}\left\{Y^{*}(u)\right\}=E\left\{\left[Y^{*}(u)\right]\right\}-E\left\{y^{*}(u)\right\}^{2} \\
& =\sum_{\alpha=1}^{n} \sum_{\beta=2}^{n} \lambda_{\alpha} \lambda_{\beta} E\left\{Y\left(u_{\beta}\right) \cdot Y\left(u_{\alpha}\right)\right\}-0^{2} \\
=\sum_{\alpha=1}^{n} \lambda_{\alpha} C\left(u-u_{\alpha}\right) &
\end{aligned}
$$

Essa equação é capaz de determinar a variância do estimador de krigagem, $Y^{*}(u)$, para qualquer local de $u$. A suavização de krigagem é diretamente proporcional à variância de krigagem. Sendo assim, não há suavização em locais onde a variância de krigagem é zero e, por outro lado, a estimativa é completamente suavizada quando os dados estão muito distantes do ponto estimado, onde as estimativas são próximas ou iguais à média e a variância de krigagem é a variância estacionária $C(0)$ (Deutsch, 2002).

Segundo Yamamoto e Landim (2013), o efeito da suavização da krigagem é gerado pela subestimativa dos valores altos e superestimativa dos valores baixos. Ainda, a suavização não é uniforme, pois é zero nos pontos amostrais e vai aumentando à medida que se distancia dos pontos observados. Como observado por Olea (2003), a suavização é inversamente proporcional à densidade de amostras. 


\subsubsection{Cokrigagem}

De acordo com Deutsch (2002), o termo cokrigagem é reservado para regressão linear que usa dados definidos para diferentes atributos. No caso do trabalho, esses dois atributos são condutividade hidráulica $(\mathrm{K})$ e capacidade específica $(\mathrm{Q} / \mathrm{s})$.

O software ISATIS aplica em sua cokrigagem um método chamado de collocated cokriging. Segundo Chilès e Definer (1999), ambas as variáveis $Y_{1}$ e $Y_{2}$, variáveis primária e secundária, respectivamente, são amostradas no domínio. No entanto, a variável primária está presente em menos pontos e sempre acompanhada de $Y_{2}$, que por sua vez está amostrada em maior número de pontos no domínio e não necessariamente acompanhada de valores de $Y_{1}$.

Como explicado por Deutsch (2002), essa técnica consiste em reter somente os dados da variável secundária $y_{2}(u)$ ou realocar os dados $y_{2}\left(u^{\prime}\right)$ o mais próximos do nó $u$ que está sendo estimado. Isso não configura um problema se a distância $\left|u-u^{\prime}\right|$ é pequena e respeita o volume de influência de $y_{2}(u)$. Sendo assim, o estimador de cokrigagem, $Y_{C O K}^{*}(u)$, é escrito como:

$$
Y_{C O K}^{*}(u)=\sum_{\alpha_{1}}^{n_{1}} \lambda_{\alpha_{1}} Y\left(u_{\alpha_{1}}\right)+\lambda^{\prime} Y_{2}(u)
$$

onde os $\lambda_{\alpha_{1}}$ os pesos aplicados às $n_{1}$ amostras de $Y$ e $\lambda^{\prime}$ são os pesos aplicados à $n_{2}$ amostras de $Y_{2}$. O sistema de cokrigagem requer conhecimento da covariância $C_{Y}(h)$ de $Y$ e a covariância cruzada $C_{Y Y_{2}}(h)$ de $Y-Y_{2}$. A covariância pode ser aproximada através do seguinte modelo:

$$
C_{Y Y_{2}}(h)=B \cdot C_{Z}(h), \forall h
$$

onde $B=\sqrt{C_{Y}(0) / C_{Y_{2}}(0)} \cdot \rho_{Y Y_{2}}(0), C_{Y}(0), C_{Y_{2}}(0)$, são covariâncias de $Y$ e $Y_{2}$, e $\rho_{Y Y_{2}}(0)$ é o coeficiente de correlação linear dos dados de $y-y_{2}$.

Essa aproximação consiste em usar apenas os dados da variável secundária que não afetam a estimativa, valores de variáveis secundárias próximas tendem a ser similares, mas isso pode afetar a estimativa de variância da cokrigagem: a variância é superestimada, algumas vezes significantemente. Nessa técnica de cokrigagem, a variância deve ser reduzida por um fator, assumido constante para todo domínio, para determinar por tentativa e erro (Deutsch, 2002). 


\subsubsection{Simulação condicional}

A simulação foi inicialmente desenvolvida para corrigir o efeito de suavização da krigagem e, dependendo da configuração dos dados, esse grau de suavização varia no espaço, podendo implicar em estruturas artificiais. De fato, as estimativas por krigagem são ponderadas, influenciando na média dos valores dos dados originais, sendo assim, apresentando menos variabilidade espacial que os dados. O mapa suavizado confeccionado pela krigagem é mais apropriado quando se quer observar a tendência local, enquanto o mapa produzido pelos métodos de simulação é mais indicado quando se decide observar padrões de tendências global, como nas simulações de fluxo. Uma gama de mapas simulados condicionalmente fornece um cálculo da incerteza em torno da distribuição espacial dos atributos. A simulação estocástica encontra suas principais aplicações em mineração, hidrogeologia e petróleo. Em resumo, a simulação estocástica é um processo que constrói alternativas equiprováveis e modelos de distribuição espacial com alta resolução e é dita condicional se o resultado das realizações honrarem os valores dos dados e sua localização (Deutsch e Journel, 1998).

Para se definir, formalmente, o conceito de simulação estocástica, segundo Deutsch e Journel (1998), considere a distribuição de um (ou mais) atributo(s) Z(u) sobre um domínio A qualquer com $u \in A$. Por simulação estocástica, entende-se o processo de construir modelos alternativos igualmente prováveis de alta resolução da distribuição espacial de Z(u). Cada realização de $\mathrm{Z}(\mathrm{u})$ é representada pelo sobrescrito $l$ da seguinte forma:

$$
\left\{z^{(l)}(u), u \in A\right\}
$$

A simulação é dita condicional (ou condicionada) se as realizações resultantes representarem valores observados em diferentes localizações, ou seja:

$$
z^{(l)}\left(u_{\alpha}\right)=z\left(u_{\alpha}\right), \forall l
$$

onde $z\left(u_{\alpha}\right)$ representa o valor do atributo $Z(u)$ observado na localização $u_{\alpha}$.

Deutsch e Journel (1992) ressaltam que o erro de suavização da krigagem decorre da falta de um componente de erro. Considerando a função aleatória $Z$ (u) como a soma do estimador e o erro correspondente:

$$
Z(u)=Z^{*}(u)+R(u)
$$

onde $R(u)$ é uma variável aleatória correspondente ao erro de estimativa.

Para restaurar a completa variabilidade da função aleatória, Z(u), pode-se simular a função aleatória $R\left(u_{0}\right)$, com média zero e covariância um, que poderia ser adicionada à estimativa: 


$$
Z_{\text {Sim }}^{l}(u)=Z^{*}(u)+R^{l}(u)
$$

em que o sobrescrito $l$ indica a $l$-ésima realização.

Conforme Deutsch e Journel (1992), a equação supracitada requer duas condições:

1- Primeiramente, a componente de erro $R^{l}(u)$ deve ser independente ou, no mínimo ortogonal ao estimador $Z^{*}(u)$;

2- A função aleatória $R(u)$ deve seguir a correlação espacial do erro real, que é desconhecido.

Como salientado por Chilès e Delfiner (1999), as simulações visam simular o mecanismo genético do fenômeno observado de forma mais realística possível, sendo qualitativamente úteis para obtenção de mapas realísticos da variabilidade espacial. Quantitativamente, as simulações também se mostram boas ferramentas para avaliar o impacto da incerteza espacial em resultados de processos complexos, tal como a modelagem de sistemas dinâmicos. As simulações condicionais são simulações espacialmente consistentes de Monte Carlo. O resultado da simulação deve ser sempre observado com olhos críticos e checado se é adequada a aplicação, pois, segundo Yamamoto e Landim (2013), algumas realizações podem mostrar cenários distintos da realidade. Isso é muito importante quando o problema estudado é a permeabilidade, fluxo de fluido ou transporte, que obriga a considerar um modelo específico além do segundo momento estatístico.

O número de simulações necessárias depende da distribuição do parâmetro de interesse. Normalmente, utilizam-se 100 simulações. Se os dados estiverem enviesados e/ou se houver fundamental atenção aos valores extremos, um maior número de simulações será necessário, ressaltando que as previsões de valores extremos geralmente não possuem robustez e que as simulações condicionais não são igualmente prováveis, algumas são extremas e outras estão próximas à média (Chilès e Delfines, 1999).

\subsubsection{Transformação por normal score}

Como tratado por Deutsch e Journel (1998), a primeira condição necessária para a função estacionária aleatória, $\mathrm{Y}(\mathrm{x})$, ser multivariável normal é que sua função de densidade acumulada univariável seja normal, ou seja:

$$
\operatorname{Pr}\{Y(u) \leq y\}=G(y), \forall y
$$

onde $\mathrm{G}(\cdot)$ é a função de densidade acumulada Gaussiana e $\mathrm{Y}(\mathrm{u})$ é assumida como padronizada, com média zero e variância igual a um. Infelizmente, a maioria dos dados das 
ciências da Terra não apresenta simetria Gaussiana nos histogramas. Esse não é um problema, desde que uma transformação não linear possa transformar qualquer função de densidade acumulada contínua para qualquer outra função de densidade acumulada.

Sendo $\mathrm{Z}$ e $\mathrm{Y}$ duas variáveis regionalizadas com as funções $F_{z}(z)$ e $F_{Y}(y)$, respectivamente, a transformação $\mathrm{Y}=\varphi(\mathrm{Z})$ identifica as probabilidades acumulativas correspondente a Z e Y p quantis:

$$
\begin{aligned}
& F_{Y}\left(y_{p}\right)=F_{Z}\left(z_{p}\right)=p, \forall p \in[0,1], \text { então: } \\
& y=F_{Y}^{-1}\left(F_{Z}(z)\right)
\end{aligned}
$$

com $F_{Y}^{-1}($. ) sendo a inversa da função de densidade acumulada da variável aleatória $\mathrm{Y}$ :

$$
y_{p}=F_{Y}^{-1}(p), \forall p \in[0,1]
$$

Se Y é normal padronizada, ou seja, com média zero e variância igual a um, com função de densidade acumulada $F_{Y}(y)=G(y)$, a transformação $G^{-1}\left(F_{Z}().\right)$ é a transformação normal score.

Na prática, os $n$ dados amostrais $z$ são ordenados de forma crescente de valores:

$$
z^{(1)} \leq z^{(2)} \leq \cdots \leq z^{(n)}
$$

A frequência acumulativa correspondente a $k$-ésimo maior valor de z é $F_{z}\left(z^{(k)}\right)=k / n$ ou $F_{Z}\left(z^{(k)}\right)=\sum_{i=1}^{k} w_{j} \in[0,1]$ se o conjunto de pesos de desagrupamento $\omega_{\mathrm{j}}$ for aplicado para $\mathrm{n}$ dados.

Portanto, a transformação de normal score de $\mathrm{z}(\mathrm{k})$ é o $k / n$ quantil da função de densidade acumulada normal padronizada:

$$
y^{(k)}=G^{-1}\left(\frac{k}{n}\right)
$$

\subsubsection{Bandas rotativas}

De acordo com Chilès e Delfiner (1999), apesar de diversos modelos de covariância possibilitarem uma simulação direta em $\mathbb{R}^{n}$, o método de bandas rotativas é mais simples de se aplicar, pois proporciona a construção de simulações no espaço de simulações em linha. Em outras palavras, o método consiste em adicionar um grande número de simulações independentes definidas em linhas sobre um plano. Segundo Olea (1999), realizações simuladas de uma função multidirecional aleatória são obtidas pela geração de uma série unidimensional de independentes realizações de uma função aleatória que compartilham uma covariância 
comum. Outra condição para a implementação do algoritmo do método é que a função aleatória seja estacionária de segunda ordem e siga uma distribuição univariável padrão normal.

\subsection{Algoritmo para o método de simulação condicional por bandas rotativas}

Com base nas explicações de Chilès e Delfiner (1999) e Olea (1999), os passos para a aplicação da simulação por bandas rotativas de uma função multidimensional aleatória segue a seguinte ordem:

1- Transformação dos dados para se obter a normal score;

2- Ajustar o melhor modelo de variância $\gamma_{n}(h)$ ou covariância $C_{n}(h)$ para os dados anamorfosados, usando técnicas padrões de modelagem de semivariograma;

3- Derivar a covariância $C_{1}(h)$ que combinações lineares de realizações independentes em linha são esperadas a fim de gerar realizações de um processo multidimensional com covariância $C_{n}(h)$. Para um caso isotrópico em $2 \mathrm{D}$, a covariância unidimensional é:

$$
C_{1}(h)=\frac{\partial}{\partial h} h C_{2}(h)
$$

Cada modelo de covariância segue uma determinada função. No caso do presente trabalho o modelo utilizado foi o esférico. A função que define esse modelo é expressa como:

$$
C_{1}(h)=\left\{\begin{array}{c}
C\left[1-\frac{3 \pi}{4}\left(\frac{h}{a}-\frac{1}{2}\left(\frac{h}{a}\right)^{3}\right)\right] \text { para } h<a \\
C\left[1 \frac{3}{2}\left(\frac{h}{a}-\frac{1}{2}\left(\frac{h}{a}\right)^{3}\right) \sin ^{-1}\left(\frac{a}{h}\right)-\frac{3}{4}\left(\frac{h}{a}\right)^{2} \sqrt{1-\left(\frac{a}{h}\right)^{2}}\right] \text { para } h \geq a
\end{array}\right.
$$

4- Gerar uma série de realizações discretas, independentes e unidimensionais ao longo de linhas que irradiam da origem de uma esfera multidimensional. Todas as realizações devem ter a mesma covariância. Na teoria é possível usar infinitas linhas, mas na prática o número de linhas varia conforme a dimensionalidade do espaço.

5- Apesar de haver diversos métodos para geração de realização em linhas, aqui só será abordada a técnica de convolução, a mesma que o software ISATIS utiliza. Sucintamente, essa técnica é uma operação matemática em que duas funções $f$ e $g$ produzem uma terceira função que é tipicamente vista como uma função modificada de uma das funções originais, dando a área sobreposta entre as duas funções como uma função que consiste nos originais é transladada. 
Essa técnica é baseada na ideia de que a propriedade $C_{1}(h)$ pode ser expressa como a convolução de uma função $p(x)$ propriamente escolhida:

$$
C_{1}(h)=\int_{-\infty}^{\infty} p(x) p(x+h) d u
$$

O modelo de covariância escolhido, por ser o mais adequado, é o esférico com variância $C(h)$, patamar e amplitude, $a$, sendo:

$$
p(x)=\left\{\begin{array}{c}
\sqrt{\frac{6 C}{\pi a^{3}}} x, \text { para } x \leq \frac{a}{2} \\
0 \text { para } x>\frac{a}{2}
\end{array}\right.
$$

Valores $y_{1}\left(u_{i}\right)$ são provenientes de uma distribuição uniforme e atribuídos a pontos $u_{i}$ em um intervalo regular, $\Delta u$ em uma linha. A realização na linha nesse caso é uma série de valores ponderados, $Z_{1}\left(u_{i}\right)$, dados por:

$$
Z_{1}\left(u_{i}\right)=\sum_{j=i-n}^{i+n} p\left|u_{j}-u_{i}\right| y\left(u_{j}\right), \text { onde } n=\frac{a-\Delta u}{2 \Delta u}
$$

6- Adicionar as contribuições das realizações das linhas para produzir a realização multidimensional, $Z_{n}\left(u_{i}\right)$. Caso planos multidimensionais perpendiculares sejam erguidos entre cada valor simulado de cada uma das $N$ realizações ao longo das direções $x_{j}$, então o espaço é particionado em bandas multidimensionais de distância $\Delta u$. Essa partição é mais fácil de ser visualizada em duas dimensões, sendo as bandas decompostas em listras (Figura 17). Dada uma realização unidimensional, cada ponto no espaço multidimensional recebe um valor simulado, $z_{1, i}(u)$, que compartilha a mesma banda. Dos valores na realização $Z_{1, i}(u)$, o única a fazer uma contribuição para a soma é aquela em que a banda contém a perpendicular entre $u_{0}$ e a linha $x_{i}$. Ou seja, o argumento de $z_{1, i}($.$) é o tamanho da projeção de u_{0}$ em $x_{i}$. Pelo teorema do limite central, cada valor simulado é uma realização de uma função multidimensional aleatória em $u_{0}$ obtido como uma adição dimensionada de um valor unidimensional simulado nos $N$ pontos projetados:

$$
z_{n}\left(u_{0}\right)=\frac{1}{\sqrt{N}} \sum_{i=1}^{N} z_{1, i}\left(u_{0} \cdot x_{i}\right)
$$




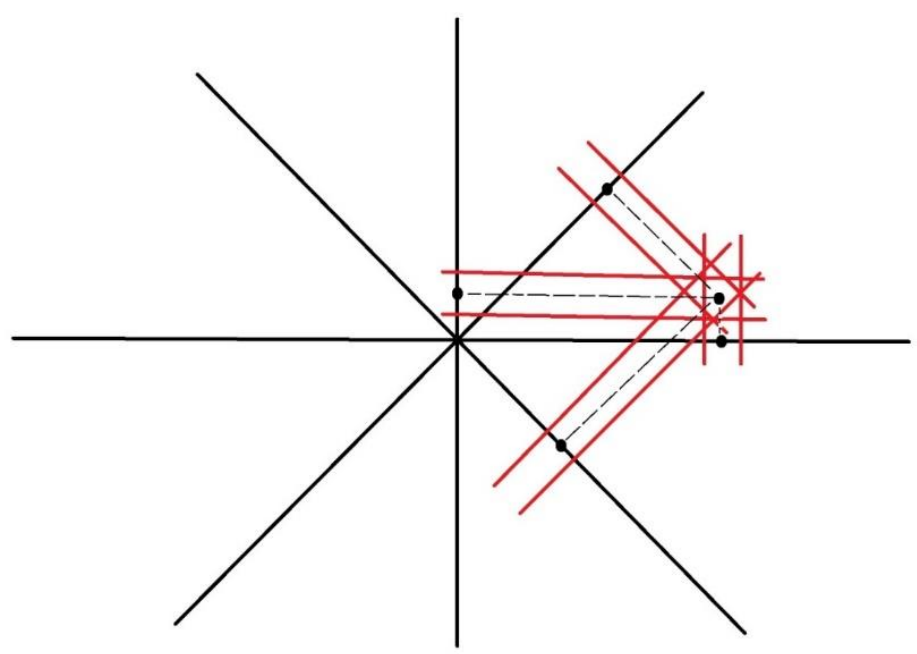

Figura 17: Ilustração do método de bandas rotativas em duas dimensões. Cada ponto simulado no plano é a média de todos os valores de linhas simuladas as quais as bandas de influência contém o ponto. Para simplificação, somente quatro linhas são usadas na figura.

7- Condicionar os dados usando a krigagem, pois o método de bandas rotativas não produz valores que honram os dados.

$\mathrm{O}$ condicionamento envolve duas séries diferentes de dados. O primeiro assume $\hat{z}_{d}\left(u_{0}\right)$ como o estimador de krigagem na localização $u_{0}$ baseado na série de dados original da normal score. Ainda, considerando que $z_{n}\left(u_{0}\right)$ como valor não condicional produzido pelo passo 5 usando a mesma normal score. Uma realização é composta por uma série de valores $z_{n}\left(u_{0}\right)$, tendo a mesma covariância que parâmetros simulados. Uma segunda série de dados é gerada empregando as mesmas $N$ realizações de linhas do passo 4 para simular valores $z_{S}\left(u_{0}\right)$ nas localizações de $u_{0}$ da série de dados original. A segunda krigagem é feita usando os valores de $z_{s}\left(u_{0}\right)$ valores como dados para obter $\hat{z}_{n}\left(u_{0}\right)$. A expressão que fornece os valores simulados condicionalmente é:

$$
z_{c}\left(u_{0}\right)=\hat{z}_{d}\left(u_{0}\right)+z_{n}\left(u_{0}\right)-\hat{z}_{n}\left(u_{0}\right)
$$

Para explicar os componentes da equação acima é necessário usar informações previamente fornecidas nessa revisão geoestatística, principalmente no que se refere à krigagem simples. Usando a explicação fornecida por Olea (1999):

i) Caso $u_{0}$ coincida com um lugar de amostragem, $z_{n}\left(u_{0}\right)=\hat{z}_{n}\left(u_{0}\right)$ e $\hat{z}_{d}\left(u_{0}\right)=z\left(u_{0}\right)$, sendo assim, $z_{c}\left(u_{0}\right)$ é um interpolador exato, pois $z_{c}\left(u_{0}\right)=z\left(u_{0}\right)$;

ii) Considerando que a krigagem é interpolador não enviesado, $E\left[Z\left(u_{0}\right)\right]=E\left[\hat{Z}_{d}\left(u_{0}\right)\right] \mathrm{e}$ $E\left[Z_{n}\left(u_{i}\right)\right]=E\left[\hat{Z}_{n}\left(u_{0}\right)\right]$. Consequentemente, o valor esperado de $Z_{c}\left(u_{0}\right)$ é o mesmo valor esperado da função aleatória da normal score $Z(u)$; 
iii) A função aleatória pode ser decomposta em duas componentes, estimativa de krigagem e erro de krigagem $Z(u)=\hat{Z}_{d}(u)+\left\{Z(u)-\hat{Z}_{d}(u)\right\}=\hat{Z}_{d}(u)+R(u)$, assumindo que a média da normal score é zero, $C(h)=E\left[\left\{\hat{Z}_{d}(u)+R(u)\right\}\left\{\hat{Z}_{d}(u+h)+R(u+h)\right\}\right]$.

Sabendo que o erro desconhecido $Z(u)-\hat{Z}_{d}(u)$ tem a mesma covariância que a o conhecido $Z(u)-\hat{Z}_{d}(u)=R_{n}(u)$, então:

$$
C(h)=E\left[\left\{\hat{Z}_{d}(u)+R(u)\right\}\left\{\hat{Z}_{d}(u+h)+R(u+h)\right\}\right]=C_{Z_{c}}(h)
$$

Isso porque $R_{n}(u)$ é independente de $\hat{Z}_{d}(u)$. Sendo assim, a covariância da combinação $Z_{c}(u)$ é a mesma da covariância da função aleatória normal score $Z(u)$.

8- Aplicar a transformação reversa para que a realização feita dos dados em normal score se converta para o espaço original.

\subsection{Outros métodos de interpolação utilizados}

Para o desenvolvimento do mapa potenciométrico de ambas as áreas é aplicado o método de ponderação pelo inverso da distância. Embora seja um método presente na maioria dos softwares que tratam de contornos, sejam esses, curvas de nível ou potenciométricas, ele não produz bons resultados para áreas grandes com poucos dados. De acordo com Kresic (2007), esse método eleva a distância à potência ponderando os pontos durante a interpolação de forma que a influência relativa de um ponto a outro decresça com a potência da distância. O resultado é a formação do que o autor chama de "bull eyes" no entorno de poços. Esse efeito é suavizado pelo software ArcGis, no entanto, não é eliminado. Na área de Bauru, devido ao maior número de pontos em uma área menor, esse efeito é menor. São Carlos, por sua vez, apresenta cones ou "bull eyes" mais presentes. Outros métodos de interpolação também foram testados, sendo esses spline (função de base radial) e triangulação com interpolação linear. A predileção pelo método de ponderação pelo inverso da distância é feita com base nas curvas potenciométricas próximas das drenagens principais e consideradas como perenes. Nesse método, as curvas apresentam um padrão mais ajustado ao esperado. 


\section{METODOLOGIA}

\subsection{Revisão Bibliográfica}

Revisão de conceitos e de trabalhos publicados a geologia e hidrogeologia das regiões de estudo, com ênfase nos Sistema Aquífero Guarani (SAG) e Sistema Aquífero Bauru (SAB) e seus respectivos comportamentos hidráulicos. Para isso são utilizados livros e artigos disponíveis no Sistema Integrado de Bibliotecas, SIBI, da Universidade de São Paulo, no Portal de Periódicos da CAPES, SciELO e ScienceDirect.

\subsection{Aquisição e Elaboração do Banco de Dados}

As fichas com os ensaios de testes de bombeamento e descrição litológica dos poços são fornecidos pelo Departamento de Águas e Energia Elétrica (DAEE) de Araraquara e São Paulo, empresa Uniper e Instituto Geológico (IG). Sendo essas fichas originalmente em papel ou fotocopiadas.

Primeiramente, separam-se as fichas dos poços por cidades e região. A segunda etapa consiste na seleção de poços que disponham de dados suficientes para subsidiar os estudos pretendidos na dissertação. A próxima etapa é a digitalização das informações de interesse para que essas possam ser usadas para o cálculo dos valores de transmissividade (T), condutividade hidráulica $(\mathrm{K})$ e capacidade especifica $(\mathrm{Q} / \mathrm{s})$. Ainda, a descrição litológica de cada poço também é digitalizada para o desenvolvimento dos modelos geológicos. Todas as informações relevantes para o estudo são compiladas em planilhas de EXCEL, do pacote Office desenvolvida pela empresa Microsoft.

Os poços inseridos na cidade Bauru apresentam uma configuração de aquífero semiconfinado. Embora o Sistema Aquífero Bauru seja considerado livre regionalmente, a esse é atribuído o caráter semiconfinado localmente. No caso dos poços que exploram o SAG, há uma seleção mais especifica devido à descrição litológica na construção dos poços apresentarem variações. Nos poços que exploram as águas desse sistema aquífero, o conjunto das Formações Botucatu e Pirambóia encontra-se distribuídos em toda área de estudo, sendo a maior parte confinada ou semiconfinado pelas Formações Adamantina e Serra Geral.

Para distinção de poços representativos de aquíferos confinados e semiconfinados, usase como critério o ajuste das curvas dos métodos de interpretação de testes de aquíferos. Ou 
seja, os testes de poços que se ajustam ao método de Theis (1935) são considerados como confinados e os que se ajustam ao método de Hantush (1956), semiconfinado. Os dados dos testes de bombeamento são processados no software Aquifer Test, desenvolvida pela empresa Schlumberger Water Services. Nesse software são calculados valores de T e Q/s.

Usando como ferramenta o software ArcGIS, desenvolvido pela empresa ESRI, mapas e imagens base pesquisados são processados para o subsídio dos modelos aqui desenvolvidos e na ilustração da disposição dos poços estudados, bem como os limites municipais e mapas geológicos e hidrogeológicos. Os mapas e imagens foram pesquisados a partir de bibliotecas virtuais do Serviço Geológico do Brasil (CPRM) e Instituto Brasileiro de Geografia e Estatística (IBGE) e na plataforma Earth Explorer da United States Geological Survey (USGS).

As planilhas dos poços instalados em São Carlos e Bauru apresentam uma variação nos critérios litológicos de classificação das formações que representam as amostras analisadas na construção de cada poço. Muitas vezes a descrição litológica não apresenta as características convencionadas para a formação que o profissional responsável pela descrição das amostras retiradas durante a construção do poço atribuiu. Com o intuito de uniformizar e criar um padrão descritivo para essas amostras, optou-se por usar a tabela 2 como guia nessa tarefa, que corresponde a uma adaptação da coluna estratigráfica da Bacia do Paraná. 
Tabela 2: Descrição da coluna estratigráfica da Bacia do Paraná para as unidades de estudo. Adaptada de IPT (1981) e IPT (2003).

\begin{tabular}{|c|c|c|}
\hline Grupo & Formação & Tipos de Rochas (Litologia) \\
\hline \multirow{2}{*}{ BAURU } & Marília & $\begin{array}{l}\text { Arenitos de granulação fina e grossa, compreendendo bancos } \\
\text { maciços com tênues estratificações cruzadas de médio porte. } \\
\text { Subordinadanadamente ocorrem lentes de siltitos, argilitos e } \\
\text { arenitos muito finos. Presença comum de nódulos } \\
\text { carbonáticos. }\end{array}$ \\
\hline & Adamantina & $\begin{array}{l}\text { Arenitos finos e muito finos, podendo apresentar cimentação e } \\
\text { nódulos carbonáticos com lentes de siltitos arenosos e } \\
\text { argilitos ocorrendo em bancos maciços, estratificação plano- } \\
\text { paralela e cruzada de pequeno a médio porte. }\end{array}$ \\
\hline \multirow{3}{*}{$\begin{array}{c}\text { SÃO } \\
\text { BENTO }\end{array}$} & Serra Geral & $\begin{array}{l}\text { Rochas vulcânicas toleíticas dispostas em derrames basálticos, } \\
\text { com coloração cinza a negra, textura afanítica, com } \\
\text { intercalação de arenitos intertrapeados, finos a médios, } \\
\text { apresentando estratificação cruzado tangencial. }\end{array}$ \\
\hline & Botucatu & $\begin{array}{l}\text { Arenitos eólicos avermelhados de granulação fina a média, } \\
\text { com estratificação cruzada de médio a grande porte. Ocorrem } \\
\text { restritamente depósitos fluviais de natureza areno- } \\
\text { conglomerática e camadas localizadas de siltitos e argilitos } \\
\text { lacustres. }\end{array}$ \\
\hline & Pirambóia & $\begin{array}{l}\text { Depósitos de arenitos finos a médios, avermelhados, siltíco- } \\
\text { argiloso, com estratificação cruzada ou plano paralela, com } \\
\text { níveis de folhelhos a arenitos argilosos variegados e raras } \\
\text { intercalações de naturezaareno-argilosa. }\end{array}$ \\
\hline $\begin{array}{c}\text { PASSA } \\
\text { DOIS }\end{array}$ & Corumbataí & $\begin{array}{l}\text { Depósitos possivelmente marinhos de planície de maré, } \\
\text { incluindo argilitos, folhelhos e siltitos cinza, arroxeados ou } \\
\text { avermelhados, com intercalações de bandas carbonáticas e } \\
\text { camadas de arenitos finos. }\end{array}$ \\
\hline
\end{tabular}

Os modelos geológicos, bem como os perfis, são trabalhados no software GMS, desenvolvido pela empresa AQUAVEO.

\subsection{Tratamento Estatístico}

Após os processos de triagem, digitalização e compilação das informações presentes nas fichas dos poços, há um tratamento estatístico dos dados. Esse tratamento consiste na verificação da distribuição primeiramente de forma gráfica da frequência dos valores de transmissividade $(T)$, capacidade específica $(\mathrm{Q} / \mathrm{s})$, condutividade hidráulica $(\mathrm{K})$.

Verificado o comportamento lognormal dessas distribuições pelos histogramas, o uso de $y=\log (T)$ passa a ser permitido como variável, tratando o problema de sua variação por uma abordagem gaussiana. Essas mesmas observações são feitas para os valores de condutividade hidráulica e capacidade específica $(\mathrm{Q} / \mathrm{s})$. Ou seja, adota-se $\log (K)$ e $\log (Q / s)$ como variáveis.

O próximo passo é a verificação da normalidade da distribuição desses valores por métodos formais para verificação da normalidade. Nesse trabalho são utilizados os métodos de Kolmogorov-Smirnov e Shapiro- Wilk. No caso dos valores oriundo do SAG, aplica-se o teste 
de $t$ de Student para verificar se os valores que satisfazem os dois métodos de normalidade são representantes de uma mesma população.

Para esse tratamento estatístico, o software utilizado é Statistica, desenvolvido pela empresa StatSoft.

\subsection{Métodos Geoestatísticos}

Os métodos geoestatísticos seguem uma sequência de passos que é similar a todos. Sendo essas:

Análise exploratória ou estrutural: Essa etapa objetiva entender o comportamento da variável de interesse por meio de análise estatística e espacial do parâmetro. A análise estatística é a estatística descritiva dessa variável. A análise espacial é o estudo da distribuição espacial e possíveis direções de anisotropia. Para tal estudo, são utilizados variogramas experimentais e mapas variogramas. Nesse primeiro o tamanho do passo ou lag é ajustado. Antes de partir para a próxima etapa, no caso do método estocástico de simulação bandas rotativas, há uma transformação dos dados por meio da transformada normal score;

Variograma modelado: Define-se o melhor modelo de variograma que se ajuste ao comportamento espacial dos dados de interesse. Para isso é necessário que os valores das estruturas sejam definidos. No caso dos métodos que utilizam o software ISATIS como ferramenta geoestatística, o efeito pepita é considerado uma estrutura, o que difere do software GEOVISUAL. O modelo escolhido deve se ajustar aos valores do efeito pepita, a variância espacial e a amplitude definidos pelo modelador;

Validação cruzada: Como o próprio nome diz, essa etapa se dedica a validar e verificar o quão o modelo ajustado é acurado para a variável de interesse. Essa avaliação é feita por meio de krigagem ordinária ou simples em que valores reais e são retirados do mapa e estimados com base na vizinhança desse ponto. Não há na literatura um valor mínimo para aprovar ou não o modelo. Caso o valor da validação cruzada não seja satisfatório para o modelador, esse deve retornar ao passo dois e redefinir os parâmetros do modelo até que o valor seja do aceitável;

Estimativa da variável pelo método escolhido: Após atingir um valor satisfatório na validação cruzada, o método geoestatístico é aplicado e obtém-se as estimativas de valores para a variável de interesse no domínio. É importante salientar que no caso do método de simulação condicional por bandas rotativas, aplica-se uma back transformation, no qual os dados são 
convertidos da distribuição adotada quando se usou a normal score na etapa um para a distribuição real.

Os softwares utilizados são ISATIS, desenvolvido pela empresa GEOVARIANCE, e GEOVISUAL, desenvolvido pelo Professor Doutor Jorge Kazuo Yamamoto e colaboradores. 


\section{RESULTADOS E DISCUSSÃO}

Os resultados e discussão são divididos em três partes:

1- Descrição das áreas, baseando-se nas informações das planilhas dos poços inseridos em São Carlos, SAG, e Bauru, SAB;

2- Tratamento estatístico dos dados do SAG e SAB, e;

3- Aplicação dos métodos geoestatísticos nas cidades de São Carlos e Bauru;

As bases de dados dos poços utilizados para a obtenção dos resultados apresentados nessa dissertação estão disponíveis nos anexos I e II, para os dados de São Carlos e Bauru, respectivamente. Essas informações consistem nos ID's criados pelo autor dessa dissertação, coordenadas em UTM de cada poço, níveis estáticos (NE), níveis dinâmicos (ND), os valores de $\mathrm{Q} / \mathrm{s}, \log (\mathrm{Q} / \mathrm{s}), \mathrm{K}, \log (\mathrm{K})$ e $\log (\mathrm{K})$ calculado pelas equações da regressão linear obtidas no tratamento estatístico.

\section{1 Áreas de Estudo}

Essa seção descreve as áreas de estudo com base em interpretações provenientes das informações das planilhas dos poços situados em São Carlos (SAG) e Bauru (SAB).

Como se observa na tabela 3 , as áreas apresentam padrões distintos. Os poços estudados em São Carlos apresentam maior profundidade, nível estático (NE) e nível dinâmico (ND) que os instalados em Bauru.

Tabela 3: Estatística descritiva e comparativa da profundidade, nível estático (NE), nível dinâmico (ND) dos poços que apresentam dados de Condutividade hidráulica e capacidade específica em São Carlos e Bauru.

\begin{tabular}{|l|c|c|c|c|c|c|}
\hline \multirow{2}{*}{ Parâmetros } & \multicolumn{2}{|c|}{ Profundidade $(\mathrm{m})$} & \multicolumn{2}{c|}{ NE $(\mathrm{m})$} & \multicolumn{2}{c|}{ ND (m) } \\
\cline { 2 - 7 } & São Carlos & Bauru & São Carlos & Bauru & São Carlos & Bauru \\
\hline Média & 258.76 & 83.13 & 101.08 & 27.53 & 123.17 & 55.28 \\
\hline Mediana & 262.27 & 77.00 & 101.69 & 25.00 & 141.69 & 48.35 \\
\hline Modo & 254.53 & 100.00 & 207.20 & 18.00 & 152.96 & 46.00 \\
\hline $\begin{array}{l}\text { Desvio } \\
\text { padrão }\end{array}$ & 119.69 & 32.10 & 50.76 & 15.11 & 70.90 & 24.90 \\
\hline Mínimo & 47.90 & 28.00 & 6.00 & 3.98 & 12.00 & 11.40 \\
\hline Máximo & 484.00 & 160.00 & 207.20 & 87.30 & 260.00 & 130.00 \\
\hline Contagem & 28 & 68 & 28 & 68 & 28 & 68 \\
\hline
\end{tabular}




\subsubsection{São Carlos}

Os poços que apresentam os valores de $\mathrm{K}$ e Q/s estão majoritariamente distribuídos na periferia da malha urbana da cidade de São Carlos, em uma área de 132,4 $\mathrm{km}^{2}$. Os poços apresentam-se de forma esparsa e por vezes agrupados, com distância média entre si de aproximadamente 2,5 km (Figura 18).

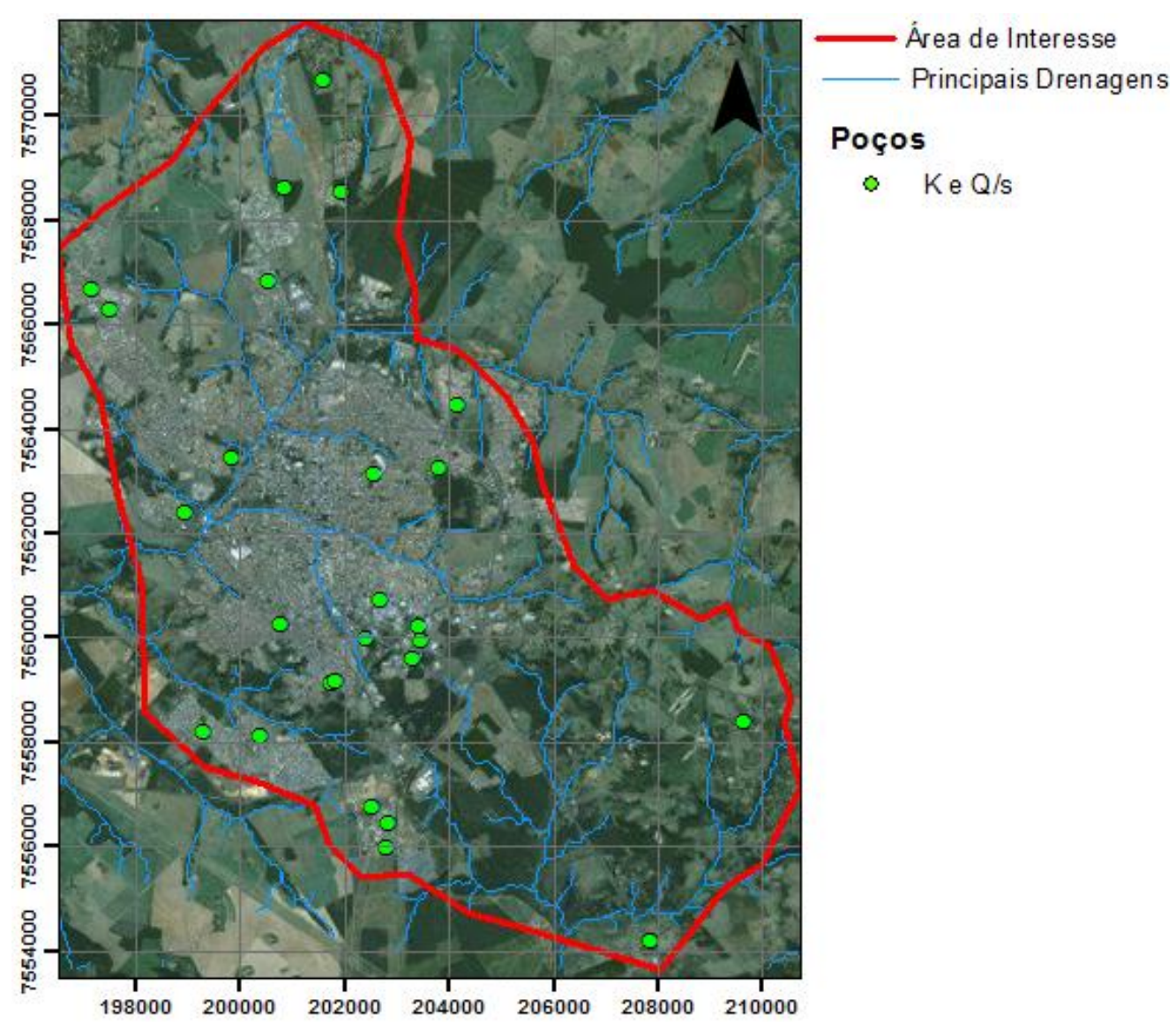

Figura 18: Malha urbana e rural de São Carlos, onde estão inseridos os poços

Essa área de interesse está inserida na Unidade de Gestão de Recursos Hídricos do Estado de São Paulo de número 13, UGRHI 13, bacia Tietê/Jacaré, na sub-bacia do Rio Jacaré-Guaçu. A topografia indica que a área de interesse faz parte de duas bacias hidrográficas distintas, sendo uma maior na porção sudoeste e uma menor na porção sudeste (figura 19). Os dois principais corpos d'água da área são o Rio Monjolinho e o córrego do Gregório. O segundo tem a sua foz no Rio monjolinho. A cota topográfica dentro dessa área varia de 716 a 946 m sobre o nível do mar (msnm). 


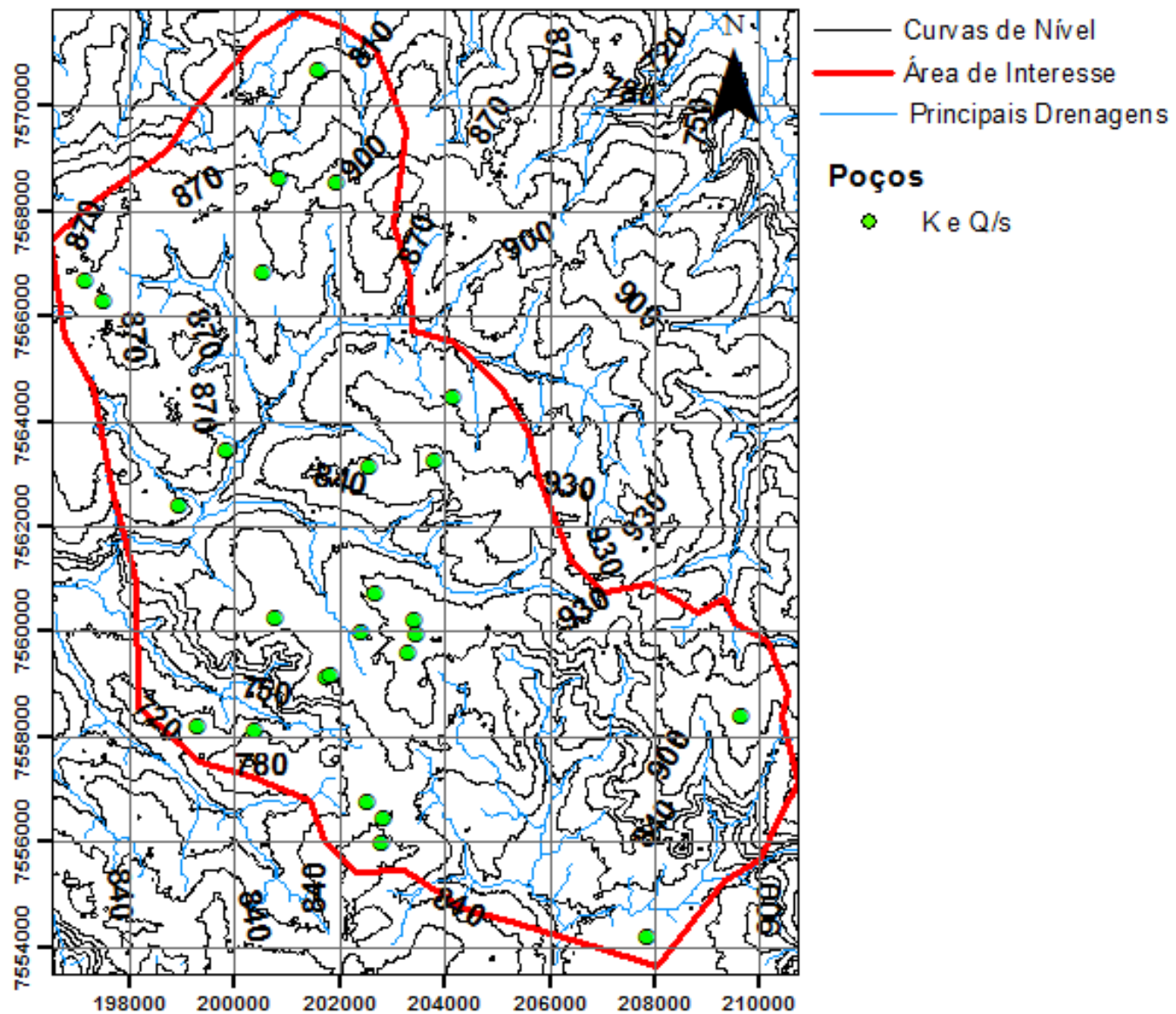

Figura 19: Topografia da área de estudo em São Carlos.

A figura 20 mostra que a tendência do fluxo da água subterrânea na área de interesse é de NW-SE. Segundo DAEE (1974), os níveis piezométricos mostram uma tendência regional do fluxo subterrâneo para as calhas do Rio Tietê e secundariamente para os vales dos Rios JacaréGuaçu e Jacaré-Pepira. No caso da área de estudo no SAG, o fluxo subterrâneo tende em direção ao Rio Jacaré-Guaçu. 


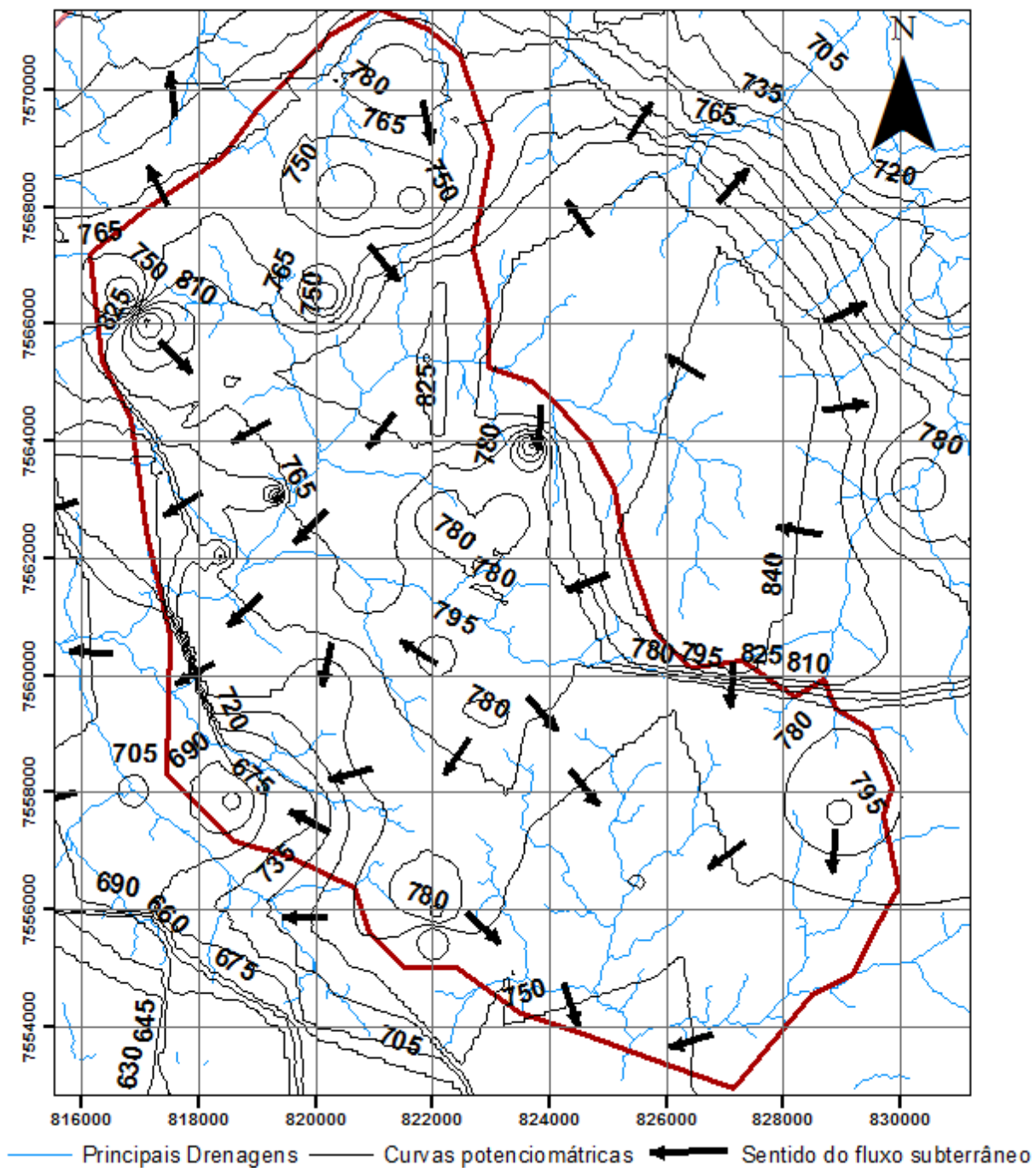

Figura 20: Mapa potenciométrico da área de estudo na cidade de São Carlos.

O mapa geológico desenvolvido pela CPRM (2006) é apresentado pela figura 21. Nele, observam-se discrepâncias com o modelo geológico proposto pela presente dissertação nessa mesma área (Figura 23). Esse modelo é baseado unicamente em descrições de amostras coletadas na construção dos poços de bombeamento e usadas para subsidiar os estudos desenvolvidos nesse trabalho. Não houve visitas ao campo. 


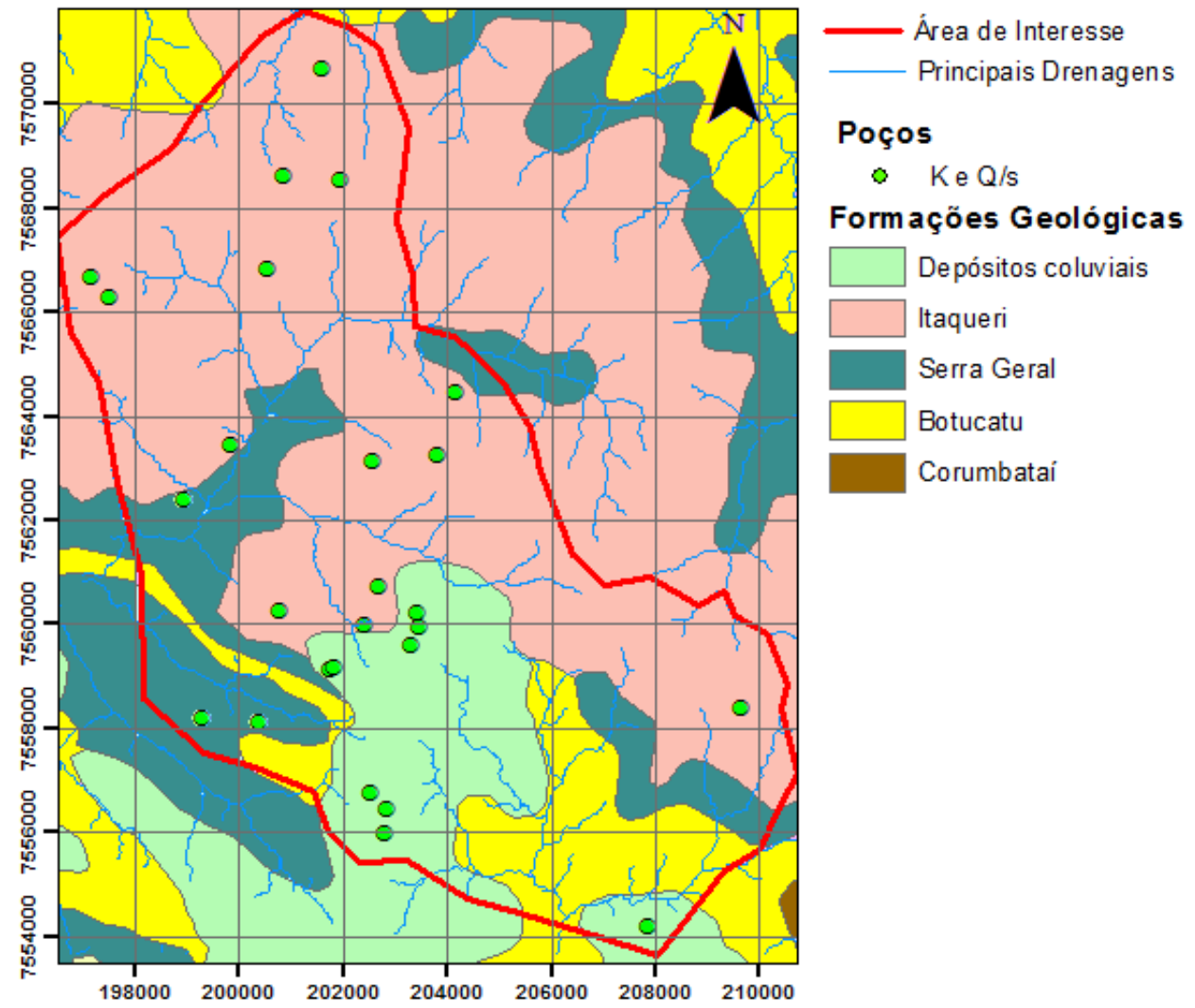

Figura 21: Mapa geológico da área de estudo na cidade de São Carlos, segundo a CPRM. Adaptado do mapa geológico do Estado de São Paulo, escala 1: 750.000, CPRM (2006).

As figuras 22, 23 e 24 mostram a geologia proposta nessa dissertação. Na Figura 22, observa-se o modelo geológico 3D em uma visão oblíqua, em que foi aplicado o exagero vertical de 10 vezes para ressaltar o relevo. As linhas coloridas representam as curvas de nível do modelo. Nas figuras 23 e 24, são apresentados o mapa geológico 2D e perfis geológicos referentes a esse mapa, respectivamente. Esses perfis são representados por quatro seções, sendo essas N-S, W-E, NW-SE e SW-NE. Como nenhum dos poços usados nesse trabalho atravessa a Formação Corumbataí, a sua base é inferida e indicada por uma linha tracejada (Figura 24). 


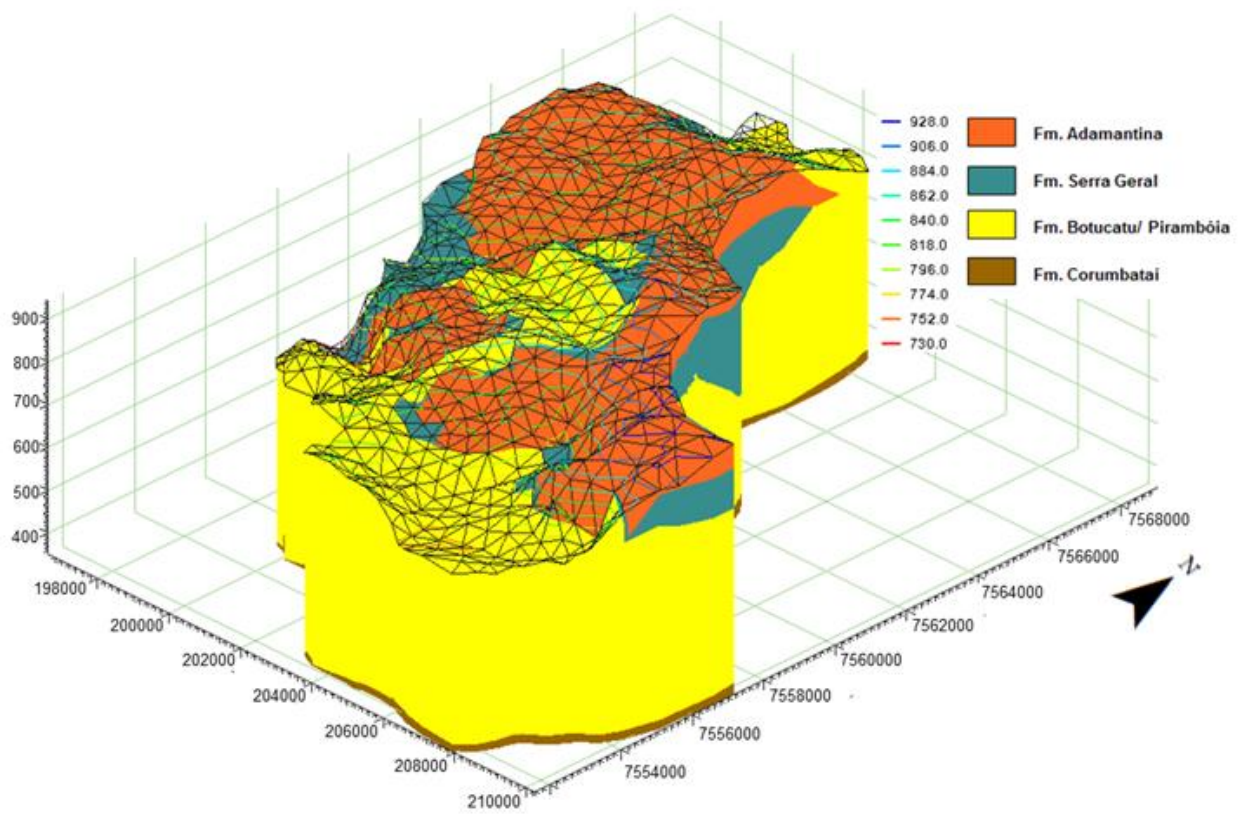

Figura 22: Modelo geológico em três dimensões da área de interesse na cidade de São Carlos. Modelo desenvolvido com base nas informações das amostras descritas na construção dos poços.

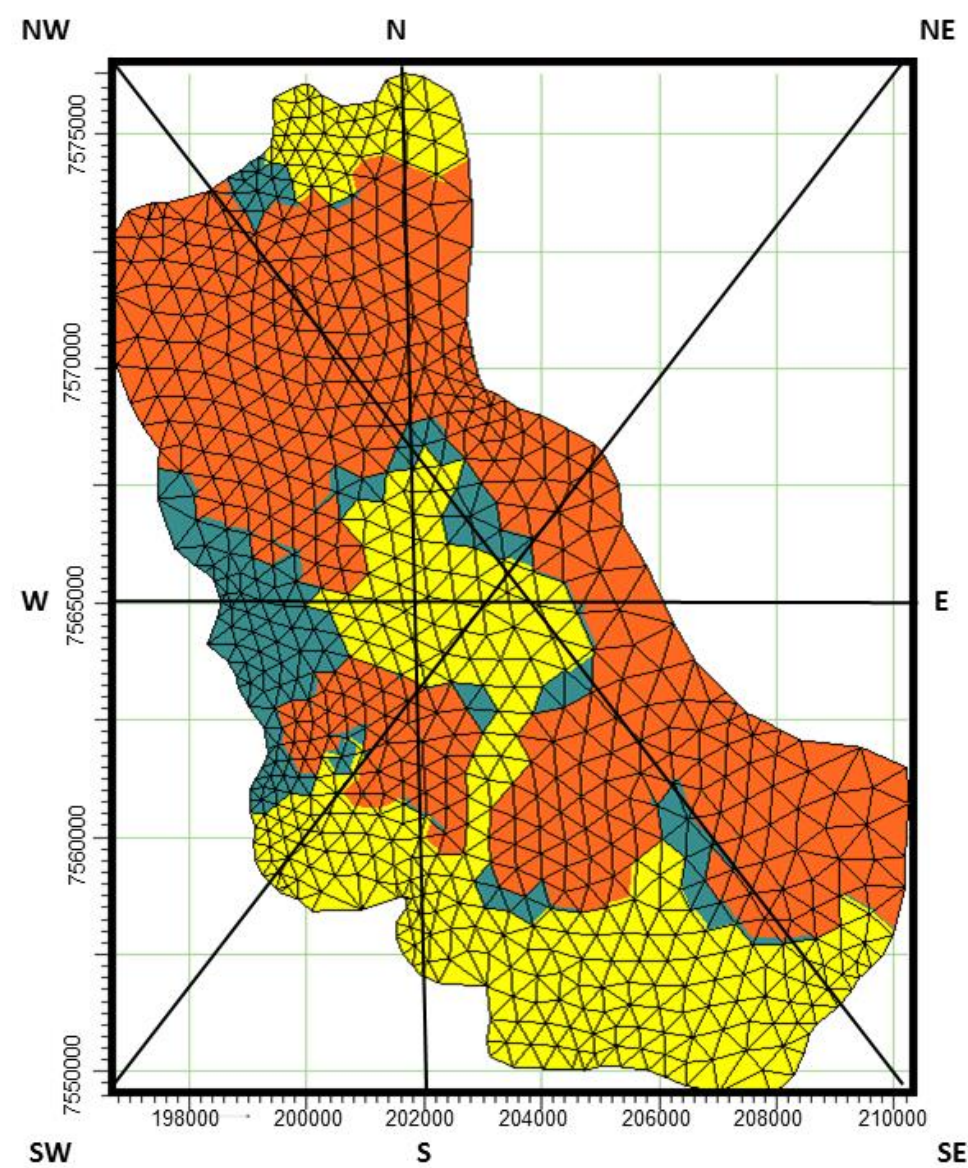

Figura 23: Mapa geológico da área de estudo na cidade de São Carlos baseado nas descrições litológicas dos poços de bombeamento estudados. As linhas representam os locais escolhidos para a confecção das seções geológicas. 

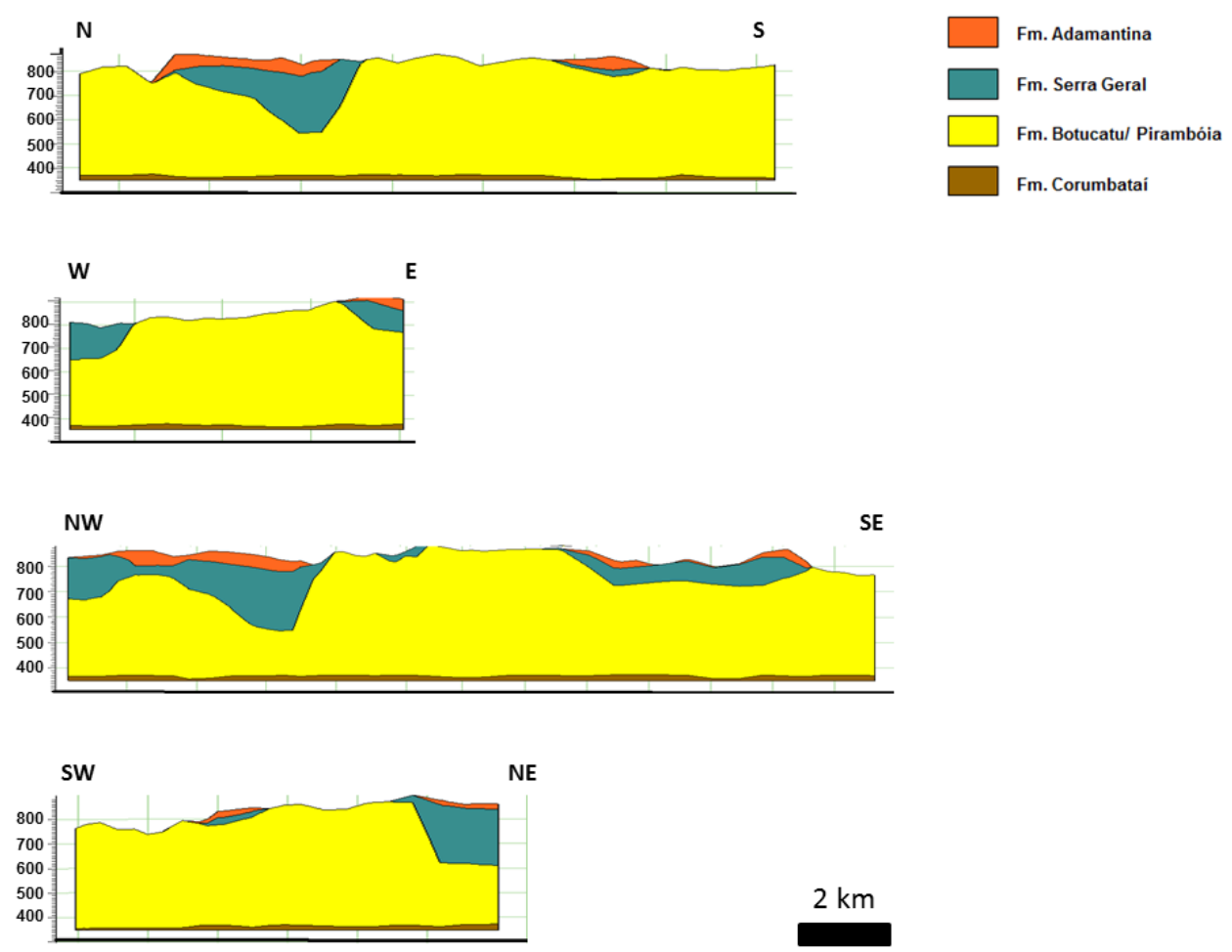

Figura 24: Seções geológicas baseadas nas descrições litológicas dos poços de bombeamento estudados na cidade de São Carlos. As linhas tracejadas representam os limites inferidos.

O mapa geológico proposto pela CPRM (2006) e o modelo geológico concluído por essa dissertação diferem na área de estudo tanto pela disposição das formações geológicas quanto pelo predomínio da Formação Itaqueri na área, segundo o mapa do serviço geológico brasileiro.

Essa formação não é mencionada em nenhuma das descrições de poços. Segundo Ladeira e Santos (2005), a Formação Itaqueri é tipicamente encontrada ao sul da área de estudo, mais especificamente na região das cidades de São Pedro, Itirapina e Charqueada. Seus sedimentos são descritos como arenitos com cimento argiloso e lentes alongadas de folhelhos e conglomerados polimíticos. Visto que o grau de detalhe no mapeamento feito pela CPRM (2006) é em escala menor, acredita-se que a distribuição dessa formação é extrapolada no mapa geológico. Ainda, de certa forma, a descrição da Formação Itaqueri apresenta semelhanças com a dada para a Formação Adamantina, principalmente por ambas serem constituídas por arenitos finos e lentes de argilitos.

A geologia observada com base nas descrições dos poços inseridos na área de estudo em São Carlos mostra que a Formação Adamantina é predominante, principalmente no que se refere às áreas de cotas topográficas mais elevadas e apresenta espessura de cinco a 20 metros. Essa formação repousa sobre os derrames basálticos da Formação Serra Geral que apresentam espessura variada de algumas dezenas de metros até $350 \mathrm{~m}$ nas bordas oeste e noroeste da área e, por sua vez, confinam o as Formações Botucatu e Pirambóia, representantes do SAG na 
região. Sotoposto a essas formações está a Formação Corumbataí, composto por sedimentos de granulometria mais fina e que atua como uma camada semipermeável, aquitarde, da base do SAG.

As Formações Botucatu e Pirambóia são unificadas e chamadas de Formação Botucatu/Pirambóia porque, na maioria das descrições das amostras dos poços estudados na área do SAG, essas duas formações não são claramente diferenciadas e classificadas como um único membro do Grupo São Bento. A Formação Botucatu/ Pirambóia aflora principalmente nas áreas de relevo mais baixo (Figura 24). Sua espessura varia de algumas dezenas de metros até aproximadamente $400 \mathrm{~m}$ na parte sudoeste da área de estudo.

Os resultados aqui discutidos convergem com as informações encontradas na literatura e sumarizadas na revisão bibliográfica da área. O uso de uma escala maior aplicado nesse trabalho é a provável causa da discrepância encontrada no mapa geológico definido pela CPRM (2006).

\subsubsection{Bauru}

Os poços que apresentam a descrição litológica e informações de $\mathrm{K}$ e $\mathrm{Q} / \mathrm{s}$ estão majoritariamente na região central da cidade de Bauru. Essa área corresponde à $30,8 \mathrm{~km}^{2}$. Embora haja alguns poços distribuídos em zonas mais periféricas e distantes, a maioria dos poços estão a uma distância média de $700 \mathrm{~m}$ uns dos outros (Figura 25). As informações dos poços que estão fora da área de interesse não são usadas para a descrição geológica. 


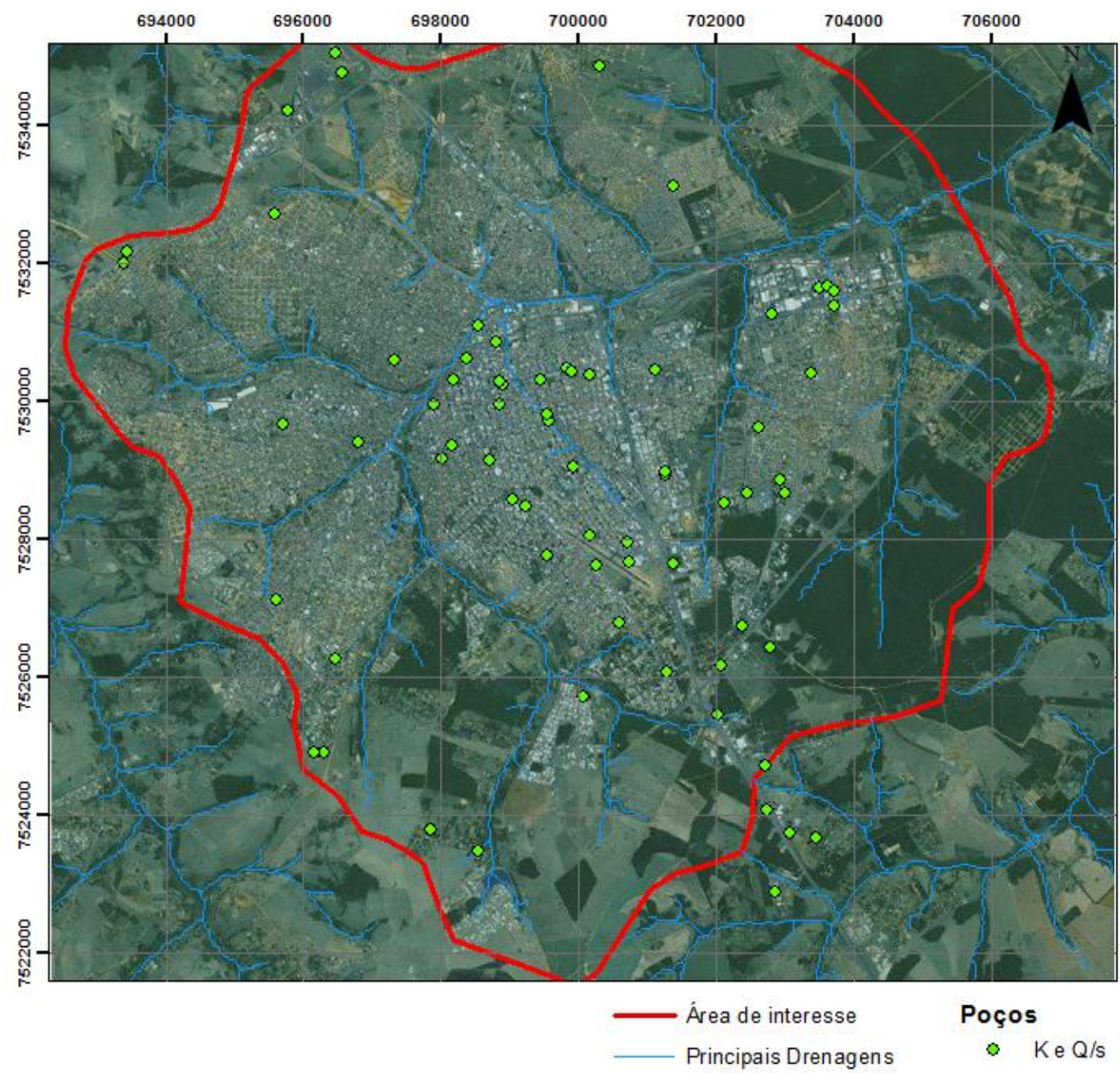

Figura 25: Malha urbana e rural de Bauru, onde estão inseridos os poços.

Assim como a maior parte da cidade de Bauru, os poços estão, em sua maioria, inseridos dentro de uma bacia hidrográfica, a Bacia do Rio Bauru que é uma sub-bacia da bacia TietêJacaré, UGRHI 13. Sendo uma bacia, a região próxima dos limites da área de interesse apresenta maior cota topográfica comparativamente com o centro da mesma, variando de 488 até $639 \mathrm{~m}$ sobre o nível do mar (msnm). A figura 26 mostra a distribuição dos poços e a topografia da área de interesse no SAB. 


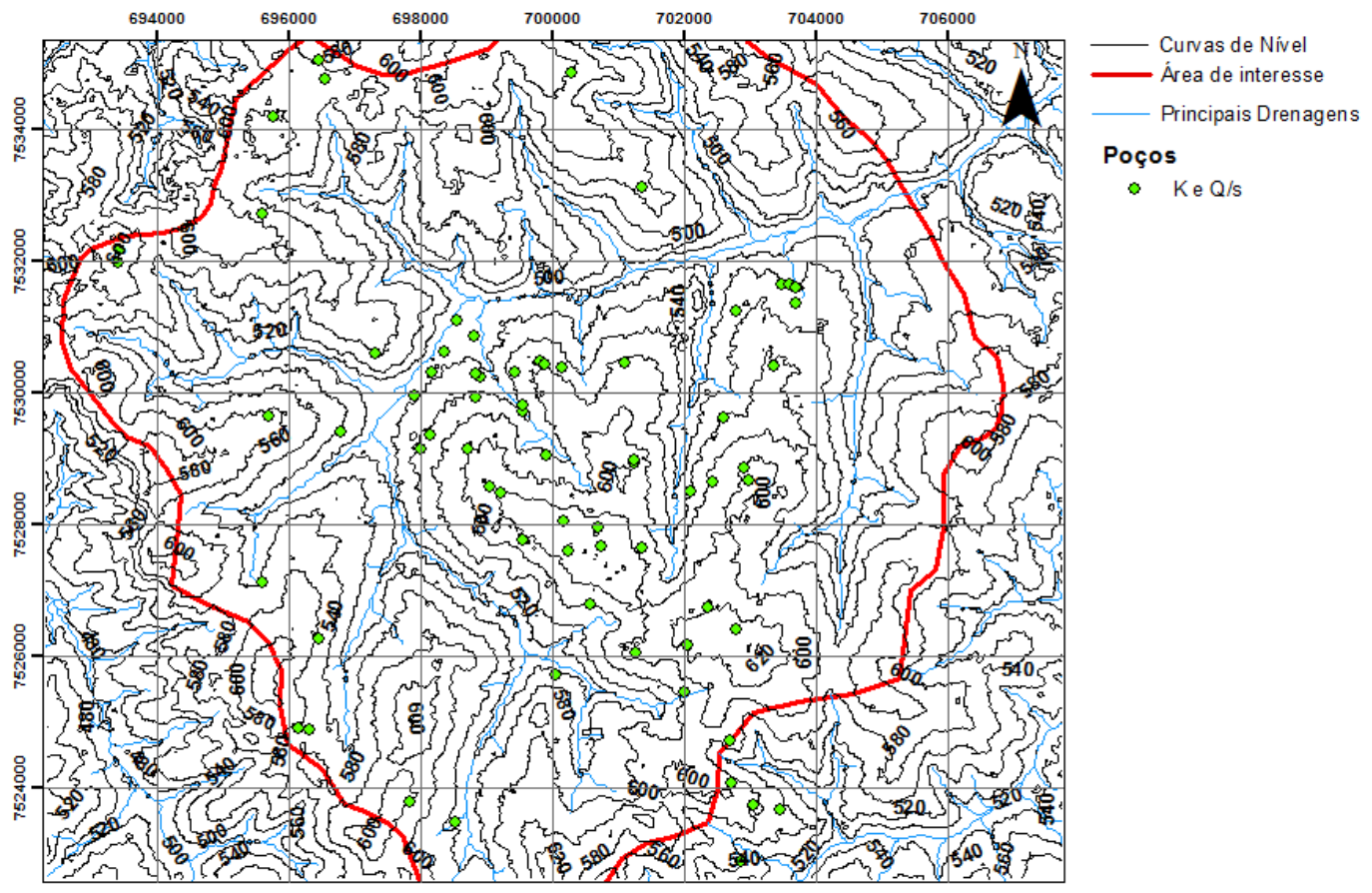

Figura 26: Topografia da área de estudo em Bauru.

A figura 27 mostra que a tendência local fluxo de água subterrânea na área do SAB em direção ao Rio Bauru, no centro da bacia. Regionalmente, o fluxo subterrâneo na direção SWNE para a sua foz no Rio Tietê. 


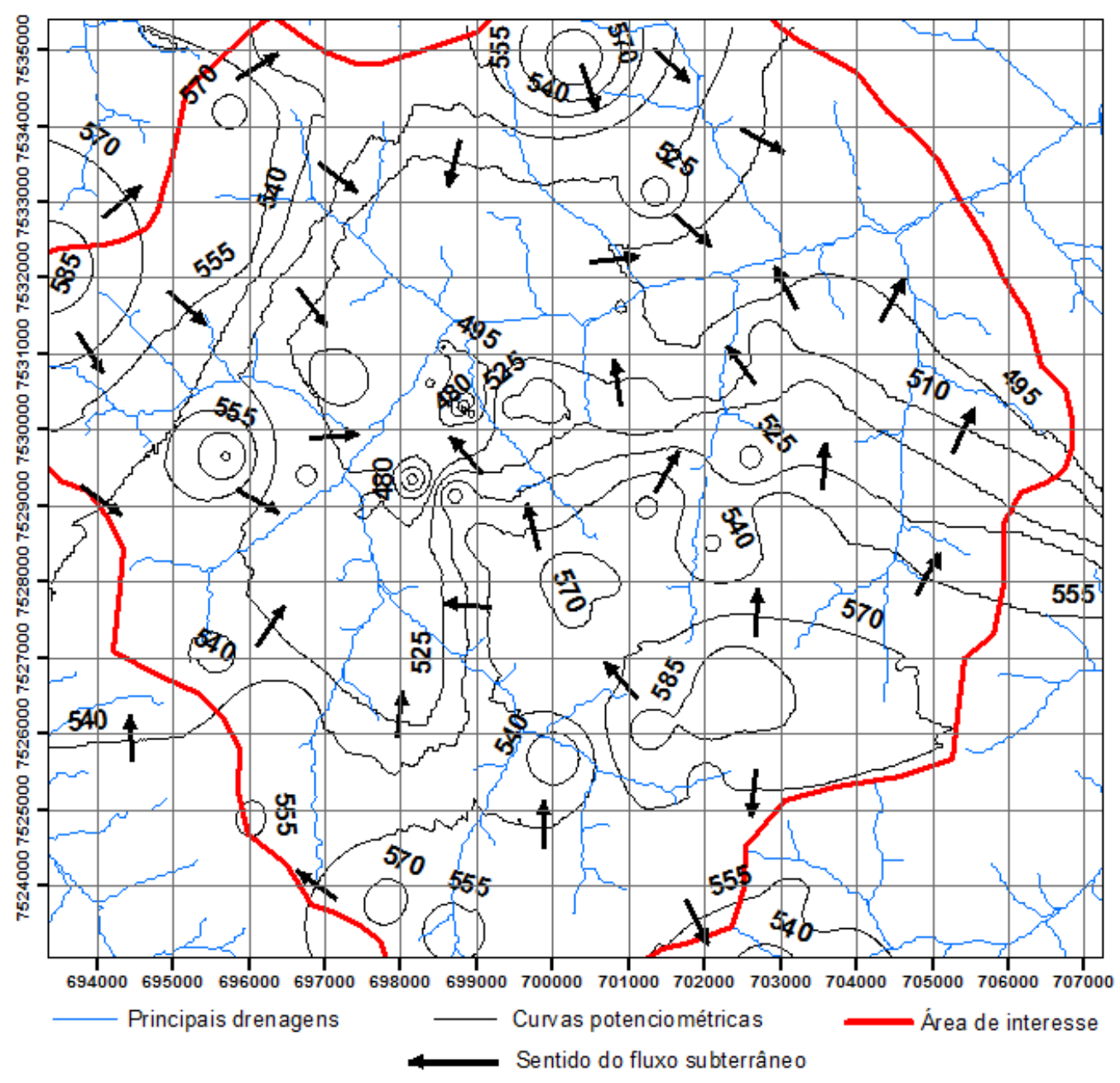

Figura 27: Mapa potenciométrico da área de estudo na cidade de Bauru

A figura 28 apresenta o mapa geológico da área segundo a CPRM (2006). Nesse mapa, a área de interesse na cidade de Bauru é representada, em superfície, quase que em sua totalidade pelos sedimentos da Formação Marília. Também presente, mas em menor fração, estão os sedimentos da Formação Vale do Rio do Peixe que, segundo Fernandes e Coimbra (2000), é o novo nome dado à Formação Adamantina. Segundo esses autores, os sedimentos da Formação Vale do Rio do Peixe são descritos como arenitos intercalados com siltitos e lamitos arenosos, sendo os arenitos muito finos a finos, marrom claro rosado alaranjado, com boa seleção e apresentando localmente cimentação de $\mathrm{CaCO}_{3}$. Assim como a Formação Adamantina, seus sedimentos recobrem os derrames da Formação Serra Geral. Essas características são atribuídas a Formação Adamantina na descrição das amostras dos poços. 


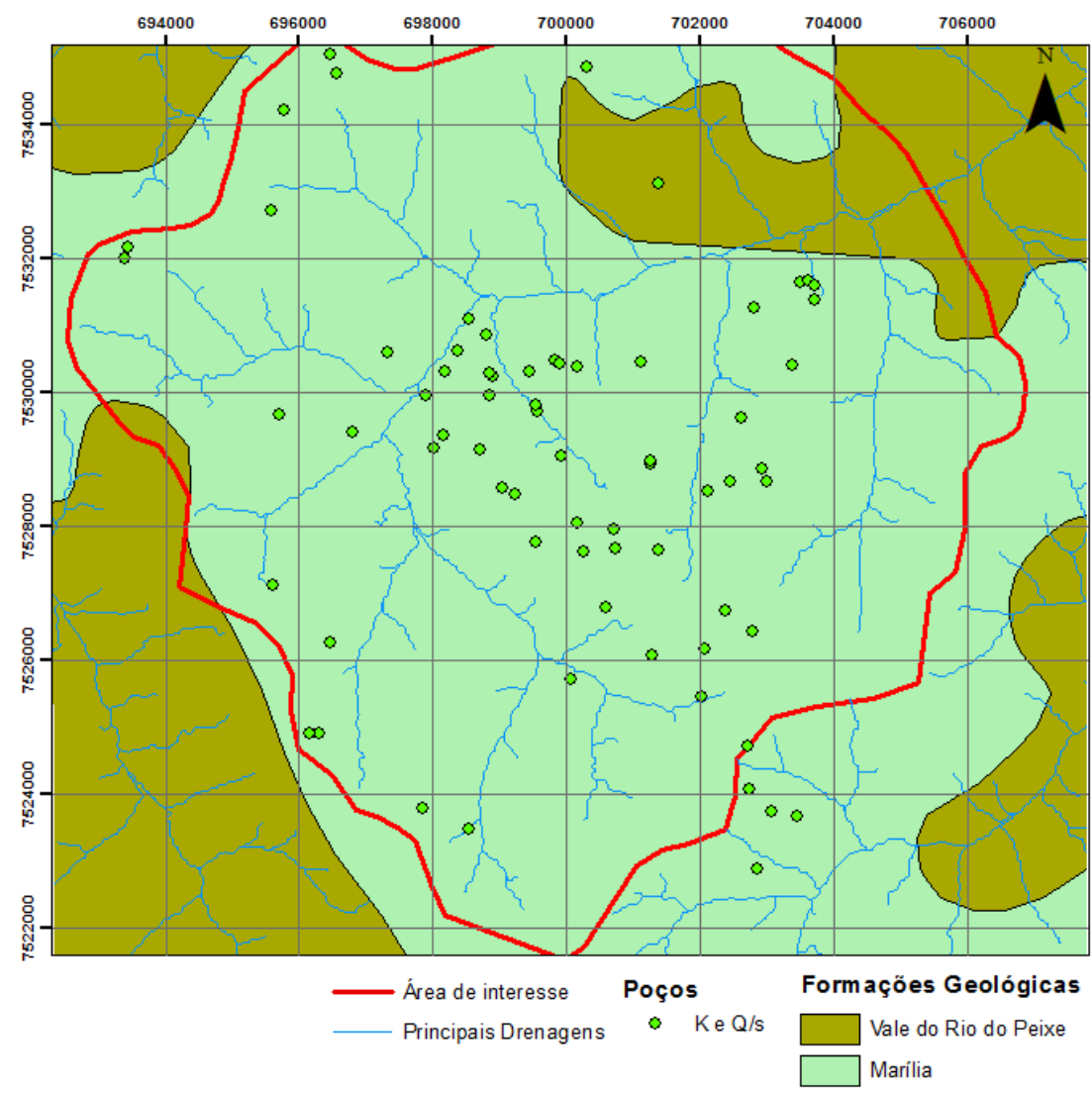

Figura 28: Mapa geológico da área de estudo na cidade de Bauru. Adaptado do mapa geológico do Estado de São Paulo, escala 1: 750.000, CPRM (2006).

As figuras 29, 30 e 31 mostram o modelo geológico baseado nas descrições das amostras dos poços instalados na área de interesse de Bauru. Na figura 29, observa-se o modelo geológico 3D em uma visão oblíqua, em que é aplicado o exagero vertical de 10 vezes para ressaltar o relevo. Ainda na figura 30, as linhas coloridas representam as curvas de nível do modelo. Nas figuras 30 e 31 são apresentados o mapa geológico desenvolvido e perfis geológicos referentes a esse mapa, respectivamente. Esses perfis são representados por quatro seções, sendo essas $\mathrm{N}$ S, W-E, NW-SE e SW-NE. Como nenhum dos poços usados nesse trabalho atravessa completamente a Formação Adamantina atingindo o topo do Grupo São Bento, como a literatura descreve, a sua base é inferida e indicada pela linha tracejada nos perfis apresentados na figura 31. 


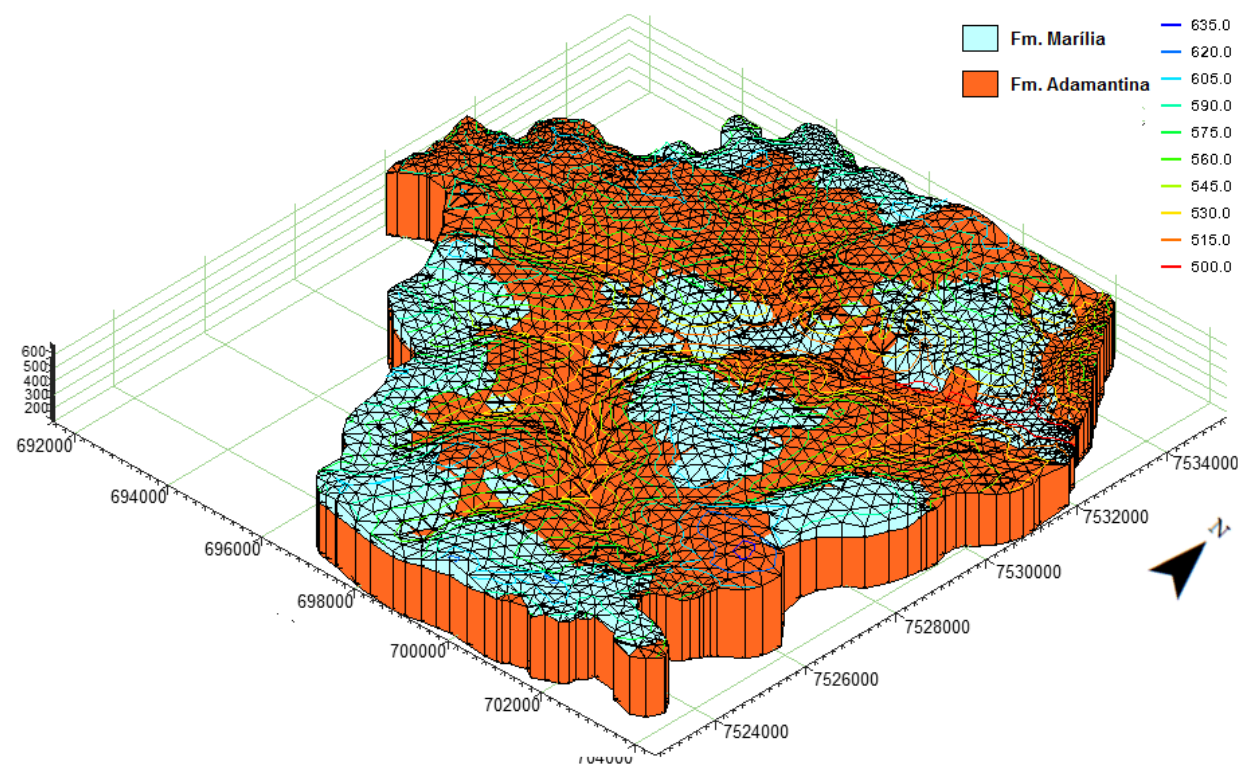

Figura 29: Modelo geológico em três dimensões da área de interesse na cidade de Bauru. Modelo desenvolvido com base nas informações das amostras descritas na construção dos poços.

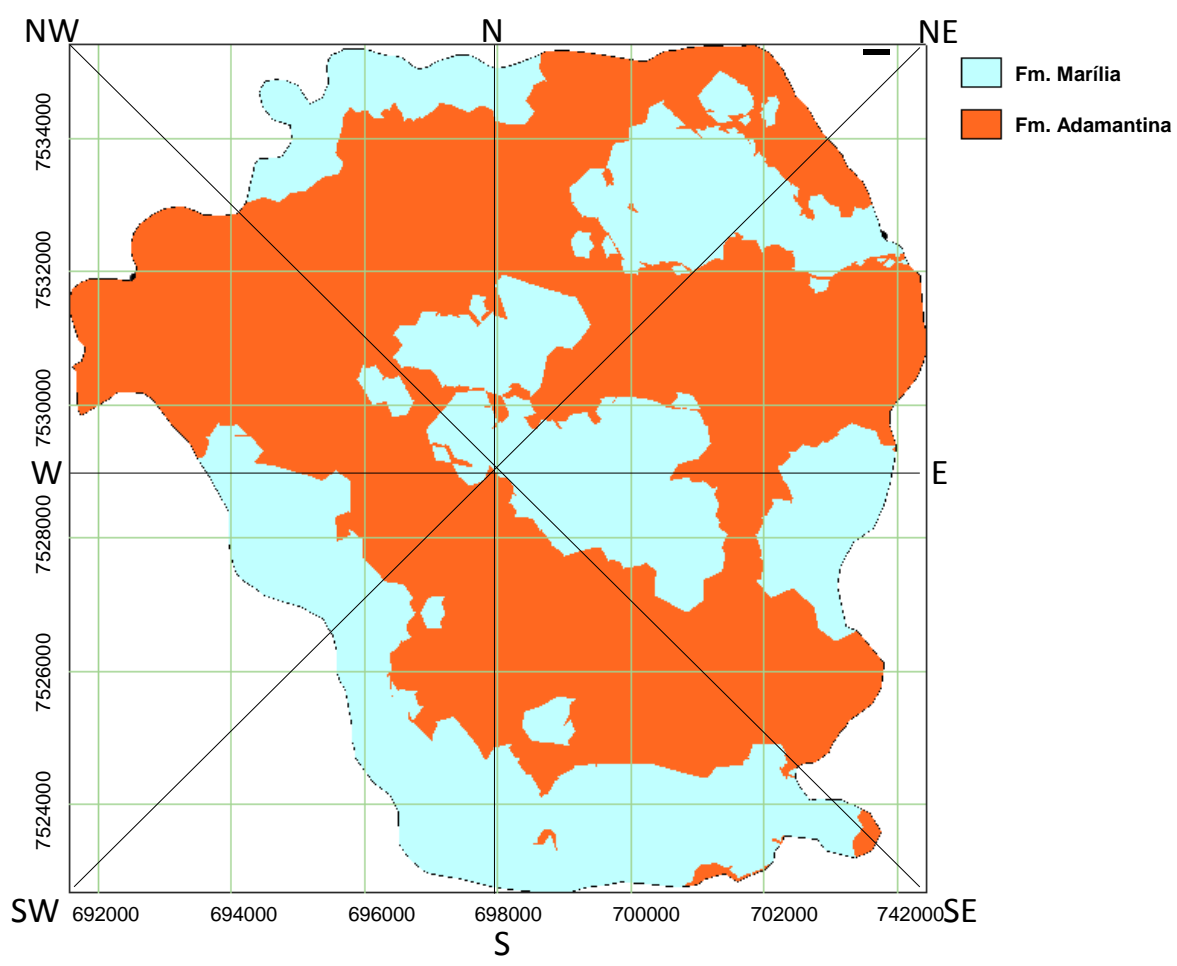

Figura 30: Mapa geológico da área de estudo na cidade de Bauru baseado nas descrições litológicas dos poços de bombeamento estudados. As linhas representam os locais escolhidos para a confecção das seções geológicas. 

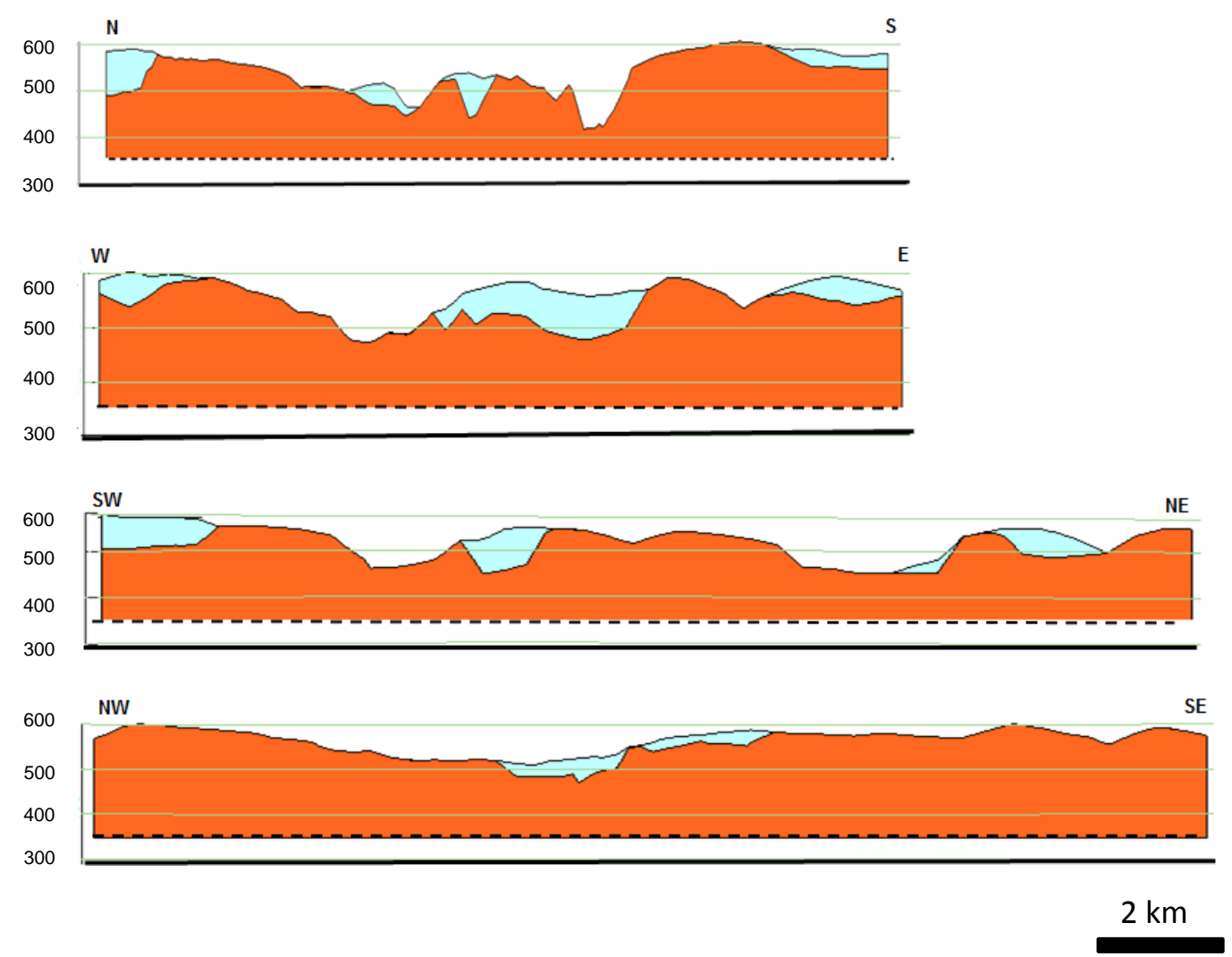

Figura 31: Seções geológicas baseadas nas descrições litológicas dos poços de bombeamento estudados na cidade de São Carlos. As linhas tracejadas representam os limites inferidos.

Assumindo que as Formações Adamantina e Vale do Rio do Peixe representam a mesma litologia, o modelo geológico proposto por essa dissertação e o mapa desenvolvido pela CPRM (2006) diferem na proporção em que as Formações Marília e Adamantina ocorrem na área de interesse do SAB.

O modelo geológico elaborado para essa dissertação mostra que a Formação Marília é frequentemente encontrada onde a topografia é mais elevada por apresentar abundante cimentação calcífera, o que a torna mais resistente à erosão, como sugerido por Paula e Silva (2003). Essa dissertação constatou que sua espessura varia de 10 a 100 m, mas frequentemente ocorre com espessura de até $20 \mathrm{~m}$ na área.

A Formação Adamantina, ou Vale do Rio do Peixe, é a unidade predominante na área, podendo ser observada tanto em relevos baixos quanto altos. A maioria dos poços exploram águas provenientes exclusivamente do seu aquífero homônimo.

Os resultados aqui discutidos confirmam as informações encontradas na literatura e sumariadas na revisão bibliográfica da área. Uma abordagem mais detalhada e localizada dada por esse trabalho é a provável causa da diferença encontrada entre o mapa geológico definido pela CPRM (2006) e o desenvolvido no presente trabalho. 


\subsection{Tratamento Estatístico}

A análise estatística parte do estudo da estatística descritiva dos parâmetros de interesse, sendo esses essencialmente os que são calculados nos métodos de interpretação dos testes de bombeamento. Esses parâmetros são: Transmissividade $(T)$, capacidade específica $(Q / s)$ e condutividade hidráulica (K). Na tabela 5, observa-se essa estatística descritiva dos poços estudados no Sistema Aquífero Guarani (SAG) em geral, isto é, todos os poços dos quais se tem informações e estão instalados nas cidades de São Carlos (38), Araraquara (26), Américo Brasiliense (2), Boa Esperança do Sul (3), Ibaté (3), Itapira (9), Luiz Antônio (1) e Ribeirão Bonito (3). Nessa mesma tabela estão a estatística descritiva dos 28 poços usados para a aplicação dos métodos geoestatísticos em São Carlos e a dos 68 poços na cidade de Bauru, que, por sua vez, representa o Sistema Aquífero Bauru (SAB) e subsidia a aplicação dos métodos geoestatísticos nessa cidade.

Tabela 4: Estatística descritiva das capacidades específicas $(Q / s)$ e condutividades hidráulicas (K) referentes aos poços estudados no SAG em geral, e mais especificamente São Carlos, e Bauru, que por sua vez representa o $S A B$.

\begin{tabular}{|l|c|c|c|c|c|c|}
\hline \multirow{2}{*}{$\begin{array}{c}\text { Parâmetro } \\
\text { s }\end{array}$} & \multicolumn{3}{|c|}{ Q/s (m²/dia) } & \multicolumn{3}{c|}{ K (m/dia) } \\
\cline { 2 - 7 } & $\begin{array}{c}\text { SAG } \\
\text { (Geral) }\end{array}$ & $\begin{array}{c}\text { SAG } \\
\text { (São Carlos) }\end{array}$ & $\begin{array}{c}\text { SAB } \\
\text { (Bauru } \\
\text { (Sa }\end{array}$ & $\begin{array}{c}\text { SAG } \\
\text { (Geral) }\end{array}$ & $\begin{array}{c}\text { SAG } \\
\text { (São Carlos) }\end{array}$ & $\begin{array}{c}\text { SAB } \\
\text { Bauru } \\
\text { ) }\end{array}$ \\
\hline Média & 85.13 & 84.4 & 6.73 & 0.8 & 0.67 & 0.06 \\
\hline Mediana & 79.79 & 61.64 & 2.69 & 0.61 & 0.46 & 0.01 \\
\hline Moda & 163.02 & 163.02 & 1.17 & - & - & - \\
\hline $\begin{array}{l}\text { Desvio } \\
\text { padrão }\end{array}$ & 69.85 & 85.41 & 10.88 & 0.74 & 0.77 & 0.15 \\
\hline Intervalo & 393.79 & 393.79 & 59.4 & 3 & 2.99 & 0.87 \\
\hline Mínimo & 2.21 & 2.21 & 0.48 & 0.01 & 0.01 & 0 \\
\hline Máximo & 396 & 396 & 59.88 & 3.01 & 3 & 0.87 \\
\hline Contagem & 85 & 28 & 68 & 85 & 28 & 68 \\
\hline
\end{tabular}

Com base nos resultados mostrados na tabela 5, observa-se que:

Quanto à capacidade específica:

Considerando que os poços com maior razão entre a vazão e o rebaixamento são mais produtivos, os poços inseridos no SAG apresentam larga vantagem comparando com os instalados no SAB;

O desvio-padrão desse parâmetro mostra novamente que o SAG tende a ser mais heterogêneo que o SAB;

Quanto à condutividade hidráulica: 
A condutividade hidráulica do SAB apresenta média e mediana, 0.06 e 0.01, respectivamente, menor que para o SAG, o que corrobora com o fato dos sedimentos das Formações Marília e Adamantina serem menos permeáveis que os das Formações Botucatu/ Pirambóia;

O desvio-padrão destaca que, apesar de menos permeável, o SAB em Bauru apresenta maior heterogeneidade.

Para o auxílio da interpretação estatística dos dados, esses podem ser apresentados na forma gráfica de histograma como na figura 32. Nessa figura, constata-se que as distribuições $\mathrm{Q} / \mathrm{s}$ e $\mathrm{K}$ apresentam uma distribuição de assimetria positiva, como previsto e discutido por Montenegro et al. (1999).

SAG
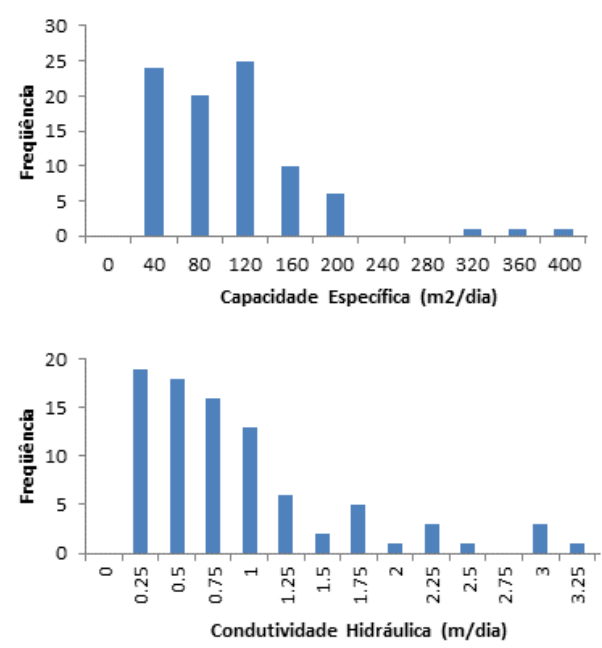

SAB
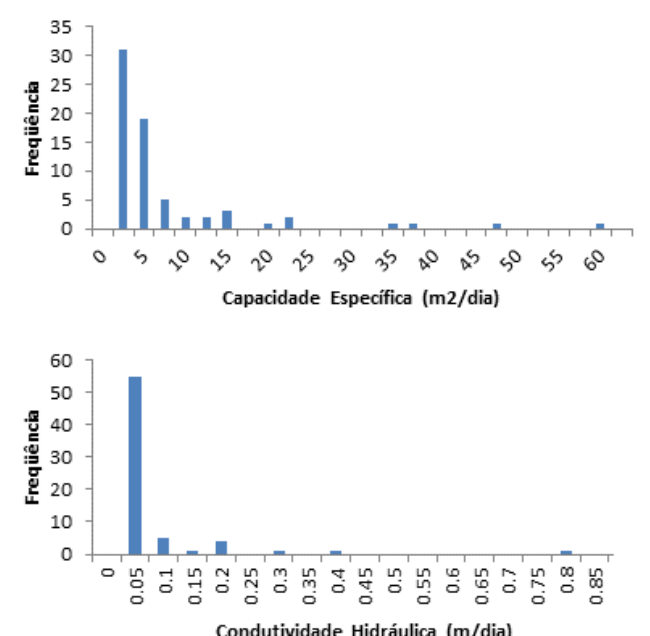

Figura 32: Histogramas dos valores de capacidade específica $(Q / s)$ e condutividade hidráulica dos poços instalados no Sistema Aquífero Guarani (SAG) e Sistema Aquífero Bauru (SAB).

Segundo Montenegro et al. (1999), devido a esse comportamento, é permitido que se use $y=\log (T)$ como variável, tratando o problema de sua variação por uma abordagem gaussiana. Essas mesmas observações são feitas para os valores de condutividade hidráulica (K) e capacidade específica $(\mathrm{Q} / \mathrm{s})$. Ou seja, adota-se $\log (K)$ e $\log (Q / s)$ como variáveis.

A partir daqui as análises estatísticas passam a ser tratados separadamente para o SAG e SAB. Inicialmente os testes de normalidade de Kolmogorov-Smirnov e Shapiro- Wilk são aplicados. Somente os parâmetros que satisfazem ambos os testes de normalidade são habilitados a passarem para a próxima etapa. No caso do SAG onde os poços estão instalados em três tipos diferentes de aquíferos, o teste $t$ de Student é conjuntamente aplicado para verificar se as distribuições apresentam a mesma origem populacional e, assim, aumentar o banco de dados para esse sistema aquífero. O SAB, por sua vez, não necessita desse teste pelo fato de todos os poços estudados nesse sistema aquífero apresentar uma única configuração, 
semiconfinado. Prosseguindo, para ambos sistemas aquíferos é feito a analise empírica da relação entre capacidade específica e condutividade hidráulica por meio de regressão linear de primeira ordem. Nessa etapa uma reta é ajustada e uma equação de primeiro grau é gerada para relacionar esses dois parâmetros. Essa equação é usada na parte geoestatística quando é aplicado o método de krigagem ordinária combinada com regressão linear.

Para os testes formais de normalidade, Kolmogorov-Smirnov e Shapiro-Wilk, assume-se como hipótese nula, $H_{0}$, a distribuição normal e a hipótese alternativa, $H_{a}$, a não distribuição normal. No caso do método Kolmogorov-Smirnov, a $H_{0}$ não é rejeitada quando o valor calculado é menor que o valor crítico baseado na tabela do método. Quanto ao método ShapiroWilk, a hipótese nula não é rejeitada caso seu valor calculado seja maior que o valor crítico baseado na tabela do método.

Embora na maioria dos artigos encontrados na literatura abordem a relação empírica entre $\mathrm{Q} / \mathrm{s}$ e T, usando os dados de capacidade específica, que é mais abundante, para inferir os valores de transmissividade. O objetivo principal para essa seção é relacionar os parâmetros $\mathrm{K}$ e $\mathrm{Q} / \mathrm{s}$. Isso se deve ao fato dos modelos hidrogeológicos trabalharem com os valores de condutividade hidráulica como dados de entrada, ao invés de transmissividade.

\subsubsection{SAG}

No tratamento estatístico, são usados todos os valores de condutividade hidráulica e capacidade específica dos 85 poços que dispõem de informações desses parâmetros no SAG. O produto final dessa etapa é o desenvolvimento de uma equação que permita estimar valores de $\mathrm{K}$ com base em valores de Q/s. Uma área na cidade de São Carlos é escolhida para se estimar esses valores e aumentar a base de dados para a aplicação de métodos geoestatísticos. A escolha dessa área tem como critério a quantidade de poços com informações de $\mathrm{K}$ e Q/s disponíveis e a distribuição espacial desses poços.

As tabelas 6, 7 e 9 mostram os resultados dos testes formais de normalidade pelos métodos de Kolmogorov-Smirnov e Shapiro-Wilk para os poços estudados instalados, respectivamente, em aquíferos livre, semiconfinado e confinado no SAG. Os valores em negrito são aqueles que atenderam as condições para que a hipótese nula não seja rejeitada. Para o método de Kolmogorov-Smirnov, assume-se o nível de significância como p=0.05. 
Tabela 5: Resultados dos testes de normalidade aferidos pelos métodos de Kolmogorov-Smirnove Shapiro-Wilk para os poços estudados instalados em aquíferos livres no SAG. Para o método de Kolmogorov-Smirnov, adota-se o nível de significância $p=0.05$.

\begin{tabular}{|l|c|c|c|c|c|}
\hline \multirow{2}{*}{ Grandeza } & \multirow{2}{*}{$\begin{array}{c}\text { Número } \\
\text { de dados }\end{array}$} & \multicolumn{2}{|c|}{ Kolmogorov-Smirnov* } & \multicolumn{2}{c|}{ Shapiro-Wilk } \\
\cline { 3 - 6 } & & Valor Calculado & Valor Crítico & Valor Calculado & Valor Crítico \\
\hline $\mathrm{T}\left(\mathrm{m}^{2} / \mathrm{d}\right)$ & 22 & $\mathbf{0 . 2 3 8 2 5}$ & 0.253 & 0.81232 & 0.91 \\
\hline $\log \mathrm{T}\left(\mathrm{m}^{2} / \mathrm{d}\right)$ & 22 & $\mathbf{0 . 0 9 6 1 7}$ & 0.253 & $\mathbf{0 . 9 7 5 6 1}$ & 0.91 \\
\hline $\mathrm{Q} / \mathrm{s}\left(\mathrm{m}^{2} / \mathrm{d}\right)$ & 22 & $\mathbf{0 . 2 2 3 2 4}$ & 0.253 & 0.90905 & 0.91 \\
\hline $\log \mathrm{Q} / \mathrm{s}\left(\mathrm{m}^{2} / \mathrm{d}\right)$ & 22 & $\mathbf{0 . 1 2 7 1 1}$ & 0.253 & $\mathbf{0 . 9 2 1 8 1}$ & 0.91 \\
\hline $\mathrm{K}(\mathrm{m} / \mathrm{d})$ & 22 & $\mathbf{0 . 2 3 7 1 1}$ & 0.253 & 0.86357 & 0.91 \\
\hline $\log \mathrm{K}(\mathrm{m} / \mathrm{d})$ & 22 & $\mathbf{0 . 1 4 5 0 1}$ & 0.253 & $\mathbf{0 . 9 3 3 1 4}$ & 0.91 \\
\hline
\end{tabular}

Tabela 6 Resultados dos testes de normalidade aferidos pelos métodos de Kolmogorov-Smirnov e Shapiro-Wilk para os poços estudados instalados em aquíferos semiconfinado no SAG. Para o método de Kolmogorov-Smirnov, adota-se o nível de significância $p=0.05$.

\begin{tabular}{|l|c|c|c|c|c|}
\hline \multicolumn{2}{|c}{ Grandeza } & \multirow{2}{*}{$\begin{array}{c}\text { Número } \\
\text { de dados }\end{array}$} & \multicolumn{2}{|c|}{ Kolmogorov-Smirnov* } & \multicolumn{2}{c|}{ Shapiro-Wilk } \\
\cline { 3 - 6 } & & Valor Calculado & Valor Crítico & Valor Calculado & Valor Crítico \\
\hline $\mathrm{T}\left(\mathrm{m}^{2} / \mathrm{d}\right)$ & 26 & 0.24437 & 0.233 & 0.78287 & 0.92 \\
\hline $\log \mathrm{T}\left(\mathrm{m}^{2} / \mathrm{d}\right)$ & 26 & $\mathbf{0 . 1 6 8 8 1}$ & 0.233 & $\mathbf{0 . 9 3 3 3 3}$ & 0.92 \\
\hline $\mathrm{Q} / \mathrm{s}\left(\mathrm{m}^{2} / \mathrm{d}\right)$ & 26 & $\mathbf{0 . 1 9 5 2 8}$ & 0.233 & 0.85494 & 0.92 \\
\hline $\log \mathrm{Q} / \mathrm{s}\left(\mathrm{m}^{2} / \mathrm{d}\right)$ & 26 & $\mathbf{0 . 1 3 5 8 6}$ & 0.233 & $\mathbf{0 . 9 6 5 3 1}$ & 0.92 \\
\hline $\mathrm{K}(\mathrm{m} / \mathrm{d})$ & 26 & $\mathbf{0 . 2 2 0 5 3}$ & 0.233 & 0.68351 & 0.92 \\
\hline $\log \mathrm{K}(\mathrm{m} / \mathrm{d})$ & 26 & $\mathbf{0 . 1 1 7 1}$ & 0.233 & $\mathbf{0 . 9 5 4 3 5}$ & 0.92 \\
\hline
\end{tabular}

$\mathrm{p}=0.05^{*}$

Tabela 7: Resultados dos testes de normalidade aferidos pelos métodos de Kolmogorov-Smirnov e Shapiro-Wilk para os poços estudados instalados em aquíferos confinado no SAG. Para o método de Kolmogorov-Smirnov, adota-se o nível de significância $p=0.05$.

\begin{tabular}{|l|c|c|c|c|c|}
\hline \multicolumn{2}{|c|}{ Grandeza } & \multirow{2}{*}{$\begin{array}{c}\text { Número } \\
\text { de dados }\end{array}$} & \multicolumn{2}{|c|}{ Kolmogorov-Smirnov* } & \multicolumn{2}{c|}{ Shapiro-Wilk } \\
\cline { 3 - 6 } & & Valor Calculado & Valor Crítico & Valor Calculado & Valor Crítico \\
\hline $\mathrm{T}\left(\mathrm{m}^{2} / \mathrm{d}\right)$ & 37 & $\mathbf{0 . 1 4 4 9 8}$ & 0.196 & 0.85709 & 0.936 \\
\hline $\log \mathrm{T}\left(\mathrm{m}^{2} / \mathrm{d}\right)$ & 37 & $\mathbf{0 . 1 5 3 9}$ & 0.196 & 0.8733 & 0.936 \\
\hline $\mathrm{Q} / \mathrm{s}\left(\mathrm{m}^{2} / \mathrm{d}\right)$ & 37 & 0.20071 & 0.196 & 0.8444 & 0.936 \\
\hline $\log \mathrm{Q} / \mathrm{s}\left(\mathrm{m}^{2} / \mathrm{d}\right)$ & 37 & 0.25561 & 0.196 & 0.76 & 0.936 \\
\hline $\mathrm{K}(\mathrm{m} / \mathrm{d})$ & 37 & 0.21791 & 0.196 & 0.89913 & 0.936 \\
\hline $\log \mathrm{K}(\mathrm{m} / \mathrm{d})$ & 37 & $\mathbf{0 . 1 0 5 8 9}$ & 0.196 & $\mathbf{0 . 9 6 9 7 5}$ & 0.936 \\
\hline
\end{tabular}


Observa-se que o método de Kolmogorov-Smirnov é menos seletivo e a hipótese nula não é rejeitada na maioria dos casos. Pelo método de Shapiro-Wilk essa aprovação diminui drasticamente. O maior índice de rejeição da $H_{0}$ é observado na tabela 8 que trata dos poços estudados instalados no SAG em uma configuração de aquífero confinado. Nesse caso, à exceção da grandeza $\log \mathrm{K}$, as grandezas não atingiram condições satisfatórias para ambos métodos e a hipótese nula foi rejeitada para os poços nesse tipo de aquífero.

Seguindo a orientação dada por Srivastav et al. (2007), empregam-se os parâmetros na forma de logaritmo por essa abordagem apresentar melhor coeficiente de correlação e distribuições lognormais. Como os resultados dos testes de normalidade foram satisfatórios tanto para os poços em aquífero livre quanto nos semiconfinados, aplica-se um teste de independência $t$ de Student para verificar se ambas as distribuições são oriundas de uma mesma população, que é a hipótese nula. A tabela 9 mostra os resultados desse teste de independência. Quando o $t$-valor é menor que o valor crítico, a $H_{0}$ não é rejeitada. $\mathrm{O}$ nível de significância assumido para esse teste é $\mathrm{p}=005$.

Tabela 8: Resultados do teste de independência para os poços estudados instalados em aquíferos livre e semiconfinado no $S A G$.

\begin{tabular}{|c|c|c|c|c|c|}
\hline \multicolumn{6}{|c|}{ Teste de independência $t$ Student: SAG - Livre e Semiconfinado } \\
\hline \multirow[b]{2}{*}{ Grandeza } & \multicolumn{2}{|c|}{ Número de dados } & \multirow[b]{2}{*}{$\begin{array}{l}\text { Graus de } \\
\text { liberdade }\end{array}$} & \multicolumn{2}{|c|}{$t$-student } \\
\hline & $\begin{array}{c}\text { Livre } \\
\text { (Grupo 1) } \\
\end{array}$ & $\begin{array}{c}\text { Semiconfinado } \\
\text { (Grupo 2) } \\
\end{array}$ & & $t$-value & $\begin{array}{l}\text { Valor } \\
\text { Crítico }\end{array}$ \\
\hline $\log \mathrm{T}\left(\mathrm{m}^{2} / \mathrm{d}\right)$ & 22 & 26 & 46 & 3.24 & 1.68 \\
\hline $\log \mathrm{Q} / \mathrm{s}\left(\mathrm{m}^{2} / \mathrm{d}\right)$ & 22 & 26 & 46 & 0.427 & 1.68 \\
\hline $\log K(\mathrm{~m} / \mathrm{d})$ & 22 & 26 & 46 & 0.253 & 1.68 \\
\hline
\end{tabular}

Os testes de $\log \mathrm{Q} / \mathrm{s}$ e $\log \mathrm{K}$ mostram-se satisfatórios e isso os habilita para a etapa final do tratamento estatístico, o desenvolvimento da relação empírica entre $\log (\mathrm{Q} / \mathrm{s})$ e $\log (\mathrm{K})$ usando regressão linear de primeira ordem e a geração de uma equação que relaciona esses dois parâmetros hidráulicos. A figura 33 e a tabela 10 mostram os resultados dessa etapa. Na figura, a reta aparece ajustada e os elementos da equação que a definem estão na tabela 10 com os respectivos desvios-padrões e o root mean square error (RMSe), equação (29). 


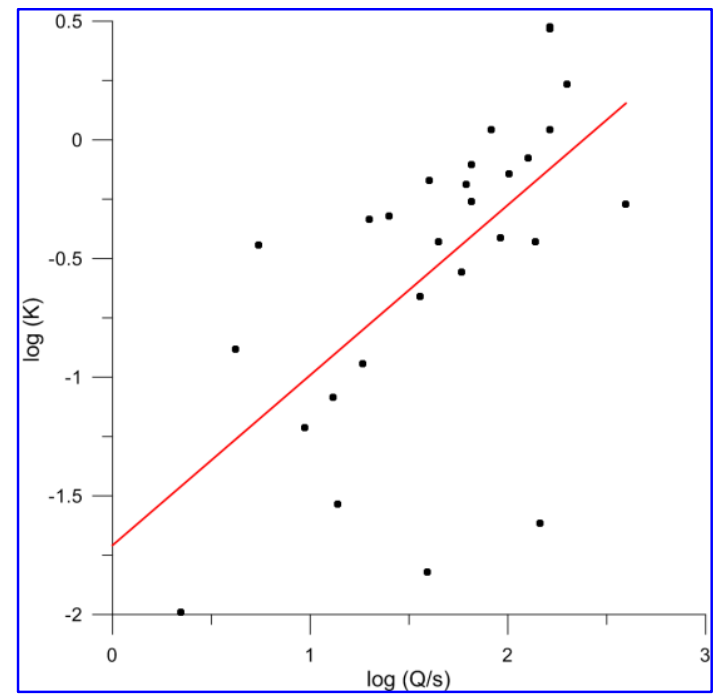

Figura 33: Representação gráfica da relação empírica ente $\log (Q / s)$ e log $(K)$ com a reta ajustada por regressão linear de primeira ordem no SAG.

Tabela 9: Valores dos elementos da equação da reta da regressão linear de primeira ordem para o SAG.

\begin{tabular}{|c|c|c|c|c|c|c|c|}
\hline \multirow{2}{*}{ Aquífero } & \multicolumn{7}{|c|}{ Ajuste da reta $\mathrm{Y}=\mathrm{a}^{*} \mathrm{X}+\mathrm{b}$} \\
\cline { 2 - 8 } & $\mathrm{Y}$ & $\mathrm{X}$ & $\mathrm{a}$ & $\sigma_{a}$ & $\mathrm{~b}$ & $\sigma_{b}$ & RMSe \\
\hline $\begin{array}{c}\text { Livre e } \\
\text { Semiconfinado }\end{array}$ & $\log \mathrm{K}$ & $\log (\mathrm{Q} / \mathrm{s})$ & 0.7172 & 0.1816 & -1.7088 & 0.3162 & 0.523 \\
\hline
\end{tabular}

O coeficiente de correlação entre $\log \mathrm{K}$ e $\log \mathrm{Q} / \mathrm{s}$ é de 0.612 . Os elementos na tabela 10 são apresentados na forma das equações como, eq. 81 e 82, sendo a relação dos parâmetros objetivados mensurada. O valor de condutividade hidráulica é dado em $\mathrm{m} /$ dia e o de capacidade específica $\mathrm{em}^{2} / \mathrm{dia}$.

$$
\log K=0.7172 \log (Q / s)-1.7088
$$

$\mathrm{Ou}$

$$
K=0.0196(Q / s)^{0.7172}
$$

\subsubsection{SAB}

A tabela 10 mostra os resultados dos testes formais de normalidade pelos métodos de Kolmogorov-Smirnov e Shapiro-Wilk para os poços estudados instalados no SAB, cidade de Bauru. Os valores em negrito são aqueles que atenderam às condições para que a hipótese nula não seja rejeitada. O nível de significância adotado é $\mathrm{p}=0.05$. 
Tabela 10: Resultados dos testes de normalidade aferidos pelos métodos de Kolmogorov-Smirnov e Shapiro-Wilk para os poços estudados instalados em aquíferos semiconfinado no SAB. Para o método de Kolmogorov-Smirnov, adota-se o nível de significância p=0.05.

\begin{tabular}{|l|c|c|c|c|c|}
\hline \multirow{2}{*}{ Grandeza } & \multirow{2}{*}{$\begin{array}{c}\text { Número } \\
\text { de dados }\end{array}$} & \multicolumn{2}{|c|}{ Kolmogorov-Smirnov* } & \multicolumn{2}{c|}{ Shapiro-Wilk } \\
\cline { 3 - 6 } & & Valor Calculado & Valor Crítico & Valor Calculado & Valor Crítico \\
\hline $\mathrm{T}\left(\mathrm{m}^{2} / \mathrm{d}\right)$ & 71 & 0.3482 & 0.1448 & 0.471 & 0.947 \\
\hline $\log \mathrm{T}\left(\mathrm{m}^{2} / \mathrm{d}\right)$ & 71 & 0.7853 & 0.1448 & $\mathbf{0 . 9 8 6}$ & 0.947 \\
\hline $\mathrm{Q} / \mathrm{s}\left(\mathrm{m}^{2} / \mathrm{d}\right)$ & 71 & 0.3015 & 0.1448 & 0.562 & 0.947 \\
\hline $\log \mathrm{Q} / \mathrm{s}\left(\mathrm{m}^{2} / \mathrm{d}\right)$ & 71 & $\mathbf{0 . 1 1 2 9}$ & 0.1448 & $\mathbf{0 . 9 6 2}$ & 0.947 \\
\hline $\mathrm{K}(\mathrm{m} / \mathrm{d})$ & 71 & 0.3316 & 0.1448 & 0.446 & 0.947 \\
\hline $\log \mathrm{K}(\mathrm{m} / \mathrm{d})$ & 71 & $\mathbf{0 . 0 8 2 2}$ & 0.1448 & $\mathbf{0 . 9 8 2}$ & 0.947 \\
\hline
\end{tabular}

Os resultados dos testes formais de normalidade demonstram que para os $\log (\mathrm{Q} / \mathrm{s})$ e os $\log (\mathrm{K})$ a hipótese nula não é rejeitada. Constatada a distribuição normal para essas variáveis, passa-se para a etapa final do tratamento estatístico: o desenvolvimento da relação empírica entre $\log (\mathrm{Q} / \mathrm{s})$ e $\log (\mathrm{K})$ usando regressão linear de primeira ordem e a geração da equação que relaciona esses dois parâmetros hidráulicos. A figura 34 é a representação gráfica da relação linear entre esses dois parâmetros e a tabela 11 mostra os elementos da equação da reta dessa relação com os respectivos desvios padrões e o root mean square error (RMSe) definido pela equação (29).

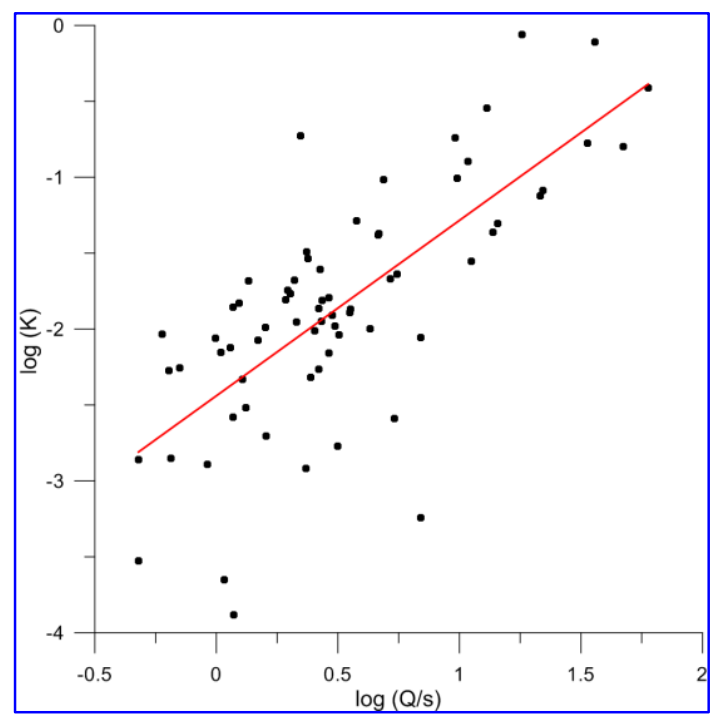

Figura 34: Representação gráfica da relação empírica ente log $(Q / s)$ e log $(K)$ com a reta ajustada por regressão linear de primeira ordem no $S A B$. 
Tabela 11: Valores dos elementos da equação da reta da regressão linear de primeira ordem para $o S A B$.

\begin{tabular}{|c|c|c|c|c|c|c|c|}
\hline \multirow{2}{*}{ Aquífero } & \multicolumn{7}{|c|}{ Ajuste da reta $\mathrm{Y}=\mathrm{a}^{*} \mathrm{x}+\mathrm{b}$} \\
\cline { 2 - 8 } & $\mathrm{Y}$ & $\mathrm{X}$ & $\mathrm{a}$ & $\sigma_{a}$ & $\mathrm{~b}$ & $\sigma_{b}$ & RMSe \\
\hline $\begin{array}{c}\text { Livre e } \\
\text { Semiconfinado }\end{array}$ & $\log \mathrm{K}$ & $\log (\mathrm{Q} / \mathrm{s})$ & 1.1553 & 0.1344 & -2.4393 & 0.094 & 0.5397 \\
\hline
\end{tabular}

O coeficiente de correlação entre as duas variáveis é de 0.763 . Os elementos na tabela 12 são simplificados na forma de equações como, eq. 83 e 84, sendo a relação dos parâmetros objetivados mensurada. $\mathrm{O}$ valor de condutividade hidráulica é dado em $\mathrm{m} / \mathrm{d}$ e o de capacidade específica $\mathrm{em} \mathrm{m}^{2} / \mathrm{d}$.

$\log K=1.1553 \log (Q / s)-2.4393$

ou

$$
K=0.0036(Q / s)^{1.1553}
$$

Embora seja desejável que o valor de RMSe seja igual à zero, não foi encontrado na literatura um valor que máximo para esse erro. Essa observação é válida tanto para o valor de erro na tabela 10 e 12 .

\subsection{Geoestatística}

Os resultados e as discussões dos métodos geoestatísticos aplicados nessa dissertação são apresentados nessa seção, quais sejam: krigagem ordinária, krigagem ordinária combinada com regressão linear, cokrigagem e bandas rotativas.

O conhecimento geológico da área é essencial para fundamentar os resultados. Os modelos geológicos de ambas as áreas estão apresentados e discutidos na seção 6.1.

Os métodos geoestatísticos são discutidos individualmente para São Carlos e Bauru. Ainda, para cada método utilizado, foi aplicada a técnica de desagrupamento ou decluster por célula para efeito de comparação. Para o SAG, a área foi discretizada em células de $2000 \mathrm{x}$ 2000 m, enquanto para o SAB, em 1000 x 1000 m. Essa técnica atribui pesos para as células, que são inversamente proporcionais ao número de poços dentro da célula. O objetivo da aplicação do desagrupamento é avaliar se técnica é capaz de melhorar a performance do método geoestatístico, usando a validação cruzada como parâmetro.

O uso dessa técnica implica em uma nova estatística nos dados estudados. Na análise exploratória ou estrutural, as estatísticas descritivas dos dados com e sem desagrupamento são apresentadas para cada método geoestatístico. Contata-se por meio de variogramas 
experimentais a não existência de uma direção de anisotropia evidente. Sendo assim, tanto em São Carlos quanto em Bauru, são ajustados variogramas omnidirecionais em todos os métodos aplicados no presente trabalho.

Outra característica vista em todos os métodos geoestatísticos aplicados nesse trabalho é a vizinhança de busca. Conforme mencionado no item 4.5.2., não há uma direção de anisotropia evidente e devido a esse fato a busca na vizinhança deixa de ser tratada como uma elipse e passa a assumir a forma de um círculo centrado no ponto que se pretende estimar. $\mathrm{O}$ seu raio pode variar de método para método e com a aplicação do método de desagrupamento nos conjuntos de dados. Para quase todos os métodos, são usados os valores da amplitude como raio de busca na vizinhança. Segundo Isaaks e Srivastava (1989), essa é a distância máxima para seu raio. Essa configuração muda em alguns casos nesse trabalho e é sempre mencionada na discussão dos métodos em que ocorre.

Para cada validação cruzada aferida a seguir, são testados diferentes valores para os parâmetros dos modelos variogramas e, por vezes, a vizinhança de busca. $\mathrm{O}$ valor alcançado representa o resultado da melhor configuração desses parâmetros e vizinhança.

As bases de dados usadas nos métodos geoestatísticos nas cidades de São Carlos e Bauru estão nos anexos I e II, respectivamente.

\subsubsection{SAG: São Carlos}

Primeiramente, são apresentados os resultados e as discussões dos métodos de interpolação estatística, tais como a krigagem ordinária, krigagem ordinária combinada com regressão linear e cokrigagem, e, na sequência, o método estocástico bandas rotativas. Posteriormente, ainda nessa seção, há uma análise comparativa dos principais resultados de cada método e a decisão de qual melhor preenche a área em São Carlos com valores de condutividade hidráulica $(\mathrm{K})$.

\subsubsection{Krigagem ordinária}

Para a aplicação do método de krigagem ordinária são usados dados de $\mathrm{K}$ provenientes de 28 poços distribuídos por uma área de aproximadamente 15 x 20 km (Figura 35). A distância média entre os poços e que melhor se adequa ao variograma experimental é de $2.500 \mathrm{~m}$. 


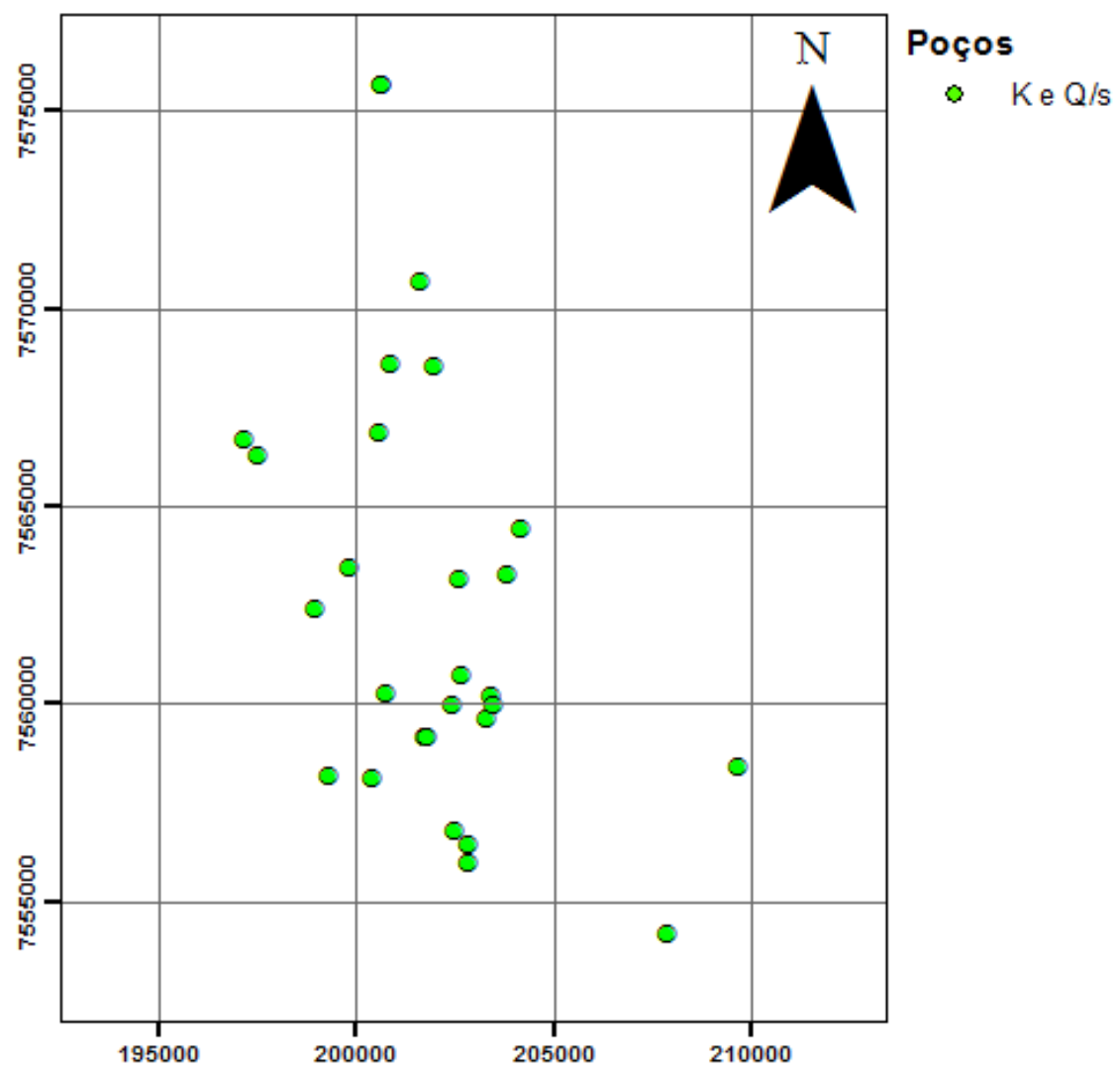

Figura 35: Representação gráfica da relação empírica ente log $(Q / s)$ e log $(K)$ com a reta ajustada por regressão linear de primeira ordem no $S A B$.

Na tabela 12 são apresentadas as estatísticas descritivas dos dados sem e com aplicação da técnica de desagrupamento. Embora os parâmetros estatísticos apresentem comportamento semelhante, a variância é reduzida com a aplicação da técnica, o que se reflete diretamente no variograma. Ainda, o valor da mediana aproxima-se mais da média.

Tabela 12: Krigagem ordinária: estatística descritiva dos valores de log $\mathrm{K}$ sem e com decluster dos poços estudados na cidade de São Carlos (SAG).

\begin{tabular}{|l|c|c|}
\hline \multirow{2}{*}{ Parâmetros } & \multicolumn{2}{|c|}{$\log \mathrm{K}(\mathrm{m} / \mathrm{d})$} \\
\cline { 2 - 3 } & Sem Decluster & Com Decluster \\
\hline Média & -0.52 & -0.52 \\
\hline Mediana & -0.37 & -0.42 \\
\hline $\begin{array}{l}\text { Desvio } \\
\text { padrão }\end{array}$ & 0.65 & 0.17 \\
\hline Variância & 0.42 & 0.39 \\
\hline Intervalo & 2.47 & 2.47 \\
\hline Mínimo & -1.99 & -1.99 \\
\hline Máximo & 0.48 & 0.48 \\
\hline Contagem & 28 & 28 \\
\hline
\end{tabular}


Pelo variograma experimental, define-se que o valor do passo ou lag é de $2.500 \mathrm{~m}$, como mencionado anteriormente, sendo usados 10 passos para o variograma sem decluster e sete para o com decluster.

Na figura 36 são apresentados os variogramas modelados para os dados sem e com decluster. Os elementos desses modelos ajustados são detalhados na tabela 13. Nos dois variogramas, o modelo se ajusta melhor com o patamar próximo à linha da variância amostral e ambos apresentam comportamento linear próximo da origem, característica inerente ao modelo esférico. No entanto, o variograma dos dados com decluster é mais estruturado e com maior amplitude, ou seja, a distância a partir da qual as amostras passam a não possuir correlação entre sim é maior e apresenta maior continuidade, e com efeito pepita mais alto e patamar mais baixo para no modelo dos dados com decluster, apresentando uma variância espacial menor.

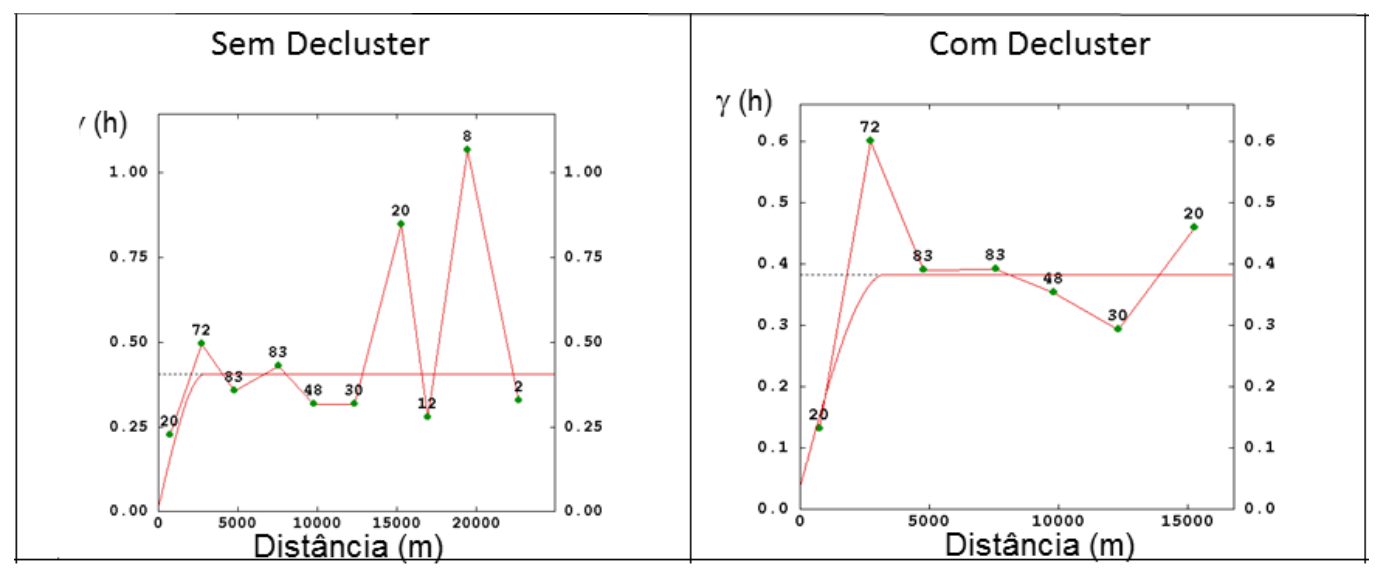

Figura 36: Krigagem ordinária: variogramas modelados sem e com aplicação da técnica de desagrupamento por célula da área de estudo de São Carlos (SAG). A linha tracejada representa a variância amostral.

Tabela 13: Elementos do modelo do variograma para os dados sem e com o uso da técnica de desagrupamento.

\begin{tabular}{|l|c|c|}
\hline $\begin{array}{c}\text { Elementos } \\
\text { do } \\
\text { variograma }\end{array}$ & $\begin{array}{c}\text { Sem } \\
\text { decluster }\end{array}$ & $\begin{array}{c}\text { Com } \\
\text { decluster }\end{array}$ \\
\hline Modelo & Esférico & Esférico \\
\hline Efeito pepita & 0.01064 & 0.03831 \\
\hline Amplitude & 2950 & 3300 \\
\hline Patamar & 0.3958 & 0.3448 \\
\hline
\end{tabular}

A figura 37 apresenta a validação cruzada e o histograma de erros padronizados para os dados sem e com a aplicação da técnica de decluster. Nela, observa-se que o modelo que melhor se adequa para a estimativa é a com a aplicação da técnica de desagrupamento, por apresentar 
o valor de 0.51. Com base no variograma de erros padronizados, verifica-se que a vizinhança está ajustada de forma que todos os pontos foram re-estimados na validação cruzada. No entanto, deve-se ressaltar a presença de outliers nos valores com decluster. Isso é evidenciado pela presença de valores fora do intervalo $[-2.5 ; 2.5]$.

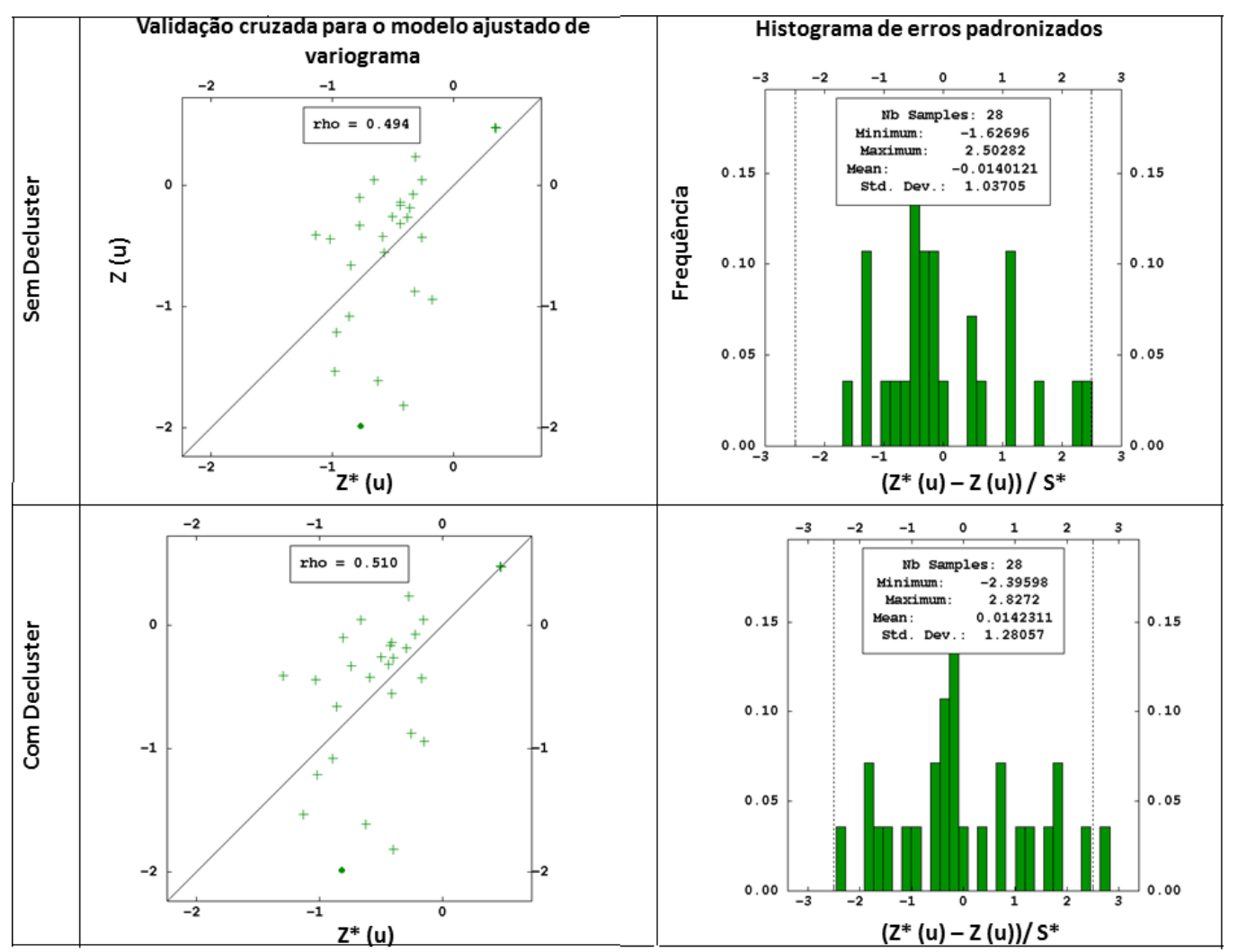

Figura 37: Krigagem ordinária: validação cruzada e histogramas de erros padronizados sem e com aplicação da técnica de desagrupamento por célula da área de estudo de São Carlos (SAG).

Com os modelos variogramas definidos, o método da krigagem ordinária é aplicado para estimar os pontos não amostrados. Os mapas das estimativas e das incertezas ou variância de krigagem são mostrados na figura 38. Na forma de histograma, a distribuição desses resultados é apresentada na figura 39. Essas figuras, sem e com decluster, não mostram significativa diferença nos resultados da krigagem. Como esperado, os valores estimados nas bordas apresentam maior incerteza, enquanto pontos mais próximos são capazes de estimar valores com menores variâncias de krigagem. Para ambos os casos, os valores estimados estão entre 0,5 e 0 , com média de 0,49 . Uma feição positiva, mas, novamente não significativa, é a diminuição da suavização da krigagem ao sul da área, onde há dois poços distantes mais de 5 $\mathrm{km}$ um do outro quando aplicado o decluster. No cômputo geral, não parece que o decluster é grande coisa. Embora rho seja ligeiramente maior, surgem outliers e a incerteza aumenta. 


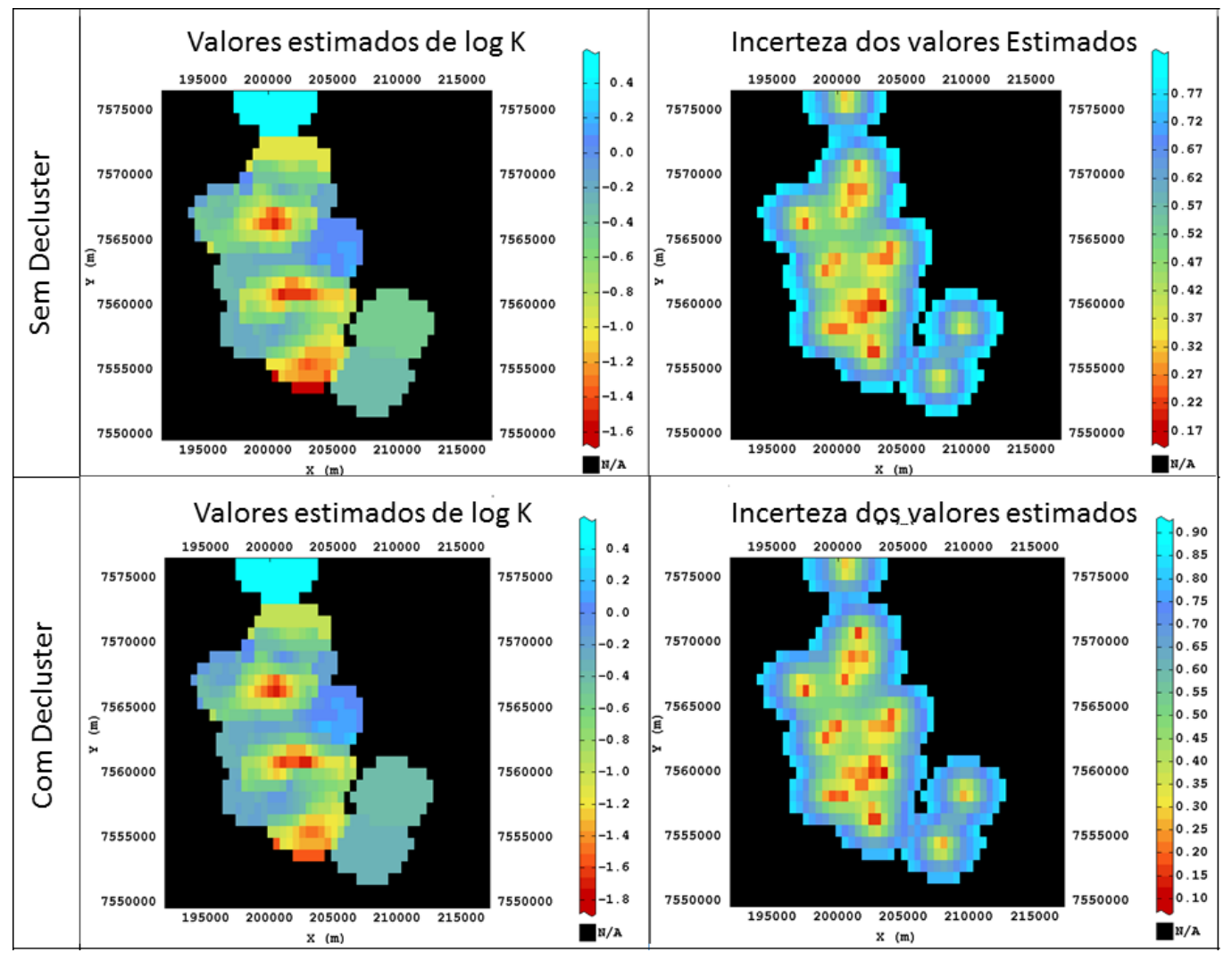

Figura 38: Krigagem ordinária: mapas das estimativas e da incerteza das estimativas de log $K$ associados ao método sem e com aplicação da técnica de desagrupamento por célula da área de estudo de São Carlos (SAG).

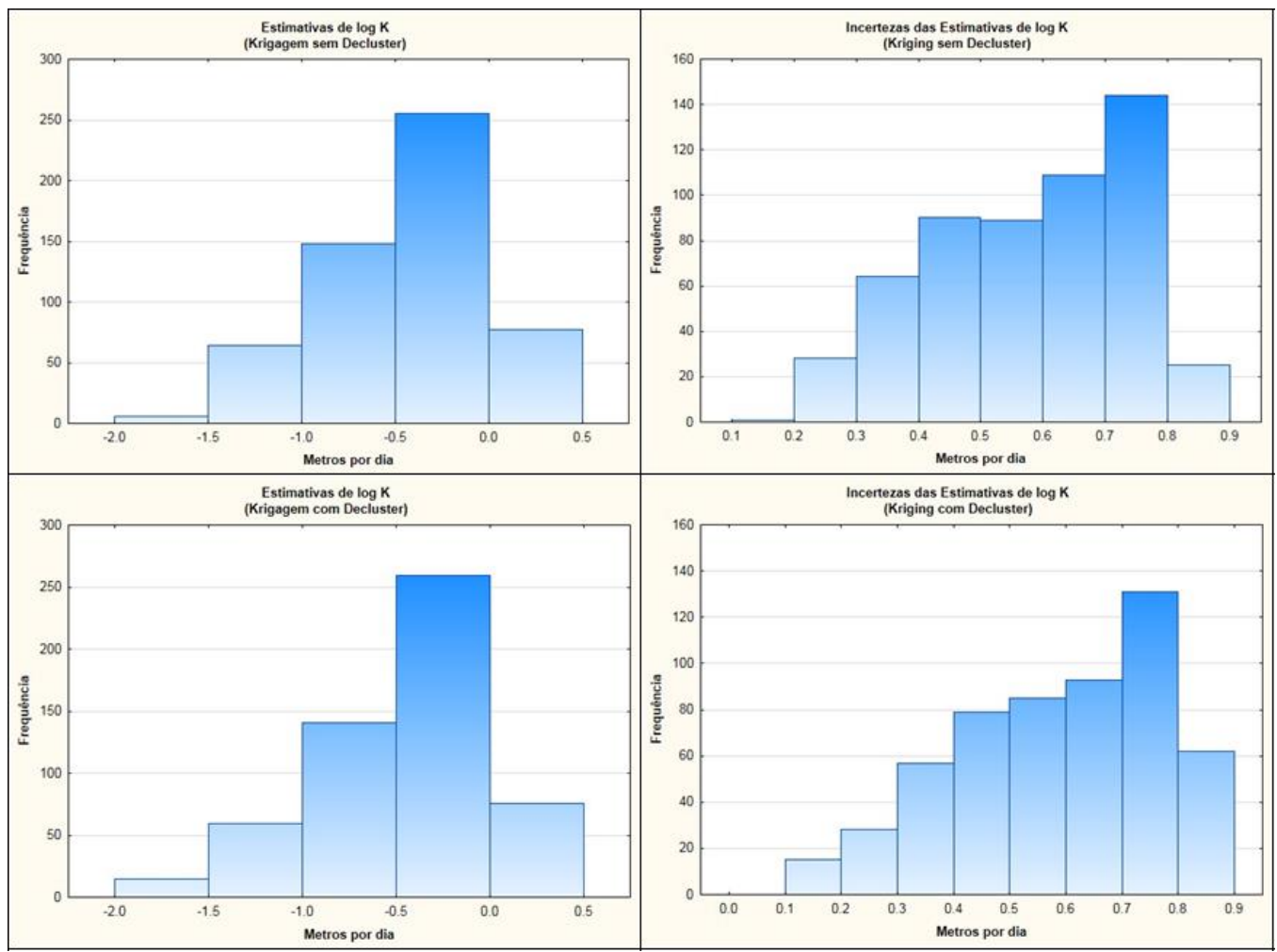

Figura 39: Krigagem ordinária: histogramas das estimativas e da incerteza das estimativas de log K associados ao método sem e com aplicação da técnica de desagrupamento por célula da área de estudo de São Carlos (SAG). 
A figura 40 apresenta os mapas das estimativas de $\log \mathrm{K}$ convertidos em condutividade hidráulica e a distribuição desses valores. Os valores estão distribuídos na faixa de 0,6 a 0,8 $\mathrm{m} /$ dia e uma média 0,7 . Segundo a estatística descritiva apresentada na tabela 8 , esses valores são próximos dos esperados para a área de São Carlos.

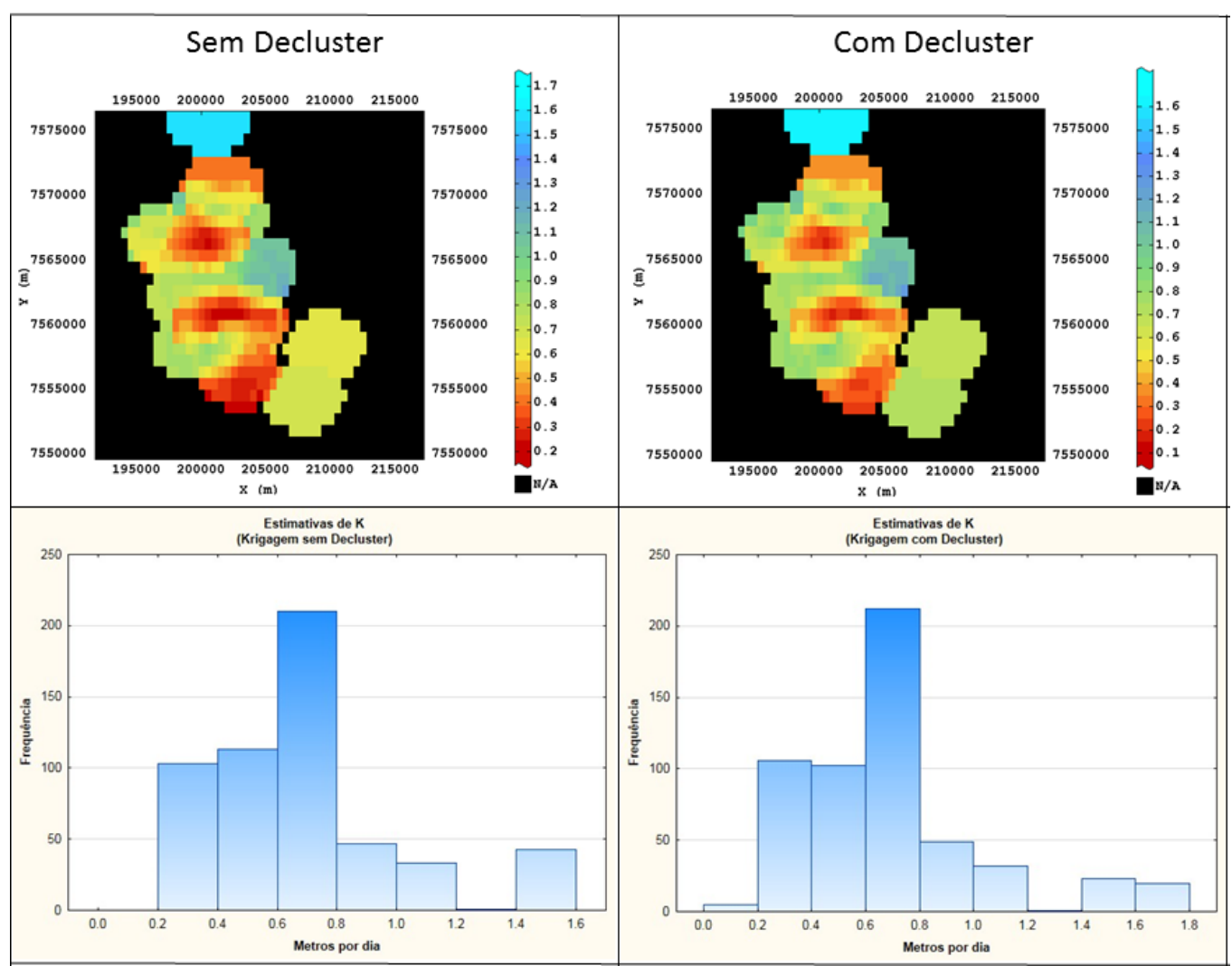

Figura 40: Krigagem ordinária: mapas e histogramas das estimativas de $K$ sem e com aplicação da técnica de desagrupamento por célula da área de estudo de São Carlos (SAG).

Com base na validação cruzada, o uso do decluster apresentou ligeira vantagem, se comparado com o mesmo método geoestatístico sem a sua aplicação. Embora grande parte das estimativas tenham confirmado a tendência dos valores esperados, com o uso ou não da técnica de desagrupamento, valores muito altos são negligenciados.

\subsubsection{Krigagem ordinária combinada com regressão linear}

Com a aplicação da equação (81) poços que possuíam apenas valores de capacidade específica, passaram a apresentar valores calculados de condutividade hidráulica. O número de dados que era 28 inicialmente aumenta para 67 na mesma área de aproximadamente de 15 x 20 km. A figura 41 mostra a distribuição espacial desses poços na área de estudo em São Carlos. 


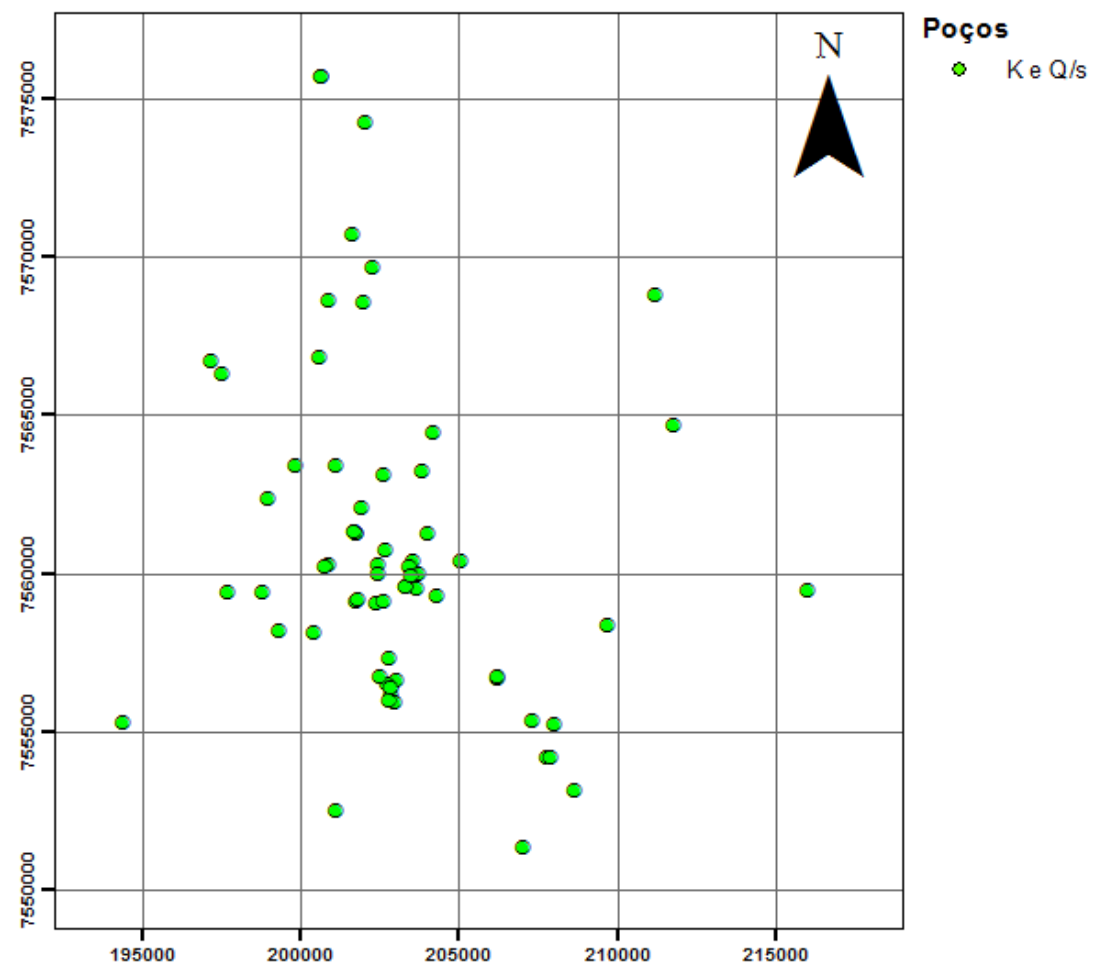

Figura 41: Krigagem ordinária combinada com regressão linear: Distribuição dos poços que apresentam valores de condutividade hidráulica (K) e capacidade específica $(Q / s)$, em São Carlos (SAG).

A estatística descritiva dos dados usados no presente método sem e com decluster é sumarizada na tabela 15. Embora os valores de máximo e mínimo não tenham se alterado, observa-se a diminuição na variância, média e mediana. Comparando com a tabela 14, o uso da equação (81) faz com que, mesmo mantendo os valores de máximo e mínimo, os valores das médias e medianas diminuam e as variâncias amostrais diminuam. Esse comportamento é observado tanto nos casos em que se usa o desagrupamento como naqueles em que essa técnica está ausente.

Tabela 14: Krigagem ordinária combinada com regressão linear: estatística descritiva dos valores de log $K$ sem e com decluster dos poços estudados na cidade de São Carlos (SAG).

\begin{tabular}{|l|c|c|}
\hline \multirow{2}{*}{ Parâmetros } & \multicolumn{2}{|c|}{$\log \mathrm{K}(\mathrm{m} / \mathrm{d})$} \\
\cline { 2 - 3 } & Sem Decluster & Com Decluster \\
\hline Média & -0.6 & -0.57 \\
\hline Mediana & -0.52 & -0.5 \\
\hline $\begin{array}{l}\text { Desvio } \\
\text { padrão }\end{array}$ & 0.52 & 0.06 \\
\hline Variância & 0.27 & 0.24 \\
\hline Intervalo & 2.47 & 2.47 \\
\hline Mínimo & -1.99 & -1.99 \\
\hline Máximo & 0.48 & 0.48 \\
\hline Contagem & 67 & 67 \\
\hline
\end{tabular}


Com base no variograma experimental, os valores dos passos atribuídos aos dados sem e com decluster são 600 e 2000 m, respectivamente. Apesar de uma diferença nessas distâncias ser esperado, tamanha discrepância não é comum. Provavelmente, o aumento do número de dados e a diminuição dos agrupamentos causou essa anomalia. Para ambos, usa-se o número de dez passos.

Os variogramas modelados sem e com decluster são vistos na figura 42. Os elementos desses modelos ajustados estão detalhados na tabela 15. Usando a linha que marca o valor da variância amostral como assíntota, os variogramas se mostram mais acurados quando próximos desses valores. Para os dois casos, o modelo definido é o esférico, pois se assume que os valores tendem a ser mais homogêneos a pequenas distâncias e essa homogeneidade diminua progressivamente com o aumento da distância. A variância espacial é maior no variograma dos dados sem o decluster e, comparando com o variograma com decluster, esse apresenta maior estruturação.

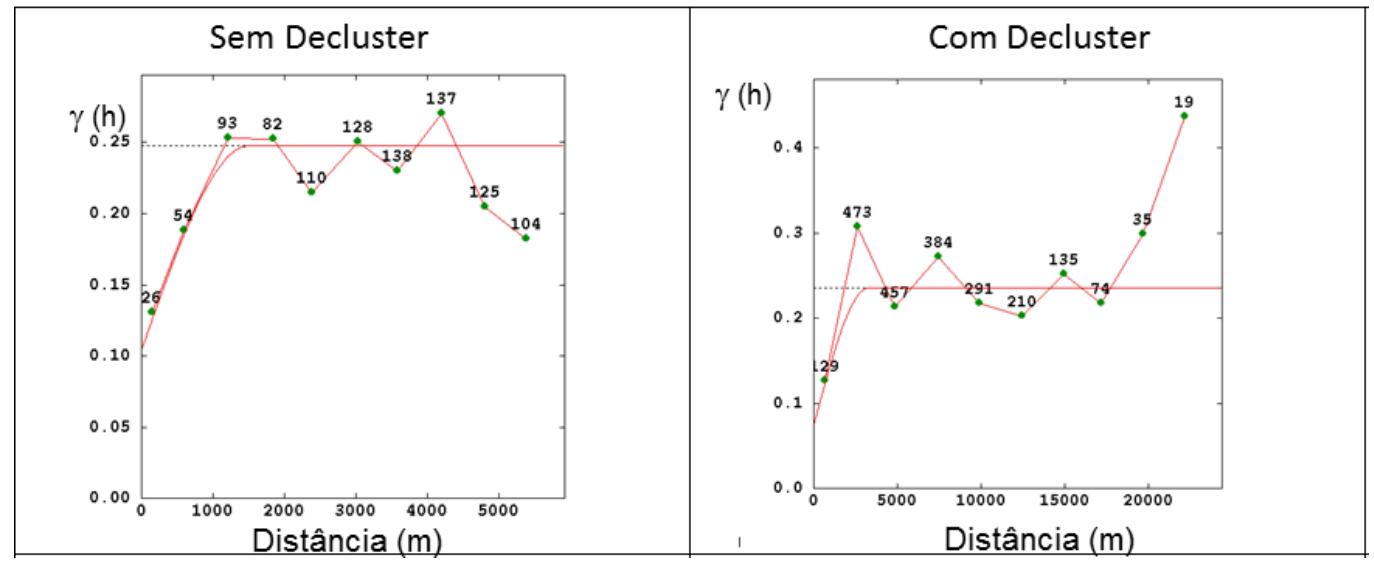

Figura 42: Krigagem ordinária combinada com regressão linear: variogramas modelados sem e com aplicação da técnica de desagrupamento por célula da área de estudo de São Carlos (SAG). A linha tracejada representa a variância amostral.

Tabela 15: Krigagem ordinária combinada com regressão linear: Elementos do modelo do variograma para os dados sem e com o uso da técnica de desagrupamento.

\begin{tabular}{|l|c|c|}
\hline $\begin{array}{c}\text { Elementos } \\
\text { do } \\
\text { variograma }\end{array}$ & $\begin{array}{c}\text { Sem } \\
\text { decluster }\end{array}$ & $\begin{array}{c}\text { Com } \\
\text { decluster }\end{array}$ \\
\hline Modelo & Esférico & Esférico \\
\hline Efeito pepita & 0.1048 & 0.07358 \\
\hline Amplitude & 1500 & 3300 \\
\hline Patamar & 0.1428 & 0.1622 \\
\hline
\end{tabular}


Na figura 43, são apresentados a validação cruzada e o histrograma de erros padronizados dos variogramas dos dados sem e com desagrupamento. Ambos os critérios indicam que no caso em que o decluster não foi aplicado, o modelo é mais acurado. Embora, os histogramas mostrem que há outliers para ambos os casos, a média mais próxima de zero e o desvio-padrão mais próximo de um mostram uma vizinhança bem ajustada quando a técnica de desagrupamento não é utilizada.

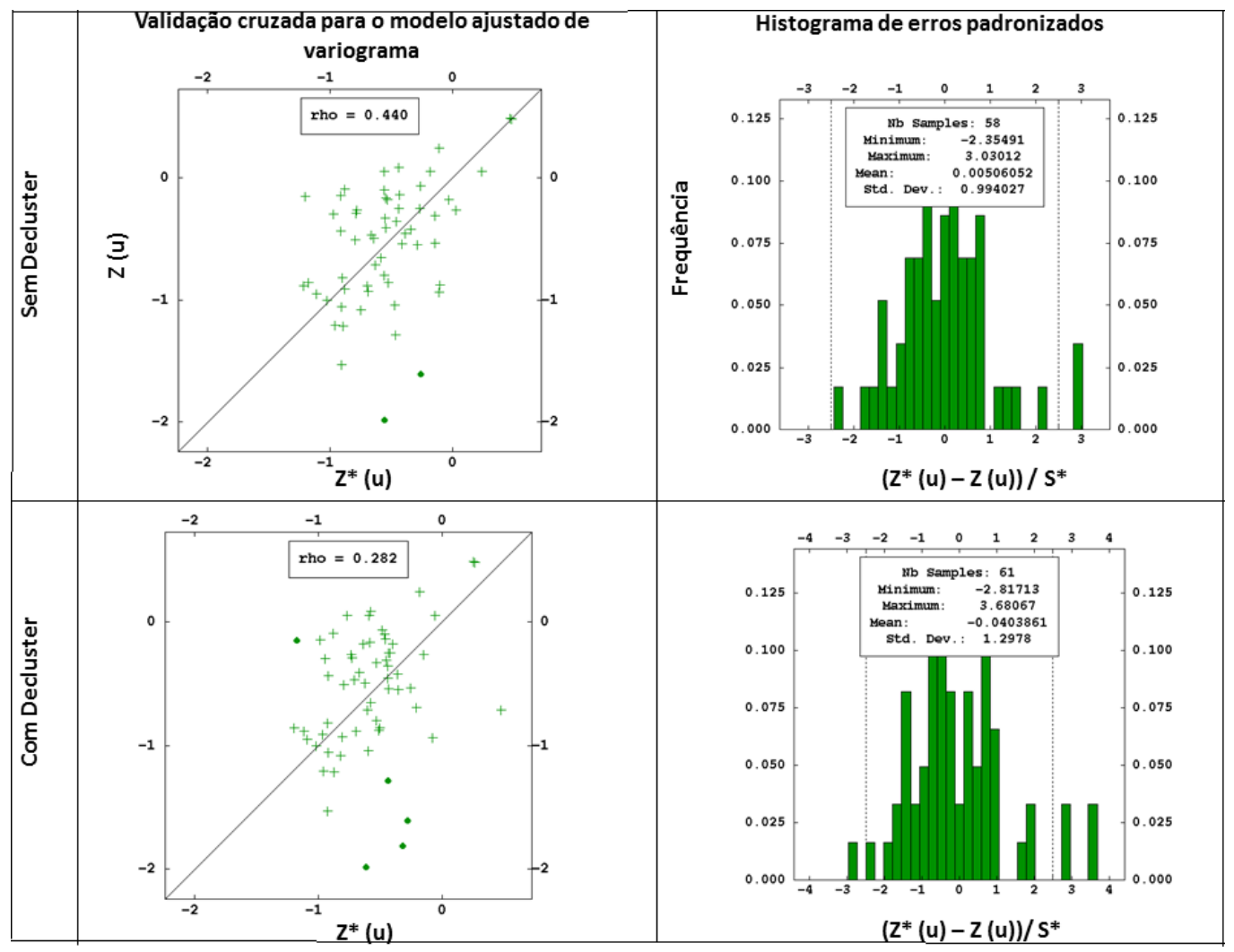

Figura 43: Krigagem ordinária combinada com regressão linear: validação cruzada $e$ histograma de erros padronizados sem e com aplicação da técnica de desagrupamento por célula da área de estudo de São Carlos (SAG).

Com os modelos variogramas definidos, o método da krigagem ordinária é aplicado para estimar os pontos não amostrados. Os mapas das estimativas e das incertezas ou variância de krigagem são mostrados na figura 44. Na forma de histograma, a distribuição desses resultados é apresentada na figura 45 . No caso das figuras que retratam os resultados dos métodos sem desagrupamento, as estimativas variam de $-1,82$ a 0,47 com média $-0,58$, e a variância de krigagem ou incerteza de 0,13 a 0,58 com média 0,45. Enquanto com a aplicação do decluster, as estimativas apresentam um valor mínimo de -1.35 e um máximo de 0.47 , com média 0.57 . Para a sua incerteza associada, a variação é de 0.11 a 0.61 e média 0.44 . Sendo assim, embora os valores não apresentem forte discrepância, os histogramas (Figura 45) mostram que as incertezas associadas às estimativas são maiores com o uso do decluster. O mapa de estimativas evidencia a vizinhança de busca para ambos os casos, ou seja, o círculo de busca ajustado no 
método com decluster é maior e consegue estimar a maiores distâncias, mas isso aumenta a incerteza.

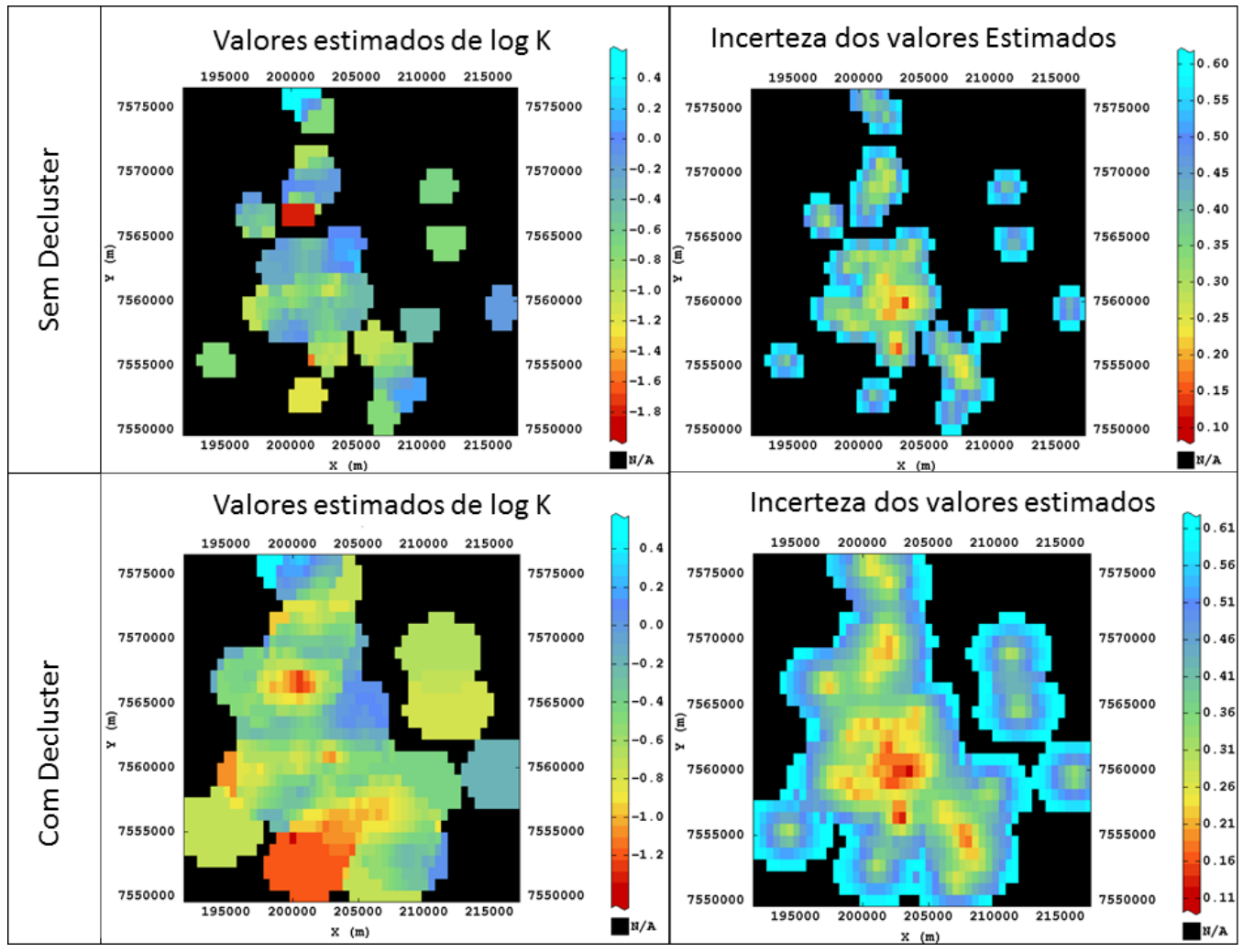

Figura 44: Krigagem ordinária combinada com regressão linear: mapas das estimativas e de incerteza associados ao método sem e com aplicação da técnica de desagrupamento por célula da área de estudo de São Carlos (SAG). 


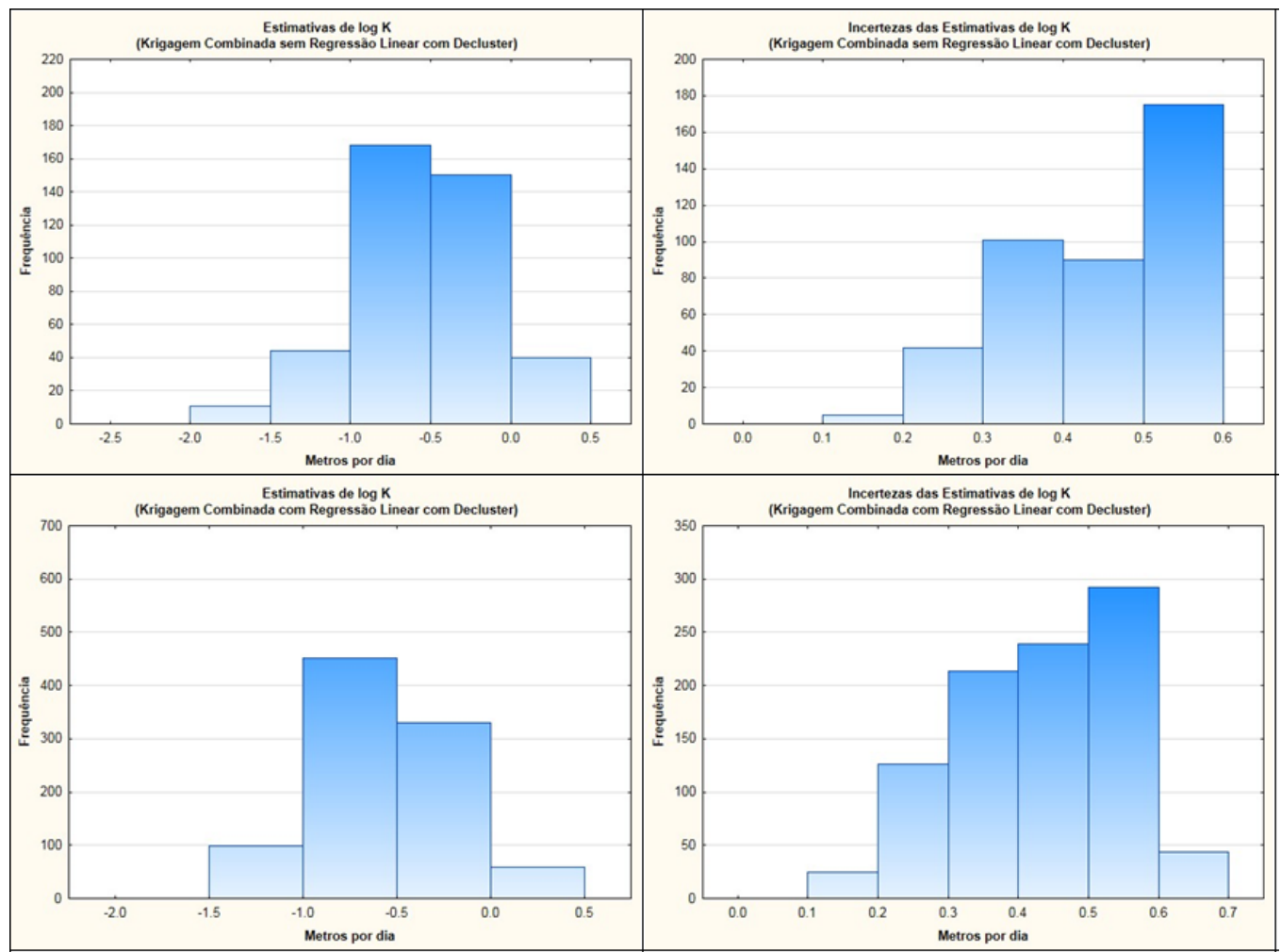

Figura 45: Krigagem ordinária combinada com regressão linear: Histogramas das estimativas $e$ de incerteza associada ao método sem e com aplicação da técnica de desagrupamento ou Decluster por célula da área de estudo de São Carlos, SAG.

Os valores das estimativas de log $\mathrm{K}$ convertidos em valores de condutividade hidráulica são apresentados em forma de mapas e variogramas para ambos os casos na figura 46. Verificase os valores com maior frequência são os esperados, em torno de 0,44 m/dia. Entretanto, valores mais altos do que esperado são encontrados com maior frequência, podendo chegar até $3 \mathrm{~m} / \mathrm{dia}$. 


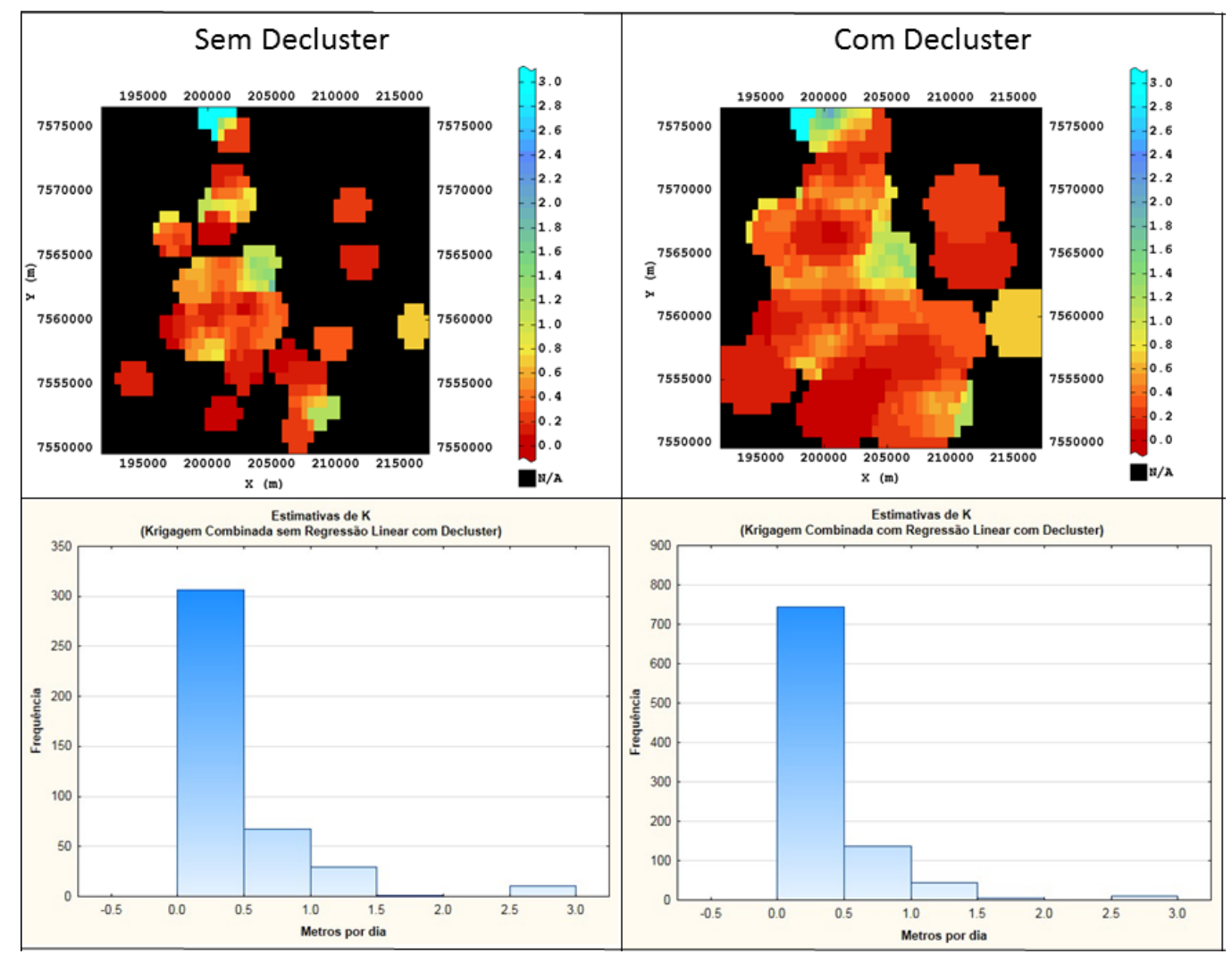

Figura 46: Krigagem ordinária combinada com regressão linear: Mapas e histogramas das estimativas sem e com aplicação da técnica de desagrupamento ou Decluster por célula da área de estudo de São Carlos, SAG.

Para a área de estudo em São Carlos, o método de krigagem ordinária combinada com regressão linear mostra-se melhor sem o uso do decluster. Para atingir o valor de validação cruzada mensurado, o raio do círculo de busca é menor que a amplitude. No entanto, há um custo para isso: como visto nos mapas de estimativa (Figuras 44 e 56) há lacunas sem valores estimados, reflexo desse ajuste mais conservador.

\subsubsection{Cokrigagem}

Na aplicação do método geoestatístico da cokrigagem na área de interesse da cidade São Carlos, são usados 28 poços que apresentam valores de $\mathrm{K}$ e $\mathrm{Q} / \mathrm{s}$, sendo a condutividade hidráulica a variável primária, e outros 67 que apresentam somente valores de capacidade específica, que é a variável secundária. A distribuição espacial desses poços está apresentada na figura 47 , onde os pontos verdes representam a localização dos poços com valores de $\mathrm{K}$ e os pontos pretos mostram os locais dos poços que possuem informação somente da variável secundária. 


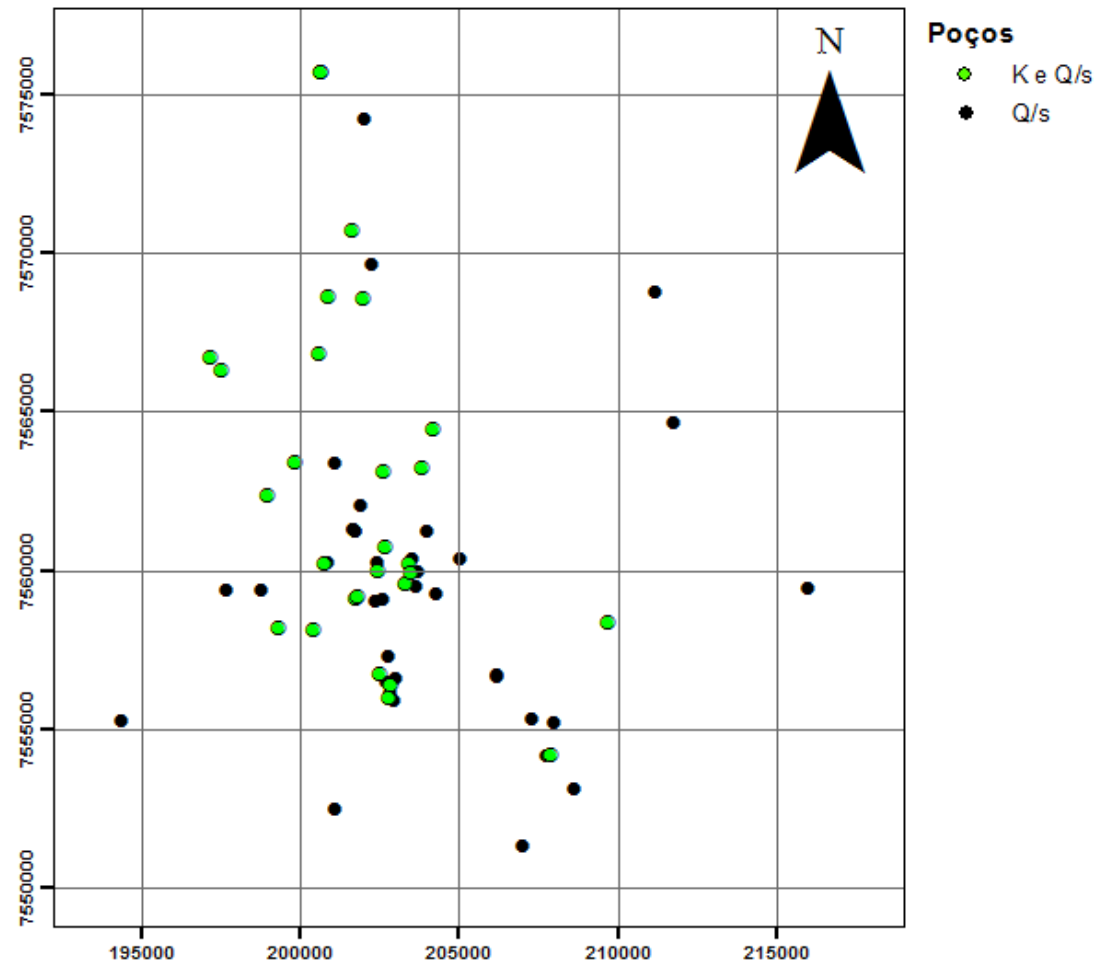

Figura 47: Cokrigagem: Distribuição dos poços que apresentam valores de condutividade hidráulica $(K) \quad e$ capacidade específica $(Q / s)$ (pontos em verde) e apenas valores de $Q / s$ (pontos em preto) na cidade de São Carlos (SAG).

A tabela 16 mostra a estatística descritiva para os valores de $\log \mathrm{K}$ e $\log \mathrm{Q} / \mathrm{s}$ sem e com aplicação da técnica de desagrupamento ou decluster. A estatística para os valores de log K é a mesma discutida na tabela 12, para krigagem ordinária. Analisando as estatísticas dos valores de $\log \mathrm{Q} / \mathrm{s}$, verifica-se que a aplicação do decluster igualou a mediana a média e diminuiu drasticamente a variância. Os valores de máximo e mínimo são mantidos com o uso do decluster.

Tabela 16: Cokrigagem ordinária: estatística descritiva dos valores de log K sem e com decluster dos poços estudados na cidade de São Carlos (SAG).

\begin{tabular}{|l|c|c|c|c|}
\hline \multirow{2}{*}{ Parâmetros } & \multicolumn{2}{|c|}{$\log \mathrm{K}(\mathrm{m} / \mathrm{d})$} & \multicolumn{2}{c|}{$\log \mathrm{Q} / \mathrm{s}\left(\mathrm{m}^{2} / \mathrm{d}\right)$} \\
\cline { 2 - 5 } & Sem Decluster & Com Decluster & Sem Decluster & Com Decluster \\
\hline Média & -0.52 & -0.52 & 1.57 & 1.63 \\
\hline Mediana & -0.37 & -0.42 & 1.62 & 1.63 \\
\hline Desvio-padrão & 0.65 & 0.17 & 0.06 & 0.07 \\
\hline Variância & 0.42 & 0.41 & 0.25 & 0.26 \\
\hline Intervalo & 2.47 & 2.47 & 2.25 & 2.25 \\
\hline Mínimo & -1.99 & -1.99 & 0.35 & 0.35 \\
\hline Máximo & 0.48 & 0.48 & 2.6 & 2.6 \\
\hline Contagem & 28 & 28 & 67 & 67 \\
\hline
\end{tabular}

No variograma experimental é definido o valor de $2.500 \mathrm{~m}$ de passo para ambos os conjuntos de dados. A figura 48 apresenta os variogramas experimentais modelados. Como 
discutido no item 4.5.4., o método de cokrigagem requer um variograma cruzado. Para que esse seja ajustado, há uma condição para que o determinante da matriz de corregionalização não seja negativo e inviabilize a aplicação do método. Para que essa condição seja satisfeita os valores dos patamares dos variogramas individuais de $\log \mathrm{K}$ e $\log \mathrm{Q} / \mathrm{s}$ multiplicados devem ser maiores que o quadrado do patamar do variograma cruzado. A configuração que melhor satisfez essa condição e atingiu maior valor de validação cruzada está na tabela 17. Nela, observa-se que os valores de amplitude são constantes nos variogramas dos dados sem e com decluster. No caso em que a técnica da desagrupamento não é aplicada, a amplitude é mais baixa, $935 \mathrm{~m}$. Novamente, os patamares que melhor se ajustam são aqueles muito próximos dos valores das suas variâncias amostrais.

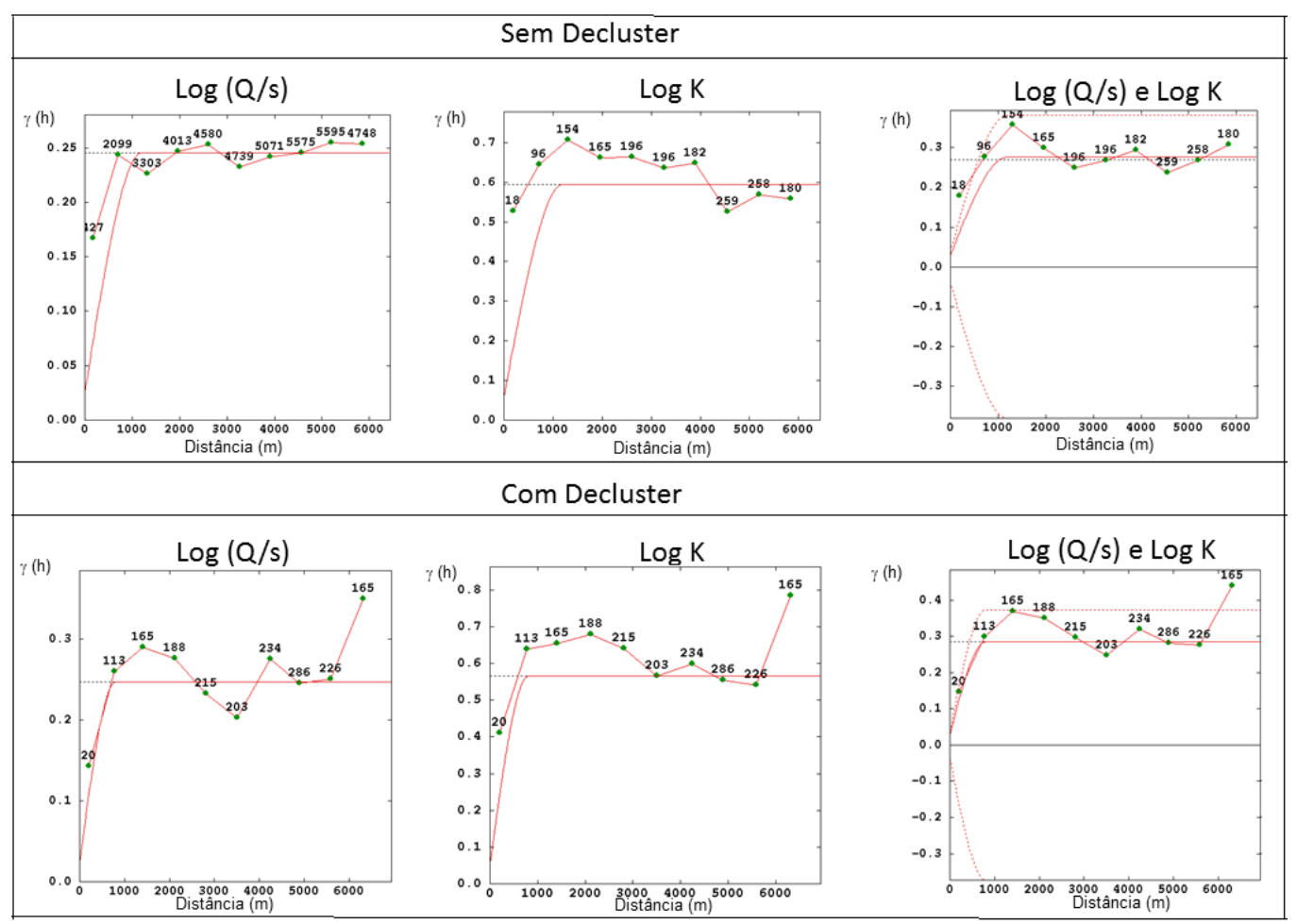

Figura 48: Cokrigagem: variogramas cruzados modelados sem e com aplicação da técnica de desagrupamento por célula da área de estudo de São Carlos (SAG). A linha tracejada representa a variância amostral.

Tabela 17: Cokrigagem: Elementos do modelo do variograma para os dados sem e com o uso de desagrupamento.

\begin{tabular}{|l|c|c|c|c|c|c|}
\hline \multirow{2}{*}{$\begin{array}{c}\text { Elementos do } \\
\text { variograma }\end{array}$} & \multicolumn{3}{|c|}{ Sem decluster } & \multicolumn{3}{c|}{ Com decluster } \\
\cline { 2 - 7 } & $\log \mathrm{Q} / \mathrm{s}$ & $\log \mathrm{K}$ & $\begin{array}{c}\text { Log Q/s e } \\
\log \mathrm{K}\end{array}$ & $\log \mathrm{Q} / \mathrm{s}$ & $\log \mathrm{K}$ & $\begin{array}{c}\text { Log Q/s e } \\
\log \mathrm{K}\end{array}$ \\
\hline Modelo & Esférico & Esférico & Esférico & Esférico & Esférico & Esférico \\
\hline Efeito pepita & 0.0346 & 0.0728 & 0.0426 & 0.0383 & 0.0265 & 0.0183 \\
\hline Amplitude & 935 & 935 & 935 & 3300 & 3300 & 3300 \\
\hline Patamar & 0.2483 & 0.5823 & 0.2746 & 0.3448 & 0.2381 & 0.2381 \\
\hline
\end{tabular}


A figura 49 mostra a validação cruzada e o histograma dos erros padronizados para os dados de $\log \mathrm{K}$ sem e com decluster. Observa-se que o modelo com o decluster apresentou um valor maior na validação (0.436) e no histograma os valores da média e desvio-padrão são mais próximos de e zero e um, respectivamente. No entanto, usando os modelos variogramas e a vizinhança de busca propostos para esse método na área de estudo do SAG, nem todos os valores foram re-estimados na validação cruzada, somente 25 dos 28 poços, como visto nos histogramas dos erros padronizados. Ainda, são detectados outliers.

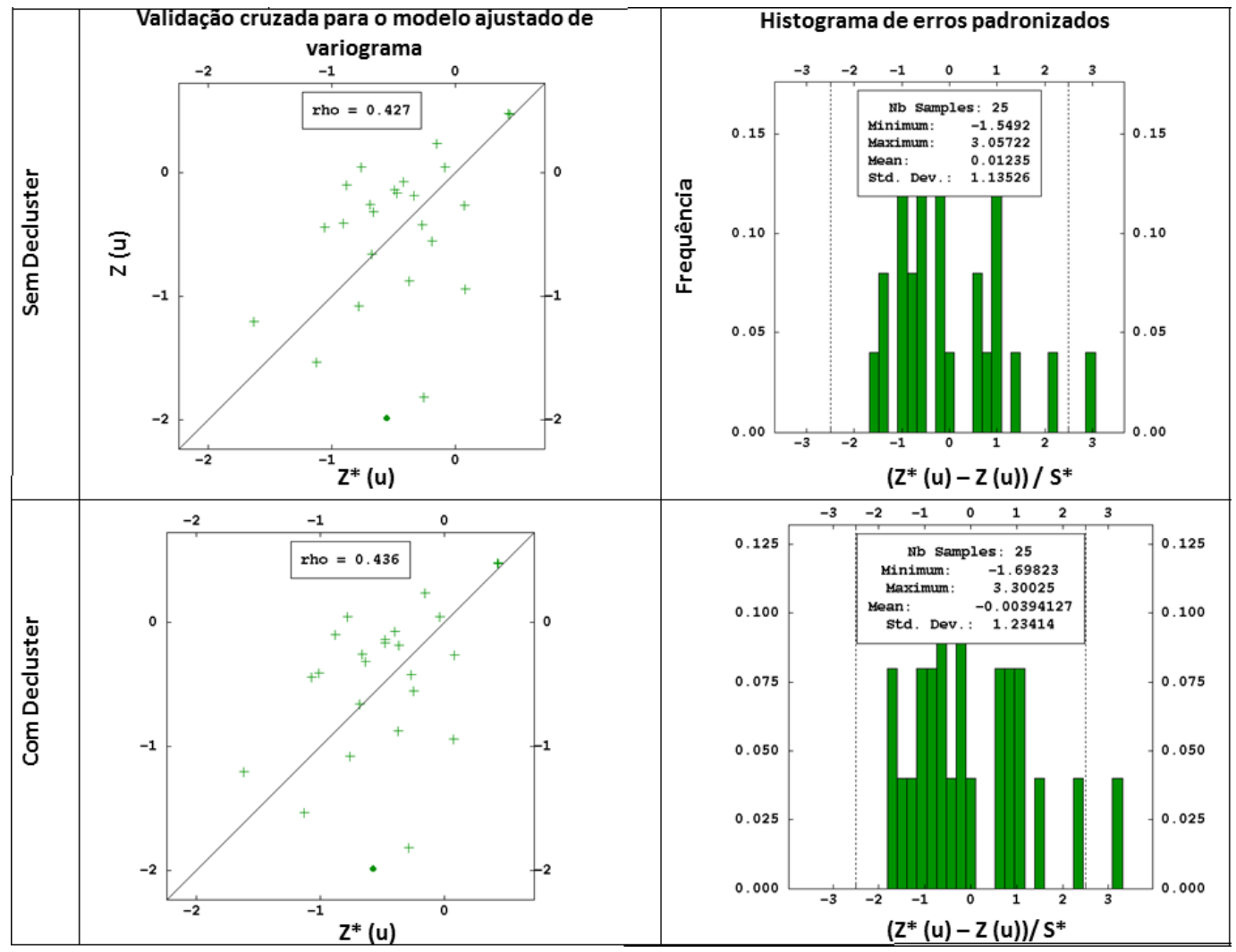

Figura 49: Cokrigagem: validação cruzada e histogramas de erros padronizados sem e com aplicação da técnica de desagrupamento por célula da área de estudo de São Carlos (SAG).

As figuras 50 e 51 apresentam os valores estimados pelo método de cokrigagem, sendo a primeira na forma de mapa e a segunda na de histograma. Para o caso em que o desagrupamento não é aplicado, os valores estimados da variável de interesse, $\log \mathrm{K}$, variam de -1.99 a 0.47 , com média de 0.47 , e a incerteza associada varia de 0.14 a 0.9 , com média 0.6. Quando essa técnica não é usada, as estimativas apresentam os mesmos valores, exceto pelo valor mínimo que é -1.87. No entanto, sem a aplicação da técnica de desagrupamento, os valores de incerteza associada mais satisfatórios, variando de 0.13 a 0.81 e média 0.55 . Para ambos os casos, são observados espaços vazios, onde não há estimativas. Isso está diretamente atrelado ao ajuste dado a vizinhança de busca. 


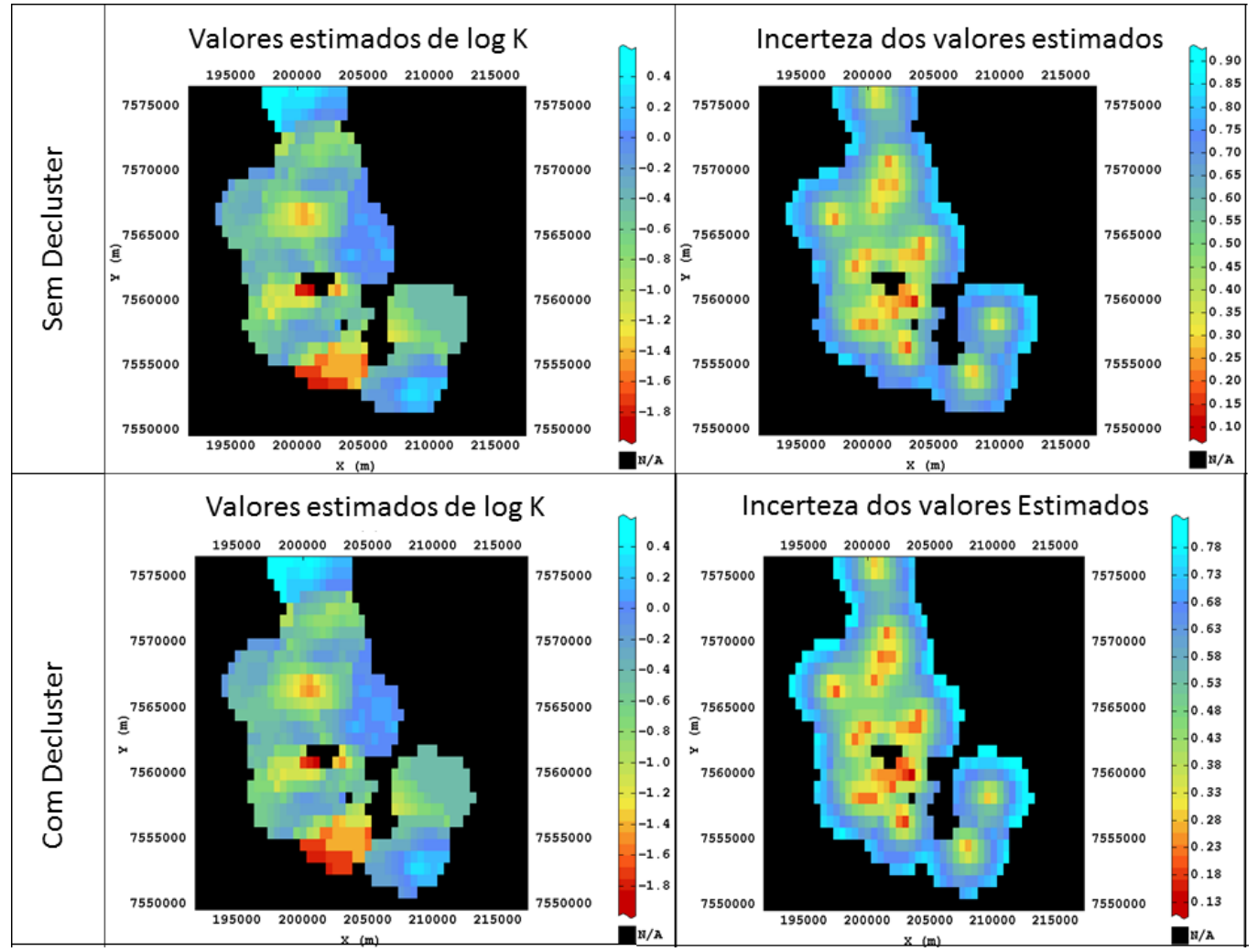

Figura 50: Cokrigagem: mapas das estimativas e de incerteza associada ao método sem e com aplicação da técnica de desagrupamento por célula da área de estudo de São Carlos, SAG.

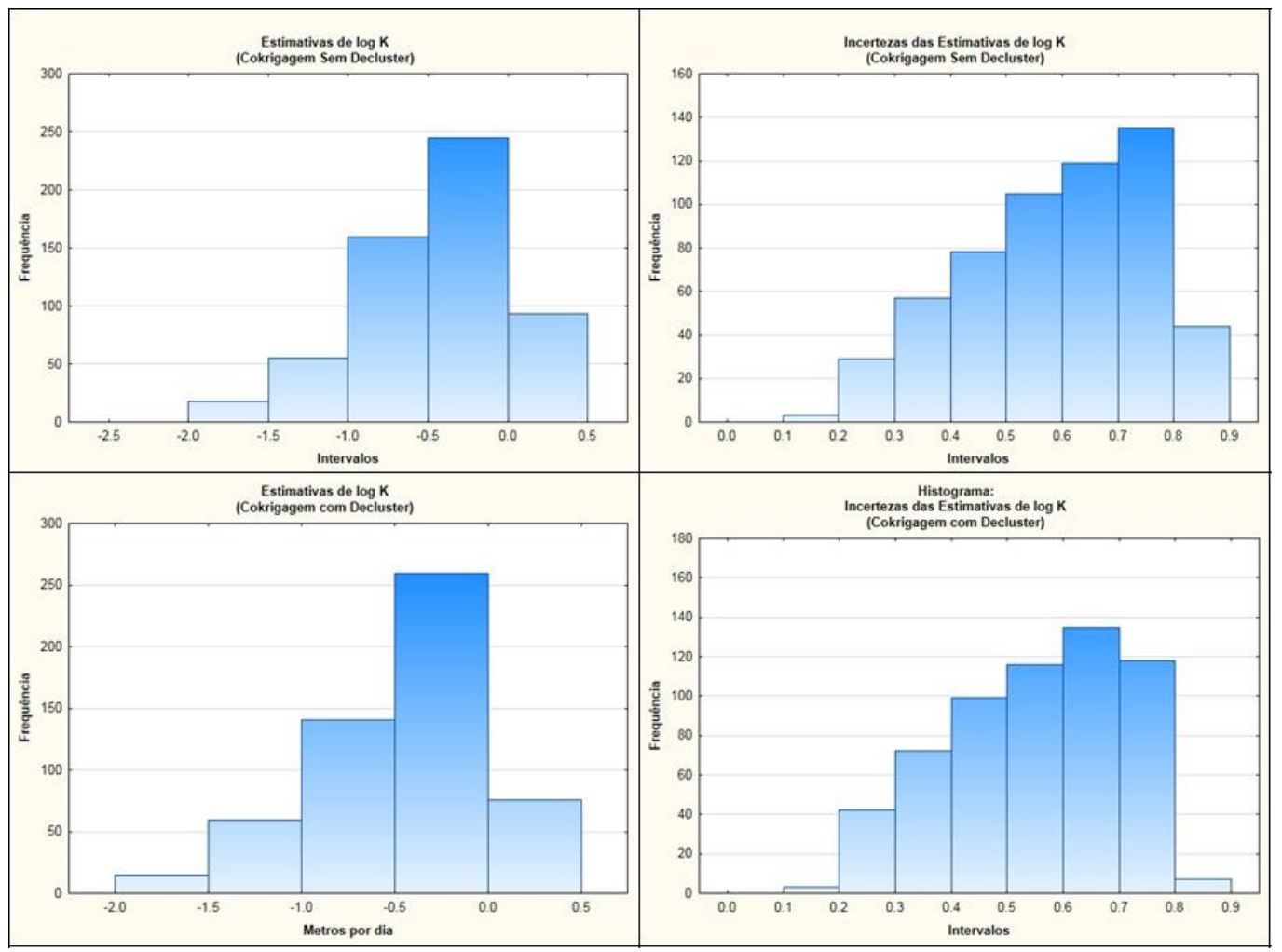

Figura 51: Cokrigagem: histogramas das estimativas e de incerteza associada ao método sem e com aplicação da técnica de desagrupamento por célula da área de estudo de São Carlos, SAG.

Os mapas e os variogramas ilustrando as estimativas de log $\mathrm{K}$ convertidos em valores de condutividade hidráulica são apresentados na figura 52. Não é possível observar nítida 
discrepância entre os resultados do método sem e com desagrupamento. Ambos apresentam distribuição similar na área e, nos histogramas, assimetria positiva bem definida com valores que variam de 0.01 a $2.97 \mathrm{~m} /$ dia e média $0.55 \mathrm{~m} /$ dia.

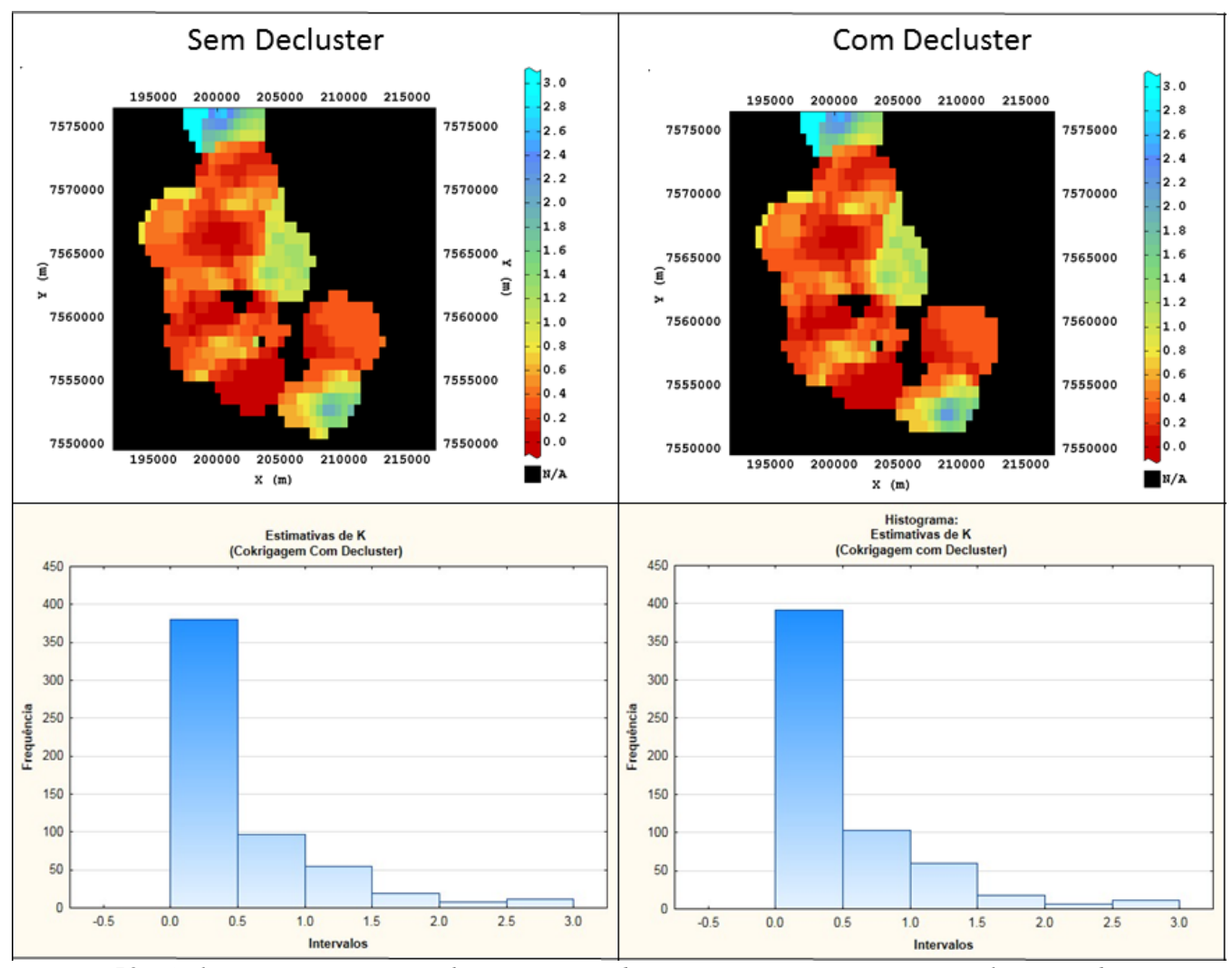

Figura 52: Cokrigagem: mapas e histogramas das estimativas sem e com aplicação da técnica de desagrupamento por célula da área de estudo de São Carlos, SAG.

Com base no que foi apresentado e discutido, a cokrigagem como método geoestatístico na área de estudo de São Carlos tem a sua performance melhorada usando a técnica de decluster ou desagrupamento, mesmo que de forma sutil. Assume-se isso baseando-se no resultado de validação cruzada. Para atingir esse resultado, são aplicados ajustes mais conservadores nos parâmetros do modelo e no raio da vizinhança. Para essa última, o valor definido é de $2.700 \mathrm{~m}$, menor que o valor da amplitude.

\subsubsection{Bandas rotativas}

Para a aplicação do método de simulação por bandas rotativas, são utilizados como base de dados 28 poços, os mesmos do método de krigagem ordinária. A distribuição espacial desses dados bem como sua estatística descritiva podem ser observadas na figura 35 e na tabela 12 , respectivamente. Esse método de simulação diferencia-se dos demais métodos geoestatísticos tratados nesse trabalho, uma vez que a análise estrutural se inicia após a aplicação da 
transformada normal score. Nessa etapa preliminar, uma função de densidade acumulada de comportamento normal e padronizada é aplicada nos dados iniciais. Assim todo o método é desenvolvido no campo gaussiano, com os valores distribuídos de forma simétrica com valores média e desvio-padrão muito próximos de zero e um, respectivamente.

Com esses dados transformados, inicia-se a análise exploratória ou estrutural. A análise da estatística descritiva é simular para os casos da aplicação ou não da técnica de desagrupamento. Ainda nessa etapa inicial, é assumido o valor do passo para ambos os casos como sendo de $2.500 \mathrm{~m}$.

Nos variogramas modelados (Figura 53) considera-se melhor estrutura para aquele que trata dos dados com decluster. Na tabela 18, observam-se os valores dos elementos desses variogramas ajustados. Os dados com decluster apresentam maior continuidade espacial por ter menor variância espacial e maior amplitude.

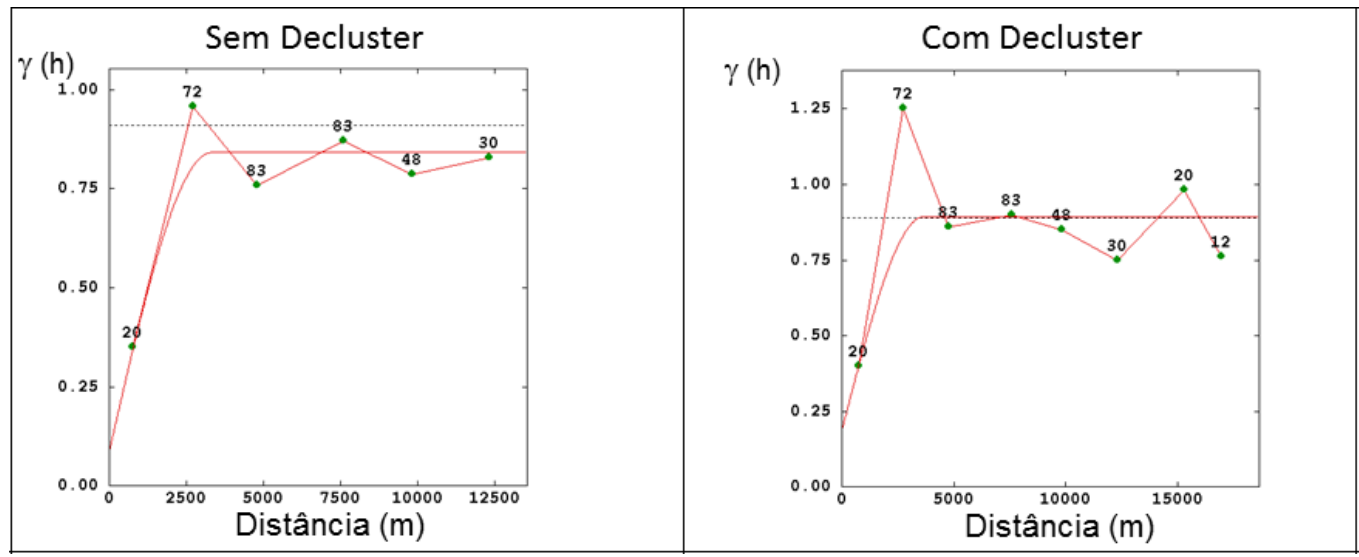

Figura 53: Bandas Rotativas: variogramas modelados, após a transformada normal score, sem e com aplicação da técnica de desagrupamento por célula da área de estudo de São Carlos (SAG). A linha tracejada representa a variância amostral.

Tabela 18: Bandas rotativas: Elementos do modelo do variograma para os dados sem e com o uso de desagrupamento.

\begin{tabular}{|l|c|c|}
\hline $\begin{array}{c}\text { Elementos } \\
\text { do } \\
\text { variograma }\end{array}$ & $\begin{array}{c}\text { Sem } \\
\text { decluster }\end{array}$ & $\begin{array}{c}\text { Com } \\
\text { decluster }\end{array}$ \\
\hline Modelo & Esférico & Esférico \\
\hline Efeito pepita & 0.0911 & 0.1907 \\
\hline Amplitude & 3300 & 3650 \\
\hline Patamar & 0.7499 & 0.7016 \\
\hline
\end{tabular}

Segundo o valor apresentado na validação cruzada e no histograma dos erros padronizados, o modelo variograma dos dados sem o decluster é mais indicado (Figura 54). Além do valor da validação cruzada, o valor da média mais próxima de zero e o desvio-padrão 
mais próximo de um no histograma de erros padronizados para esses valores corroboram para essa conclusão. No entanto, para a vizinhança ajustada, não foram todos os valores reestimados, 26 de 28 pontos, na validação cruzada.

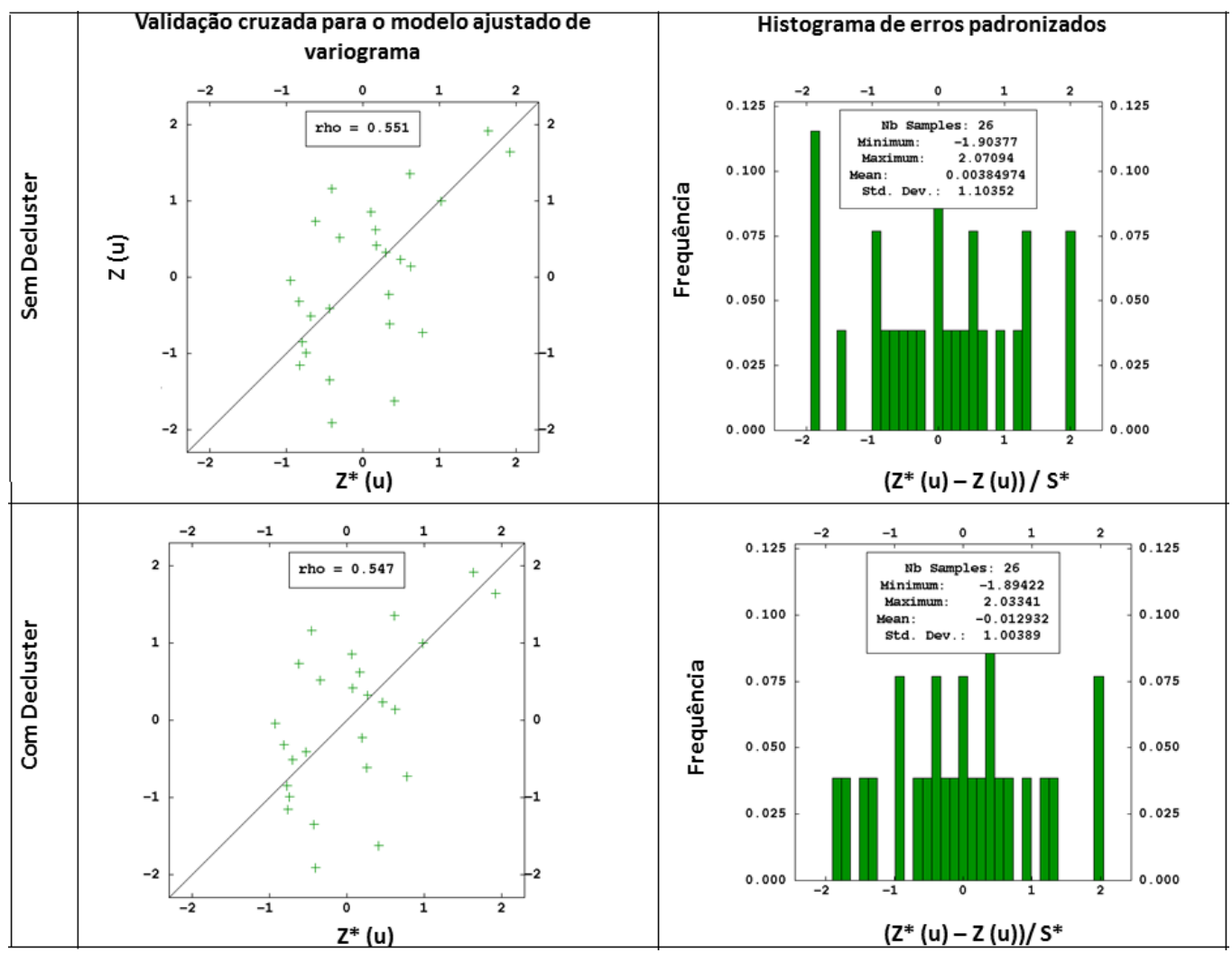

Figura 54: Bandas Rotativas: Validação cruzada e histogramas de erros padronizados sem e com aplicação da técnica de desagrupamento por célula da área de estudo de São Carlos, SAG.

Definidos os modelos variogramas para ambos os casos, os valores de $\log \mathrm{K}$ são estimados e seus resultados são apresentados nas figuras 55 e 56 nas formas de mapas e histogramas, respectivamente. Essas estimativas são a representação dos valores médios das 100 realizações simuladas, tendendo aos valores da krigagem ordinária. Como mostrado nas figuras, os resultados para o caso com decluster variam de -1.59 a 0.25 e média -0.53 e, a incerteza associada ao método varia de 0.14 a 0.77 , com média 0.52 . Quando o desagrupamento é aplicado, a variabilidade desses resultados diminui um pouco, variando de -1.39 a 0.32 , com média 0,38 e, sua incerteza varia de 0.17 a 0.8 , com média 0.51 . Nos mapas de estimativas, há um espaço vazio ao sul da área, mostrando que a vizinhança de busca não foi capaz de estimar naquele local. 


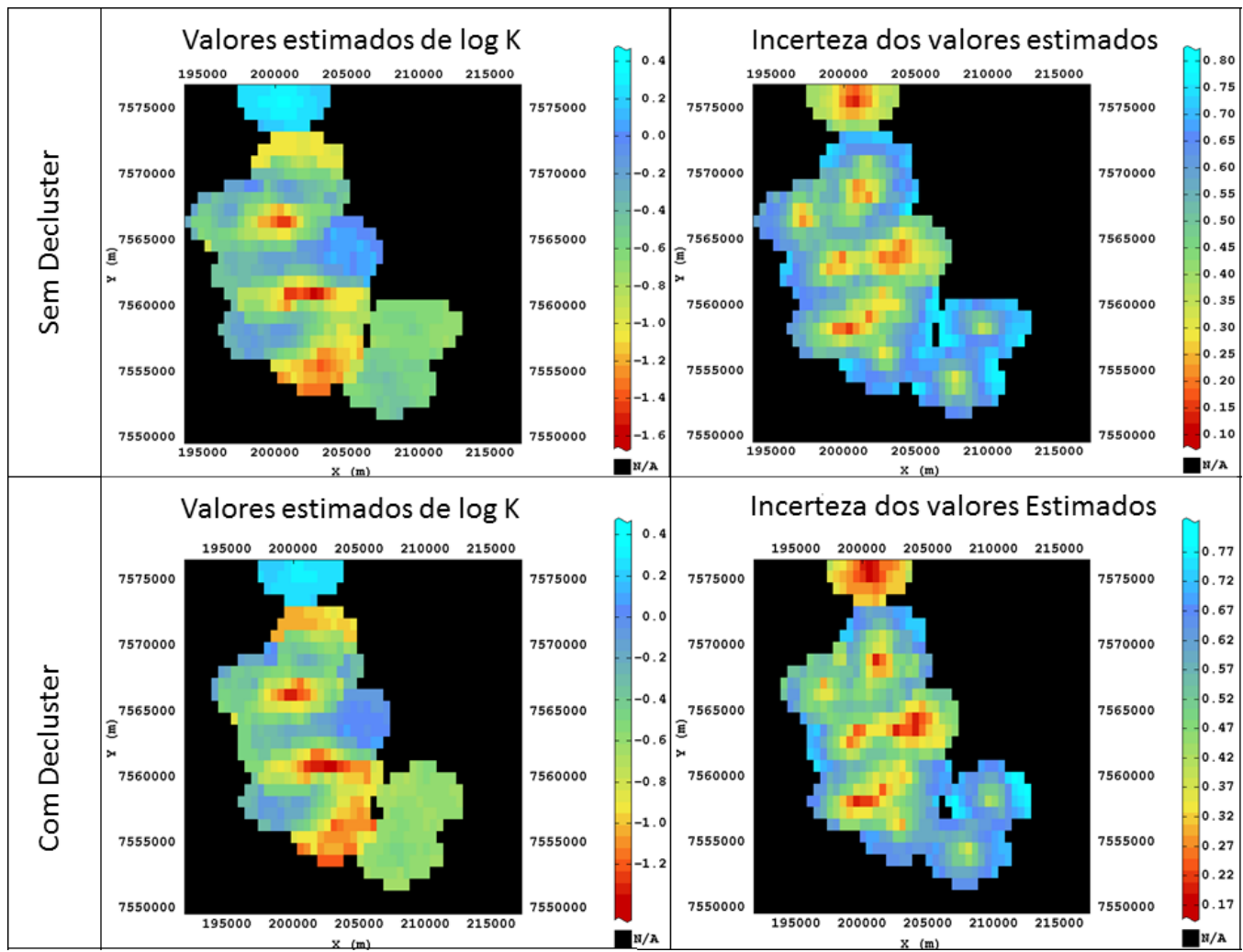

Figura 55: Bandas rotativas: mapas das estimativas e de incerteza associada ao método sem e com aplicação da técnica de desagrupamento por célula da área de estudo de São Carlos, SAG.

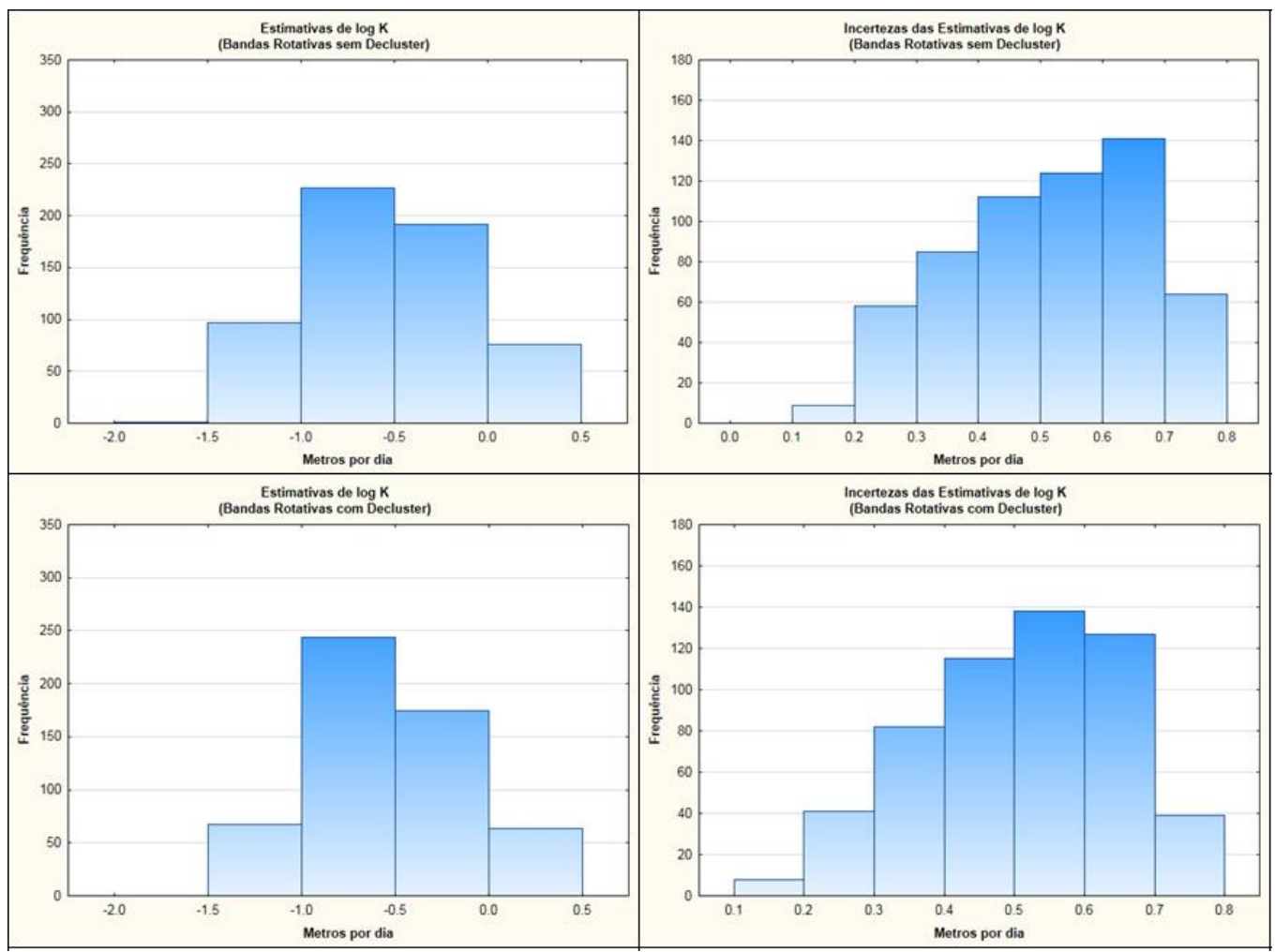

Figura 56: : Bandas Rotativas: histogramas das estimativas e de incerteza associada ao método sem e com aplicação da técnica de desagrupamento por célula da área de estudo de São Carlos, SAG.

Os valores das estimativas de log $\mathrm{K}$ convertidos em valores de condutividade hidráulica são apresentados em forma de mapas e variogramas para ambos os casos (Figura 57). Verifica- 
se que a distribuição das estimativas de $\mathrm{K}$ apresenta uma distribuição assimétrica positiva e seus valores variam de 0,03 a 2,26 m/dia, com média de $0.46 \mathrm{~m} /$ dia, para o caso sem a aplicação do decluster, e de 0,04 a 2,09 m/dia, com média de 0,46 m/dia para o caso de decluster. Esses valores apresentam um comportamento condizente com o esperado na estatística descritiva para valores de condutividade hidráulica (Tabela 4).

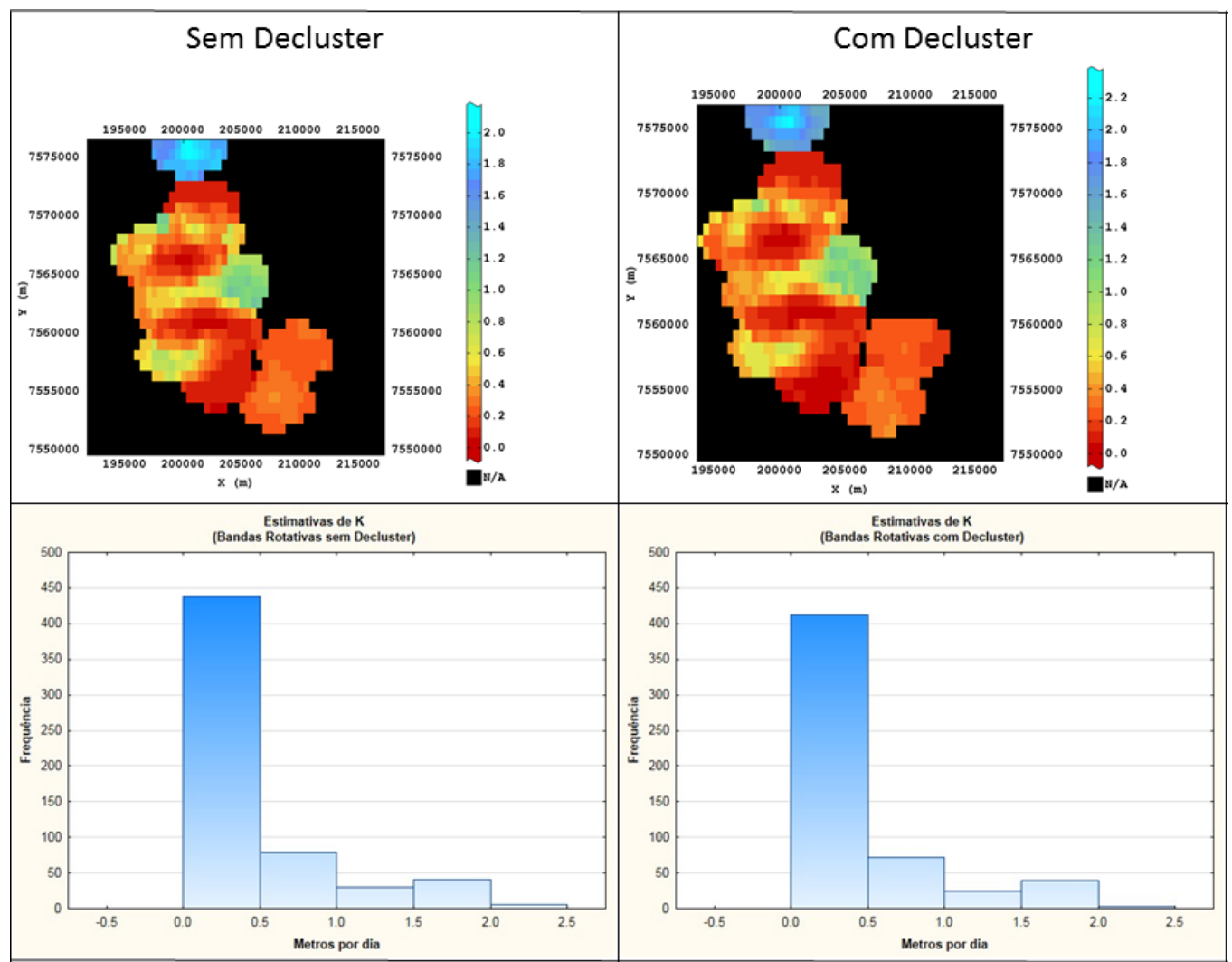

Figura 57: Bandas rotativas: mapas e histogramas das estimativas sem e com aplicação da técnica de desagrupamento por célula da área de estudo de São Carlos (SAG).

O método de simulação por bandas rotativas mostra-se mais eficaz, com base na validação cruzada, quando esse é aplicado sem a técnica de desagrupamento, na área de interesse de São Carlos. Para atingir esse resultado de validação, ajusta-se o raio de busca para $3.000 \mathrm{~m}$, menor que a amplitude.

\subsubsection{Estudos comparativo dos métodos geoestatísticos aplicados em São Carlos (SAG)}

Os resultados dos testes geoestatísticos sem e com a aplicação da técnica de desagrupamento são apresentados de forma resumida nas tabelas 19 e 20, respectivamente. 
Tabela 19: Sumário dos resultados dos métodos geoestatísticos sem a aplicação da técnica de desagrupamento ou decluster por célula na área de interesse em São Carlos (SAG).

\begin{tabular}{|c|c|c|c|c|c|c|c|c|c|}
\hline \multicolumn{10}{|c|}{ São Carlos ( Sem Decluster) } \\
\hline \multirow{2}{*}{ Métodos } & \multicolumn{4}{|c|}{ Valores Estimados } & \multicolumn{4}{|c|}{ Incerteza dos valores estimados } & \multirow{2}{*}{$\begin{array}{l}\text { Validação } \\
\text { Cruzada }\end{array}$} \\
\hline & Mínimo & Máximo & Média & Variância & Mínimo & Máximo & Média & Variância & \\
\hline Krigagem Ordinária & -1.54 & 0.47 & -0.47 & 0.2 & 0.18 & 0.82 & 0.59 & 0.4 & 0.49 \\
\hline Cokrigagem & -1.89 & 0.47 & -0.47 & 0.21 & 0.14 & 0.84 & 0.6 & 0.4 & 0.43 \\
\hline $\begin{array}{l}\text { Krigagem Ordinária } \\
\text { Combinada com } \\
\text { Regressão Linear }\end{array}$ & -1.82 & 0.47 & -0.55 & 0.18 & 0.13 & 0.58 & 0.45 & 0.33 & 0.44 \\
\hline Turning Bands & -0.159 & 0.35 & -0.53 & 0.17 & 0.14 & 0.77 & 0.52 & 0.39 & 0.55 \\
\hline
\end{tabular}

Tabela 20: Sumário dos resultados dos métodos geoestatísticos sem a aplicação da técnica de desagrupamento ou decluster por célula na área de interesse em São Carlos.

\begin{tabular}{|c|c|c|c|c|c|c|c|c|c|}
\hline \multicolumn{10}{|c|}{ São Carlos ( com Decluster) } \\
\hline \multirow{2}{*}{ Método } & \multicolumn{4}{|c|}{ Valores Estimados } & \multicolumn{4}{|c|}{ Incerteza dos valores estimados } & \multirow{2}{*}{$\begin{array}{c}\text { Validação } \\
\text { Cruzada }\end{array}$} \\
\hline & Mínimo & Máximo & Média & Variância & Mínimo & Máximo & Média & Variância & \\
\hline Krigagem Ordinária & -1.71 & 0.47 & -0.47 & 0.23 & 0.11 & 0.84 & 0.59 & 0.42 & 0.51 \\
\hline Cokrigagem & -1.87 & 0.47 & -0.47 & 0.22 & 0.13 & 0.81 & 0.55 & 0.4 & 0.44 \\
\hline $\begin{array}{c}\text { Krigagem Ordinária } \\
\text { Combinada com } \\
\text { Regressão Linear }\end{array}$ & -1.36 & 0.47 & -0.57 & 0.12 & 0.11 & 0.61 & 0.44 & 0.35 & 0.28 \\
\hline Turning Bands & -1.39 & 0.32 & -0.51 & 0.14 & 0.17 & 0.8 & 0.51 & 0.37 & 0.55 \\
\hline
\end{tabular}

Com base na discussão dos métodos e nas tabelas 19 e 20, constata-se que:

1- O uso da técnica de desagrupamento aproxima os valores das médias e das medianas populacionais. Ainda, o uso da técnica melhora a estruturação dos modelos variogramas de forma que as variâncias espaciais, a diferença entre o efeito pepita e o patamar, onde o modelo estabiliza, tenham maior influência;

2- Todos os modelos variogramas apresentam comportamento linear próximo da origem, característica inerente ao modelo esférico, ou seja, há grande homogeneidade destes pontos em pequenas distâncias e uma progressiva perda de homogeneidade com o aumento da distância;

3- À exceção do modelo variograma ajustado para o método de simulação por bandas rotativas sem decluster (Figura 53), os demais obtidos pelos outros métodos atingiram o melhor resultado de validação cruzada quando os seus patamares são ajustados para valores muito próximos da variância amostral, nesses casos, a linha que indica essa variância comporta-se como uma assíntota;

4- O método de bandas rotativas com a aplicação da técnica de desagrupamento ou decluster por células apresenta o melhor valor de validação cruzada dentre os métodos testados para a área;

5- A aplicação do histograma dos erros padronizados mostra-se uma boa ferramenta para avaliar preliminarmente o ajuste da vizinhança de busca e a presença de outliers;

6- Buscando-se os melhores resultados para a validação cruzada, a vizinhança de busca por vezes é ajustada com um raio menor que não é capaz de estimar a totalidade da área de interesse. Sendo assim, os mapas de estimativa podem apresentar valores não estimados; 
7- A incerteza associada ao método de krigagem ordinária combinada com regressão linear apresenta valores mais baixos. Isso reflete o significativo aumento de dados e sua distribuição na área de interesse;

8- Com a aplicação do exponencial nos valores de $\log \mathrm{K}$, os valores de condutividade hidráulica mostram-se coerentes com a estatística descritiva para os poços utilizados na área de São Carlos;

9- Em todos mapas de estimativa, observa-se que a região mais a norte apresenta o maior valor de K, coincidindo com o local onde se encontra o poço mais condutivo. Por se tratar de um ponto mais isolado que os demais, a vizinhança de busca ajustada não é capaz de usar outros pontos para estimar a região.

Assume-se que as estimativas dadas pelo método de simulação por bandas rotativas (Figura 57) com a técnica de desagrupamento por células correspondem àquelas que melhor representam a distribuição das condutividades hidráulicas na área de interesse em São Carlos, tendo em vista os resultados obtidos com a validação cruzada. Na figura 58, o mapa das estimativas por esse método (figura 58A) é comparado com os mapas geológico desenvolvido por esse trabalho se baseando nas descrições das amostras dos poços instalados na área (Figura 58B), topográfico (Figura 58C) e no potenciométrico (Figura 58D). 


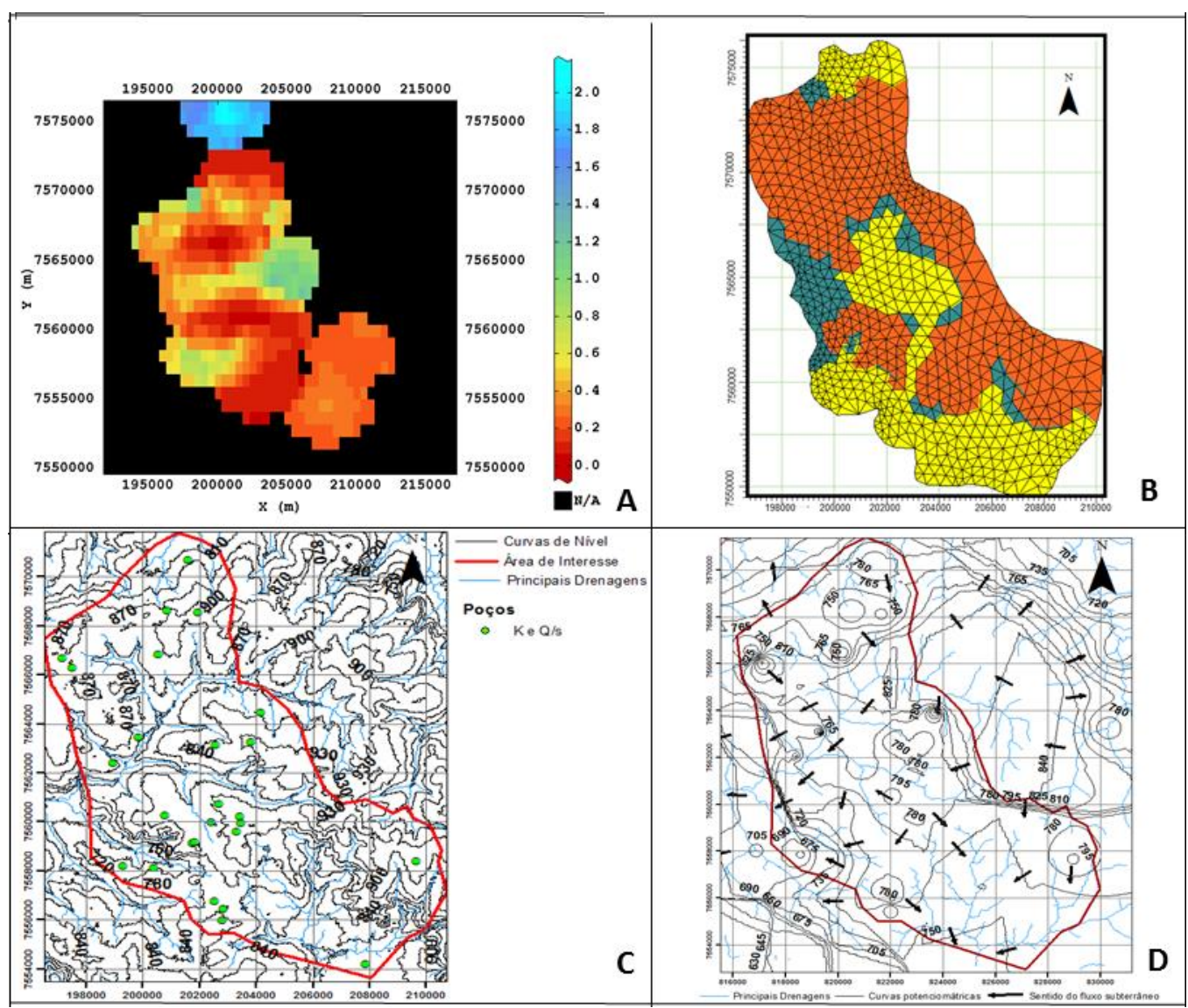

Figura 58: Mapas comparativos entre a distribuição dos valores estimados de condutividade hidráulica (A), pelo método de bandas rotativas, a geologia inferida com base nas descrições dos poços $(B)$, topografia $(C)$ e potenciométrico na área de interesse de São Carlos.

Exceto pela parte mais a norte no mapa de estimativa, onde está a região de maior condutividade hidráulica, os quatro mapas representam a mesma área em São Carlos. Os valores de condutividade mais elevados estão na zona leste da área, onde o SAG aparece abaixo das Formações Adamantina e Serra Geral. Nessa região, o basalto apresenta espessura média 150 m. Nas áreas onde o SAG aflora, o parâmetro hidráulico de interesse varia entre valores próximos de zero e $0.6 \mathrm{~m} /$ dia. O SAG aflora ao norte e se apresenta muito pouco condutivo, enquanto, nas zonas SW e central, os valores de K chegam a 0.6 m/d.

Com base na comparação dos mapas 58A e 58B apresentados na figura 58, não é possível definir um padrão nos valores de K para a área estudada em São Carlos. Entretanto, observa-se que os valores desse parâmetro hidráulico apresentam aumento significativo onde os corpos d'água superficiais estão encaixados (Figura 58C). Isso indica que os sedimentos dos leitos dessas drenagens apresentam maior condutividade.

Relacionando as distâncias entre as curvas potenciométricas (Figura 58D) e o mapa de estimativas de condutividade hidráulica (Figura 58A), observa-se que os valores desse parâmetro hidráulico apresentam valores maiores onde as curvas são mais espaçadas. Mais especificamente ao sul, onde os valores de $\mathrm{K}$ variam entre 0.2 e $0.4 \mathrm{~m} / \mathrm{dia}$, e em duas áreas mais 
ao centro, onde estão os dois principais corpos d'água da área de estudo, sendo esses o Rio Monjolinho, mais ao norte, e o córrego do Gregório, no centro. Esse segundo tem a sua foz no primeiro. Os valores dessa região variam de 0.5 a $0.7 \mathrm{~m} /$ dia.

\subsubsection{SAB: Bauru}

Inicialmente, são apresentados os resultados e as discussões dos métodos de interpolação estatística, tais como a krigagem ordinária, krigagem ordinária combinada com regressão linear e cokrigagem, e, na sequência, o método estocástico bandas rotativas. Posteriormente, ainda nessa seção, há uma análise comparativa dos principais resultados de cada método e a decisão de qual melhor preenche a área em Bauru com valores de condutividade hidráulica (K).

\subsubsection{Krigagem ordinária}

O método de krigagem ordinária aplicado na área de interesse na cidade de Bauru usa 69 poços que apresentam valores de condutividade hidráulica $(K)$ distribuídos em uma área de aproximadamente 14 x $10 \mathrm{~km}$, como visto na figura 59 .

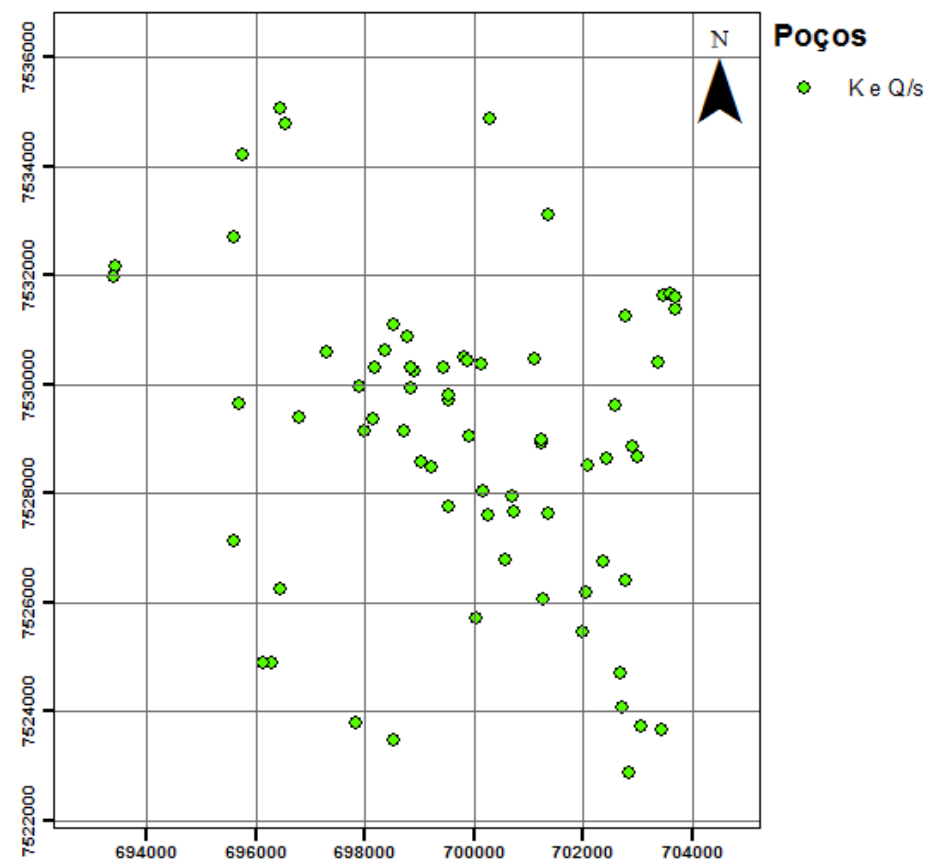

Figura 59: Distribuição dos poços que apresentam informações sobre os valores de condutividade hidráulica $(K)$ e capacidade específica $(Q / s)$ na cidade de Bauru. 
Na tabela 21 são apresentadas as estatísticas descritivas dos dados sem e com aplicação da técnica de desagrupamento. Embora os parâmetros estatísticos apresentem comportamento semelhante, a variância é reduzida com a aplicação da técnica o que reflete diretamente no variograma.

Tabela 21: Krigagem ordinária: estatística descritiva dos valores de log $K$ sem e com decluster dos poços estudados na cidade de Bauru, SAB.

\begin{tabular}{|l|c|c|}
\hline \multirow{2}{*}{ Parâmetros } & \multicolumn{2}{|c|}{$\log \mathrm{K}(\mathrm{m} / \mathrm{d})$} \\
\cline { 2 - 3 } & Sem Decluster & Com Decluster \\
\hline Média & -1.86 & -1.85 \\
\hline Mediana & -1.87 & -1.89 \\
\hline $\begin{array}{l}\text { Desvio } \\
\text { padrão }\end{array}$ & 0.36 & 0.32 \\
\hline Variância & 0.6 & 0.57 \\
\hline Intervalo & 3.82 & 3.82 \\
\hline Mínimo & -3.88 & -3.88 \\
\hline Máximo & -0.06 & -0.06 \\
\hline Contagem & 69 & 69 \\
\hline
\end{tabular}

Pelo variograma experimental, define-se que o valor do passo ou lag é de $700 \mathrm{~m}$ e usados 10 desses para o variograma sem decluster e sete para o que trata os dados com a aplicação da técnica.

$\mathrm{Na}$ figura 60 são apresentados os variogramas modelados para os dados sem e com decluster. Os elementos desses modelos ajustados são detalhados na tabela 22. Em ambos os variogramas, os patamares se ajustam melhor acima da linha da variância amostral. O modelo variograma referente aos dados com decluster apresentam melhor estruturação, com maior variância espacial e amplitude.

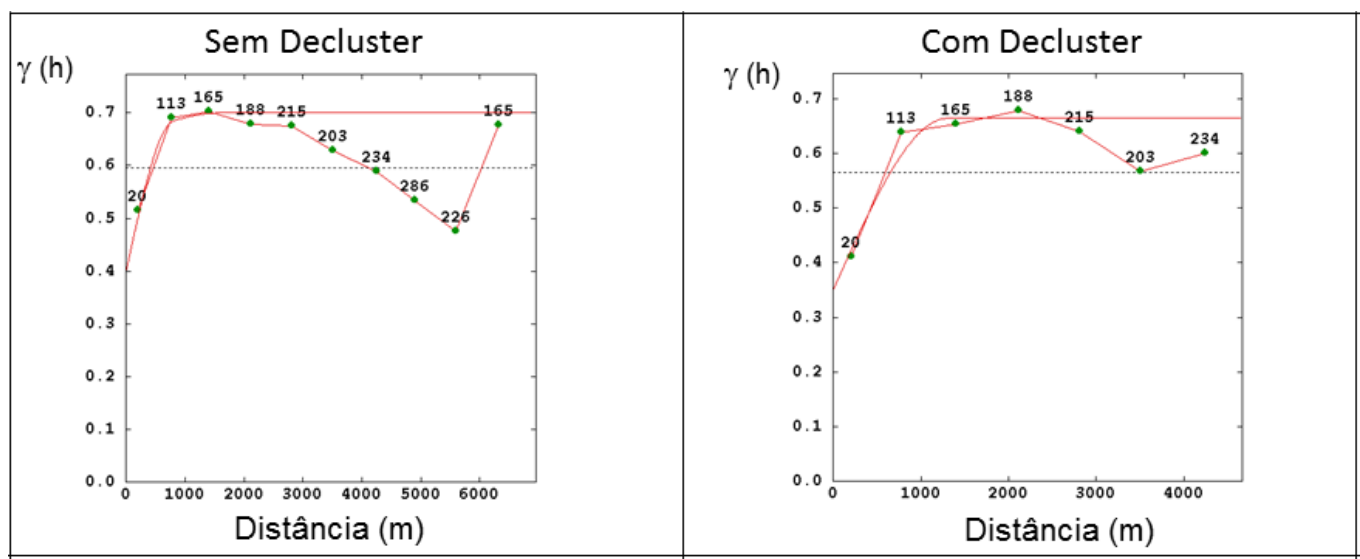

Figura 60: Krigagem ordinária: variogramas modelados sem e com aplicação da técnica de desagrupamento por célula da área de estudo de Bauru, SAB. A linha tracejada representa a variância amostral. 
Tabela 22: Krigagem ordinária: variogramas modelados sem e com aplicação da técnica de desagrupamento por célula da área de estudo de Bauru, SAB. A linha tracejada representa a variância amostral.

\begin{tabular}{|l|c|c|}
\hline $\begin{array}{c}\text { Elementos } \\
\text { do } \\
\text { variograma }\end{array}$ & $\begin{array}{c}\text { Sem } \\
\text { decluster }\end{array}$ & $\begin{array}{c}\text { Com } \\
\text { decluster }\end{array}$ \\
\hline Modelo & Esférico & Esférico \\
\hline Efeito pepita & 0.4 & 0.35 \\
\hline Amplitude & 800 & 1300 \\
\hline Patamar & 0.25 & 0.29 \\
\hline
\end{tabular}

A figura 61 apresenta a validação cruzada e o histograma de erros padronizados para os dados sem e com a aplicação da técnica de decluster. Nela, observa-se que o modelo que melhor se adéqua para a estimativa é a com a aplicação da técnica de desagrupamento, que, no caso é com o decluster. Com base no variograma de erros padronizados, verifica-se que a vizinhança não está ajustada de forma que todos os pontos sejam re-estimados na validação cruzada, pois conseguiu re-estimar 64 dos 69 poços. Outra constatação, não são identificados outliers para ambos os casos.

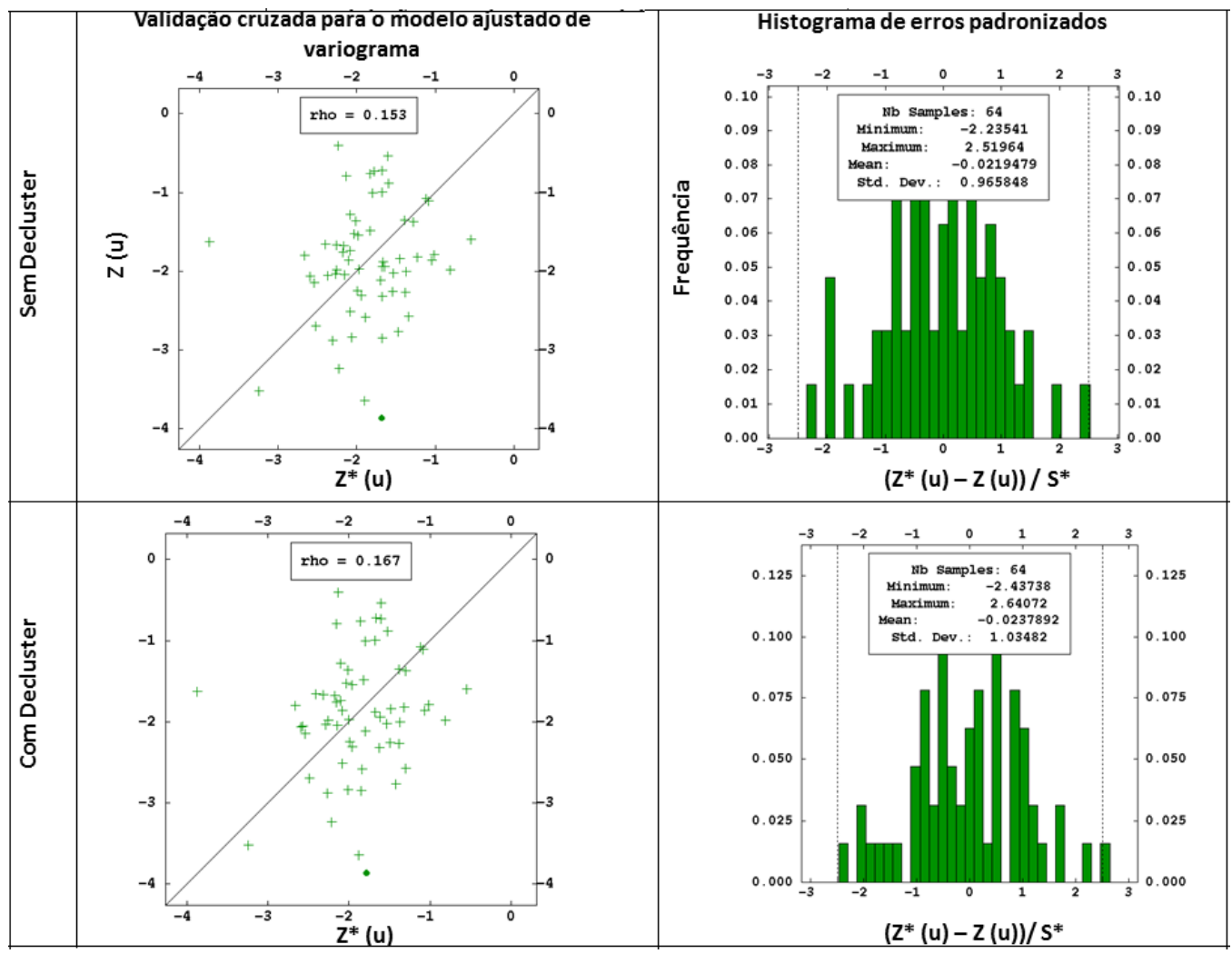

Figura 61: Krigagem Ordinária: Validação cruzada e histogramas de erros padronizados sem e com aplicação da técnica de desagrupamento ou decluster por célula da área de estudo de Bauru, SAB. 
Com os modelos variogramas definidos, o método da krigagem ordinária é aplicado para estimar os pontos não amostrados. O mapa das estimativas e das incertezas ou variância de krigagem são mostrados na figura 62. Na forma de histograma, a distribuição desses resultados é apresentada na figura 63. Os valores estimados com os dados sem decluster varia de -3.53 a 0.41, com média - 1.86 e a incerteza associada ao método varia de 0.32 a 0.94 , com média 0.71 . Com decluster, essas estimativas variam no mesmo intervalo e apresentam a mesma média. No entanto, apresentam menor incerteza, com valores que variam de 0.29 a 0.95 e média de 0.68 .

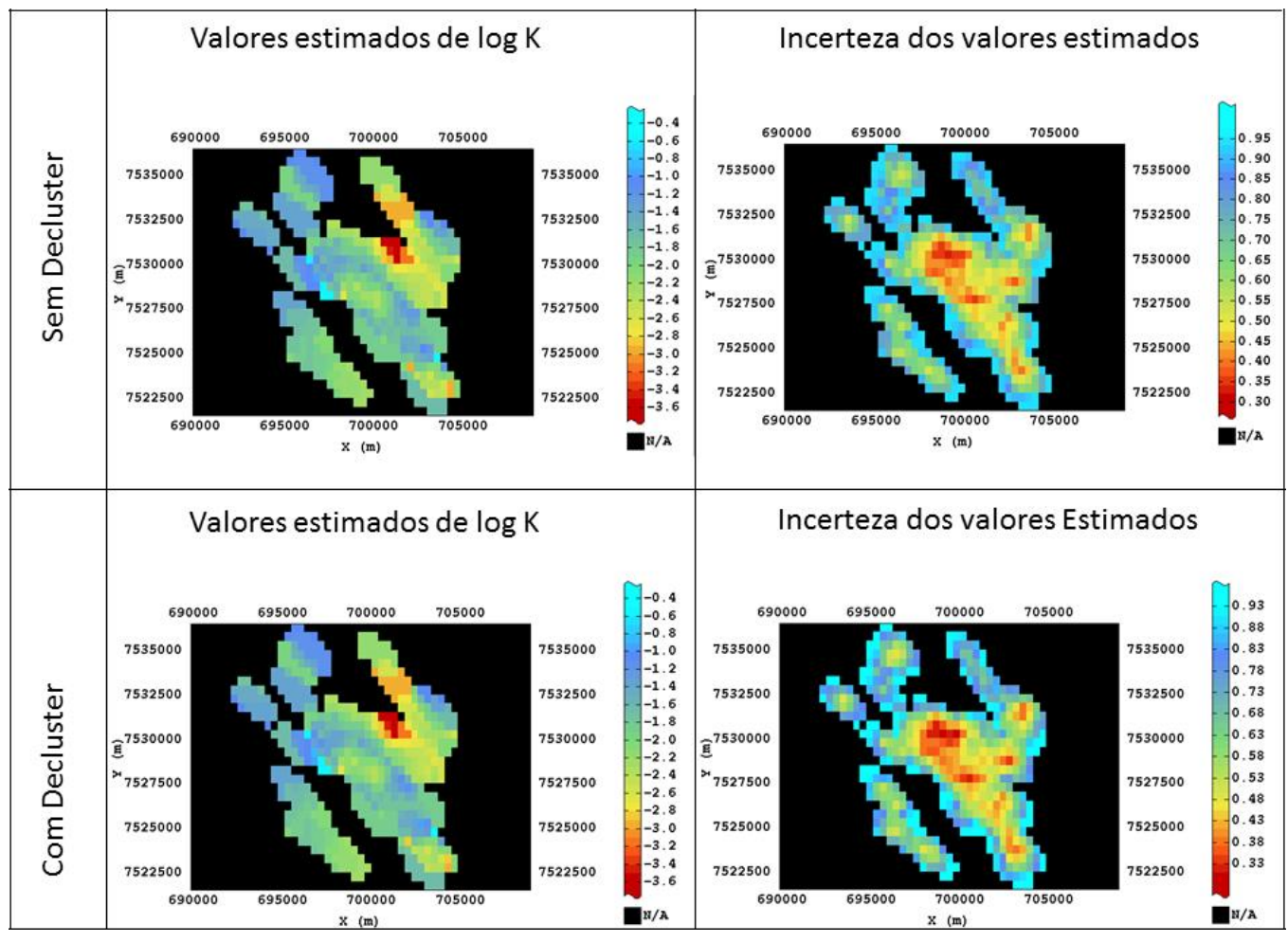

Figura 62: Krigagem Ordinária: Mapas das estimativas e de incerteza associada ao método sem e com aplicação da técnica de desagrupamento por célula da área de estudo de Bauru, SAB. 


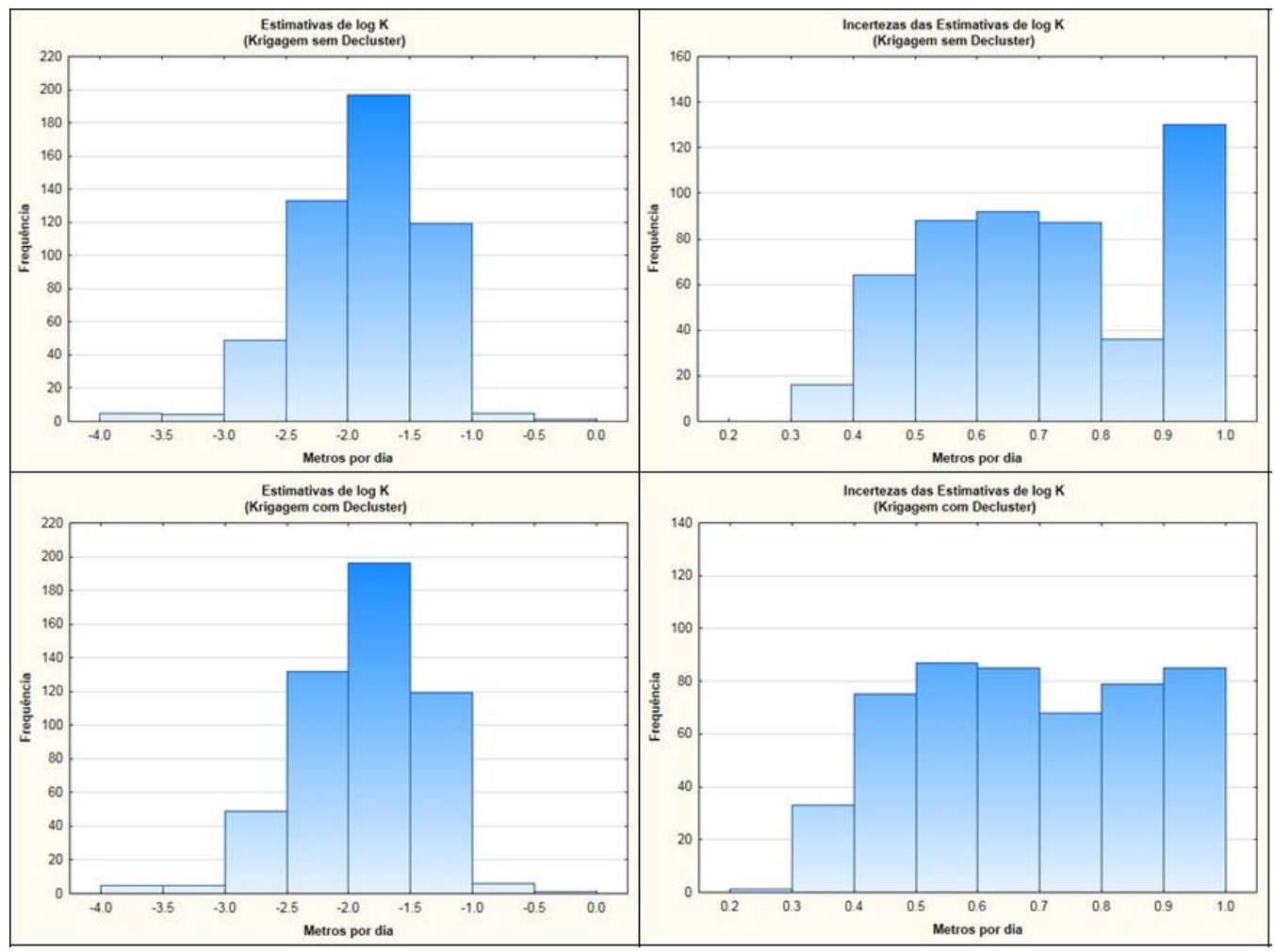

Figura 63: Krigagem Ordinária: Histogramas das estimativas e de incerteza associada ao método sem e com aplicação da técnica de desagrupamento ou Decluster por célula da área de estudo de Bauru, SAB.

A figura 64 apresenta os mapas das estimativas de log $\mathrm{K}$ convertidos em condutividade hidráulica e a distribuição desses valores. Esses valores variam na faixa de 0.02 a $0.39 \mathrm{~m} / \mathrm{dia}$ e uma média $0.03 \mathrm{~m} /$ dia. Segundo a estatística descritiva apresentada na tabela 7 , esses valores são próximos dos esperados para a área de Bauru. 


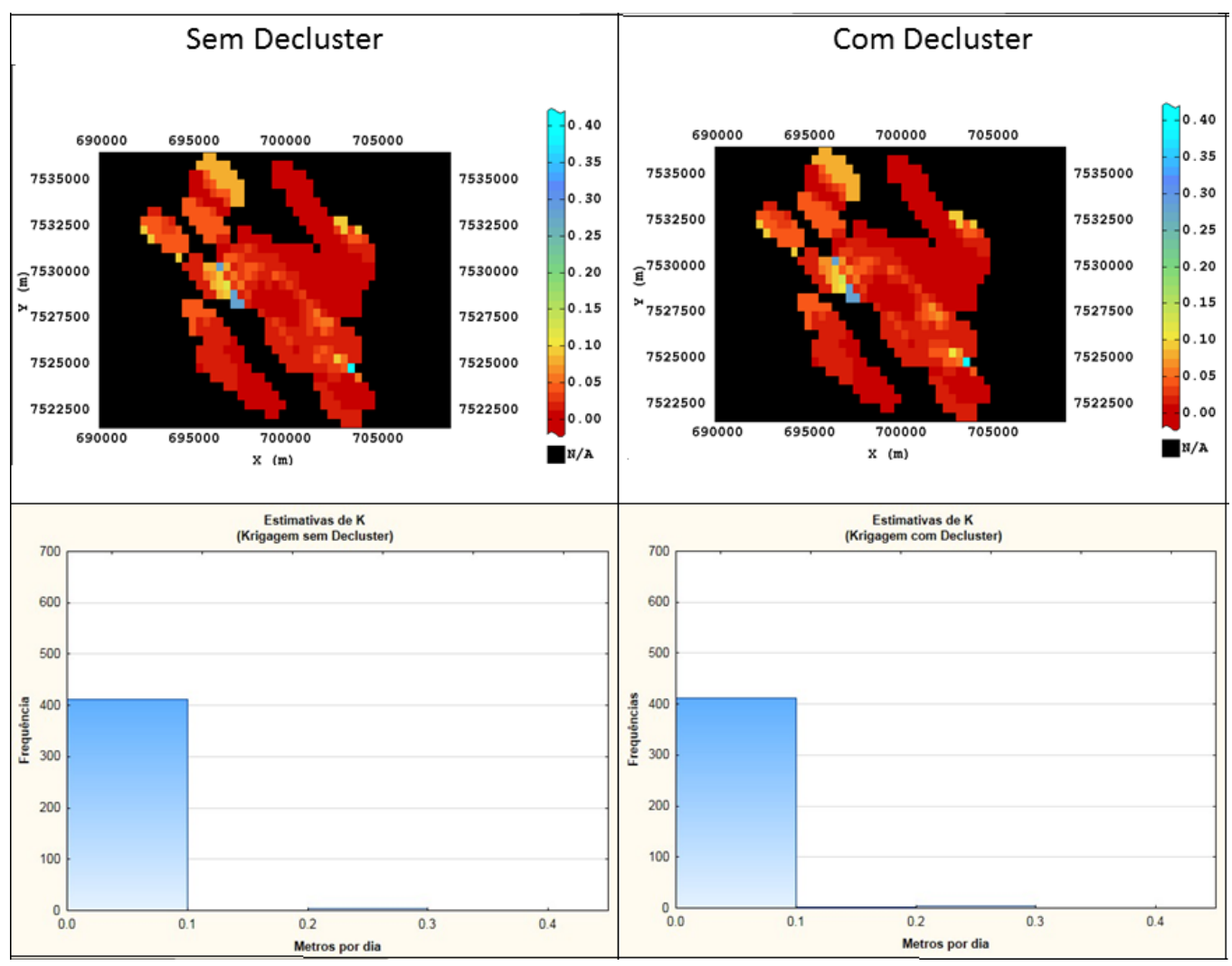

Figura 64: Krigagem ordinária: Mapas e histogramas das estimativas sem e com aplicação da técnica de desagrupamento por célula da área de estudo de Bauru, SAB.

Com base na validação cruzada, o uso do decluster apresentou ligeira vantagem, se comparado com o mesmo método geoestatístico sem a sua aplicação.

\subsubsection{Krigagem ordinária combinada com regressão linear}

Com a aplicação da equação (83) poços que possuíam apenas valores de capacidade específica, passaram a apresentar valores inferidos de condutividade hidráulica. O número de dados que era 69 inicialmente aumenta para 343 na mesma área de aproximadamente de $14 \mathrm{x}$ $10 \mathrm{~km}$. A figura 65 mostra a distribuição espacial desses poços na área de estudo em São Carlos. 


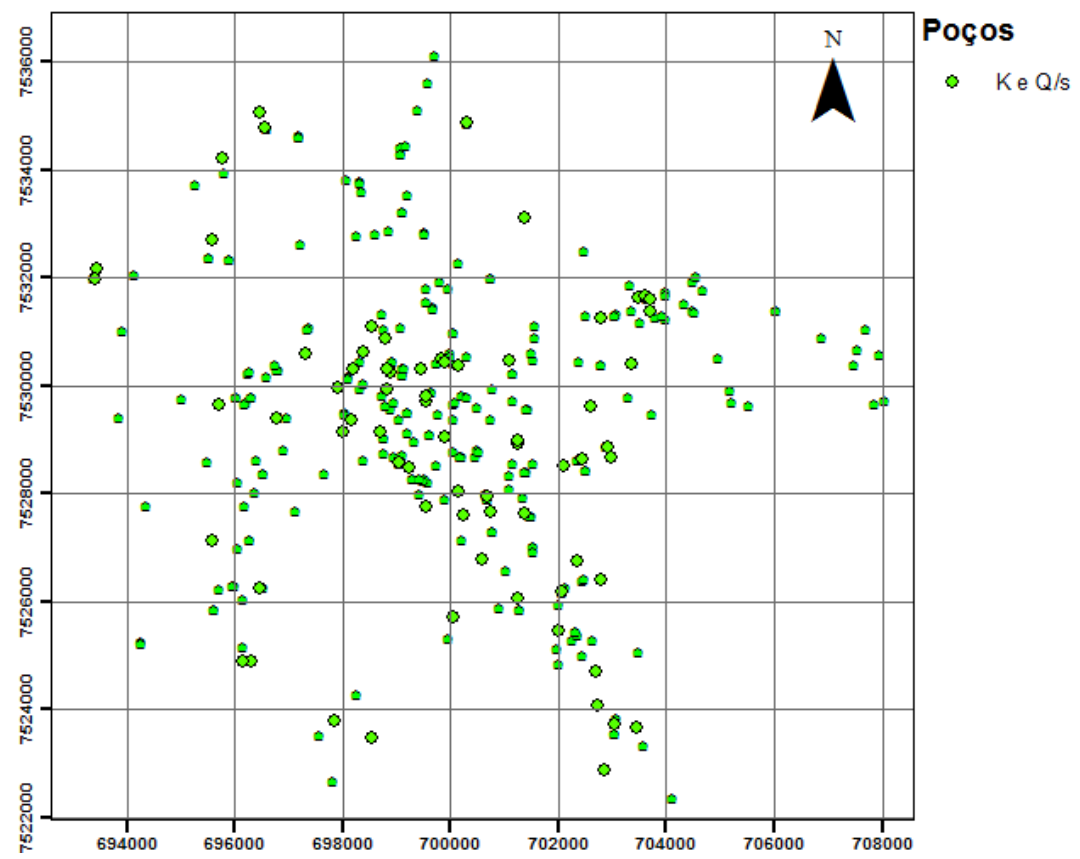

Figura 65: Krigagem ordinária combinada com regressão linear: Distribuição dos poços que apresentam informações sobre os valores de condutividade hidráulica $(K)$ e capacidade específica $(Q /$ s) em Bauru.

A estatística descritiva dos dados usados no presente método sem e com decluster é sumariada na tabela 23. Embora os valores de máximo e mínimo não tenham se alterado, observa-se diminuição na variância, média e mediana. Comparando com a tabela 22, o uso da equação (83) faz com que, mesmo mantendo os valores de máximo e mínimo, as variâncias amostrais diminuam. Esse comportamento é observado tanto nos casos em que se usa o desagrupamento quanto nos que essa técnica está ausente.

Tabela 23: Krigagem ordinária combinada com regressão linear: Estatística descritiva dos valores de log $K$ sem e com decluster dos poços estudados na cidade de Bauru, SAB.

\begin{tabular}{|l|c|c|}
\hline \multirow{2}{*}{$\begin{array}{c}\text { Parâmetr } \\
\text { os }\end{array}$} & \multicolumn{2}{|c|}{$\log \mathrm{K}(\mathrm{m} / \mathrm{d})$} \\
\cline { 2 - 3 } & Sem Decluster & Com Decluster \\
\hline Média & -1.7 & -1.68 \\
\hline Mediana & -1.74 & -1.7 \\
\hline $\begin{array}{l}\text { Desvio } \\
\text { padrão }\end{array}$ & 0.62 & 0.06 \\
\hline Variância & 0.38 & 0.24 \\
\hline Intervalo & 4.49 & 4.49 \\
\hline Mínimo & -3.88 & -3.88 \\
\hline Máximo & 0.61 & 0.61 \\
\hline Contagem & 343 & 343 \\
\hline
\end{tabular}


Com base no variograma experimental, os valores dos passos atribuídos os dados sem e com decluster são 500 e 700 m, respectivamente. Para o primeiro são usados dez passos e, no segundo, sete.

Os variogramas modelados sem e com decluster são vistos na figura 66. Os elementos desses modelos ajustados são detalhados na tabela 24. Para o modelo dos dados sem decluster, o patamar mostra melhor ajuste quando esse está próximo do valor da variância amostral, diferentemente do modelo com decluster, em que o melhor ajuste é feito quando o patamar está acima dessa linha. O modelo com decluster apresenta melhor estruturação. Sua variância espacial é maior, no entanto, a maior amplitude faz com que o variograma seja melhor modelado. Outra consideração a ser feita é a diminuição no número de pares em cada passo nesse modelo.

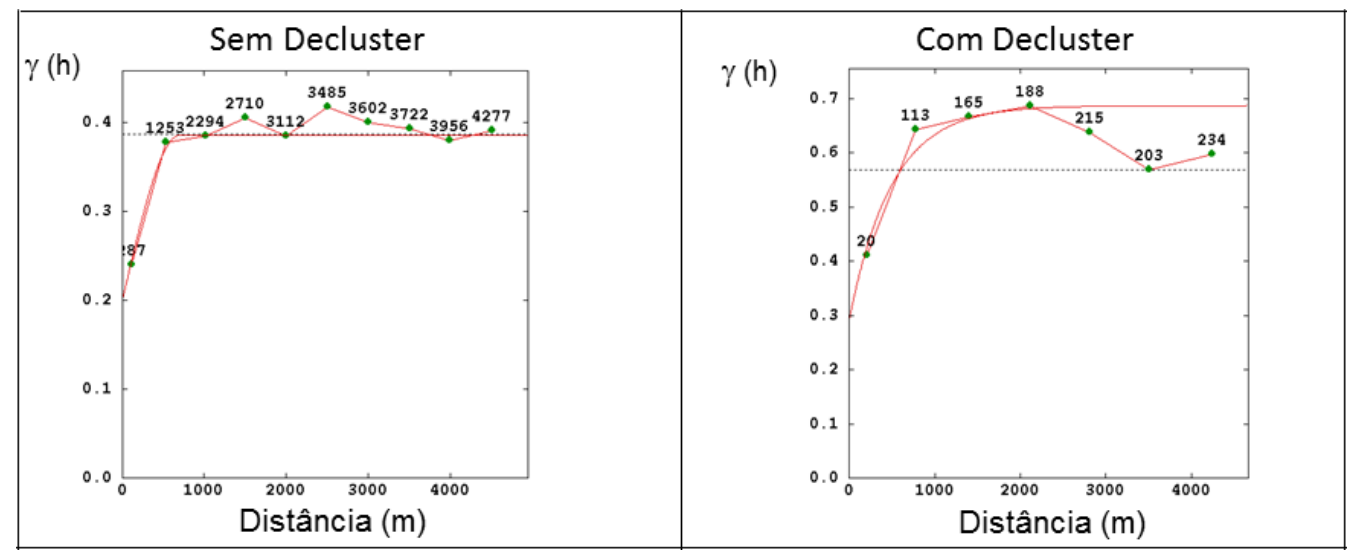

Figura 66: Krigagem Ordinária combinada com regressão linear: variogramas modelados sem e com aplicação da técnica de desagrupamento por célula da área de estudo de Bauru, SAB. A linha tracejada representa a variância amostral.

Tabela 24: Elementos do modelo do variograma para os dados sem e com o uso da técnica de desagrupamento.

\begin{tabular}{|l|c|c|}
\hline $\begin{array}{c}\text { Elementos } \\
\text { do } \\
\text { variograma }\end{array}$ & $\begin{array}{c}\text { Sem } \\
\text { decluster }\end{array}$ & $\begin{array}{c}\text { Com } \\
\text { decluster }\end{array}$ \\
\hline Modelo & Esférico & Esférico \\
\hline Efeito pepita & 0.2 & 0.293 \\
\hline Amplitude & 700 & 1500 \\
\hline Patamar & 0.186 & 0.3941 \\
\hline
\end{tabular}

Na figura 66 são apresentados a validação cruzada e o histograma de erros padronizados dos variogramas dos dados sem e com desagrupamento. Ambos indicam que no caso em que o 
decluster foi aplicado, o modelo é mais acurado. Embora, o histograma mostre que há outliers para ambos os casos, a média mais próxima de zero e o desvio-padrão mais próximo de um mostram uma vizinhança bem ajustada quando essa técnica é utilizada na presente configuração.

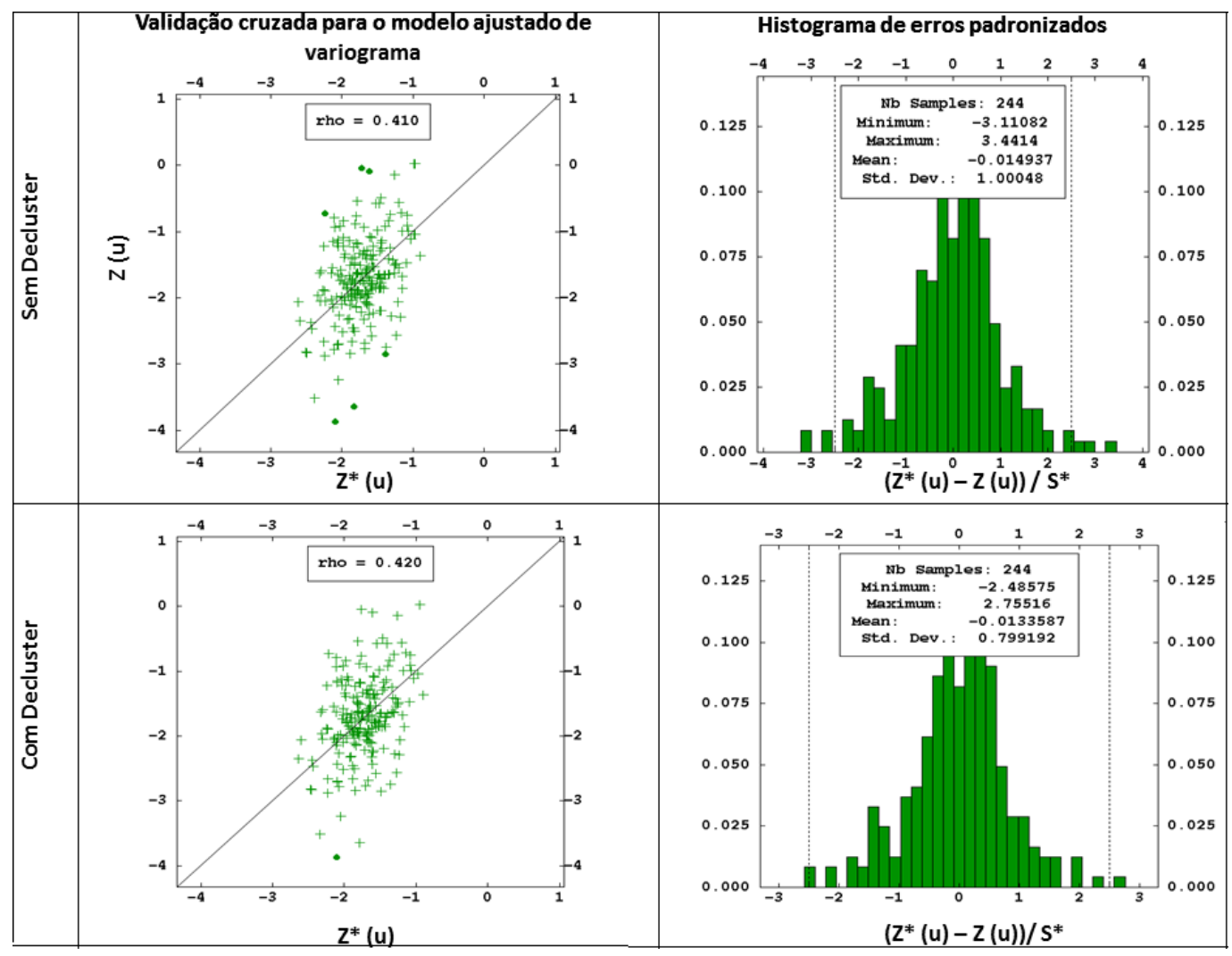

Figura 67: Krigagem Ordinária combinada com regressão linear: Validação cruzada $e$ histogramas de erros padronizados sem e com aplicação da técnica de desagrupamento ou decluster por célula da área de estudo de Bauru, SAB.

Com os modelos variogramas definidos, o método da krigagem ordinária é aplicado para estimar os pontos não amostrados. O mapa das estimativas e das incertezas ou variância de krigagem são mostrados na figura 68. Na forma de histograma, a distribuição desses resultados é apresentada na figura 69. No caso das figuras que retratam os resultados dos métodos sem desagrupamento, as estimativas variam de -2.5 a -0.62 com média -1.7 , e a variância de krigagem ou incerteza de 0.15 a 0.54 com média 0.32 . Enquanto com a aplicação do decluster, as estimativas apresentam um valor mínimo de -3.88 e o máximo de -0.06 , com média -1.84 . Para a sua incerteza associada, a variação é de 0.19 a 0.67 e média 0.38 . 


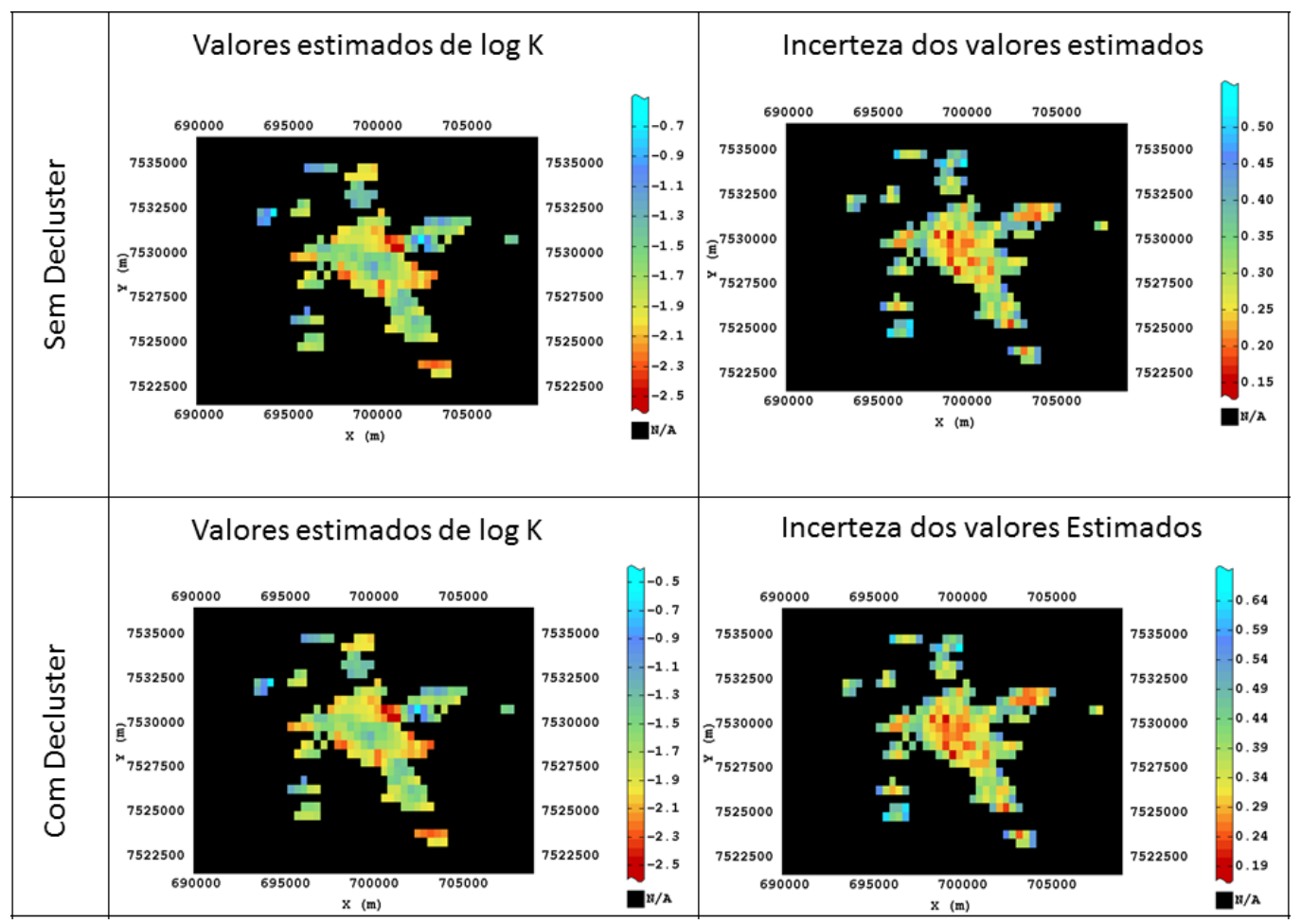

Figura 68: Krigagem ordinária combinada com regressão linear: mapas das estimativas e de incerteza associada ao método sem e com aplicação da técnica de desagrupamento por célula da área de estudo de Bauru, SAB.

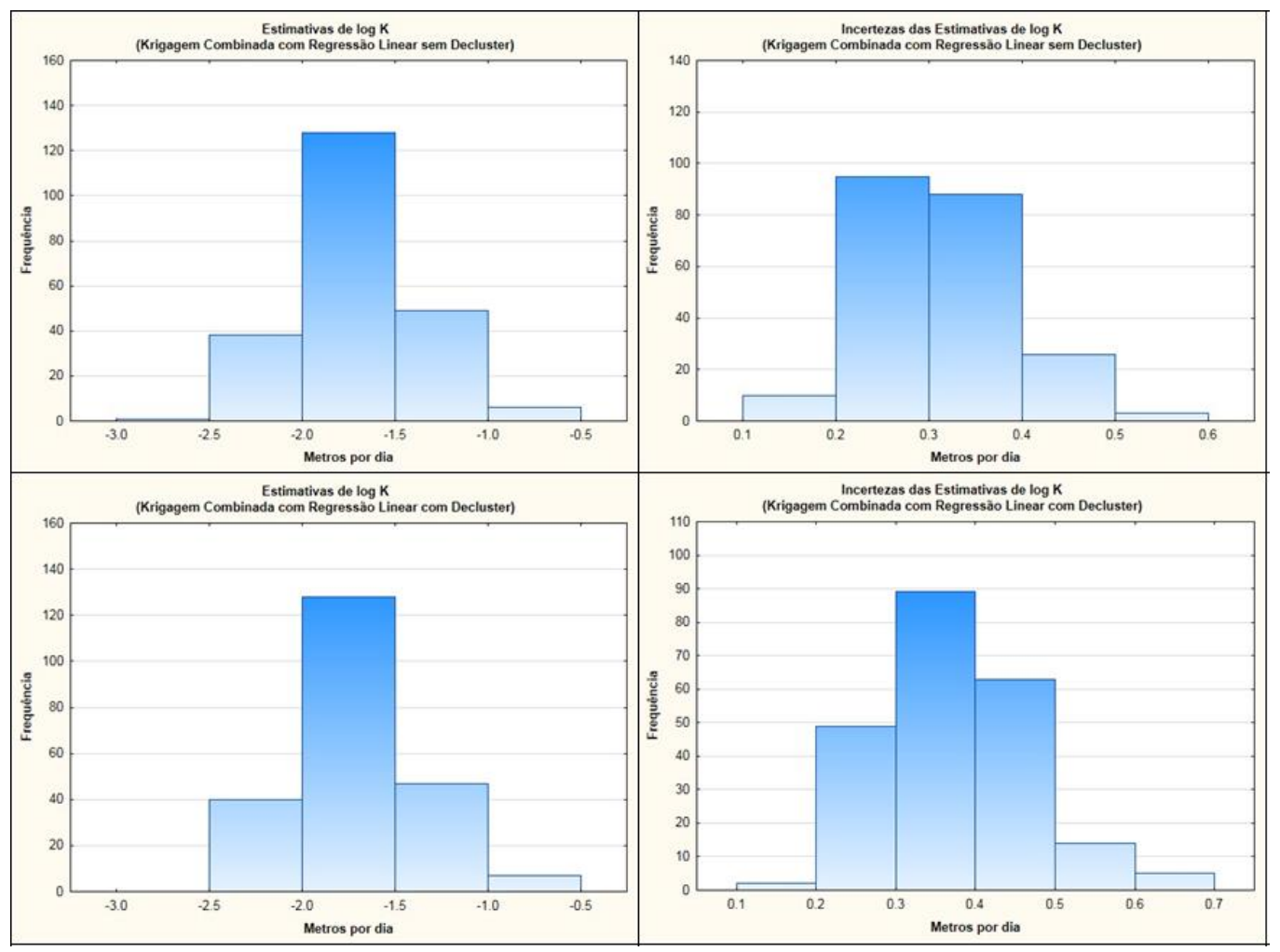

Figura 69: Krigagem ordinária combinada com regressão linear: histogramas das estimativas e de incerteza associada ao método sem e com aplicação da técnica de desagrupamento por célula da área de estudo de Bauru, SAB. 
Os valores das estimativas de log $\mathrm{K}$ convertidos em valores de condutividade hidráulica são apresentados em forma de mapas e variogramas para ambos os casos, figura 70. Os valores das estimativas apresentam valores baixos, sendo que o método sem aplicação do decluster, os valores variam de 0.01 a $0.24 \mathrm{~m} /$ dia e média $0.03 \mathrm{~m} /$ dia. Para estimativas quando a técnica de desagrupamento é aplicada, esses valores variam de 0.01 a 0.26 , com média de 0.03 .

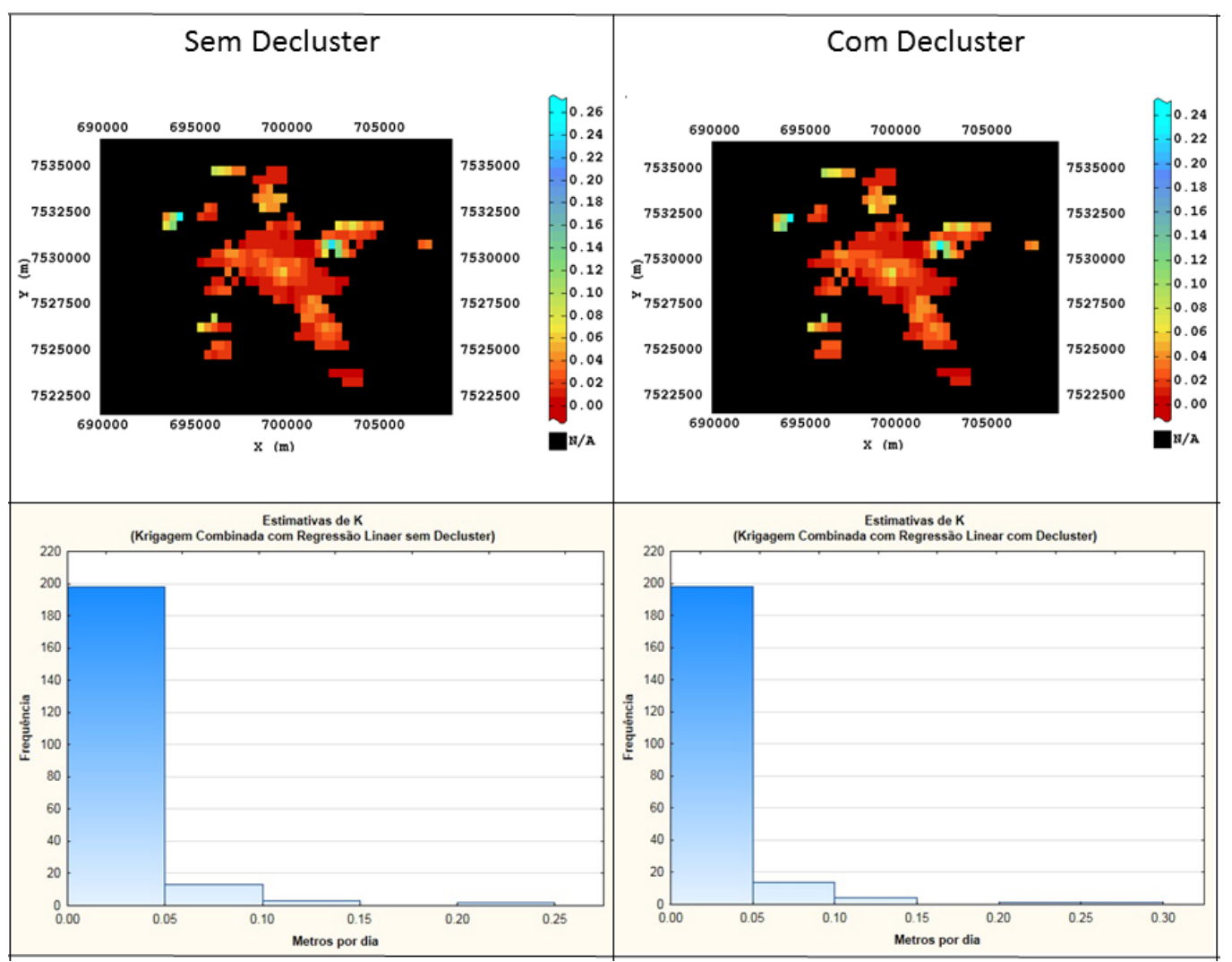

Figura 70: Krigagem ordinária combinada com regressão linear: mapas e histogramas das estimativas sem e com aplicação da técnica de desagrupamento por célula da área de estudo de Bauru, SAB.

Para a área de estudo em Bauru, o método de krigagem ordinária combinada com regressão linear se mostra melhor com o uso do decluster.

\subsubsection{Cokrigagem}

$\mathrm{Na}$ aplicação do método geoestatístico da cokrigagem na área de interesse da cidade Bauru, são usados 67 poços que apresentam valores de $\mathrm{K}$ e $\mathrm{Q} / \mathrm{s}$, sendo a condutividade hidráulica a variável primária, e outros 343 que apresentam somente valores de capacidade específica, que é a variável secundária. A distribuição espacial desses poços está apresentada na figura 71 , onde os pontos verdes representam a localização dos poços com valores de $\mathrm{K}$ e os 
pontos pretos mostram os locais dos poços que possuem informação somente da variável secundária.

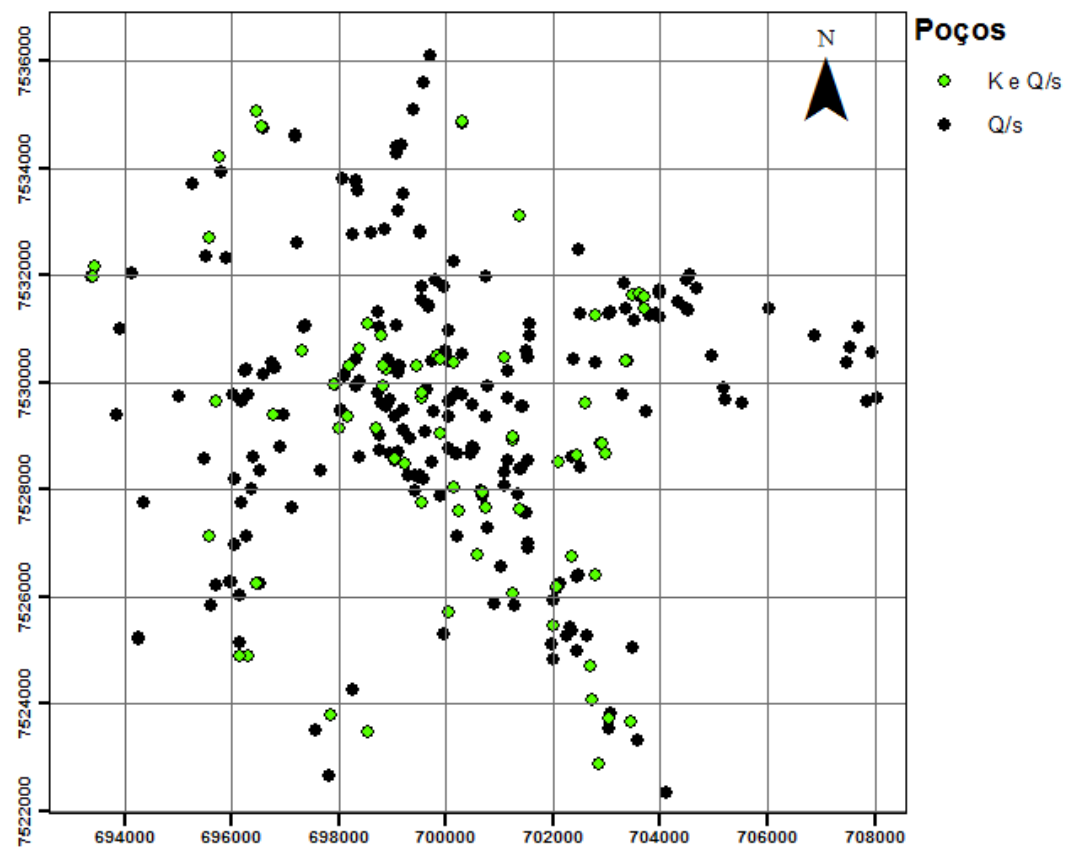

Figura 71: Cokrigagem: Distribuição dos poços que apresentam informações sobre os valores de condutividade hidráulica $(K)$ e capacidade específica $(Q / s)$ em Bauru.

A tabela 25 mostra a estatística descritiva para os valores de $\log \mathrm{K}$ e $\log \mathrm{Q} / \mathrm{s}$ sem e com aplicação da técnica de desagrupamento ou decluster. A estatística para os valores de log K são as mesmas discutidas na tabela 21, para krigagem ordinária. Analisando as estatísticas dos valores de $\log \mathrm{Q} / \mathrm{s}$, verifica-se que a aplicação do decluster elevou a mediana a média e diminuiu a variância. Os valores de máximo e mínimo são mantidos com o uso do decluster.

Tabela 25: Estatística descritiva dos valores de log $K$ sem e com decluster dos poços estudados na cidade de Bauru, SAB.

\begin{tabular}{|l|c|c|c|c|}
\hline \multirow{2}{*}{ Parâmetros } & \multicolumn{2}{|c|}{$\log \mathrm{K}(\mathrm{m} / \mathrm{d})$} & \multicolumn{2}{c|}{$\log \mathrm{Q} / \mathrm{s}(\mathrm{m} 2 / \mathrm{d})$} \\
\cline { 2 - 5 } & Sem Decluster & Com Decluster & Sem Decluster & Com Decluster \\
\hline Média & -1.86 & -1.85 & 0.64 & 0.67 \\
\hline Mediana & -1.87 & -1.89 & 0.59 & 0.63 \\
\hline $\begin{array}{l}\text { Desvio } \\
\text { padrão }\end{array}$ & 0.78 & 0.32 & 0.49 & 0.52 \\
\hline Variância & 0.6 & 0.57 & 0.24 & 0.23 \\
\hline Intervalo & 3.82 & 3.82 & 3.66 & 3.66 \\
\hline Mínimo & -3.88 & -3.88 & -1.02 & -1.02 \\
\hline Máximo & -0.06 & -0.06 & 2.64 & 2.64 \\
\hline Contagem & 69 & 69 & 343 & 343 \\
\hline
\end{tabular}


No variograma experimental é definido o valor de $650 \mathrm{~m}$ de passo para os dados sem o decluster e $700 \mathrm{~m}$ para os com a técnica. A figura 72 apresenta os variogramas experimentais modelados. Como discutido na revisão dos métodos, o método de cokrigagem requer um variograma cruzado. Para que esse seja ajustado, há uma condição para que o determinante da matriz de correginalização não seja negativo e inviabilize a aplicação do método. Para que essa condição seja satisfeita os valores dos patamares dos variogramas individuais de $\log \mathrm{K}$ e $\log$ Q/s multiplicados devem ser maiores que o valor do patamar do variograma cruzado multiplicado por ele mesmo. A configuração que melhor satisfez essa condição e atingiu maior valor de validação cruzada está na tabela 26. Nela, observam-se que os valores de amplitude são constantes nos variogramas dos dados sem e com decluster. No caso em que a técnica da desagrupamento não é aplicada, a amplitude é mais alta, $1.200 \mathrm{~m}$, que quando essa não é utilizada nos dados. Os valores dos patamares que melhor se ajustaram são aqueles muito próximos dos valores das suas variâncias amostrais.

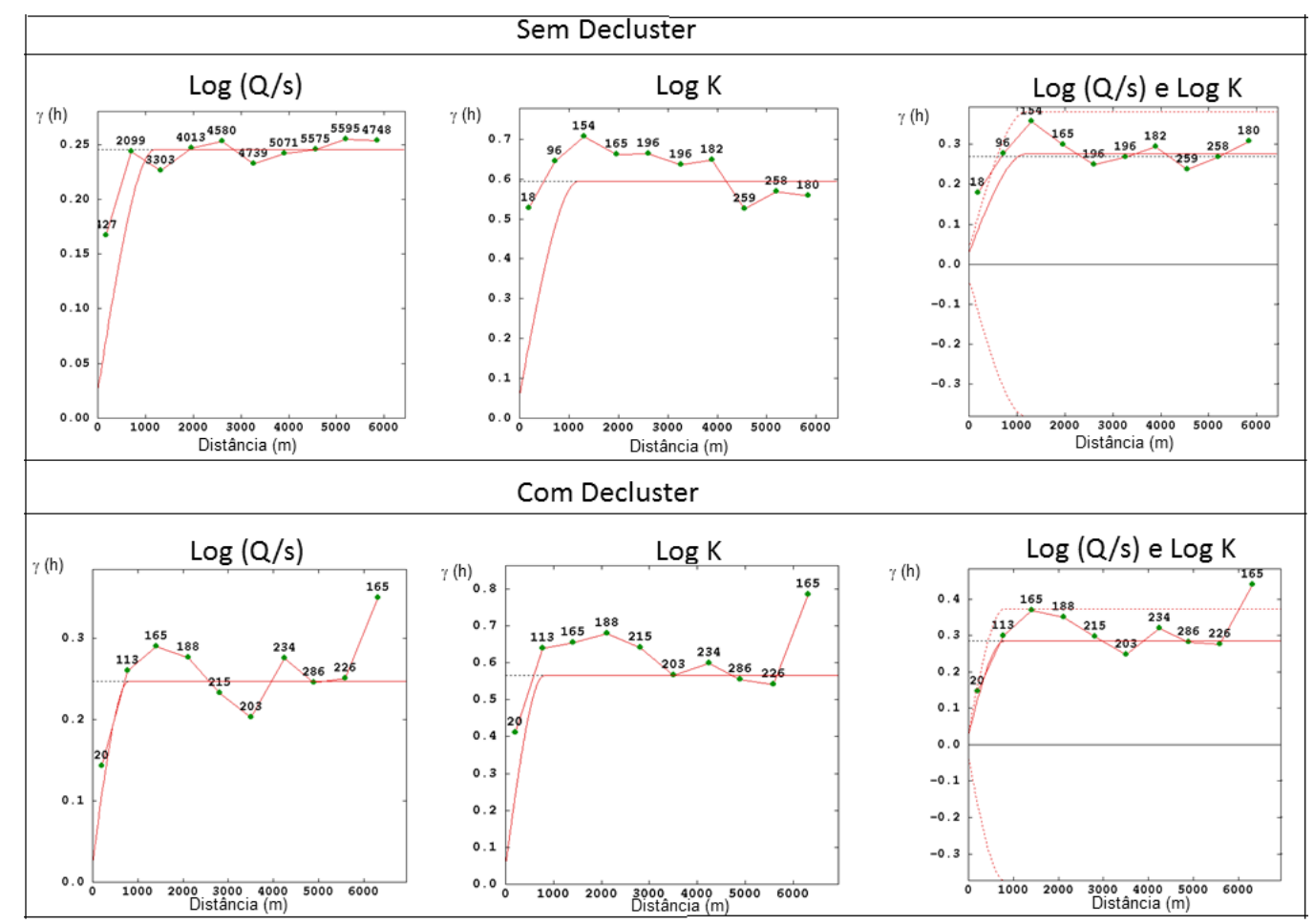

Figura 72: Cokrigagem: Variogramas cruzados modelados sem e com aplicação da técnica de desagrupamento ou Decluster por célula da área de estudo de Bauru, SAB. A linha tracejada representa a variância amostral. 
Tabela 26: Elementos do modelo do variograma para os dados sem e com o uso da técnica de desagrupamento.

\begin{tabular}{|l|c|c|c|c|c|c|}
\hline \multirow{2}{*}{$\begin{array}{c}\text { Elementos } \\
\text { do } \\
\text { variograma }\end{array}$} & \multicolumn{3}{|c|}{ Sem decluster } & \multicolumn{3}{c|}{ Com decluster } \\
\cline { 2 - 7 } & $\log \mathrm{Q} / \mathrm{s}$ & $\log \mathrm{K}$ & $\begin{array}{c}\text { Log Q/s e } \\
\log \mathrm{K}\end{array}$ & $\log \mathrm{Q} / \mathrm{s}$ & $\log \mathrm{K}$ & $\begin{array}{c}\text { Log Q/s e } \\
\log \mathrm{K}\end{array}$ \\
\hline Modelo & Esférico & Esférico & Esférico & Esférico & Esférico & Esférico \\
\hline $\begin{array}{l}\text { Efeito } \\
\text { pepita }\end{array}$ & 0.0545 & 0.02455 & 0.2768 & 0.05648 & 0.0247 & 0.0285 \\
\hline Amplitude & 1200 & 1200 & 1200 & 800 & 800 & 800 \\
\hline Patamar & 0.5354 & 0.221 & 0.2491 & 0.5083 & 0.2224 & 0.2565 \\
\hline
\end{tabular}

A figura 73 mostra a validação cruzada e o histograma dos erros padronizados para os dados de $\log \mathrm{K}$ sem e com decluster. Nela, observa-se que o modelo com o decluster apresentou um valor menor na validação e os valores da média e desvio padrão são mais próximos de e zero e um, respectivamente, no histograma. No entanto, usando os modelos variogramas e a vizinhança de busca propostos para esse método na área de estudo do SAG, nem todos os valores foram re-estimados na validação cruzada, como visto nos histogramas dos erros padronizados. Ainda, são detectados outliers.

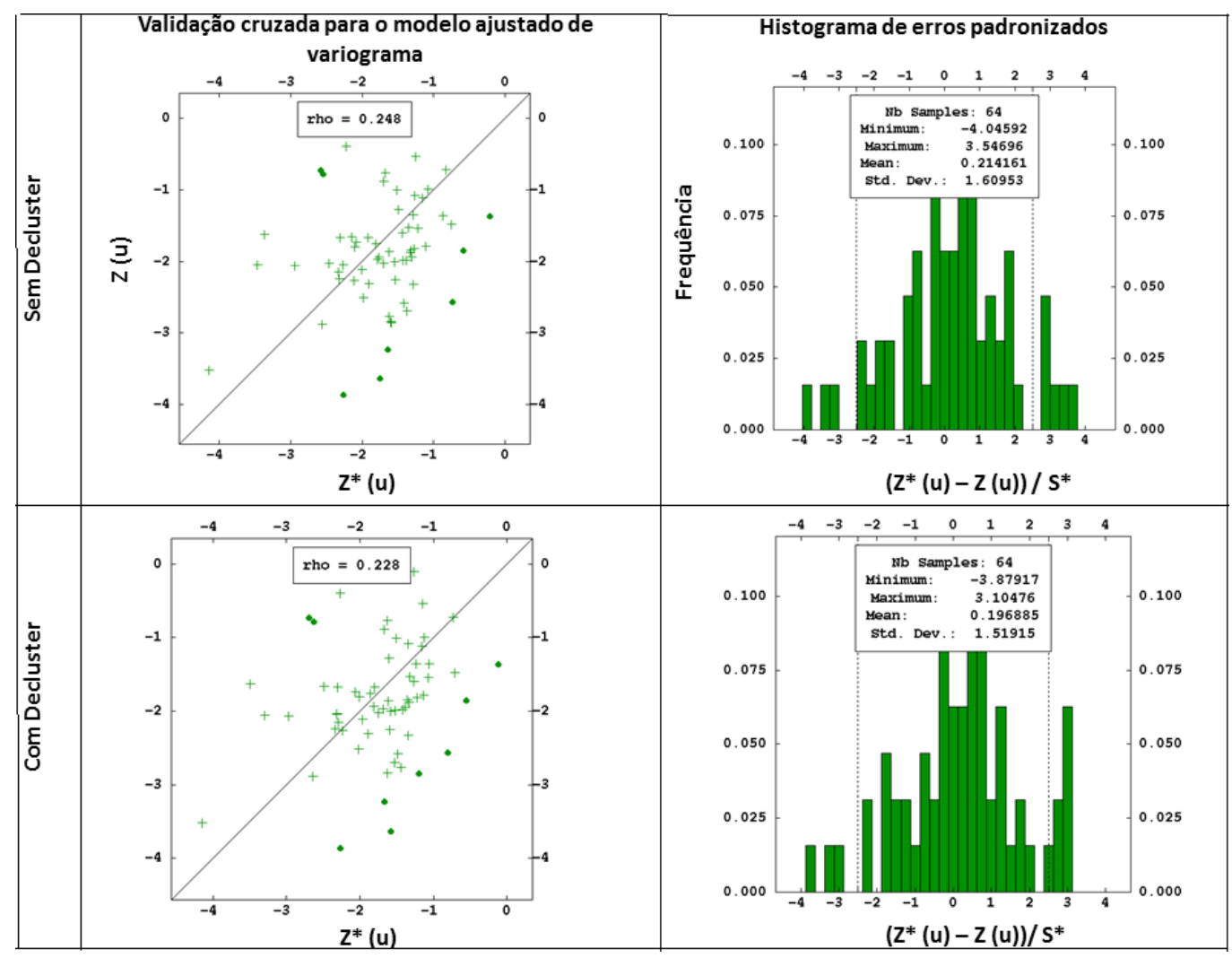

Figura 73: Cokrigagem: Validação cruzada e histogramas de erros padronizados sem e com aplicação da técnica de desagrupamento ou decluster por célula da área de estudo de Bauru, SAB. 
As figuras 74 e 75 apresentam os valores estimados pelo método de cokrigagem, sendo a primeira na forma de mapa e a segunda na de histograma. Para o caso em que o desagrupamento não é aplicado, os valores estimados da variável de interesse, log K, varia de -3.52 a 0.36 , com média de -1.69 , e a incerteza associada varia de 0.19 a 0.95 , com média 0.57 . Quando essa técnica é usada, as estimativas apresentam variação entre -3.34 e 0.21 , com média de -1.68 , sendo a incerteza associada entre 0.21 e 0.87 , com média 0.58 . Com base nesses dados, quando a técnica de desagrupamento é aplicada, a incerteza é maior para o método.

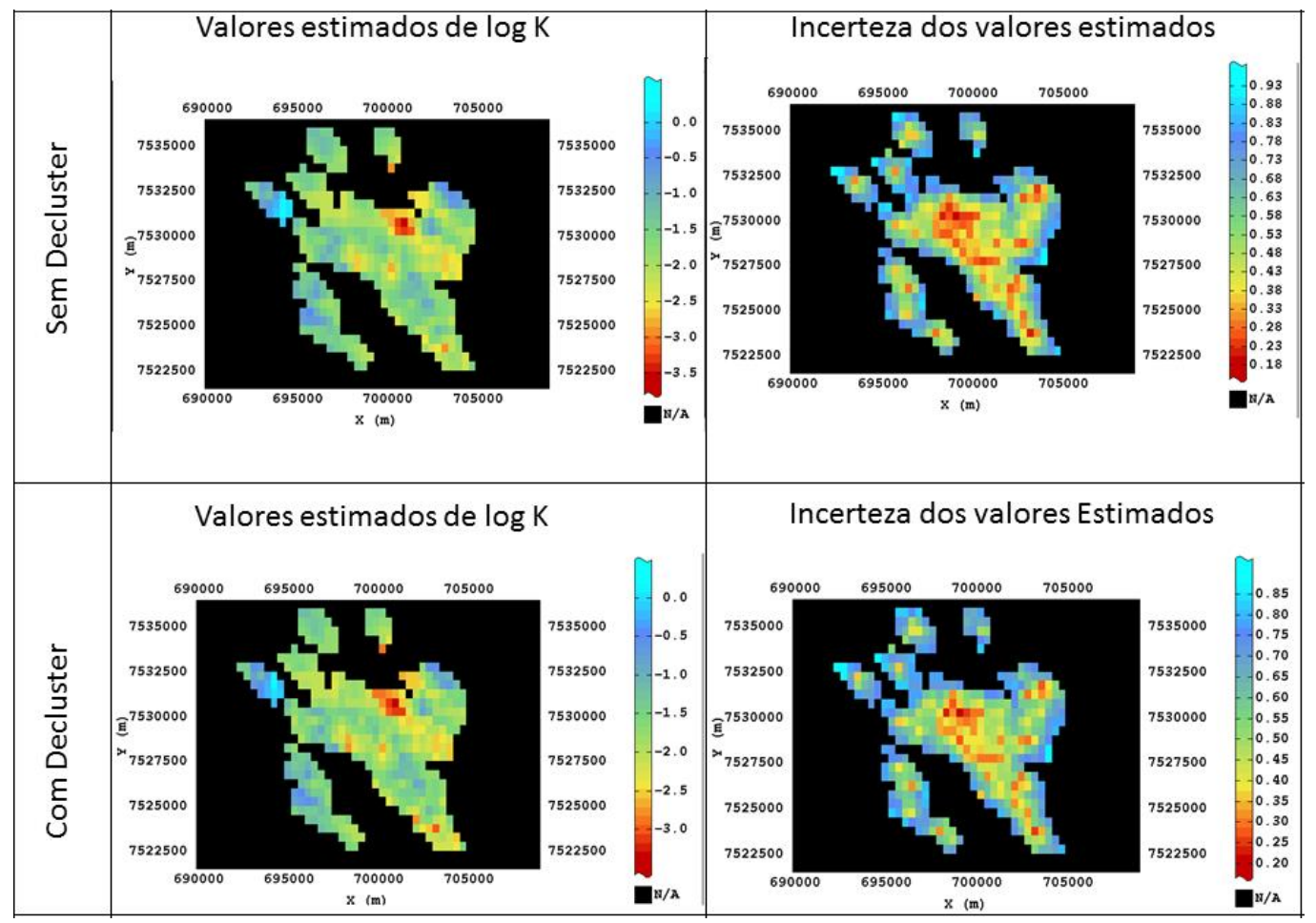

Figura 74: Cokrigagem: Mapas das estimativas e de incerteza associada ao método sem e com aplicação da técnica de desagrupamento ou Decluster por célula da área de estudo de Bauru, $S A B$. 


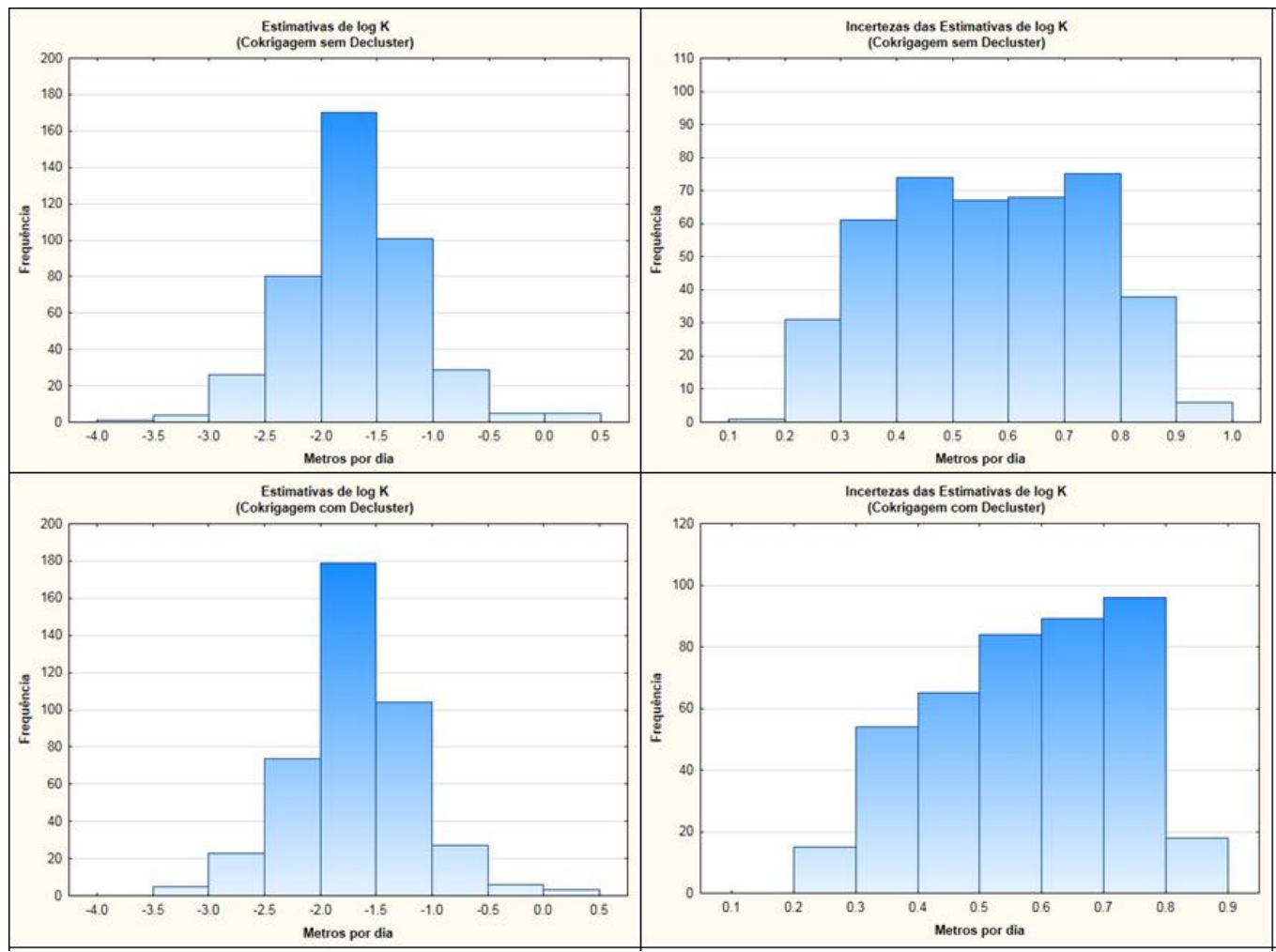

Figura 75: Cokrigagem: Histogramas das estimativas e de incerteza associada ao método sem e com aplicação da técnica de desagrupamento ou Decluster por célula da área de estudo de Bauru, $S A B$.

Os mapas e os variogramas ilustrando das estimativas de $\log \mathrm{K}$ convertidos em valores de condutividade hidráulica são apresentados na figura 76. Não é possível observar nítida discrepância entre os resultados do método sem e com desagrupamento. Ambos apresentam distribuição similar na área e, nos histogramas, assimetria positiva bem definida com valores que variam de 0.03 a 1.61 e média $0.55 \mathrm{~m} / \mathrm{d}$. 


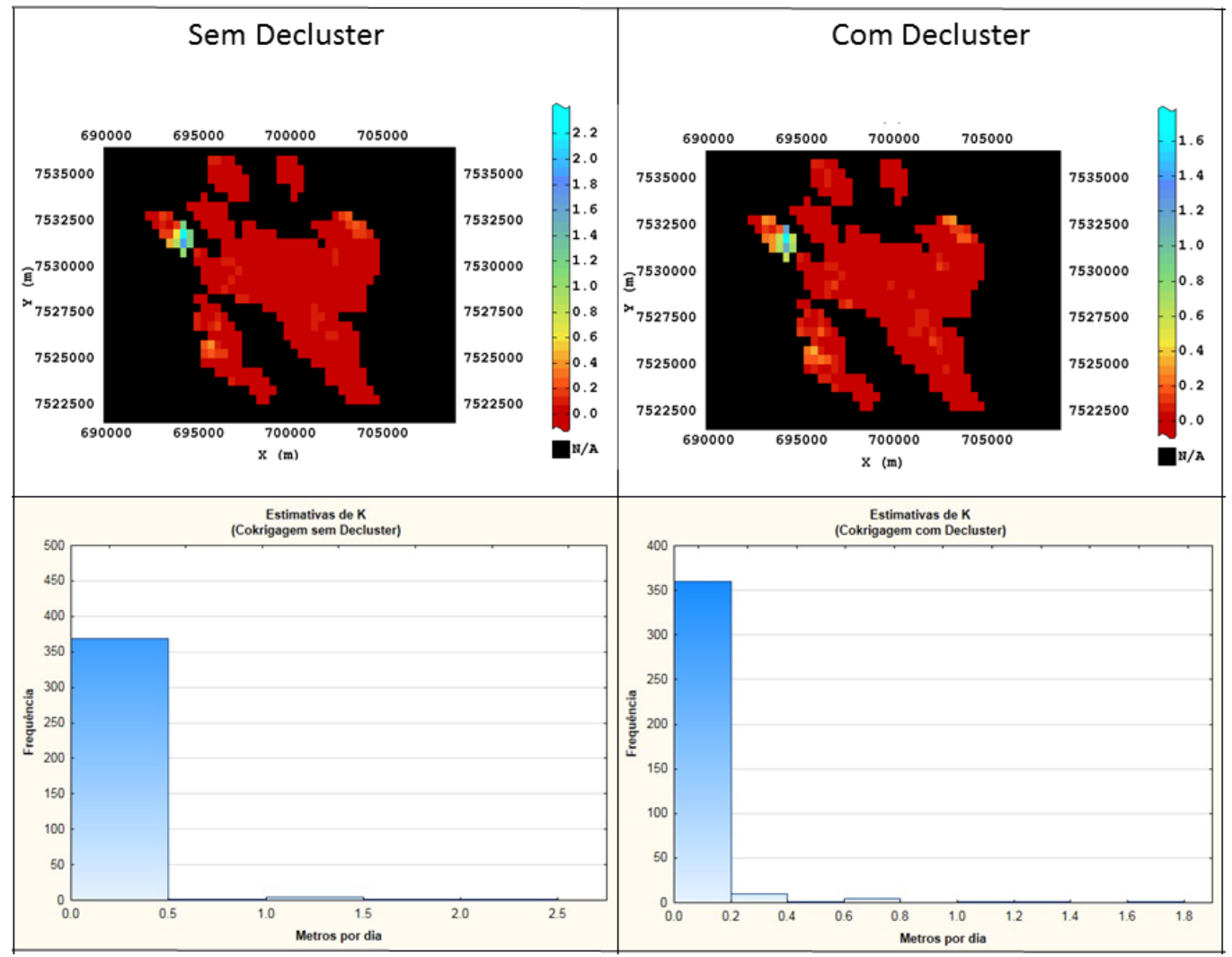

Figura 76: Cokrigagem: Mapas e histogramas das estimativas sem e com aplicação da técnica de desagrupamento ou Decluster por célula da área de estudo de Bauru, SAB.

Com base no que foi apresentado e discutido, a cokrigagem como método geoestatístico na área de estudo de Bauru não tem a sua performance melhorada usando a técnica de decluster ou desagrupamento. Assume-se isso se baseando no resultado de validação cruzada.

\subsubsection{Bandas rotativas}

Para a aplicação do método de simulação por bandas rotativas, são utilizados como base de dados 69 poços, os mesmos do método de krigagem ordinária, sendo a distribuição espacial desses mostrada na figura 59 e suas estatísticas descritivas na tabela 21. Esse método de simulação se diferencia dos demais métodos geoestatísticos aplicados e discutidos na área de interesse de Bauru até aqui, pois a análise estrutural se inicia após a transformada normal score ser aplicada. Nessa etapa preliminar, uma função de densidade acumulada de comportamento normal e padronizada é aplicada nos dados iniciais. Assim todo o método é desenvolvido no campo gaussiano, com os valores distribuídos de forma simétrica com valores média e desviopadrão muito próximos de zero e um, respectivamente.

Com esses dados transformados, inicia-se a analise exploratória ou estrutural. A análise da estatística descritiva é simular para os casos da aplicação ou não da técnica de 
desagrupamento. Ainda nessa etapa inicial, foi assumido que o valor do passo para ambos os casos como sendo de $850 \mathrm{~m}$.

Nos variogramas modelados, apresentados na figura 77, considera-se melhor estrutura para aquele que trata dos dados com decluster. Na tabela 27 , observa-se os valores dos elementos desses variogramas ajustados. Ambos os modelos apresentam a mesma amplitude, no entanto, a variância espacial é maior que a encontrada no modelo sem essa técnica.

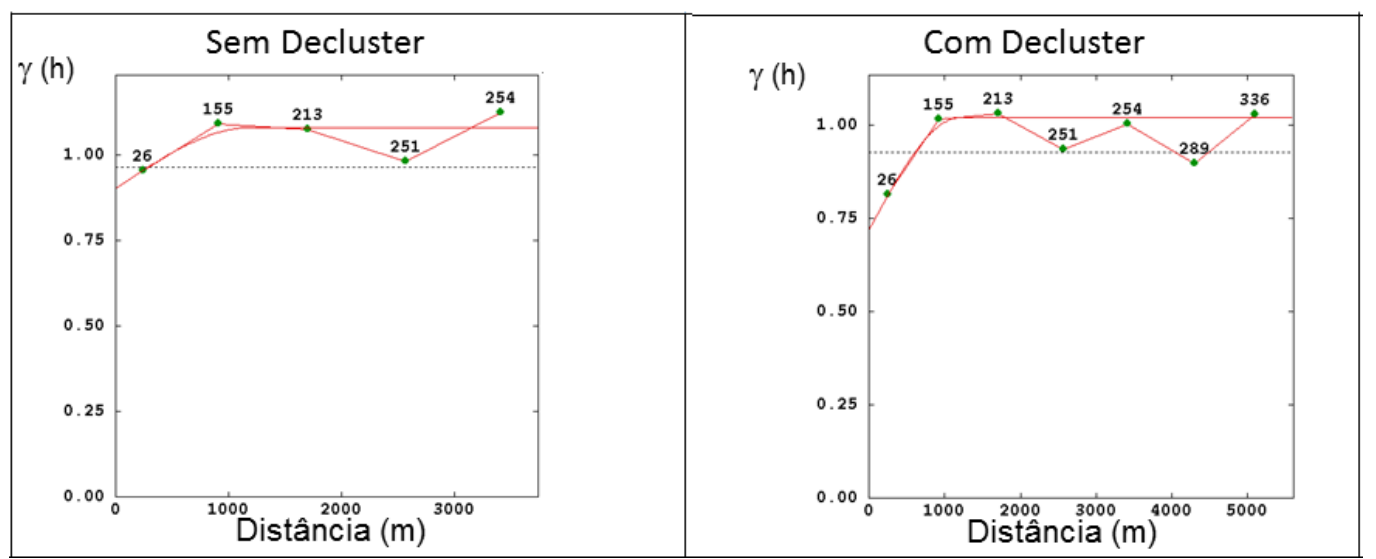

Figura 77: Bandas Rotativas: Variogramas modelados, após a transformada normal score, sem e com aplicação da técnica de desagrupamento por célula da área de estudo de Bauru, SAB. A linha tracejada representa a variância amostral.

Tabela 27: Elementos do modelo do variograma para os dados sem e com o uso da técnica de desagrupamento.

\begin{tabular}{|c|c|c|}
\hline $\begin{array}{c}\text { Elementos } \\
\text { do } \\
\text { variograma }\end{array}$ & $\begin{array}{c}\text { Sem } \\
\text { decluster }\end{array}$ & $\begin{array}{c}\text { Com } \\
\text { decluster }\end{array}$ \\
\hline Modelo & Esférico & Esférico \\
\hline $\begin{array}{l}\text { Efeito } \\
\text { pepita }\end{array}$ & 0.9 & 0.72 \\
\hline Amplitude & 1200 & 1200 \\
\hline Patamar & 0.18 & 0.3 \\
\hline
\end{tabular}

Segundo o valor apresentado na validação cruzada e no histograma dos erros padronizados, o modelo variograma dos dados sem o decluster é mais indicado. Além do valor da validação cruzada, o valor da média mais próxima de zero e o desvio-padrão mais próximo de um no histograma de erros padronizados para esses valores corroboram para essa conclusão. No entanto, para a vizinhança ajustada, não foram todos os valores re-estimados na validação cruzada. Essas observações são baseadas na figura 78. 


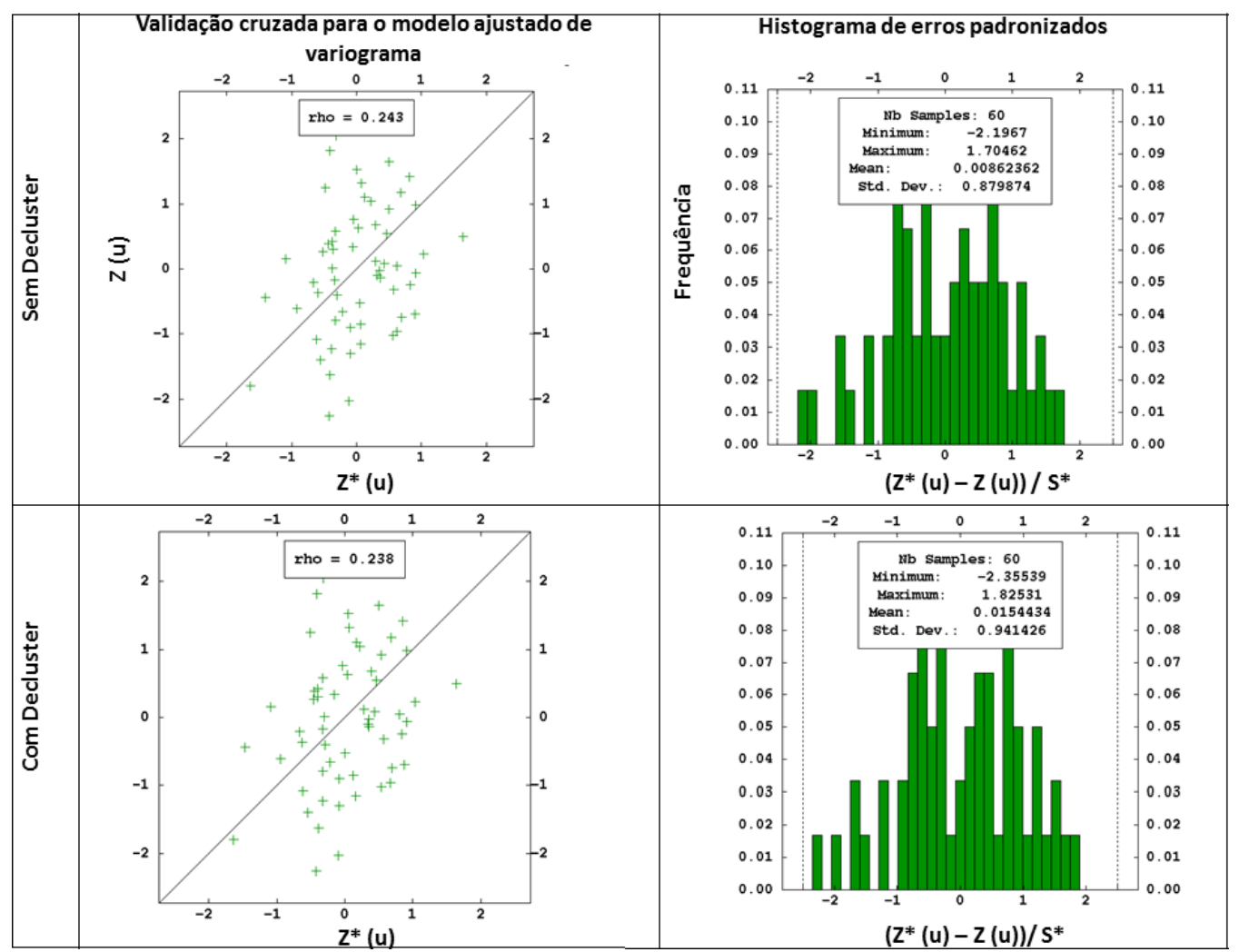

Figura 78: Bandas Rotativas: Variogramas modelados, após a transformada normal score, sem e com aplicação da técnica de desagrupamento por célula da área de estudo de Bauru, SAB. A linha tracejada representa a variância amostral.

Definidos os modelos variogramas para ambos os casos, os valores de $\log \mathrm{K}$ são estimados e seus resultados são apresentados nas figuras 78 e 79 nas formas de mapa e histograma, respectivamente. Essas estimativas são a representação dos valores médios das 100 realizações simuladas, tendendo aos valores da krigagem ordinária. Como mostrados nas figuras, os resultados para o caso sem decluster variam de -1.59 a 0.21 e média -0.58 e, a incerteza associada ao método varia de 0.15 a 0.54, com média 0.32. Quando o desagrupamento é aplicado, as estimativas variam de -2.47 a -0.59, com média 1,7 e, sua incerteza varia de 0.19 a 0.38 , com média 0.01 . Sendo assim, os modelos com decluster apresentam maior incerteza. 


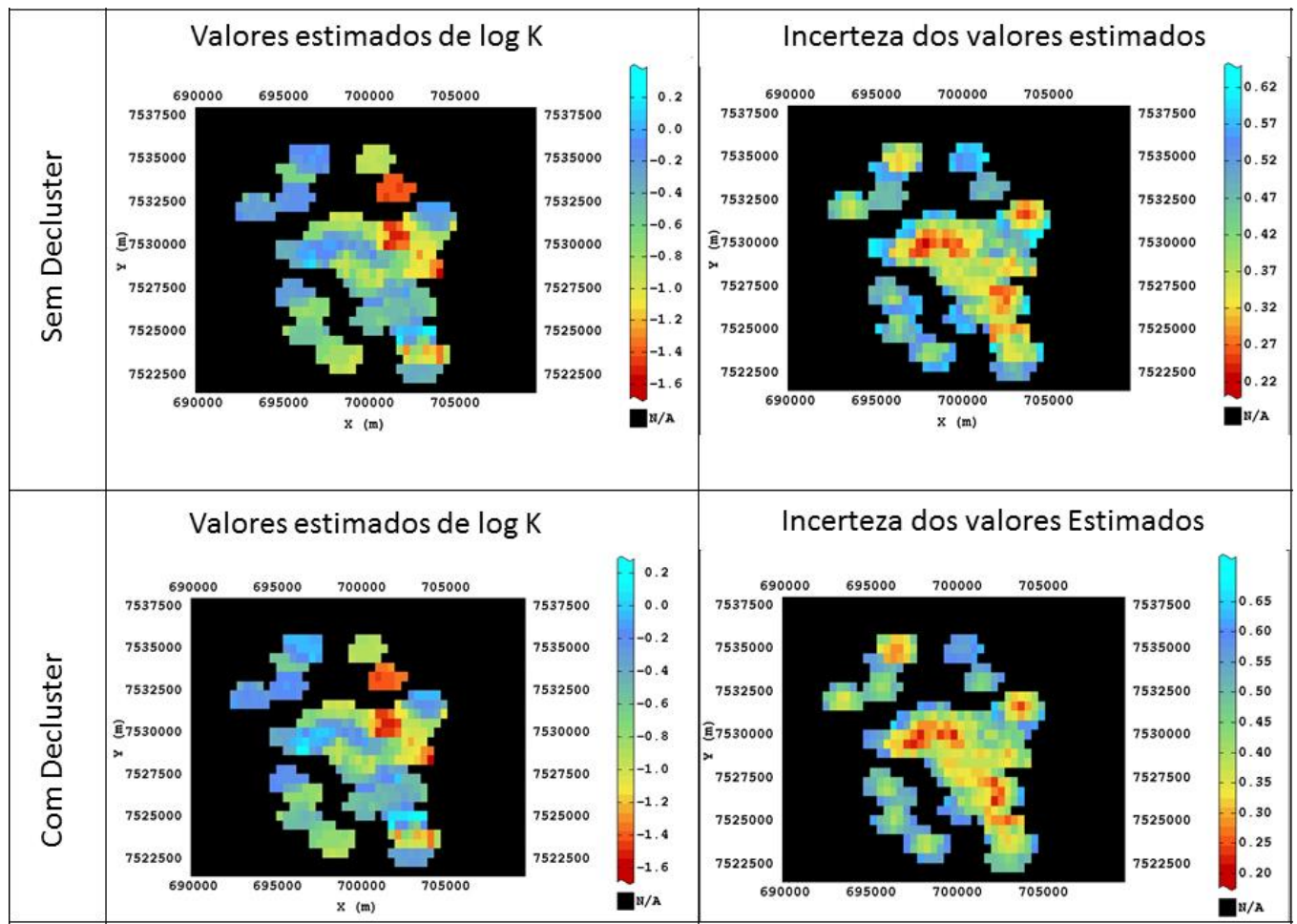

Figura 79: Bandas rotativas: mapas das estimativas e de incerteza associada ao método sem e com aplicação da técnica de desagrupamento por célula da área de estudo de Bauru, SAB.

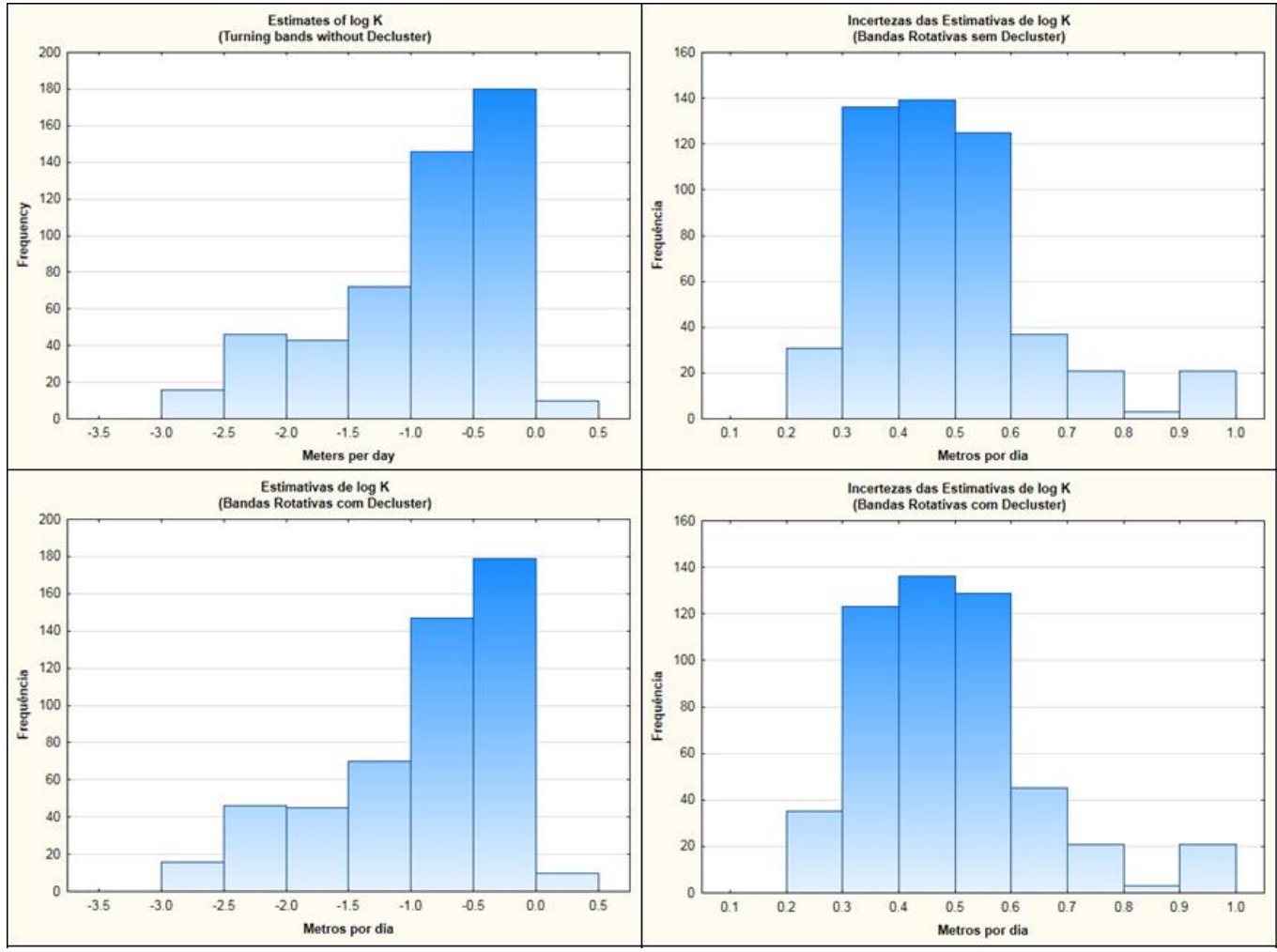

Figura 80: Bandas rotativas: histogramas das estimativas e de incerteza associada ao método sem e com aplicação da técnica de desagrupamento por célula da área de estudo de Bauru, SAB.

Os valores das estimativas de $\log \mathrm{K}$ convertidos em valores de condutividade hidráulica são apresentados em forma de mapas e variogramas para ambos os casos, figura 81. Para ambos os casos, verifica-se que a distribuição das estimativas de $\mathrm{K}$ apresentam uma distribuição 
assimétrica positiva e seus valores variam de 0.03 a $1.6 \mathrm{~m} / \mathrm{dia}$, com média de $0.37 \mathrm{~m} / \mathrm{dia}$, para o caso sem a aplicação do decluster, e, com a aplicação da técnica de desagrupamento, variam de 0.04 a $1.54 \mathrm{~m} /$ dia, com média de $0.37 \mathrm{~m} /$ dia. Esses valores apresentam um comportamento condizente com o esperado na estatística descritiva para valores de condutividade hidráulica apresentada na tabela 7 .

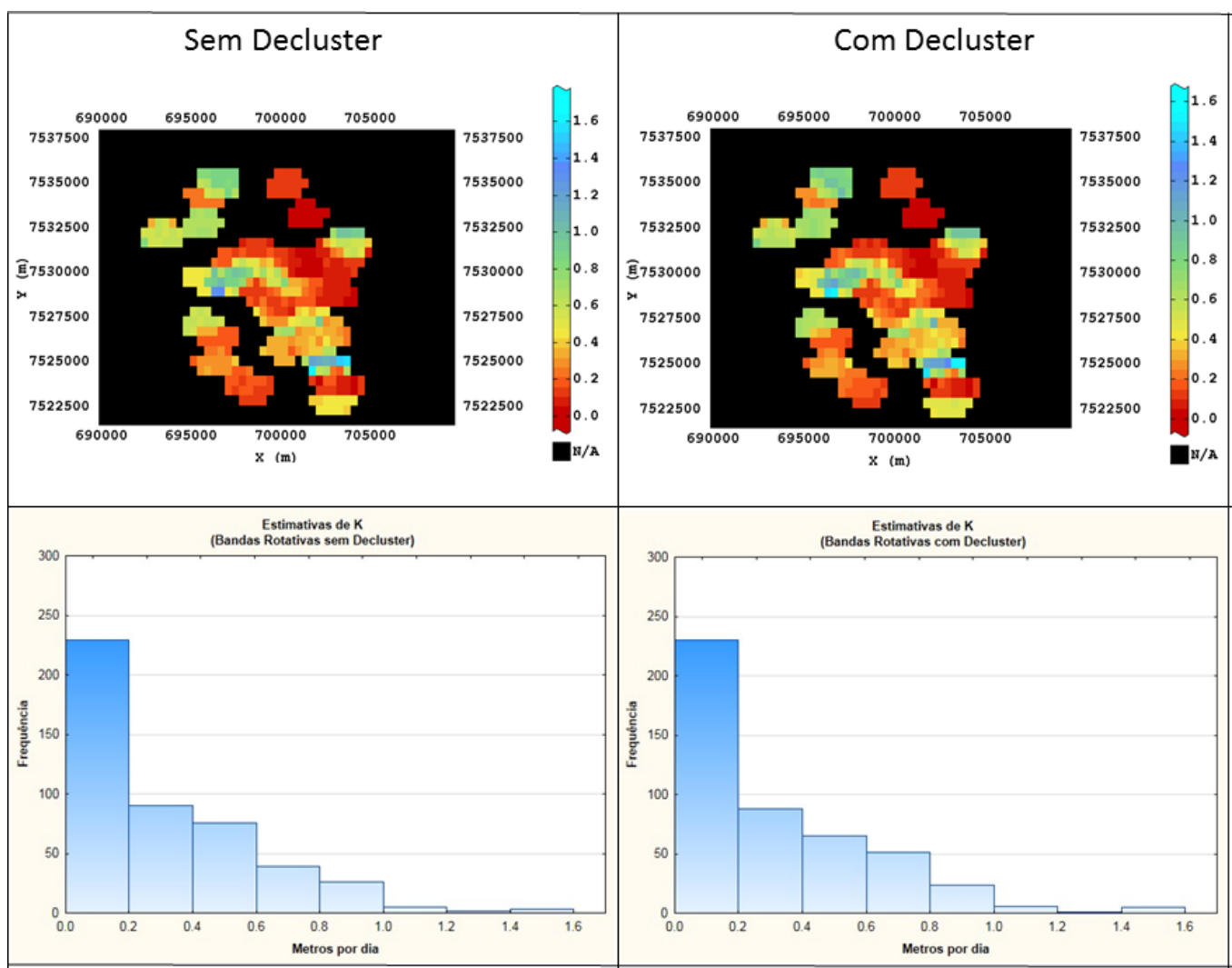

Figura 81: Bandas Rotativas: Mapas e histogramas das estimativas sem e com aplicação da técnica de desagrupamento por célula da área de estudo de Bauru, SAB.

O método de simulação por bandas rotativas se mostra mais eficaz, com base na validação cruzada, quando esse é aplicada sem a técnica de desagrupamento, na área de interesse de Bauru.

\subsubsection{Estudo Comparativo dos métodos geoestatísticos aplicados em Bauru (SAB)}

Os resultados dos testes geoestatísticos sem e com a aplicação da técnica de desagrupamento são apresentados de forma resumida nas tabelas 29 e 30, respectivamente. 
Tabela 29: Sumário dos resultados dos métodos geoestatísticos sem a aplicação de desagrupamento por célula na área de interesse em Bauru.

\begin{tabular}{|c|c|c|c|c|c|c|c|c|c|}
\hline \multicolumn{10}{|c|}{ São Carlos ( Sem Decluster) } \\
\hline \multirow{2}{*}{ Métodos } & \multicolumn{4}{|c|}{ Valores Estimados } & \multicolumn{4}{|c|}{ Incerteza dos valores estimados } & \multirow{2}{*}{$\begin{array}{l}\text { Validação } \\
\text { Cruzada }\end{array}$} \\
\hline & Mínimo & Máximo & Média & Variância & Mínimo & Máximo & Média & Variância & \\
\hline Krigagem Ordinária & -3.57 & -0.41 & -1.86 & 0.08 & 0.32 & 0.94 & 0.71 & 0.03 & 0.15 \\
\hline Cokrigagem & -3.52 & 0.36 & -1.69 & 0.3 & 0.19 & 0.95 & 0.57 & 0.03 & 0.25 \\
\hline $\begin{array}{c}\text { Krigagem Ordinária } \\
\text { Combinada com } \\
\text { Regressão Linear }\end{array}$ & -2.5 & -0.62 & -17 & 0.11 & 0.15 & 0.54 & 0.32 & 0.01 & 0.41 \\
\hline Turning Bands & -1.59 & 0.21 & -0.58 & 0.15 & 0.23 & 0.62 & 0.44 & 0.01 & 0.24 \\
\hline
\end{tabular}

Tabela 30: Sumário dos resultados dos métodos geoestatísticos sem a aplicação de desagrupamento por célula na área de interesse em Bauru.

\begin{tabular}{|c|c|c|c|c|c|c|c|c|c|}
\hline \multicolumn{10}{|c|}{ São Carlos ( com Decluster) } \\
\hline \multirow{2}{*}{ Método } & \multicolumn{4}{|c|}{ Valores Estimados } & \multicolumn{4}{|c|}{ Incerteza dos valores estimados } & \multirow{2}{*}{$\begin{array}{c}\text { Validação } \\
\text { Cruzada }\end{array}$} \\
\hline & Mínimo & Máximo & Média & Variância & Mínimo & Máximo & Média & Variância & \\
\hline Krigagem Ordinária & -3.53 & -0.41 & -1.86 & 0.27 & 0.29 & 0.95 & 0.68 & 0.03 & 0.17 \\
\hline Cokrigagem & -3.34 & 0.21 & -1.68 & 0.28 & 0.21 & 0.87 & 0.58 & 0.02 & 0.23 \\
\hline $\begin{array}{l}\text { Krigagem Ordinária } \\
\text { Combinada com } \\
\text { Regressão Linear }\end{array}$ & -2.47 & -0.59 & -1.7 & 0.11 & 0.19 & 0.67 & 0.38 & 0.01 & 0.42 \\
\hline Turning Bands & -1.56 & 0.19 & -0.58 & 0.16 & 0.22 & 0.66 & 0.44 & 0.01 & 0.24 \\
\hline
\end{tabular}

Com base na discussão dos métodos e nas tabelas 29 e 30, constata-se que:

1- A aplicação da técnica de desagrupamento por células diminui a diferença entre os valores da média e mediana, assim como o valor da variância amostral. Com a aplicação dessa técnica, os variogramas apresentam melhor estruturação, pois diminui a influência do efeito pepita, o que aumenta a atuação da variância espacial no patamar;

2- Todos os modelos variogramas apresentam comportamento linear próximo da origem, característica inerente ao modelo esférico, ou seja, há grande homogeneidade para pontos com pequenas distâncias e uma progressiva perda de homogeneidade com o aumento da distância;

3- À exceção dos variogramas modelados para a cokrigagem (Figura 72), os melhores ajustes para os modelos são feitos quando os patamares estão acima da linha da variância amostral;

4- O método de krigagem ordinária combinada com regressão linear com a aplicação da técnica de desagrupamento por células apresenta o melhor valor de validação cruzada, 0.42 , dentre dos métodos tratados para a área de interesse;

5- A aplicação do histograma dos erros padronizados mostra-se uma boa ferramenta para avaliar preliminarmente o ajuste da vizinhança de busca e a presença de outliers;

6- O uso da amplitude como tamanho do raio do círculo de vizinhança de busca revela-se adequado quando se busca atingir o melhor valor de validação cruzada. No entanto, como se observa em todos os mapas de estimativa para o $\mathrm{SAB}$, esse raio não é capaz de abranger toda a área, formando "ilhas" de estimativas. Como o número de dados é muito alto para a área, seria 
mais prudente o uso de um algoritmo de vizinhança local. Nesse trabalho, usa-se a vizinhança global;

7- A incerteza associada aos métodos de krigagem ordinária combinada com regressão linear simulação condicional por bandas rotativas apresentam valores mais baixos, 0.01. Isso reflete o significativo aumento de dados e sua distribuição na área de interesse;

8- Com a aplicação do exponencial nos valores de $\log \mathrm{K}$, os valores de condutividade hidráulica mostram-se coerentes com a estatística descritiva para os poços utilizados na área de Bauru;

9- A área é homogênea e com valores baixos para a variável hidráulica de interesse.

Assume-se que as estimativas dadas pelo método krigagem ordinária combinada com regressão linear com a técnica de desagrupamento por células correspondem àquelas que melhor representam a distribuição das condutividades hidráulicas na área de interesse em São Carlos, tendo em vista os resultados obtidos com a validação cruzada. Na figura 82, o mapa das estimativas por esse método é comparado com o modelo geológico proposto por esse trabalho na mesma área.

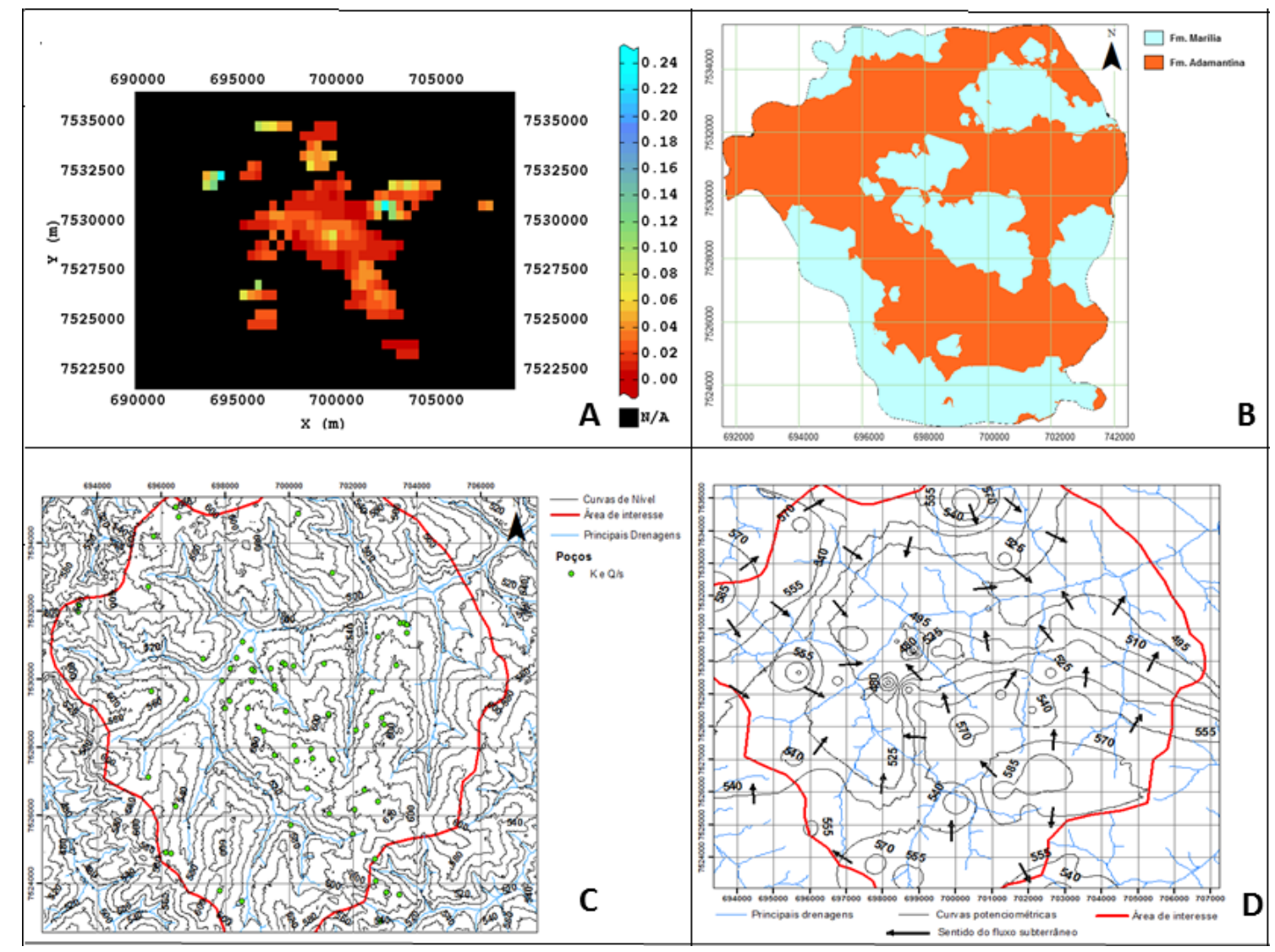

Figura 82: Mapas comparativos entre a distribuição dos valores estimados de condutividade hidráulica (A), pelo método de bandas rotativas, a geologia inferida com base nas descrições dos poços (B), topografia $(C)$ e potenciométrico na área de interesse de Bauru. 
As descontinuidades no mapa de estimativas (Figura 82A) limitam as comparações com o mapa geológico (Figura 82B) desenvolvido nessa dissertação e baseado na descrição das amostras dos poços instalados na área de interesse. No entanto, constata-se que a homogeneidade de baixos valores de condutividade hidráulica é condicionada pelos arenitos de granulação fina a muito fina, com presença de nódulos carbonáticos da Formação Adamantina, que é onipresente em toda área de estudo na cidade de Bauru.

O mapa de estimativas apresenta aumento dos valores de K seguindo uma tendência que parte de sudeste até o centro, onde ruma para noroeste. Essa trajetória é a mesma que o rio Bauru faz na área. Tal corpo d'água nasce dentro da bacia hidrográfica que delimita a área de estudo. Nessas mesmas regiões da área de estudo estão coincidem as curvas potenciométricas mais espaçadas. O mapa topográfico (Figura 82C) e o potenciométrico (Figura 82D) ilustram o curso do Rio Bauru e as curvas potenciométricas, corroborando com essas afirmações. De acordo com Kresic (2007), quando um aquífero, ou uma porção de interesse, apresenta espessura uniforme, gradientes hidráulicos mais íngremes indicam menor condutividade hidráulica no meio poroso, enquanto, maior espaço entre os contornos potenciométricos significa maior condutividade. 


\section{CONCLUSÃO}

Essa dissertação estima os valores de condutividade hidráulica $(\mathrm{K})$ aplicando métodos geoestatísticos a partir de informações de poços de bombeamento em duas áreas de distintas: uma em São Carlos, onde seus poços retiram água do Sistema Aquífero Guarani (SAG) e outra na cidade de Bauru, onde seus poços exploram águas do Sistema Aquífero Bauru (SAB). Para isso, é realizado extenso levantamento de dados com suporte de documentos com informações dos testes de bombeamento dos poços e ferramentas SIG. Pode-se separar esse trabalho em três etapas: entendimento de aspectos da área, tais como geologia, topografia e hidrogeologia e suas interações; estudo estatístico de $\mathrm{K}$ e a sua relação com a capacidade específica $(\mathrm{Q} / \mathrm{s})$, objetivando o aumento do banco de dados de condutividade hidráulica; e a aplicação de métodos geoestatísticos para a estimativa de valores de condutividade hidráulica nas áreas de estudo.

As amostras descritas durante a instalação dos poços e disponíveis nos bancos de dados fornecem excelente subsídio para o conhecimento das áreas de estudo. Levando-se em conta o modelo geológico desenvolvido para cada área é possível constatar que:

1- São Carlos:

a) Em São Carlos, o fluxo subterrâneo tende em direção aos principais corpos d'água, sendo esses o córrego do Gregório e o Rio Monjolinho, refletindo uma tendência regional de fluxo em que a água é direcionada para os rios e afluentes que desaguam no Rio Tietê;

b) A área é predominantemente coberta por sedimentos da Formação Adamantina, com espessura de 5 a 20 m. Abaixo dessa formação, estão os membros do Grupo São Bento, as Formações Serra Geral, Botucatu e Pirambóia e o membro do Grupo Passa Dois, Formação Corumbataí. Os basaltos da Formação Serra Geral apresentam espessura variada podendo alcançar valores de até 350 m. Os componentes do SAG, Formações Botucatu e Pirambóia, são descritos como uma só formação indistinta e são trapeados por basaltos da Formação Serra Geral. O SAG aflora nas regiões norte, central e sul da área. Sua espessura é variada de dezenas de metros até aproximadamente $400 \mathrm{~m}$. Sotoposto a essa formação, encontra-se a Formação Corumbataí que atua como o aquitarde do SAG. Os Filtros desses poços estão instalados em meio aos arenitos das Formações Botucatu e Pirambóia.

2- Bauru:

a) A área de interesse da cidade Bauru está inserida em uma bacia hidrográfica, onde o fluxo subterrâneo tem como direção preferencial o centro da bacia, mais precisamente o Rio Bauru, que tem sua origem dentro da área; 
b) A geologia da área é composta pelas Formações Marília e Adamantina que são membros do Grupo Bauru. A primeira está presente de forma disseminada, preferencialmente em cotas mais elevadas, como morros e apresenta espessura de 10 a $100 \mathrm{~m}$, sendo mais comum encontrar 20 m. A Formação Adamantina é predominante na área e sua presença independe da cota topográfica. Na maioria dos poços dessa área os filtros estão instalados exclusivamente nessa formação.

Aplicando os testes de normalidade de Kolmogorov-Smirnov (K-S) e Shapiro-Wilk (SW), no tratamento estatístico, verifica-se que os poços do SAG instalados em aquíferos livres e semiconfinados apresentam valores de $\log \mathrm{K}$ com distribuição normal e, pelo teste de $t$ de Student, constata-se que ambos são oriundos de uma mesma distribuição e, dessa forma, gabaritando-os para a etapa final do tratamento estatístico. Nessa etapa, busca-se o desenvolvimento da relação empírica entre $\log \mathrm{Q} / \mathrm{s}$ e $\log \mathrm{K}$ usando regressão linear de primeira ordem e a geração de uma equação que relaciona esses dois parâmetros hidráulicos. Para os poços instalados no SAB, assume-se que todos estão em aquíferos semiconfinados e, portanto, não há necessidade da aplicação do teste $t$ de Student, quando os testes K-S e W-S provam-se satisfatórios, como no caso desse trabalho. A correlação entre $\log \mathrm{Q} / \mathrm{s}$ e $\log \mathrm{K}$ para os poços do SAG é de 0,612, enquanto para os poços do SAB, essa correlação é de 0,763. A aplicação da regressão linear gera uma equação para cada sistema aquífero (equações 83 e 85 para o SAG e $\mathrm{SAB}$, respectivamente), o que aumenta o número de valores de $\log \mathrm{K}$ conhecidos. Essas equações permitem que o número de valores conhecidos de log $\mathrm{K}$ aumente de 28 para 67 em São Carlos e de 69 para 343, em Bauru. Esses valores são utilizados quando o método de krigagem ordinária combinada com regressão linear é aplicado em cada área.

A estratégia adotada para estimar valores de condutividade hidráulica nas áreas de interesse nesse trabalho é a aplicação de três métodos geoestatísticos: krigagem ordinária, cokrigagem e simulação condicional por bandas rotativas. Visto que há agrupamentos de poços nas áreas, a técnica de desagrupamento ou declustering por células é aplicada para a avaliar sua capacidade de melhorar o desempenho dos métodos geoestatísticos. Feito isso, é possível concluir que:

1- Não são identificadas anisotropia nas áreas de estudo, na análise exploratória. Sendo assim é adotado o variograma omnidirecional;

2- A aplicação da técnica de desagrupamento por células diminui a diferença entre os valores da média e mediana, assim como o valor da variância amostral. Com a aplicação dessa técnica, os variogramas apresentam melhor estruturação, pois é diminuída a influência do efeito pepita, o que aumenta a atuação da variância espacial no patamar; 
3- Todos os modelos variogramas apresentam comportamento linear próximo da origem, característica inerente ao modelo esférico, ou seja, há grande homogeneidade para pontos com pequenas distâncias e uma progressiva perda de homogeneidade com o aumento da distância;

4- Em São Carlos, os melhores valores de validação cruzada são atingidos quando os modelos variogramas estabilizam seus patamares tangenciando a linha tracejada que marca a variância amostral. Em Bauru, esse padrão não se repete, sendo as validações cruzadas mais satisfatórias atingidas quando o patamar ultrapassa o valor da variância amostral. Embora a situação apresentada em São Carlos seja a mais desejada, os valores acima ou abaixo da variância amostral não invalidam o modelo, uma vez que a estabilização do patamar depende da média das variâncias de cada direção. Direções com maior variância podem influenciar no comportamento do patamar;

5- A aplicação histograma dos erros padronizados mostra-se uma boa ferramenta para avaliar preliminarmente o ajuste da vizinhança de busca e a presença de outliers;

6- Os métodos geoestatísticos que apresentam melhores performances, considerando as validações cruzadas como critério de seleção, são simulação condicional por bandas rotativas e krigagem combinada com regressão linear para São Carlos e Bauru, respectivamente;

7- Embora o uso da distância definida como amplitude para o raio do círculo de vizinhança de busca se mostre mais adequado para atingir o melhor valor de validação cruzada, esse valor não satisfaz todas as vizinhanças, sendo assim há regiões em que não é possível estimar valores de K. Pode-se observar esse efeito mais perceptivelmente nos mapas de estimativa do parâmetro hidráulico na área de estudo em Bauru. Recomenda-se o uso de algoritmo de vizinhança local, ao invés da global como usado nesse trabalho;

8- As regiões que apresentam maiores valores estimados de $\mathrm{K}$ coincidem com as mesmas onde as curvas potenciométricas apresentam maiores espaçamentos nas áreas de estudo.

$\mathrm{O}$ aumento da base de dados propiciado pelo tratamento estatístico, usando as equações 81 e 83 para estimar valores de $\mathrm{K}$ a partir de valores de Q/s, mostra-se adequado para ambas as áreas. Em São Carlos, mesmo não atingindo o valor de validação cruzada mais satisfatório, 0.55, alcançado pelo método de simulação de bandas rotativas, alcança o valor de 0.44 quando a krigagem ordinária combinada com regressão linear é aplicada. Em Bauru, esse método se mostra o mais satisfatório.

Devido à complexidade hidrogeológica e ao tamanho das áreas, erros são associados aos métodos, sendo assim, um estudo geoestatístico abrangendo áreas menores, sobretudo em São Carlos, pode ser uma alternativa para minimizar erros. O uso do tratamento estatístico é capaz de aumentar o número de dados disponíveis e, assim, aumentar a acurácia dos métodos. 


\section{REFERÊNCIAS BIBLIOGRÁFICAS}

ADLER, P.M.; THOVERT, J.F. (1999). Fractures and Fracture Networks. Kluwer: Dordrecht. AHMED, S.; MARSILY, G. (1987). Comparison of Methods for Estimating Transmissivity Using Data on Transmissivity and Specific Capacity. Water Resources Researchs, v 23, n 9, p. 1717-1737.

ALTIOK, T.; MELAMED, B. (2007). Simulation modeling and analysis with arena. Elsevier Academic Press, 456p.

ARAÚJO L.M., FRANÇA A.B., POTTER P.E. (1995). Aqüífero Gigante do Mercosul no Brasil, Argentina, Uruguai e Paraguai; Mapas Hidrogeológicos das Formações Botucatu, Pirambóia, Rosário do Sul, Buena Vista, Missiones e Tacuarembo. Curitiba, UFPR PETROBRÁS, Mapas, escala 1:2.500.000.

ARAÚJO, M L. M.; FRANÇA, A. B.; POTTER, P. E. (1999). Hydrology of the Mercosul aquifer system in the Paraná and Chaco- Basins, South America, and, comparison with the Navajo-Nuggt aquifer system, USA. Hydrogeology Journal, v 7(3), p. 313-336

ARMSTRONG, M. (1988). Basic linear geostatistics. Berlin, Springer, New York. xi, 153 p..

BARROS, G. (2001). Reavaliação geoestatística dos recursos/reservas de fosfato da Mina de Cajati, SP. São Paulo. 108 p.

BITTENCOURT, A. V. L. (2003). Sistema Aquífero Guarani- Considerações preliminares sobre a influência do Arco de Ponta Grossa no Fluxo das águas subterrâneas. Águas Subterrâneas, São Paulo. V.17, p. 91-111.

BON, E. H. (1979) Exploration techniques Employed in The Pulau Tujuh Tin discovery. Trans. Inst. Min. Metal, 88 (A13-A22).

BORGHETTI, N. R.B.; BORGHETTI, J. R.; ROSA FILHO, E. F. (2004). Aquífero Guarania verdadeira integração dos países do Mercosul. Curitiba: Nova Editora. 214p.

BOUR, O.; DAVY, P. (1998). On the connectivity of three dimensional fault networks. Water Resources Research, v 34, p. 2611-2622.

BRESSAN, M. A. ; VENDRAME, Í. F. ; MEDEIROS, G. A. (2002). Análise do Método de Cooper-Jacob em uma Área da Bacia do Rio Alambari, SJC - SP.. In: VII ENCITA, São José dos Campos. Análise do Método de Cooper-Jacob em uma Área da Bacia do Rio Alambari, SJC - SP., 2002. v. ANAIS.

CAMPBELL, M.D., Starrett, M.S., Fowler, J.D., and Klein, J.J. (1990). Slug tests and hydraulic conductivity. Ground Water Management, 2: 85-99.

CAMPOS, H. C. N. S. (1999). Modelacíon conceptual y matemática del acuífero Guaraní, Cono Sur. Mapa Hidrogeológico do Aquífero Guarani. Acta Geológica Leopoldensia, v. 23 (4), p. 3 50 . 
CASTRO, M. C.; GOBLET, P. (2003). Calibration of regional groundwater flow models: Working toward a better understanding of site-specific systems: Water Resour. Res., v. 39, no. 6, art. 1172.

CASTRO, M. C.; GOBLET, P.; LEDOUX, E.; VIOLETTE, S.; DE MARSILY, G. (1998). Noble gases as natural tracers of water circulation in the Paris Basin 2. Calibration of a groundwater flow model using noble gas isotope data: Water Resour. Res., v. 34, no. 10, p. $2467-2483$

CENTRO DE PESQUISAS METEOROLÓGICAS E CLIMÁTICAS APLICADAS À AGRICULTURA (CEPAGRI). Bauru. Disponível em: <http://www.cpa.unicamp.br/outrasinformacoes/clima_muni_068.html>. Acessado em 12 de Novembro de 2015.

CEY, E. E.; RUDOLPH, D. L.; PARKING, G. W.; ARAVENA, R. (1998). Quantifying Groundwater Discharge to a Small Perennial Stream in Southern Ontario, Canada. Journal of Hydrology, v. 210, p. 21-37.

CHILÈS, JEAN-PAUL. DELFINER, PIERRE. (1999). Geostatistics modeling spatial uncertainty. New York, Wiley, c1999. xi, 695 p. Wiley series in probability and statistics. Applied probability and statistics section. "A Wiley-Interscience publication.

CHRISTENSEN, S. (1997). On the strategy of estimating regional-scale transmissivity fields: Ground Water, v. 35, no. 1, p. 131-139

CICHOTA, R.; Jong van LIER, Q. e ROJAS, C.A.L. (2003). Variabilidade espacial da taxa de infiltração em Argissolo Vermelho. R. Bras. Ci. Solo, 27:789-798.

CONOVER, W. J. (1999). Practical Nonparametric Statistics. Third Edition, Jonh Wiley e Sons. Inc. New York.

COOPER, H.H.; BREDEHOEFT, J.D.; PAPADOPOLUS I.S. (1967) Response of a finitediameter well to an instantaneous charge of water.Water Resources Research, v.3, n. 1, p. 263-269.

COPTY, N. K., M. S. SARIOGLU, AND A. N. FINDIKAKIS. (2006), Equivalent transmissivity of heterogeneous leaky aquifers for steady state radial flow, Water Resour. Res., 42, W04416, doi:10.1029/2005WR004673.

CORRÊA. U. M. P. (1995). Estudo das águas subterrâneas das bacias hidrográficas dos rios Jacaré-Guaçu e Jacaré-Pepira no Estado de São Paulo. 3 v, 107 p. Dissertação (Mestrado)Escola de Engenharia de São Carlos, Universidade de São Paulo, São Carlos. 1995.

CPRM- Serviço Geológico do Brasil. (2006). Mapa Geológico do Estado de São Paulo. Ministério de Minas e Energia- Secretária de Geologia, Mineração e Transformação Mineral. Brasília. Escala 1: 750.000.

DAEE - Departamento de Águas e Energia Elétrica. IG - Instituto Geológico. IPT - Instituto de Pesquisas Tecnológicas do Estado de São Paulo. CPRM - Serviço Geológico do Brasil (2005). Mapa de águas subterrâneas do Estado de SP: escala 1:1.000.000 : nota explicativa / [coordenação geral Gerôncio Rocha] - São Paulo

DAEE- Departamento de Águas e Energia Elétrica. (1990). Plano estadual de recursos hídricos: Primeiro plano do estado. Síntese. São Paulo. 
DAEE-Departamento de Águas e Energia Elétrica. (1974). Estudo de Águas Subterrâneas: Região Administrativa n6, Ribairão Preto. São Paulo: v. 4.

DESBARATS A, LOGAN C, HINTON M, SHARPE, D. (2004). Geostatistical mapping of specific capacity in the Oak Ridges Moraine aquifer. In: Proc 57th Canadian Geotechnical Conference and the 5th Joint CGS-IAH Conference on Geo-Engineering for the Society and its Environment, Old Quebec.

DEUTSCH C. V. E JOURNEL A.G. (1998) GSLIB: Geostatistical Software Library and User's Guide, Oxford University Press.

DEUTSCH, C. V.(2002). Geostatistical reservoir modeling. Oxford, Oxford University Pres, New York :. xi, 376 p.

DAVIS, J. C. (1986). Statistics and data analysis in geology. New York, Wiley, Chichester. xvi, 638 str.

DOGAN, M., R. L. VAN DAM, G. C. BOHLING, J. J. BUTLER JR., AND D. W. HYNDMAN. (2011). Hydrostratigraphic analysis of the MADE site with full-resolution GPR and direct-push hydraulic profiling, Geophys. Res. Lett., 38, L06405, doi:10.1029/2010GL046439.

FABBRI, P. (1997). Transmissivity in the geothermal Euganean basin: a geostatistical analysis. Ground Water 35(5):881-887.

FANG, J; TACHER, L. (2003). An efficient and accurate algorithm for generating spatiallycorrelated random fields. Communications in Numarical Methods in Engineering, v 19, 801808 .

FEITOSA, F. A. C.; FEITOSA, E.C.; DEMETRIO, J.G.A. (2008). HIDROGEOLOGIA: conceitos e aplicações. 3. ed. rev. e ampl. Rio de Janeiro, RJ: CPRM, 812 p., il.

FERNANDES L. A.; COIMBRA A. M. (2000). Revisão estratigráfica da parte oriental da Bacia Bauru (Neocretáceo). Rev. Bras. Geoc.,30:723-734

FERNANDES, L. A. (1998). Estratigrafia e evolução geológica da parte oriental da Bacia Bauru (Ks, Brasil). 216 p. Tese (Doutorado)- Instituto de Geociências, Universidade de São Paulo, São Paulo, 1998.

FETTER, C. W.(1988). Applied hydrogelogy . 2ed. New York: Macmillan.

FOSTER, S.; HIRATA, R.; VIDAL, A; SCHMIDT, G; GARDUÑO, H. (2009). The Guarani Aquifer initiative - towards realistic groundwater management in a transboundary context. Case Profile Collection 9. The World Bank, Washington (DC), 28 p.

FREEZE, R. A. e CHERRY.(1979.) . Groundwater; Prentice Hall, Englewood Cliffs, 604p.

GILBOA, Y. (1977). The goundwaterresources of Urugauy. Hydrological Science-Bulletin-des Sciences Hydrologiques, XXII, p.115-126.

GODOY, M. C. (2003). The effective Management of geological risk in long-term production scheduling of open oit mine. PhD Thesis, W. H. Bryan Mining Geological Research Centre, The university of Queensland, Brisbane. $256 \mathrm{p}$. 
GOMES, N.M.; SILVA, A.M.; MELlO, C.R.; FARIA, M.A. eOLIVEIRA, P.M. (2007). Métodos de ajuste e modelos de semivariograma aplicados ao estudo da variabilidade espacial de atributos físico-hídricos do solo. R. Bras. Ci. Solo, 31:435-443.

GÓMEZ-HERNÁNDEZ, J. J.; WEN, X. H. (1998). To be or not to be multi-gaussian?: a reflection on stochastic hydrogeology. Advances in Water Resources, v.21, n. 1, 47-61.

GONCALVES, A. D. M. A.; LIBARDI, P. L. (2013). Análise da determinação da condutividade hidráulica do solo pelo método do perfil instantâneo. Revista Brasileira de Ciência do Solo (Impresso), v. 37, p. 1174-1184.

GULDEN, L. E., E. ROSERO, Z.-L. YANG, M. RODELL, C. S. JACKSON, G.-Y. NIU, P. J.F. YEH, AND J. FAMIGLIETTI (2007), Improving land-surface model hydrology: Is an explicit aquifer model better than a deeper soil profile? Geophys. Res. Lett., 34, L09402, doi:10.1029/2007GL029804.

HAMM S-Y, CHEONG J-Y, JANG S, JUNG C-Y, KIM B-S (2005) Relationship between transmissivity and specific capacity in the volcanic aquifers of Jeju Island, Korea. J Hydrol 310:111-121.

HANTUSH, M. S. (1956). Analysis of data from pumping tests in leaky aquifers. Transactions, American Geophysical Union, v. 37. p. 702-714.

HANTUSH, M.S., (1961). Drawdown around a partially penetrating well, Jour. of the Hyd. Div., Proc. of the Am. Soc. of Civil Eng., vol. 87, no. HY4, pp. 83-98.

HIRATA, R.; SANGIORGE, M. ; Wahnfried, I.; BAITZ VIVIANI-LIMA, J. (2012). Explotação do Sistema Aquífero Guarani em Araraquara. Geologia USP. Série Científica, v. 12, p. 115-127, 2012.

HUGHSON, L.; HUNTLEY, D.; RAZACK, M. (1996) Cokriging limited transmissivity data using widely sampled specific capacity from pump tests in an alluvial aquifer: Ground Water, v. 34 , no. 1 , p. $12-18$.

INSTITUTO BRASILEIRO DE GEOGRAFIA E ESTATÍSTICA. Bauru. Disponível em: $<$ http://cidades.ibge.gov.br/painel/painel.php?codmun=350600> .Acessado em 20 de Novembro de 2015.

INSTITUTO BRASILEIRO DE GEOGRAFIA E ESTATÍSTICA. São Carlos. Disponível em: $<$ http://cidades.ibge.gov.br/xtras/perfil.php?codmun=354890> .Acessado em 20 de Novembro de 2015.

IPQ. (2012).- Manual de Boas Práticas para Execução e Exploração de Furos de Captação de Águas Subterrâneas. Lisboa.

IPT- INSTITUTO DE PESQUISAS TECNOLÓGICAS. (2003). Diagnóstico da situação atual dos recursos hídricos e estabelecimento de diretrizes técnicas para a elaboração do Plano da Bacia Hidrográfica do Tietê/ Jacaré. IPT. Relatório 40,674. São Paulo.

IPT-INSTITUTO DE PESQUISAS TECNOLÓGICAS. (1981). Mapas Geológicos do Estado de São Paulo. Escala 1:500.000. São Paulo. IPT Monografias, 6. Publicação 1184, v. 2. 
IPT-INSTITUTO DE PESQUISAS TECNOLÓGICAS. (1989). Estudo e Implementação de novas técnicas e desenvolvimento de programas em geoestatística: aplicação em geologia. São Paulo, IPT. 98p. (IPT Relatório 27.799).

JALLUDIN M, RAZACK M (2004) Assessment of hydraulic properties of sedimentary and volcanic aquifer systems under arid conditions in the Republic of Djibouti (Horn of Africa). Hydrogeol J 12:159-170.

KITANIDIS, P. K. (1997). Introduction to geostatistics applications to hydrogeology. Cambridge, Cambridge University,, 249 p.

LADEIRA, F. S. B.; SANTOS, M. (2008). O uso de paleossolos para a interpretação paleoclimática: o caso das formações Marília (Cretáceo) e Itaqueri (Paleógeno) no Estado de São Paulo. In: $8^{\circ}$ Simpósio Brasileiro de Climatologia Geográfica, Alto Caparaó. Anais do $8^{\circ}$ Simpósio Brasileiro de Climatologia Geográfica, 2008. p. 514-526.

LANDIM, P. M. B. (2003). Analise estatística de dados geológicos. 2. ed. rev. ampl. São Paulo, Editora UNESP, 253 p.

LANDIM, P. M. B. ; STURARO, J R (2002). Krigagem Indicativa aplicada à elaboração de mapas probabilísticos de riscos - Laboratório de Geomatemática, DGA/IGCE/UNESP, Rio Claro - Texto Didático 06. 2002.

MACE RE, SMYTH R, XU L, LIANG J (2000) Hydraulic conductivity and storativity of the Carrizo-Wilcox aquifer in Texas. Bureau of Economic Geology, The University of Texas at Austin, Austin, TX.

MACE, R. E. Determination of transmissivity from specific capacity tests in a karst Aquifer. Ground water. Vol 35, no 5, 1997.

MACE, R.E. (1997) Determination of transmissivity from specific capacity tests in a karst aquifer. Ground Water 35:738-742 Mace RE (2000) Estimating transmissivity from specificcapacity data.

MACE, R.E.; SMYTH, R.; XU, L.; LIANG, J. (2000) Hydraulic conductivity and storativity of the Carrizo-Wilcox aquifer in Texas. Bureau of Economic Geology, The University of Texas at Austin, Austin, TX

MANTOGLOU, A.; WILSON, J. L. The turning bands method for simulation of random fields using line generation by a spectral method. Water Resources Research, v.18, n. 5, p. 1379-1394, 1982.

MARQUES, L. S.; ERNESTO, M. (2004). O Magmatismo Toleítico da Bacia do Paraná. In: MANTESSO NETO, V.; BARTORELLI, A.; CARNEIRO, A. D. R.; BRITO-NEVES, B. B. Geologia do Continente Sul-Americano: Evolução da Obra de Fernando Flávio Marques de Almeida. São Paulo: Beca. p. 245-264.

MEIER, P. M.; CARRERA, J.; SANCHEZ-VILA, X. 1998. An evaluation of Jacob's method for interpretation of pumping tests in heterogeneous formations. Water Resource Research, $\mathrm{V}$ 34, p. 1011-1025. 
MONTAÑO, J.; COLLAZO, M. P.; DE COULD, P. (1998). Caracteristica de la Evolucion Del Sistema Acuifero Guarani em el Uruguay. X Congresso Brasileiro de Águas Subterrâneas, Associação Brasileira de Águas Subterrâneas- ABAS. São Paulo. Anais v. 1, p. 19.

NAKIĆ, Z., POSAVEC, K. AND BAČANI, A. (2007), A Visual Basic Spreadsheet Macro for Geochemical Background Analysis. Groundwater, 45: 642-647.

OLEA R. A. (2007). Declustering of Clustered Preferential Sampling for Histogram and Semivariogram Inference. In: Mathematical Geology, 2007, v. 39, nº 5.

OLEA, R. A. (2003). Geostatistics for engineers and earth scientists. 3. print. Boston, Mass. [u.a.], Kluwer Academic Publ., 2003. xv, 303 p. Literaturverz. S. [261] - 266.

OlIVA, A. ; CHANG, H.K. ; CAETANO-CHANG, M. R. (2005). Determinação da condutividade hidráulica da Formação Rio Claro: análise comparativa através de análise granulométrica e ensaios com permeâmetro guelph e testes de slug. Águas Subterrâneas (São Paulo), v. 19, p. 1-17.

OLIVEIRA, L. A.; VIEIRA, A. S. (2010). Estado da Arte do Sistema Aquífero Guarani. Caminhos de Geografia- revista on line. Instituto de Geografia UFU. V. 11, n. 34, p. 174- 189.

PATRIARCHE, D.; CASTRO, M. C.; GOBLET, P. (2004). Large-scale hydraulic conductivities inferred from three-dimensional groundwater flow and $4 \mathrm{He}$ transport modeling in the Carrizo aquifer, Texas: J. Geophys. Res., v. 109, no. B11, art. B11202.

PATRIARCHE, D.; CASTRO, M. C.; GOOVAERTS, P. (2005). Estimating Regional Hydraulic Conductivity Fileds- a comparative Study of Geostatistical Methods. Mathematical Geology, v. 37, n 6.

PAULA E SILVA, F. (2003.).Geologia de subsuperfície e hidroestratigrafia do Grupo Bauru no Estado de São Paulo. Instituto de Geociências e Ciências Exatas. UNESP (Tese de Doutorado). Rio Claro. 166 p.

PAULA E SILVA, F.; CAVAGUTI, N. (1994). Nova caracterização estratigráfica e tectônica do Mesozóico na cidade de Bauru - SP. Geociências, Rio Claro, v. 1, p. 83-99.

PEDE, M. A. Z. (2004). Caracterização da Condutividade Hidráulica do Embasamento Cristalino Alterado Saturado na Região Metropolitana de São Paulo. Dissertação (Mestrado em Pós-Graduação em Geociências e Meio Ambiente) - Universidade Estadual Paulista.

PIUCI, J.; CAMPOS, H. (1984). Potencial do aquífero Botucatu na região de Araraquara (SP). In: CONGRESSO BRASILEIRO DE ÁGUAS SUBTERRÂNEAS, Fortaleza. Anais... Fortaleza: ABAS, p. 323-342.

PIUCI, J.; DINIZ, H. N. (1985). Conhecimento do Aquífero Botucatu na Cidade de AraraquaraSP. Revista do Instituto Geológico. v. 6, p. 23-44.

PRANDI, E. (2010). Gestão integrada das águas do Sistema Aquífero Bauru nas Bacias Hidrográficas dos rios Aguapeí e Peixe/SP. Instituto de Geociências e Ciências Exatas, Universidade Estadual Paulista, Rio Claro, Tese de Doutorado, 142 p. e anexos.

PREFEITURA DE BAURU. Geografia. Disponível em : < http://www.bauru.sp.gov.br/>. Acessado em 20 de Novembro de 2015. 
PYRCZ M.J., DEUTSCH C. V. (2003), Declustering and Debiasing. In: Searston, S. (eds.) Geostatistical Association of Australasia, Newsletter 19, October.

PYRCZ M.J., GRINGARTEN E., FRYKMAN P., DEUTSCH C. V., (2006), Representative Input Parameters for Geostatistical Simulation. In: Coburn T. C., Yarus R. J., Chambers R. L., eds., Stochastic Modeling and Geostatistics: Principles, Methods and Case Studies, Volume II: AAPG Computer Applications in Geology 5, p. 123-137.

RABELO, J. L. W. (2006), Edson Cezar (orient). Estudo da recarga do aqüífero Guarani no sistema Jacaré-Tietê. São Carlos, 2006. 200 p.

RAZACK, M.; HUNTLEY, D. (1991) Assessing transmissivity from specific capacity in a large and heterogeneous aluvial aquifer. Ground Water 29:856-861

RAZALI, N. M.; WAH, Y. B. (2011).Power comparisons of Shapiro-Wilk, KolmogorovSmirnov, Lilliefors and Anderson-Darling tests. Journalof Statistical Modeling and Analytics, vol. 2, n 1, 21-33.

ROCHA, G. (1997). O grande manancial do Cone Sul. Estudos Avançados, Universidade de São Paulo, São Paulo. V. 30, p 191-213.

ROGERS, P. P. (2006). Water crisis: myth or reality? London: Fundación Marcelino Botín, taylor e Francis, 331p.

ROYLE, A. G.(1979). Why geoestatistics? Engeneering e Mining Journal, 180 (5): 92-101.

S. K. SRIVASTAV; M. W. LUBCZYNSKI; A. K. BIYANI. (2007). Upscaling of transmissivity, derived from specific capacity: a hydrogeomorphological approach applied to the Doon Valley aquifer system in India, Hydrogeology Journal, 15, 7, 1251

SCHNEIDER, R.L., MÜHLMANN, H., TOMMASI, E., MEDEIROS, R.A., DAEMON, R.F. e NOGUEIRA, A.A. (1974). Revisão Estratigráfica da Bacia do Paraná. In: CONGRESSO BRASILEIRO DE GEOLOGIA, 28., 1974, Porto Alegre. Anais... Porto Alegre, SBG, v.1, p. 41-66.

SILVA, S.R.; CHANG, H.K. (2010). Hidroquímica dos Sistemas Aquíferos Bauru e Guarani na Região Metropolitana de Bauru (SP). Águas Subterrâneas (São Paulo), v. 24, p. 69-84.

SOARES A.P., SOARES P.C., HOLZ M. (2008). Correlações conflitantes no limite PermoTriássico no sul da Bacia do Paraná: o contato entre duas Superseqüências e implicações na configuração espacial do Aqüífero Guarani. Revista Pesquisas em Geociências, 35(2):115-133.

SOARES, J. J.; SILVA, D. W. da e LIMA, M. I. S. (2003) Current State and projection of the probable original vegetation of the São Carlos region of São Paulo State, Brazil. Braz. J. Biol. [online], vol.63, n.3, pp. 527-536. ISSN 1678-4375.

SOARES, P. C. (1975). Divisão estratigráfica do Mesozóico no Estado de São Paulo. Rev Bras Geoc 5: 229-252.

SOUZA, L. E., WEISS, A. L., COSTA, J. F. C. L., KOPPE, J. C. (2001). Impacto do agrupamento preferencial de amostras na inferência estatística: aplicações em mineração. In: Revista Escola de Minas v.54 n.4 Ouro Preto out./dez. 
STRADIOTO, M.R. ; KIANG, C. H. ; CHANG, M. R. C. (2008) . Caracterização petrográfica e aspectos diagenéticos dos arenitos do Grupo Bauru na região sudoeste do Estado de São Paulo. REM. Revista Escola de Minas (Impresso), v. 61, p. 433-441.

THEIS, C.V., (1935). The relation between the lowering of the piezometric surface and the rate and duration of discharge of a well using groundwater storage, Am. Geophys. Union Trans., vol. 16, pp. 519-524.

VARNIER, C. ; IRITANI, M. A. ; VIOTTI, M. ; ODA, G. H. ; FERREIRA, L. M. R. (2010). Nitrato nas Águas Subterrâneas do Sistema Aquífero Bauru, Área Urbana do Município de Marília (SP). Revista do Instituto Geológico, v. 31, p. 1-21.

VERBOVŠEK, T. (2008). Estimation of Transmissivity and Hydraulic Conductivity from Specific Capacity and Specific Capacity Index in Dolomite Aquifers. J. Hydrol. Eng., 13(9), 817-823.

VERBOVŠEK, TIMOTEJ. (2009). Hydrogeology and Geochemistry of Fractured DolomitesA Case Study of Slovenia. In: Aquifers: Formation, Transport and Pollution ISBN: 978-161668-051-0 Editor: Rachel H. Laughton, Nova Science Publishers, Inc.

WAHNFRIED, I. D. (2010) Recarga do Sistema Aquifero Guarani através da Formação Serra Geral: definição de zonas de proteção. f. Tese (Doutorado em Recursos Minerais e Hidrogeologia) - Instituto de Geociências, Fundação de Amparo à Pesquisa do Estado de São Paulo. Orientador: Ricardo César Aoki Hirata.

WEN, X. H.; GÓMEZ-HERNÁNDEZ, J. J. (1998). Numerical modeling of macrodispersion in heterogeneous media: a comparison of multi-gaussian and non-multi-gaussian models. Journal of Contaminant Hydrology, v. 30, 129-156.

WEN, X. H.; KUNG, C. S.(1993). Stochastic simulation of solute transport in heterogeneous formation: a comparison of parametric and nonparametric geostatistical approaches. Ground Water, v. 31, n. 6, p. 953-965.

WLADIS, D.; GUSTAFSON, G. (1999). Regional characterization of hydraulic properties of rock using air-lift data: Hydrogeol. J., v. 7, no. 2, p. 168-179

YAMAMOTO, J. K. (2001) Avaliação e classificação de reservas minerais. São Paulo, EDUSP, FAPESP, 226 p.. Acadêmica.

YAMAMOTO, J. K.; LANDIM, P. M. B. (2013). Geoestatística conceitos e aplicações. São Paulo, Oficina de Textos, 2013. 215 p.

YOON, H., D. B. HART, AND S. A. MCKENNA (2013), Parameter estimation and predictive uncertainty in stochastic inverse modeling of groundwater flow: Comparing null-space Monte Carlo and multiple starting point methods, Water Resour. Res., 49, doi: 10.1002/wrcr.20064.

ZINN, B.; HARVEY, C. F.(2003). When good statistical models of aquifer heterogeneity go bad: a comparison of flow, dispersion, and mass transfer in connected and multivariate Gaussian hydraulic conductivity fields. Water Resources Research, v. 39, n. 3, 1051. 
ANEXO I 
Tabela 28: Informações dos poços instalado na área de interesse na cidade de Bauru. Na tabela são apresentadas as coordenadas em UTM (X e Y), a cota topográfica (Z), nível d'água estático (N.E.), nível d'água dinâmico (N.D.), capacidade especifica e seu logaritmo (Q/s e log $Q /$ s, respectivamente) e condutividade hidráulica e seu logaritmo ( $K$ e log $K$, respectivamente) e o valor do logaritmo de condutividade hidráulica calculado pela equação 83 (log K calculado por regressão linear. “- “significa que a informação não está disponível.

\begin{tabular}{|c|c|c|c|c|c|c|c|c|c|c|}
\hline ID & $\mathbf{X}$ & $\mathbf{Y}$ & $\begin{array}{c}\mathbf{Z} \\
(\mathbf{m})\end{array}$ & $\begin{array}{c}\text { N.E. } \\
(\mathbf{m})\end{array}$ & $\begin{array}{c}\mathbf{N} . \mathbf{D} . \\
(\mathbf{m})\end{array}$ & $\begin{array}{c}\mathbf{Q} / \mathbf{s} \\
\left(\mathbf{m}^{2} / \mathbf{d}\right)\end{array}$ & $\begin{array}{c}\text { log Q/s } \\
\left(\mathbf{m}^{2} / \mathbf{d}\right)\end{array}$ & $\begin{array}{c}\mathbf{K} \\
(\mathbf{m} / \mathbf{d})\end{array}$ & $\begin{array}{c}\text { log K} \\
(\mathbf{m} / \mathbf{d})\end{array}$ & $\begin{array}{c}\text { log K (m/d) calculado } \\
\text { por regressão linear }\end{array}$ \\
\hline 1 & 202800 & 7556000 & 876 & 115.15 & 260 & 13.7588 & 1.1386 & 0.0291 & -1.5364 & -1.5364 \\
\hline 2 & 200374 & 7558131 & 880 & 64.88 & - & 126.4155 & 2.1018 & 0.8404 & -0.0755 & -0.0755 \\
\hline 3 & 201950 & 7568560 & 880 & 139.91 & 161.03 & 61.6442 & 1.7899 & 0.6496 & -0.1873 & -0.1873 \\
\hline 4 & 200610 & 7575700 & 824 & 207.2 & 210.28 & 163.0189 & 2.2122 & 3.0000 & 0.4771 & 0.4771 \\
\hline 5 & 199280 & 7558190 & 780 & 99.33 & 170.16 & 65.4909 & 1.8162 & 0.5480 & -0.2612 & -0.2612 \\
\hline 6 & 201750 & 7559150 & - & 100.2 & 152.96 & 39.9728 & 1.6018 & 0.6748 & -0.1709 & -0.1709 \\
\hline 7 & 200550 & 7566850 & 870 & 128.5 & 154.51 & 39.0311 & 1.5914 & 0.0151 & -1.8206 & -1.8206 \\
\hline 8 & 199830 & 7563440 & 840 & 128.9 & 167.04 & 101.7323 & 2.0075 & 0.7170 & -0.1445 & -0.1445 \\
\hline 9 & 204150 & 7564450 & 890 & 137 & 167 & 82.4649 & 1.9163 & 1.1040 & 0.0430 & 0.0430 \\
\hline 10 & 200750 & 7560250 & 855 & 103.18 & 142.8 & 145.6472 & 2.1633 & 0.0242 & -1.6155 & -1.6155 \\
\hline 11 & 200605 & 7575700 & 824 & 207.2 & 210.38 & 163.0189 & 2.2122 & 2.9432 & 0.4688 & 0.4688 \\
\hline 12 & 197494 & 7566310 & 862 & 9.07 & 19.67 & 4.1887 & 0.6221 & 0.1311 & -0.8824 & -0.8824 \\
\hline 13 & 200835 & 7568620 & 880 & 117.25 & 140.58 & 163.0416 & 2.2123 & 1.1053 & 0.0435 & 0.0435 \\
\hline 14 & 202400 & 7559990 & 850 & 66.91 & 101.12 & 91.7205 & 1.9625 & 0.3852 & -0.4143 & -0.4143 \\
\hline 15 & 203800 & 7563250 & 910 & 144 & 163.48 & 199.7248 & 2.3004 & 1.7100 & 0.2330 & 0.2330 \\
\hline 16 & 202832 & 7556432 & 840 & 38 & 52 & 9.4286 & 0.9744 & 0.0613 & -1.2126 & -1.2126 \\
\hline 17 & 197150 & 7566700 & 870 & 138.7 & 154.46 & 65.3299 & 1.8151 & 0.7879 & -0.1035 & -0.1035 \\
\hline 18 & 202506 & 7556768 & 830 & 40.7 & 48 & 5.5000 & 0.7404 & 0.3594 & -0.4445 & -0.4445 \\
\hline 19 & 201600 & 7570700 & 810 & 15 & 80 & 18.4615 & 1.2663 & 0.1136 & -0.9448 & -0.9448 \\
\hline 20 & 201800 & 7559170 & 850 & 100.2 & 152.96 & 44.4882 & 1.6482 & 0.3723 & -0.4291 & -0.4291 \\
\hline
\end{tabular}




\begin{tabular}{|c|c|c|c|c|c|c|c|c|c|c|}
\hline ID & $\mathbf{X}$ & $\mathbf{Y}$ & $\begin{array}{c}\mathbf{Z} \\
(\mathbf{m})\end{array}$ & $\begin{array}{c}\text { N.E. } \\
(\mathbf{m})\end{array}$ & $\begin{array}{c}\text { N.D. } \\
(\mathbf{m})\end{array}$ & $\begin{array}{c}\mathbf{Q} / \mathbf{s} \\
\left(\mathbf{m}^{2} / \mathbf{d}\right)\end{array}$ & $\begin{array}{c}\text { log Q/s } \\
\left(\mathbf{m}^{2} / \mathbf{d}\right)\end{array}$ & $\begin{array}{c}\mathbf{K} \\
(\mathbf{m} / \mathbf{d})\end{array}$ & $\begin{array}{c}\text { log K } \\
(\mathbf{m} / \mathbf{d})\end{array}$ & $\begin{array}{c}\text { log K (m/d) calculado } \\
\text { por regressão linear }\end{array}$ \\
\hline 21 & 209650 & 7558400 & 945 & 150.3 & 156.58 & 137.58 & 2.1385541 & 0.373 & -0.42839 & -0.428388206 \\
\hline 22 & 203310 & 7559600 & 880 & 93.75 & 109.23 & 58.4651 & 1.76689682 & 0.276 & -0.55839 & -0.558392133 \\
\hline 23 & 203420 & 7560220 & 875 & 90 & 102 & 13.0909 & 1.11696981 & 0.082 & -1.08619 & -1.086186148 \\
\hline 24 & 202570 & 7563140 & - & 109.8 & 117.46 & 396 & 2.59769519 & 0.537 & -0.26991 & -0.269910195 \\
\hline 25 & 207850 & 7554210 & 770 & 6 & 12 & 20 & 1.30103 & 0.462 & -0.33567 & -0.335671481 \\
\hline 26 & 202680 & 7560740 & 870 & 71.32 & 93 & 2.21402 & 0.34518196 & 0.01 & -1.99209 & -1.992085531 \\
\hline 27 & 203450 & 7559950 & 840 & 118 & 130 & 36 & 1.5563025 & 0.218 & -0.66129 & -0.661294556 \\
\hline 28 & 198930 & 7562390 & 635 & 89.73 & 118.95 & 25.0185 & 1.39826093 & 0.478 & -0.32034 & -0.320335151 \\
\hline 29 & 202260 & 7569650 & 880 & 66 & 77.2 & 169.704 & 2.22969208 & - & - & -0.109664841 \\
\hline 30 & 202000 & 7574250 & 790 & 25 & 30 & 24 & 1.38021124 & - & - & -1.7088 \\
\hline 31 & 211180 & 7568820 & 720 & 40 & 60 & 28.8 & 1.45939249 & - & - & -0.662123708 \\
\hline 32 & 211780 & 7564710 & 800 & 8.63 & 9.87 & 21 & 1.32221929 & - & - & -0.760504322 \\
\hline 33 & 203710 & 7559980 & 880 & 104 & 118 & 48 & 1.68124124 & - & - & -0.503013785 \\
\hline 34 & 203620 & 7559550 & 870 & 80 & 82 & 105.6 & 2.02366392 & - & - & -0.257428238 \\
\hline 35 & 201900 & 7562060 & 805 & 40 & 58 & 133.32 & 2.1248953 & - & - & -0.184825087 \\
\hline 36 & 203980 & 7561300 & 830 & 52.5 & 88.89 & 91.536 & 1.96159193 & - & - & -0.301946268 \\
\hline 37 & 200860 & 7560280 & 855 & 103.18 & 142.8 & 145.68 & 2.16339993 & - & - & -0.157209568 \\
\hline 38 & 205040 & 7560400 & 860 & 104.28 & 132.54 & 54.936 & 1.73985703 & - & - & -0.460974535 \\
\hline 39 & 201070 & 7563420 & 852 & 108 & 125 & 42.336 & 1.62670982 & - & - & -0.542123715 \\
\hline 40 & 201700 & 7561320 & 830 & 15.96 & 70 & 3.768 & 0.57611089 & - & - & -1.295613267 \\
\hline
\end{tabular}


Continuação

\begin{tabular}{|c|c|c|c|c|c|c|c|c|c|c|}
\hline ID & $\mathbf{X}$ & $\mathbf{Y}$ & $\begin{array}{c}\mathrm{Z} \\
(\mathrm{m})\end{array}$ & $\begin{array}{c}\text { N.E. } \\
(\mathrm{m})\end{array}$ & $\begin{array}{c}\text { N.D. } \\
(\mathbf{m})\end{array}$ & $\begin{array}{c}\mathrm{Q} / \mathbf{s} \\
\left(\mathbf{m}^{2} / \mathbf{d}\right)\end{array}$ & $\begin{array}{c}\text { log Q/s } \\
\left(\mathbf{m}^{2} / \mathbf{d}\right)\end{array}$ & $\begin{array}{c}\mathbf{K} \\
(\mathbf{m} / \mathbf{d})\end{array}$ & $\begin{array}{c}\text { log K } \\
(\mathbf{m} / \mathbf{d})\end{array}$ & $\begin{array}{c}\text { log K (m/d) calculado } \\
\text { por regressão linear }\end{array}$ \\
\hline 41 & 201750 & 7561270 & 830 & 96.18 & 101.2 & 23.904 & 1.37847058 & - & - & -0.7201609 \\
\hline 42 & 201740 & 7561250 & 825 & 81 & 90 & 99.984 & 1.99993051 & - & - & -0.27444984 \\
\hline 43 & 201700 & 7561350 & 830 & 91.4 & 104.95 & 91.92 & 1.96341002 & - & - & -0.300642337 \\
\hline 44 & 197650 & 7559400 & 732 & 33 & 67 & 8.328 & 0.92054072 & - & - & -1.048588198 \\
\hline 45 & 202370 & 7559070 & 0 & 94.47 & 104 & 15.096 & 1.17886189 & - & - & -0.863320255 \\
\hline 46 & 203540 & 7560390 & 875 & 90 & 101 & 12.576 & 1.09954253 & - & - & -0.920208098 \\
\hline 47 & 207320 & 7555340 & 790 & 20 & 28 & 12 & 1.07918125 & - & - & -0.93481121 \\
\hline 48 & 201120 & 7552540 & 860 & 140 & 170 & 4.8 & 0.68124124 & - & - & -1.220213785 \\
\hline 49 & 208600 & 7553140 & 751 & 0 & 1.57 & 310.32 & 2.49180977 & - & - & 0.078325965 \\
\hline 50 & 207970 & 7555260 & 780 & 8 & 15 & 13.704 & 1.13684735 & - & - & -0.893453081 \\
\hline 51 & 202450 & 7560300 & 850 & 81.51 & 87.51 & 146.4 & 2.16554108 & - & - & -0.15567394 \\
\hline 52 & 202830 & 7556430 & 840 & 38 & 52 & 9.36 & 0.97127585 & - & - & -1.012200961 \\
\hline 53 & 207760 & 7554190 & 770 & 5 & 23 & 41.28 & 1.61573969 & - & - & -0.549991495 \\
\hline 54 & 206170 & 7556720 & 780 & 8 & 15 & 13.704 & 1.13684735 & - & - & -0.893453081 \\
\hline 55 & 206200 & 7556740 & 780 & 10 & 20 & 4.8 & 0.68124124 & - & - & -1.220213785 \\
\hline 56 & 202824 & 7556194 & 830 & 45.5 & 59.7 & 11.064 & 1.04391217 & - & - & -0.960106194 \\
\hline 57 & 202790 & 7557340 & 830 & 23.98 & 27.09 & 45.984 & 1.66260675 & - & - & -0.516378441 \\
\hline 58 & 202980 & 7556650 & 830 & 23 & 30.02 & 17.088 & 1.23269124 & - & - & -0.824713846 \\
\hline 59 & 203290 & 7559600 & 880 & 106.75 & 111.35 & 279.648 & 2.44661172 & - & - & 0.045909924 \\
\hline 60 & 198800 & 7559390 & 733 & 11.4 & 13.6 & 52.32 & 1.71866774 & - & - & -0.4761715 \\
\hline
\end{tabular}


Continuação

\begin{tabular}{|c|c|c|c|c|c|c|c|c|c|c|}
\hline ID & $\mathbf{X}$ & $\mathbf{Y}$ & $\begin{array}{c}\mathbf{Z} \\
(\mathbf{m})\end{array}$ & $\begin{array}{c}\text { N.E. } \\
(\mathbf{m})\end{array}$ & $\begin{array}{c}\mathbf{N} . D . \\
(\mathbf{m})\end{array}$ & $\begin{array}{c}\mathbf{Q} / \mathbf{s} \\
\left(\mathbf{m}^{2} / \mathbf{d}\right)\end{array}$ & $\begin{array}{c}\log \mathbf{Q} / \mathbf{s} \\
\left(\mathbf{m}^{2} / \mathbf{d}\right)\end{array}$ & $\begin{array}{c}\mathbf{K} \\
(\mathbf{m} / \mathbf{d})\end{array}$ & $\begin{array}{c}\text { log K} \\
(\mathbf{m} / \mathbf{d})\end{array}$ & $\begin{array}{c}\text { log K (m/d) calculado } \\
\text { por regressão linear }\end{array}$ \\
\hline 61 & 202950 & 7555930 & 850 & 54 & 60.2 & 14.952 & 1.17469929 & - & - & -0.86630567 \\
\hline 62 & 194360 & 7555280 & 820 & 28 & 44 & 22.488 & 1.35195083 & - & - & -0.739180863 \\
\hline 63 & 202590 & 7559100 & 850 & 87 & 93.58 & 18.216 & 1.26045302 & - & - & -0.804803096 \\
\hline 64 & 207000 & 7551370 & 0 & 2.5 & 5.62 & 25.368 & 1.40428623 & - & - & -0.701645917 \\
\hline 65 & 204290 & 7559320 & 848 & 84.97 & 93.83 & 74.472 & 1.87199302 & - & - & -0.366206608 \\
\hline 66 & 202690 & 7556500 & 835 & 12.18 & 18.15 & 8.04 & 0.90525605 & - & - & -1.059550362 \\
\hline 67 & 216000 & 7559500 & 830 & 20 & 40 & 144 & 2.15836249 & - & - & -0.160822421 \\
\hline
\end{tabular}


ANEXO II 
Tabela 29: Informações dos poços instalado na área de interesse na cidade de Bauru. Na tabela são apresentadas as coordenadas em UTM (X e Y), a cota topográfica (Z), nivel d'água estático (N.E.), nivvel d'água dinâmico (N.D.), capacidade especifica e seu logaritmo (Q/s e log Q/s, respectivamente) e condutividade hidráulica e seu logaritmo ( $K$ e log $K$, respectivamente) e o valor do logaritmo de condutividade hidráulica calculado pela equação 85 (log K calculado por regressão linear. "“- " significa que a informação não está disponivel.

\begin{tabular}{|c|c|c|c|c|c|c|c|c|c|c|}
\hline ID & $\mathbf{X}$ & $\mathbf{Y}$ & $\begin{array}{c}\mathbf{Z} \\
(\mathbf{m})\end{array}$ & $\begin{array}{c}\mathbf{N} . \mathrm{E} . \\
(\mathbf{m})\end{array}$ & $\begin{array}{c}\mathbf{N} . \mathbf{D} . \\
(\mathbf{m})\end{array}$ & $\begin{array}{c}\mathbf{Q} / \mathbf{s} \\
\left(\mathbf{m}^{2} / \mathbf{d}\right)\end{array}$ & $\begin{array}{c}\text { log Q/s } \\
\left(\mathbf{m}^{2} / \mathbf{d}\right)\end{array}$ & $\begin{array}{c}\text { K } \\
(\mathbf{m} / \mathbf{d})\end{array}$ & $\begin{array}{c}\text { log K} \\
(\mathbf{m} / \mathbf{d})\end{array}$ & $\begin{array}{c}\text { log K (m/d) calculado } \\
\text { por regressão linear }\end{array}$ \\
\hline 1 & 7526740 & 702360 & 585 & 22.15 & 41.5 & 1.24031 & 0.09353027 & 0.015 & -1.82757 & -1.827573695 \\
\hline 2 & 7529650 & 695700 & 580 & 19.1 & 48.7 & 2.67568 & 0.42743347 & 0.025 & -1.60862 & -1.608623761 \\
\hline 3 & 7529350 & 698150 & 530 & 87.3 & 96.44 & 47.2648 & 1.67453755 & 0.159 & -0.79769 & -0.797693358 \\
\hline 4 & 7528920 & 701250 & 580 & 3.6 & 22.3 & 3.57025 & 0.55269838 & 0.013 & -1.86995 & -1.869948516 \\
\hline 5 & 7527600 & 700250 & 539 & 40 & 46 & 3.2 & 0.50514998 & 0.009 & -2.0381 & -2.038104526 \\
\hline 6 & 7529140 & 698710 & 597 & 18 & 43 & 0.47809 & -0.3204925 & 0.001 & -2.86012 & -2.860120914 \\
\hline 7 & 7529620 & 702610 & 550 & 42 & 90 & 1.6 & 0.20411998 & 0.002 & -2.70611 & -2.706109252 \\
\hline 8 & 7522880 & 702850 & 542 & 35.4 & 87.3 & 5.54913 & 0.74422513 & 0.023 & -1.63891 & -1.638912716 \\
\hline 9 & 7529950 & 697900 & 510 & 10.51 & 20.5 & 9.60961 & 0.98270574 & 0.183 & -0.73874 & -0.738737131 \\
\hline 10 & 7529939 & 698834 & 525 & 35.22 & 71.5 & 2.64609 & 0.42260395 & 0.005 & -2.2644 & -2.2644011 \\
\hline 11 & 7527118 & 695592 & 559 & 20.2 & 30.5 & 4.66019 & 0.66840401 & 0.043 & -1.36991 & -1.369911285 \\
\hline 12 & 7530480 & 699820 & 545 & 21 & 60 & 3.07692 & 0.48811664 & 0.01 & -1.98216 & -1.982159172 \\
\hline 13 & 7526167 & 702061 & 600 & 32 & 57.45 & 2.35756 & 0.37246346 & 0.032 & -1.49069 & -1.490694062 \\
\hline 14 & 7531250 & 702786 & 527 & 11 & 21 & 5.4 & 0.73239376 & 0.003 & -2.58875 & -2.588754525 \\
\hline 15 & 7524888 & 696304 & 573 & 24.1 & 44.3 & 2.37624 & 0.37588987 & 0.029 & -1.53511 & -1.535113202 \\
\hline 16 & 7530230 & 698900 & 528 & 24.5 & 45 & 1.17073 & 0.06845738 & 0.014 & -1.85428 & -1.854277657 \\
\hline 17 & 7525718 & 700058 & 545 & 16.6 & 66.5 & 1.92385 & 0.28417069 & 0.016 & -1.80543 & -1.805425335 \\
\hline 18 & 7528650 & 702430 & 560 & 42.1 & 68.5 & 2.72727 & 0.43572857 & 0.015 & -1.81291 & -1.812913357 \\
\hline 19 & 7534765 & 696559 & 592 & 39.5 & 63.5 & 21.573 & 1.33391122 & 0.076 & -1.12115 & -1.121145748 \\
\hline 20 & 7535050 & 696450 & 591 & 43.23 & 65 & 22.0633 & 1.34367106 & 0.082 & -1.08842 & -1.088421903 \\
\hline
\end{tabular}


Continuação

\begin{tabular}{|c|c|c|c|c|c|c|c|c|c|c|}
\hline ID & $\mathbf{X}$ & $\mathbf{Y}$ & $\begin{array}{c}\mathbf{Z} \\
(\mathbf{m})\end{array}$ & $\begin{array}{c}\mathbf{N} . \mathbf{E} . \\
(\mathbf{m})\end{array}$ & $\begin{array}{c}\mathbf{N} . \mathbf{D} . \\
(\mathbf{m})\end{array}$ & $\begin{array}{c}\mathbf{Q} / \mathbf{s} \\
\left(\mathbf{m}^{2} / \mathbf{d}\right)\end{array}$ & $\begin{array}{c}\text { log Q/s } \\
\left(\mathbf{m}^{2} / \mathbf{d}\right)\end{array}$ & $\begin{array}{c}\text { K } \\
(\mathbf{m} / \mathbf{d})\end{array}$ & $\begin{array}{c}\text { log K} \\
(\mathbf{m} / \mathbf{d})\end{array}$ & $\begin{array}{c}\text { log K (m/d) calculado } \\
\text { por regressão linear }\end{array}$ \\
\hline 21 & 7531640 & 703480 & 530 & 11.5 & 38 & 9.78113 & 0.99038912 & 0.098 & -1.00728 & -1.007277001 \\
\hline 22 & 7531650 & 703600 & 530 & 10.5 & 54 & 4.63448 & 0.66600127 & 0.042 & -1.3813 & -1.381298337 \\
\hline 23 & 7531600 & 703700 & 530 & 11.5 & 38.5 & 2.22222 & 0.34678749 & 0.187 & -0.72916 & -0.72916479 \\
\hline 24 & 7530290 & 698840 & 557 & 85 & 93 & 33.6 & 1.52633928 & 0.168 & -0.77469 & -0.774690718 \\
\hline 25 & 7527350 & 688250 & 460 & 15 & 25 & 3.53684 & 0.54861567 & 0.013 & -1.89034 & -1.890342483 \\
\hline 26 & 7526411 & 702782 & 637 & 42 & 72 & 4.28571 & 0.63202321 & 0.01 & -1.99662 & -1.996620259 \\
\hline 27 & 7530590 & 697320 & 560 & 39.85 & 56.65 & 1.14286 & 0.05799195 & 0.008 & -2.12241 & -2.1224064 \\
\hline 28 & 7530860 & 698800 & 519 & 25 & 46 & 2.34172 & 0.36953446 & 0.001 & -2.91721 & -2.91721463 \\
\hline 29 & 7533110 & 701360 & 590 & 31.08 & 77.2 & 5.18868 & 0.71505682 & 0.022 & -1.66756 & -1.66756154 \\
\hline 30 & 7528470 & 699220 & 580 & 44.66 & 73.4 & 0.6 & -0.2218487 & 0.009 & -2.03361 & -2.033608601 \\
\hline 31 & 7524893 & 696143 & 585 & 18 & 40 & 2.53968 & 0.40477943 & 0.01 & -2.01351 & -2.013510707 \\
\hline 32 & 7526256 & 696457 & 542 & 26.1 & 45 & 2.90909 & 0.46375729 & 0.016 & -1.79588 & -1.795880017 \\
\hline 33 & 7532169 & 693437 & 605 & 21.5 & 38.1 & 0.99338 & -0.0028857 & 0.009 & -2.0609 & -2.060900829 \\
\hline 34 & 7523653 & 703446 & 589 & 16.3 & 46.5 & 1.32597 & 0.12253267 & 0.003 & -2.52043 & -2.520432009 \\
\hline 35 & 7528559 & 699038 & 589 & 29.3 & 47.4 & 1.07958 & 0.03325675 & $2 \mathrm{E}-04$ & -3.65223 & -3.652226601 \\
\hline 36 & 7528050 & 700160 & 605 & 28.3 & 56.59 & 1.5894 & 0.20123429 & 0.01 & -1.99003 & -1.990028515 \\
\hline 37 & 7523780 & 697840 & 582 & 22.1 & 52.3 & 3.00752 & 0.47820835 & 0.012 & -1.90826 & -1.908256209 \\
\hline 38 & 7534200 & 695770 & 600 & 28.4 & 68.3 & 2.13333 & 0.32905872 & 0.011 & -1.95399 & -1.953987117 \\
\hline 39 & 7530300 & 699440 & 498 & 15 & 24 & 0.64 & -0.19382 & 0.005 & -2.27621 & -2.276206412 \\
\hline 40 & 7526052 & 701262 & 609 & 12.1 & 34.35 & 3.77953 & 0.57743752 & 0.052 & -1.28708 & -1.287075559 \\
\hline
\end{tabular}


Continuação

\begin{tabular}{|c|c|c|c|c|c|c|c|c|c|c|}
\hline ID & $\mathbf{X}$ & $\mathbf{Y}$ & $\begin{array}{c}\mathbf{Z} \\
(\mathbf{m})\end{array}$ & $\begin{array}{c}\mathbf{N} . \mathrm{E} . \\
(\mathbf{m})\end{array}$ & $\begin{array}{c}\mathbf{N} . \mathbf{D} . \\
(\mathbf{m})\end{array}$ & $\begin{array}{c}\mathbf{Q} / \mathbf{s} \\
\left(\mathbf{m}^{2} / \mathbf{d}\right)\end{array}$ & $\begin{array}{c}\text { log Q/s } \\
\left(\mathbf{m}^{2} / \mathbf{d}\right)\end{array}$ & $\begin{array}{c}\mathbf{K} \\
(\mathbf{m} / \mathbf{d})\end{array}$ & $\begin{array}{c}\text { log K} \\
(\mathbf{m} / \mathbf{d})\end{array}$ & $\begin{array}{c}\text { log K (m/d) calculado } \\
\text { por regressão linear }\end{array}$ \\
\hline 41 & 7526780 & 700580 & 548 & 18.3 & 31 & 0.70588 & -0.1512677 & 0.006 & -2.25403 & -2.254033433 \\
\hline 42 & 7523461 & 698532 & 525 & 4.35 & 21.35 & 4.87549 & 0.6880184 & 0.097 & -1.01472 & -1.014723257 \\
\hline 43 & 7531985 & 693394 & 603 & 17.42 & 32.68 & 1.04348 & 0.01848341 & 0.007 & -2.15583 & -2.15582895 \\
\hline 44 & 7575928 & 701995 & 610 & 40.11 & 55.23 & 2.44615 & 0.38848377 & 0.005 & -2.31932 & -2.319324619 \\
\hline 45 & 7534858 & 700297 & 570 & 18 & 41 & 1.96346 & 0.29302159 & 0.018 & -1.74473 & -1.744727495 \\
\hline 46 & 7531088 & 698544 & 506 & 32 & 84 & 2.63736 & 0.42116985 & 0.014 & -1.86491 & -1.864910346 \\
\hline 47 & 7527944 & 700695 & 590 & 43.5 & 80.17 & 2.70804 & 0.43265499 & 0.011 & -1.94983 & -1.949833391 \\
\hline 48 & 7529710 & 699550 & 537 & 15 & 60.45 & 2.9005 & 0.4624724 & 0.007 & -2.15872 & -2.158717163 \\
\hline 49 & 7530621 & 698370 & 581 & 25 & 60.45 & 1.17647 & 0.07058107 & $1 \mathrm{E}-04$ & -3.88097 & -3.880970123 \\
\hline 50 & 7528853 & 702904 & 615 & 45 & 119.47 & 0.64865 & -0.1879905 & 0.001 & -2.84976 & -2.849755398 \\
\hline 51 & 7523734 & 703059 & 587 & 35 & 86 & 1.35849 & 0.13305663 & 0.021 & -1.68329 & -1.6832898 \\
\hline 52 & 7528510 & 702100 & 560 & 23 & 60 & 2.01493 & 0.30425897 & 0.017 & -1.76531 & -1.765314026 \\
\hline 53 & 7530430 & 699880 & 545 & 25.5 & 52 & 2.10066 & 0.32235503 & 0.021 & -1.67717 & -1.677172875 \\
\hline 54 & 7528980 & 701240 & 575 & 20.55 & 41.99 & 1.48883 & 0.1728462 & 0.008 & -2.07218 & -2.072180687 \\
\hline 55 & 7527760 & 699540 & 518 & 25.5 & 48.35 & 6.94737 & 0.84182033 & $6 \mathrm{E}-04$ & -3.24304 & -3.243038049 \\
\hline 56 & 7530397 & 703369 & 551 & 28.44 & 44.56 & 12.938 & 1.11186733 & 0.285 & -0.54487 & -0.544873039 \\
\hline 57 & 7530370 & 700140 & 518 & 28 & 48 & 10.8628 & 1.03594181 & 0.128 & -0.89411 & -0.894108688 \\
\hline 58 & 7529400 & 696790 & 525 & 3.98 & 11.4 & 0.47727 & -0.3212334 & $3 \mathrm{E}-04$ & -3.52591 & -3.5259052 \\
\hline 59 & 7530310 & 698180 & 510 & 18.01 & 25.08 & 3.15789 & 0.49939765 & 0.002 & -2.77328 & -2.773275399 \\
\hline 60 & 7530450 & 701100 & 550 & 42 & 130 & 13.7143 & 1.13717319 & 0.043 & -1.36173 & -1.361727836 \\
\hline & & & & & & & & & & \\
\hline
\end{tabular}


Continuação

\begin{tabular}{|c|c|c|c|c|c|c|c|c|c|c|}
\hline ID & $x$ & $\mathbf{Y}$ & $\begin{array}{c}Z \\
(m)\end{array}$ & $\begin{array}{l}\text { N.E. } \\
\text { (m) }\end{array}$ & $\begin{array}{l}\text { N.D. } \\
\text { (m) }\end{array}$ & $\begin{array}{c}Q / s \\
\left(m^{2} / d\right)\end{array}$ & $\begin{array}{l}\log Q / s \\
\left(m^{2} / d\right)\end{array}$ & $\begin{array}{c}K \\
(m / d)\end{array}$ & $\begin{array}{l}\log K \\
(\mathrm{~m} / \mathrm{d})\end{array}$ & $\begin{array}{l}\log K(m / d) \text { calculado } \\
\text { por regressão linear }\end{array}$ \\
\hline 61 & 7529150 & 698000 & 535 & 35 & 83 & 11.1807 & 1.04846722 & 0.028 & -1.55201 & -1.552009987 \\
\hline 62 & 7525445 & 702009 & 589 & 20 & 78 & 1.17073 & 0.06845738 & 0.003 & -2.57848 & -2.578480805 \\
\hline 63 & 7529040 & 699910 & 536 & 11.8 & 25.8 & 36.0752 & 1.55720822 & 0.773 & -0.11168 & -0.111676806 \\
\hline 64 & 7531365 & 703701 & 520 & 19.5 & 40 & 59.8753 & 1.77724741 & 0.389 & -0.40965 & -0.409646768 \\
\hline 65 & 7527641 & 701371 & 590 & 33.88 & 38.67 & 6.912 & 0.83960373 & 0.009 & -2.05626 & -2.056255924 \\
\hline 66 & 7524700 & 702700 & 565 & 28.45 & 38.07 & 14.4 & 1.15836249 & 0.05 & -1.30332 & -1.303321792 \\
\hline 67 & 7524070 & 702720 & 590 & 33 & 58 & 1.28 & 0.10720997 & 0.005 & -2.33204 & -2.332042493 \\
\hline 68 & 7532709 & 695590 & 597 & 22 & 28 & 0.91837 & -0.0369836 & 0.001 & -2.89166 & -2.891660525 \\
\hline 69 & 7527670 & 700730 & 602 & 45 & 120 & 18.1474 & 1.25881556 & 0.866 & -0.06261 & -0.062605782 \\
\hline 70 & 7528670 & 702988 & 601 & 44.8 & 84 & 2.5248 & 0.40222698 & - & - & -1.974607168 \\
\hline 71 & 7529800 & 699540 & 530 & 4.65 & 9.94 & 3.3672 & 0.52726891 & - & - & -1.830146225 \\
\hline 72 & 7531310 & 703090 & 540 & 37 & 94 & 0.6648 & -0.177309 & - & - & -2.644145075 \\
\hline 73 & 7529600 & 705520 & 560 & 37 & 94 & 3.312 & 0.52009033 & - & - & -1.838439644 \\
\hline 74 & 7529690 & 705230 & 562 & 26 & 50 & 6.3 & 0.79934055 & - & - & -1.515821863 \\
\hline 75 & 7529930 & 698310 & - & 23.1 & 52 & 1.824 & 0.26102483 & - & - & -2.137738009 \\
\hline 76 & 7528070 & 701090 & 599 & 41 & 65 & 28.0008 & 1.44717044 & - & - & -0.767383991 \\
\hline 77 & 7527110 & 700210 & 609 & 18 & 31 & 39.984 & 1.60188624 & - & - & -0.588640828 \\
\hline 78 & 7525848 & 695616 & 601 & 55.6 & 61 & 2.0928 & 0.32072773 & - & - & -2.068763257 \\
\hline 79 & 7529547 & 698879 & 510 & 117.6 & 122.1 & 3.01704 & 0.47958107 & - & - & -1.885239992 \\
\hline 80 & 7523810 & 703060 & 565 & 35.08 & 105 & 2.4528 & 0.38966214 & - & - & -1.989123333 \\
\hline
\end{tabular}


Continuação

\begin{tabular}{|c|c|c|c|c|c|c|c|c|c|c|}
\hline ID & $\mathbf{X}$ & $\mathbf{Y}$ & $\begin{array}{c}\mathbf{Z} \\
(\mathbf{m})\end{array}$ & $\begin{array}{c}\text { N.E. } \\
(\mathbf{m})\end{array}$ & $\begin{array}{c}\mathbf{N} . \mathbf{D} . \\
(\mathbf{m})\end{array}$ & $\begin{array}{c}\mathbf{Q} / \mathbf{s} \\
\left(\mathbf{m}^{2} / \mathbf{d}\right)\end{array}$ & $\begin{array}{c}\text { log Q/s } \\
\left(\mathbf{m}^{\mathbf{2} / \mathbf{d})}\right.\end{array}$ & $\begin{array}{c}\mathbf{K} \\
(\mathbf{m} / \mathbf{d})\end{array}$ & $\begin{array}{c}\text { log K} \\
(\mathbf{m} / \mathbf{d})\end{array}$ & $\begin{array}{c}\text { log K (m/d) calculado } \\
\text { por regressão linear }\end{array}$ \\
\hline 81 & 7528260 & 699310 & 580 & 54 & 89 & 10.6752 & 1.02837602 & - & - & -1.251217184 \\
\hline 82 & 7528270 & 699300 & 580 & 43 & 88 & 4.944 & 0.69407846 & - & - & -1.637431153 \\
\hline 83 & 7528200 & 696050 & 545 & 10.88 & 13.69 & 3.636 & 0.56062387 & - & - & -1.791611238 \\
\hline 84 & 7523531 & 703059 & 584 & 32.1 & 66 & 0.5328 & -0.2734358 & - & - & -2.755200361 \\
\hline 85 & 7530430 & 698330 & 510 & 10 & 29.3 & 4.8 & 0.68124124 & - & - & -1.652261998 \\
\hline 86 & 7529950 & 697950 & 560 & 23.5 & 45 & 6 & 0.77815125 & - & - & -1.54030186 \\
\hline 87 & 7527872 & 700677 & 614 & 45 & 60 & 4.896 & 0.68984141 & - & - & -1.64232622 \\
\hline 88 & 7528350 & 696533 & 604 & 16.52 & 24.65 & 0.4656 & -0.331987 & - & - & -2.822844614 \\
\hline 89 & 7530303 & 699105 & 501 & 12.38 & 19.71 & 0.4992 & -0.3017254 & - & - & -2.787883382 \\
\hline 90 & 7530206 & 701154 & 572 & 32.75 & 66.2 & 0.84 & -0.0757207 & - & - & -2.526780141 \\
\hline 91 & 7529660 & 696200 & 660 & 20 & 44 & 2.88 & 0.45939249 & - & - & -1.908563859 \\
\hline 92 & 7531428 & 699667 & 600 & 10 & 38.2 & 133.32 & 2.1248953 & - & - & 0.015591546 \\
\hline 93 & 7530400 & 699750 & 556 & 35.5 & 48 & 4.7352 & 0.67533833 & - & - & -1.659081631 \\
\hline 94 & 7529092 & 699607 & 554 & 11.58 & 12.48 & 1.944 & 0.28869626 & - & - & -2.10576921 \\
\hline 95 & 7530175 & 699105 & 528 & 10.5 & 27.5 & 3.768 & 0.57611089 & - & - & -1.773719084 \\
\hline 96 & 7529470 & 703750 & 609 & 20.1 & 44.5 & 11.016 & 1.04202393 & - & - & -1.235449757 \\
\hline 97 & 7531289 & 703032 & 520 & 21 & 40 & 4.9872 & 0.69785678 & - & - & -1.633066056 \\
\hline 98 & 7529810 & 698730 & 665 & 27.48 & 38.22 & 0.6 & -0.2218487 & - & - & -2.69560186 \\
\hline 99 & 7530463 & 701523 & 559 & 35.5 & 44.16 & 19.9992 & 1.30101262 & - & - & -0.936240116 \\
\hline 100 & 7528590 & 698370 & 548 & 18 & 30 & 12.2016 & 1.08641678 & - & - & -1.18416269 \\
\hline
\end{tabular}


Continuação

\begin{tabular}{|c|c|c|c|c|c|c|c|c|c|c|}
\hline ID & $\mathbf{X}$ & $\mathbf{Y}$ & $\begin{array}{c}\mathbf{Z} \\
(\mathbf{m})\end{array}$ & $\begin{array}{c}\text { N.E. } \\
(\mathbf{m})\end{array}$ & $\begin{array}{c}\mathbf{N} . \mathbf{D} . \\
(\mathbf{m})\end{array}$ & $\begin{array}{c}\mathbf{Q} / \mathbf{s} \\
\left(\mathbf{m}^{2} / \mathbf{d}\right)\end{array}$ & $\begin{array}{c}\text { log Q/s } \\
\left(\mathbf{m}^{\mathbf{2} / \mathbf{d})}\right.\end{array}$ & $\begin{array}{c}\mathbf{K} \\
(\mathbf{m} / \mathbf{d})\end{array}$ & $\begin{array}{c}\text { log K} \\
(\mathbf{m} / \mathbf{d})\end{array}$ & $\begin{array}{c}\text { log K (m/d) calculado } \\
\text { por regressão linear }\end{array}$ \\
\hline 101 & 7532800 & 698600 & 570 & 31 & 37 & 6.168 & 0.79014437 & - & - & -1.526446215 \\
\hline 102 & 7528210 & 699580 & 585 & 51 & 62.8 & 4.188 & 0.62200667 & - & - & -1.720695691 \\
\hline 103 & 7530590 & 701510 & 550 & 22 & 36 & 13.44 & 1.12839927 & - & - & -1.135660325 \\
\hline 104 & 7529868 & 699659 & 538 & 16.5 & 44 & 0.6336 & -0.1981848 & - & - & -2.668262936 \\
\hline 105 & 7531316 & 698718 & 508 & 10.5 & 15.5 & 14.4 & 1.15836249 & - & - & -1.101043813 \\
\hline 106 & 7529767 & 696315 & 553 & 29.5 & 90.1 & 3.216 & 0.50731604 & - & - & -1.853197779 \\
\hline 107 & 7527990 & 699410 & 560 & 38 & 51 & 7.7328 & 0.88833678 & - & - & -1.413004521 \\
\hline 108 & 7528730 & 698760 & 570 & 34 & 75 & 22.56 & 1.3533391 & - & - & -0.875787343 \\
\hline 109 & 7529100 & 699200 & 575 & 30 & 48 & 20.712 & 1.31622204 & - & - & -0.91866868 \\
\hline 110 & 7527750 & 694350 & 574 & 48.3 & 54.2 & 6 & 0.77815125 & - & - & -1.54030186 \\
\hline 111 & 7534758 & 696590 & 591 & 36.5 & 90 & 4.656 & 0.66801297 & - & - & -1.667544614 \\
\hline 112 & 7534599 & 697202 & 578 & 20 & 48 & 10.212 & 1.00911081 & - & - & -1.273474286 \\
\hline 113 & 7533199 & 699123 & 580 & 34.4 & 37.75 & 4.0008 & 0.60214684 & - & - & -1.743639754 \\
\hline 114 & 7529790 & 700210 & 570 & 26.1 & 35.5 & 2.37024 & 0.37479232 & - & - & -2.006302429 \\
\hline 115 & 7528674 & 700175 & 545 & 22.5 & 65.3 & 3.312 & 0.52009033 & - & - & -1.838439644 \\
\hline 116 & 7531370 & 704480 & 521 & 13.5 & 54 & 1.8864 & 0.27563379 & - & - & -2.120860285 \\
\hline 117 & 7529570 & 700480 & 571 & 20 & 100 & 3.5664 & 0.55223005 & - & - & -1.801308622 \\
\hline 118 & 7528660 & 700460 & 570 & 16.38 & 64.54 & 7.0944 & 0.85091567 & - & - & -1.456237125 \\
\hline 119 & 7533204 & 684773 & 540 & 48 & 97 & 8.2272 & 0.91525205 & - & - & -1.381909301 \\
\hline 120 & 7531460 & 686241 & 480 & 23 & 46 & 1.44 & 0.15836249 & - & - & -2.256343813 \\
\hline
\end{tabular}


Continuação

\begin{tabular}{|c|c|c|c|c|c|c|c|c|c|c|}
\hline ID & $\mathbf{X}$ & $\mathbf{Y}$ & $\begin{array}{c}\mathbf{Z} \\
(\mathbf{m})\end{array}$ & $\begin{array}{c}\text { N.E. } \\
(\mathbf{m})\end{array}$ & $\begin{array}{c}\mathbf{N} . \mathbf{D} . \\
(\mathbf{m})\end{array}$ & $\begin{array}{c}\mathbf{Q} / \mathbf{s} \\
\left(\mathbf{m}^{2} / \mathbf{d}\right)\end{array}$ & $\begin{array}{c}\text { log Q/s } \\
\left(\mathbf{m}^{\mathbf{2} / \mathbf{d})}\right.\end{array}$ & $\begin{array}{c}\mathbf{K} \\
(\mathbf{m} / \mathbf{d})\end{array}$ & $\begin{array}{c}\text { log K} \\
(\mathbf{m} / \mathbf{d})\end{array}$ & $\begin{array}{c}\text { log K (m/d) calculado } \\
\text { por regressão linear }\end{array}$ \\
\hline 121 & 7530322 & 686841 & 520 & 58 & 72 & 3 & 0.47712125 & - & - & -1.888081814 \\
\hline 122 & 7531045 & 697364 & 606 & 23 & 34.5 & 11.016 & 1.04202393 & - & - & -1.235449757 \\
\hline 123 & 7528310 & 701100 & 580 & 32 & 62 & 6.5064 & 0.81334076 & - & - & -1.499647421 \\
\hline 124 & 7528543 & 701543 & 600 & 41.5 & 46.29 & 1.2 & 0.07918125 & - & - & -2.347821906 \\
\hline 125 & 7527577 & 701488 & 591 & 24.45 & 51 & 5.64 & 0.7512791 & - & - & -1.571347251 \\
\hline 126 & 7534392 & 699079 & 557 & 11.33 & 21.3 & 8.47056 & 0.92791212 & - & - & -1.367283124 \\
\hline 127 & 7525361 & 702364 & 601 & 20 & 54 & 2.9208 & 0.46550182 & - & - & -1.901505747 \\
\hline 128 & 7526995 & 701525 & 587 & 23 & 40 & 11.28 & 1.0523091 & - & - & -1.223567297 \\
\hline 129 & 7530138 & 698112 & 513 & 36.85 & 76.28 & 17.736 & 1.24885568 & - & - & -0.996497033 \\
\hline 130 & 7529342 & 691845 & 608 & 35 & 45 & 0.5856 & -0.2323989 & - & - & -2.707790486 \\
\hline 131 & 7529775 & 700310 & 555 & 20.62 & 27.58 & 1.1424 & 0.05781819 & - & - & -2.37250264 \\
\hline 132 & 7532250 & 700160 & 550 & 21.1 & 70.18 & 3.7848 & 0.57804294 & - & - & -1.771486997 \\
\hline 133 & 7529750 & 695000 & 565 & 38.5 & 65.8 & 12 & 1.07918125 & - & - & -1.192521906 \\
\hline 134 & 7534283 & 699071 & 587 & 38 & 63.1 & 6.3984 & 0.80607139 & - & - & -1.508045727 \\
\hline 135 & 7531250 & 703800 & 535 & 12 & 40 & 3.68376 & 0.56629133 & - & - & -1.785063629 \\
\hline 136 & 7525850 & 701288 & 500 & 21 & 36 & 7.9992 & 0.90304656 & - & - & -1.396010315 \\
\hline 137 & 7527910 & 701330 & 610 & 17 & 60 & 5.28 & 0.72263392 & - & - & -1.604441029 \\
\hline 138 & 7528670 & 698950 & 571 & 43 & 58 & 2.4 & 0.38021124 & - & - & -2.000041952 \\
\hline 139 & 7524250 & 698250 & 565 & 33.32 & 46.95 & 3.9192 & 0.59319743 & - & - & -1.753979013 \\
\hline 140 & 7530974 & 700047 & 522 & 21 & 36 & 1.9512 & 0.29030179 & - & - & -2.103914345 \\
\hline
\end{tabular}


Continuação

\begin{tabular}{|c|c|c|c|c|c|c|c|c|c|c|}
\hline ID & $\mathbf{X}$ & $\mathbf{Y}$ & $\begin{array}{c}\mathbf{Z} \\
(\mathbf{m})\end{array}$ & $\begin{array}{c}\text { N.E. } \\
(\mathbf{m})\end{array}$ & $\begin{array}{c}\mathbf{N} . \mathbf{D} . \\
(\mathbf{m})\end{array}$ & $\begin{array}{c}\mathbf{Q} / \mathbf{s} \\
\left(\mathbf{m}^{2} / \mathbf{d}\right)\end{array}$ & $\begin{array}{c}\text { log Q/s } \\
\left(\mathbf{m}^{\mathbf{2} / \mathbf{d})}\right.\end{array}$ & $\begin{array}{c}\mathbf{K} \\
(\mathbf{m} / \mathbf{d})\end{array}$ & $\begin{array}{c}\text { log K} \\
(\mathbf{m} / \mathbf{d})\end{array}$ & $\begin{array}{c}\text { log K (m/d) calculado } \\
\text { por regressão linear }\end{array}$ \\
\hline 141 & 7528600 & 702340 & 566 & 21 & 51 & 2.88 & 0.45939249 & - & - & -1.908563859 \\
\hline 142 & 7529776 & 696036 & 569 & 18.2 & 30.5 & 2.6616 & 0.42514279 & - & - & -1.948132537 \\
\hline 143 & 7532347 & 695523 & 601 & 42.38 & 57.65 & 41.616 & 1.61926033 & - & - & -0.568568535 \\
\hline 144 & 7531100 & 701550 & 530 & 40 & 85.05 & 5.46 & 0.73719264 & - & - & -1.58762134 \\
\hline 145 & 7531850 & 703340 & 525 & 76.7 & 85.58 & 6 & 0.77815125 & - & - & -1.54030186 \\
\hline 146 & 7527291 & 700784 & 620 & 48.4 & 62.46 & 28.8 & 1.45939249 & - & - & -0.753263859 \\
\hline 147 & 7525224 & 694257 & 620 & 62 & 122 & 5.4 & 0.73239376 & - & - & -1.593165489 \\
\hline 148 & 7530261 & 696798 & 530 & 4 & 6.5 & 4.2648 & 0.62989867 & - & - & -1.711578067 \\
\hline 149 & 7527756 & 696178 & 665 & 34 & 42 & 0.9504 & -0.0220936 & - & - & -2.464824704 \\
\hline 150 & 7530442 & 698927 & 547 & 12.5 & 17 & 2.64 & 0.42160393 & - & - & -1.952220983 \\
\hline 151 & 7528247 & 699504 & 606 & 23 & 48.2 & 2.5248 & 0.40222698 & - & - & -1.974607168 \\
\hline 152 & 7525273 & 702264 & 610 & 23.43 & 30.62 & 15.888 & 1.20106923 & - & - & -1.051704717 \\
\hline 153 & 7529640 & 696170 & 560 & 21 & 40 & 3.156 & 0.49913699 & - & - & -1.86264703 \\
\hline 154 & 7530383 & 702802 & 565 & 28.5 & 51.15 & 3.192 & 0.50406288 & - & - & -1.856956152 \\
\hline 155 & 7526030 & 696161 & 577 & 30 & 68 & 3.6 & 0.5563025 & - & - & -1.796603721 \\
\hline 156 & 7529498 & 699195 & 582 & 21 & 38 & 8.088 & 0.90784114 & - & - & -1.390471128 \\
\hline 157 & 7533759 & 698330 & 613 & 27.26 & 42.51 & 5.4792 & 0.73871715 & - & - & -1.585860073 \\
\hline 158 & 7531973 & 700731 & 259 & 21.2 & 29.5 & 1.7952 & 0.25411284 & - & - & -2.145723436 \\
\hline 159 & 7522350 & 704100 & 525 & 18 & 30.7 & 0.5832 & -0.2341825 & - & - & -2.709851025 \\
\hline 160 & 7529478 & 698047 & 566 & 40.1 & 80.16 & 9 & 0.95424251 & - & - & -1.336863629 \\
\hline
\end{tabular}


Continuação

\begin{tabular}{|c|c|c|c|c|c|c|c|c|c|c|}
\hline ID & $\mathbf{X}$ & $\mathbf{Y}$ & $\begin{array}{c}\mathbf{Z} \\
(\mathbf{m})\end{array}$ & $\begin{array}{c}\text { N.E. } \\
(\mathbf{m})\end{array}$ & $\begin{array}{c}\mathbf{N} . \mathbf{D} . \\
(\mathbf{m})\end{array}$ & $\begin{array}{c}\mathbf{Q} / \mathbf{s} \\
\left(\mathbf{m}^{2} / \mathbf{d}\right)\end{array}$ & $\begin{array}{c}\text { log Q/s } \\
\left(\mathbf{m}^{\mathbf{2} / \mathbf{d})}\right.\end{array}$ & $\begin{array}{c}\mathbf{K} \\
(\mathbf{m} / \mathbf{d})\end{array}$ & $\begin{array}{c}\text { log K} \\
(\mathbf{m} / \mathbf{d})\end{array}$ & $\begin{array}{c}\text { log K (m/d) calculado } \\
\text { por regressão linear }\end{array}$ \\
\hline 161 & 7528394 & 701394 & 598 & 49 & 90 & 4.1856 & 0.62175772 & - & - & -1.720983303 \\
\hline 162 & 7527116 & 696263 & 563 & 34 & 58 & 1.44 & 0.15836249 & - & - & -2.256343813 \\
\hline 163 & 7528419 & 702502 & 635 & 37 & 80 & 19.44 & 1.28869626 & - & - & -0.95046921 \\
\hline 164 & 7529542 & 701423 & 589 & 12.5 & 37.45 & 4.1616 & 0.61926033 & - & - & -1.723868535 \\
\hline 165 & 7529026 & 698775 & 583 & 48.7 & 85.7 & 10.5 & 1.0211893 & - & - & -1.259520003 \\
\hline 166 & 7530390 & 703390 & 540 & 15.18 & 38.25 & 3.36 & 0.52633928 & - & - & -1.831220233 \\
\hline 167 & 7532808 & 699517 & 585 & 17 & 25 & 8.208 & 0.91423735 & - & - & -1.383081592 \\
\hline 168 & 7531369 & 706046 & 530 & 10 & 42 & 7.5672 & 0.87893521 & - & - & -1.423866149 \\
\hline 169 & 7525430 & 702329 & 601 & 18 & 37 & 2.20488 & 0.34338496 & - & - & -2.042587358 \\
\hline 170 & 7528500 & 699750 & 560 & 41 & 54 & 2.0568 & 0.31319206 & - & - & -2.077469209 \\
\hline 171 & 7532310 & 695891 & 499 & 38.1 & 52.25 & 8.568 & 0.93287946 & - & - & -1.361544362 \\
\hline 172 & 7531920 & 704490 & 564 & 11 & 44.6 & 1.344 & 0.12839927 & - & - & -2.290960325 \\
\hline 173 & 7545540 & 684350 & 600 & 43.2 & 82.05 & 4.392 & 0.64266233 & - & - & -1.696832208 \\
\hline 174 & 7540870 & 689540 & 548 & 48.6 & 71 & 2.664 & 0.42553422 & - & - & -1.947680315 \\
\hline 175 & 7542330 & 689340 & 587 & 25 & 44 & 17.592 & 1.24531522 & - & - & -1.000587331 \\
\hline 176 & 7542390 & 689410 & 537 & 44.7 & 58.67 & 20.712 & 1.31622204 & - & - & -0.91866868 \\
\hline 177 & 7542310 & 689570 & 563 & 52.64 & 70.25 & 3.6 & 0.5563025 & - & - & -1.796603721 \\
\hline 178 & 7542060 & 693070 & 540 & 23 & 36 & 19.68 & 1.29402509 & - & - & -0.944312809 \\
\hline 179 & 7549350 & 685210 & 534 & 32.25 & 78.07 & 2.112 & 0.32469391 & - & - & -2.064181121 \\
\hline 180 & 7529100 & 675700 & 545 & 42 & 95.75 & 439.2 & 2.64266233 & - & - & 0.613767792 \\
\hline
\end{tabular}


Continuação

\begin{tabular}{|c|c|c|c|c|c|c|c|c|c|c|}
\hline ID & $\mathbf{X}$ & $\mathbf{Y}$ & $\begin{array}{c}\mathbf{Z} \\
(\mathbf{m})\end{array}$ & $\begin{array}{c}\text { N.E. } \\
(\mathbf{m})\end{array}$ & $\begin{array}{c}\mathbf{N} . \mathbf{D} . \\
(\mathbf{m})\end{array}$ & $\begin{array}{c}\mathbf{Q} / \mathbf{s} \\
\left(\mathbf{m}^{2} / \mathbf{d}\right)\end{array}$ & $\begin{array}{c}\text { log Q/s } \\
\left(\mathbf{m}^{\mathbf{2} / \mathbf{d})}\right.\end{array}$ & $\begin{array}{c}\mathbf{K} \\
(\mathbf{m} / \mathbf{d})\end{array}$ & $\begin{array}{c}\text { log K} \\
(\mathbf{m} / \mathbf{d})\end{array}$ & $\begin{array}{c}\text { log K (m/d) calculado } \\
\text { por regressão linear }\end{array}$ \\
\hline 181 & 7529350 & 700750 & 566 & 34 & 76 & 148.8 & 2.17260293 & - & - & 0.070708166 \\
\hline 182 & 7528780 & 696920 & 571 & 29 & 108 & 272.64 & 2.43558957 & - & - & 0.374536634 \\
\hline 183 & 7524830 & 702020 & 589 & 22 & 71 & 9.888 & 0.99510846 & - & - & -1.289651199 \\
\hline 184 & 7531210 & 704000 & 583 & 21 & 39 & 2.88 & 0.45939249 & - & - & -1.908563859 \\
\hline 185 & 7534760 & 696550 & 586 & 39.5 & 63.5 & 3.768 & 0.57611089 & - & - & -1.773719084 \\
\hline 186 & 7534750 & 696590 & 613 & 36.5 & 90 & 2.16 & 0.33445375 & - & - & -2.052905581 \\
\hline 187 & 7528750 & 700050 & - & 10 & 22 & 1.944 & 0.28869626 & - & - & -2.10576921 \\
\hline 188 & 7531750 & 704670 & 540 & 51.8 & 74.7 & 0.624 & -0.2048154 & - & - & -2.675923244 \\
\hline 189 & 7527890 & 699890 & 620 & 23.5 & 46 & 4.176 & 0.62076049 & - & - & -1.722135406 \\
\hline 190 & 7533200 & 684770 & - & 48 & 97 & 4.416 & 0.64502906 & - & - & -1.694097922 \\
\hline 191 & 7531460 & 686240 & 499 & 23 & 46 & 7.368 & 0.86734962 & - & - & -1.437250987 \\
\hline 192 & 7530320 & 686840 & 542.4 & 58 & 72 & 48 & 1.68124124 & - & - & -0.496961998 \\
\hline 193 & 7530420 & 702370 & 578 & 59 & 74.61 & 9.552 & 0.98009431 & - & - & -1.306997039 \\
\hline 194 & 7531010 & 693920 & 600 & 104 & 112.21 & 0.912 & -0.0400052 & - & - & -2.485517963 \\
\hline 195 & 7532030 & 694140 & 585 & 131.72 & 143.66 & 3.6 & 0.5563025 & - & - & -1.796603721 \\
\hline 196 & 7526370 & 702430 & 530 & 52 & 68 & 8.712 & 0.94011787 & - & - & -1.353181829 \\
\hline 197 & 7528850 & 702900 & 560 & 45 & 119.47 & 5.4 & 0.73239376 & - & - & -1.593165489 \\
\hline 198 & 7531030 & 698770 & 561 & 18.3 & 31 & 3.768 & 0.57611089 & - & - & -1.773719084 \\
\hline 199 & 7531060 & 699070 & 652 & 18 & 40 & 3.216 & 0.50731604 & - & - & -1.853197779 \\
\hline 200 & 7527940 & 700690 & - & 43.5 & 80.17 & 1.536 & 0.18639122 & - & - & -2.223962229 \\
\hline
\end{tabular}


Continuação

\begin{tabular}{|c|c|c|c|c|c|c|c|c|c|c|}
\hline ID & $\mathrm{x}$ & $Y$ & $\begin{array}{c}Z \\
(m)\end{array}$ & $\begin{array}{l}\text { N.E. } \\
\text { (m) }\end{array}$ & $\begin{array}{l}\text { N.D. } \\
\text { (m) }\end{array}$ & $\begin{array}{c}Q / s \\
\left(m^{2} / d\right)\end{array}$ & $\begin{array}{l}\log Q / s \\
\left(\mathrm{~m}^{2} / \mathrm{d}\right)\end{array}$ & $\begin{array}{c}K \\
(m / d)\end{array}$ & $\begin{array}{l}\log K \\
(\mathrm{~m} / \mathrm{d})\end{array}$ & $\begin{array}{l}\log K(m / d) \text { calculado } \\
\text { por regressão linear }\end{array}$ \\
\hline 201 & 7526050 & 701260 & 580 & 12.1 & 34.35 & 2.472 & 0.39304847 & - & - & -1.985211107 \\
\hline 202 & 7529860 & 699650 & 592 & 16.5 & 44 & 12.936 & 1.11180001 & - & - & -1.154837452 \\
\hline 203 & 7528800 & 700490 & 565 & 11.6 & 27.82 & 12.696 & 1.10366691 & - & - & -1.164233615 \\
\hline 204 & 7526200 & 695700 & 523 & 15.5 & 28.5 & 3.192 & 0.50406288 & - & - & -1.856956152 \\
\hline 205 & 7526250 & 702130 & 562 & 54.8 & 70 & 4.272 & 0.63063124 & - & - & -1.710731724 \\
\hline 206 & 7530030 & 698390 & 585 & 35.66 & 43.18 & 4.728 & 0.67467747 & - & - & -1.659845121 \\
\hline 207 & 7528670 & 702980 & 550 & 44.8 & 84 & 4.728 & 0.67467747 & - & - & -1.659845121 \\
\hline 208 & 7531790 & 699960 & 524 & 12 & 16 & 0.624 & -0.2048154 & - & - & -2.675923244 \\
\hline 209 & 7531900 & 699810 & 570 & 76 & 98 & 11.28 & 1.0523091 & - & - & -1.223567297 \\
\hline 210 & 7531250 & 702780 & 531 & 11 & 21 & 1.92 & 0.28330123 & - & - & -2.11200209 \\
\hline 211 & 7531280 & 703030 & 524 & 21 & 40 & 3.192 & 0.50406288 & - & - & -1.856956152 \\
\hline 212 & 7427640 & 701370 & 587 & 33.88 & 38.67 & 2.688 & 0.42942926 & - & - & -1.943180371 \\
\hline 213 & 7530500 & 704950 & 530.5 & 6.21 & 28.5 & 24 & 1.38021124 & - & - & -0.844741952 \\
\hline 214 & 7528680 & 700210 & 580 & 16.5 & 86.2 & 14.4 & 1.15836249 & - & - & -1.101043813 \\
\hline 215 & 7528550 & 699030 & 580 & 30.18 & 49.55 & 2.64 & 0.42160393 & - & - & -1.952220983 \\
\hline 216 & 7529400 & 696970 & 466.1 & 3.98 & 11.4 & 2.568 & 0.40959502 & - & - & -1.966094874 \\
\hline 217 & 7532010 & 704550 & 575 & 18 & 26 & 3.144 & 0.49748254 & - & - & -1.864558425 \\
\hline 218 & 7525220 & 694250 & 545 & 62 & 122 & 2.4 & 0.38021124 & - & - & -2.000041952 \\
\hline 219 & 7529360 & 700040 & 560 & 18.17 & 30.5 & 1.08 & 0.03342376 & - & - & -2.400685535 \\
\hline 220 & 7529370 & 699040 & - & 12 & 31 & 0.576 & -0.2395775 & - & - & -2.716083905 \\
\hline
\end{tabular}


Continuação

\begin{tabular}{|c|c|c|c|c|c|c|c|c|c|c|}
\hline ID & $\mathbf{X}$ & $\mathbf{Y}$ & $\begin{array}{c}\mathbf{Z} \\
(\mathbf{m})\end{array}$ & $\begin{array}{c}\text { N.E. } \\
(\mathbf{m})\end{array}$ & $\begin{array}{c}\mathbf{N} . \mathbf{D} . \\
(\mathbf{m})\end{array}$ & $\begin{array}{c}\mathbf{Q} / \mathbf{s} \\
\left(\mathbf{m}^{2} / \mathbf{d}\right)\end{array}$ & $\begin{array}{c}\text { log Q/s } \\
\left(\mathbf{m}^{\mathbf{2} / \mathbf{d})}\right.\end{array}$ & $\begin{array}{c}\mathbf{K} \\
(\mathbf{m} / \mathbf{d})\end{array}$ & $\begin{array}{c}\text { log K} \\
(\mathbf{m} / \mathbf{d})\end{array}$ & $\begin{array}{c}\text { log K (m/d) calculado } \\
\text { por regressão linear }\end{array}$ \\
\hline 221 & 7530170 & 699100 & - & 10.5 & 27.5 & 6 & 0.77815125 & - & - & -1.54030186 \\
\hline 222 & 7529760 & 696310 & - & 29.5 & 90.1 & 4.248 & 0.62818451 & - & - & -1.713558438 \\
\hline 223 & 7529390 & 693840 & - & 35 & 45 & 4.176 & 0.62076049 & - & - & -1.722135406 \\
\hline 224 & 7525710 & 700050 & - & 16.6 & 66.5 & 2.64 & 0.42160393 & - & - & -1.952220983 \\
\hline 225 & 7526410 & 702480 & - & 42 & 72 & 10.488 & 1.02069268 & - & - & -1.260093748 \\
\hline 226 & 7530620 & 698370 & - & 25 & 60.45 & 2.88 & 0.45939249 & - & - & -1.908563859 \\
\hline 227 & 7531290 & 702510 & - & 68 & 75 & 1.032 & 0.0136797 & - & - & -2.423495846 \\
\hline 228 & 7532700 & 695590 & - & 22 & 28 & 2.88 & 0.45939249 & - & - & -1.908563859 \\
\hline 229 & 7529930 & 698830 & - & 35.22 & 71.5 & 8.448 & 0.92675391 & - & - & -1.368621213 \\
\hline 230 & 7529890 & 705190 & - & 16 & 30 & 12.264 & 1.08863214 & - & - & -1.181603287 \\
\hline 231 & 7534610 & 697190 & - & 23 & 56 & 8.088 & 0.90784114 & - & - & -1.390471128 \\
\hline 232 & 7530970 & 700040 & - & 21 & 36 & 6 & 0.77815125 & - & - & -1.54030186 \\
\hline 233 & 7524890 & 696140 & - & 18 & 40 & 1.944 & 0.28869626 & - & - & -2.10576921 \\
\hline 234 & 7528390 & 701390 & - & 49 & 90 & 1.2 & 0.07918125 & - & - & -2.347821906 \\
\hline 235 & 7534590 & 697200 & - & 20 & 48 & 0.696 & -0.1573908 & - & - & -2.621133545 \\
\hline 236 & 7530440 & 698920 & - & 12.5 & 17 & 2.52 & 0.40140054 & - & - & -1.975561955 \\
\hline 237 & 7528410 & 702500 & - & 37 & 80 & 11.016 & 1.04202393 & - & - & -1.235449757 \\
\hline 238 & 7525270 & 702640 & - & 23.43 & 30.62 & 4.8 & 0.68124124 & - & - & -1.652261998 \\
\hline 239 & 7532800 & 699510 & - & 17 & 25 & 27.984 & 1.44690979 & - & - & -0.767685117 \\
\hline 240 & 7532340 & 695520 & - & 42.38 & 57.65 & 4.968 & 0.69618159 & - & - & -1.635001412 \\
\hline
\end{tabular}


Continuação

\begin{tabular}{|c|c|c|c|c|c|c|c|c|c|c|}
\hline ID & $\mathbf{X}$ & $\mathbf{Y}$ & $\begin{array}{c}\mathbf{Z} \\
(\mathbf{m})\end{array}$ & $\begin{array}{c}\text { N.E. } \\
(\mathbf{m})\end{array}$ & $\begin{array}{c}\mathbf{N} . \mathbf{D} . \\
(\mathbf{m})\end{array}$ & $\begin{array}{c}\mathbf{Q} / \mathbf{s} \\
\left(\mathbf{m}^{2} / \mathbf{d}\right)\end{array}$ & $\begin{array}{c}\text { log Q/s } \\
\left(\mathbf{m}^{\mathbf{2} / \mathbf{d})}\right.\end{array}$ & $\begin{array}{c}\mathbf{K} \\
(\mathbf{m} / \mathbf{d})\end{array}$ & $\begin{array}{c}\text { log K} \\
(\mathbf{m} / \mathbf{d})\end{array}$ & $\begin{array}{c}\text { log K (m/d) calculado } \\
\text { por regressão linear }\end{array}$ \\
\hline 241 & 7534850 & 700290 & - & 18 & 41 & 2.352 & 0.37143732 & - & - & -2.010178467 \\
\hline 242 & 7532160 & 693430 & - & 21.5 & 38.1 & 2.376 & 0.37584644 & - & - & -2.005084612 \\
\hline 243 & 7526990 & 701520 & - & 23 & 40 & 39.984 & 1.60188624 & - & - & -0.588640828 \\
\hline 244 & 7531720 & 704000 & - & 14.35 & 23.15 & 133.32 & 2.1248953 & - & - & 0.015591546 \\
\hline 245 & 7531970 & 700730 & - & 21.2 & 29.5 & 17.736 & 1.24885568 & - & - & -0.996497033 \\
\hline 246 & 7529490 & 699190 & - & 21 & 38 & 1.44 & 0.15836249 & - & - & -2.256343813 \\
\hline 247 & 7531080 & 698540 & - & 35.87 & 85.1 & 1.944 & 0.28869626 & - & - & -2.10576921 \\
\hline 248 & 7534390 & 699070 & - & 11.33 & 21.3 & 4.752 & 0.67687643 & - & - & -1.657304658 \\
\hline 249 & 7523460 & 698530 & - & 4.35 & 21.35 & 3.6 & 0.5563025 & - & - & -1.796603721 \\
\hline 250 & 7526250 & 696540 & - & 26.1 & 45 & 1.176 & 0.07040732 & - & - & -2.357958421 \\
\hline 251 & 7528540 & 701150 & - & 41.5 & 46.29 & 6.384 & 0.80509288 & - & - & -1.509176198 \\
\hline 252 & 7526900 & 701540 & - & 29.15 & 54.1 & 5.64 & 0.7512791 & - & - & -1.571347251 \\
\hline 253 & 7525840 & 695610 & - & 55.6 & 61.6 & 4.8 & 0.68124124 & - & - & -1.652261998 \\
\hline 254 & 7535090 & 699400 & - & 22 & 35 & 0.84 & -0.0757207 & - & - & -2.526780141 \\
\hline 255 & 7525880 & 700900 & - & 0 & 0 & 1.32 & 0.12057393 & - & - & -2.300000937 \\
\hline 256 & 7524880 & 696300 & - & 24.1 & 44.3 & 2.112 & 0.32469391 & - & - & -2.064181121 \\
\hline 257 & 7529610 & 698800 & - & 117.6 & 122.1 & 23.808 & 1.37672291 & - & - & -0.848772018 \\
\hline 258 & 7529090 & 699600 & - & 11.58 & 12.48 & 6 & 0.77815125 & - & - & -1.54030186 \\
\hline 259 & 7529770 & 703310 & - & 20.62 & 27.58 & 0.936 & -0.0287242 & - & - & -2.472485012 \\
\hline 260 & 7529540 & 701420 & - & 12.5 & 37.45 & 3.6 & 0.5563025 & - & - & -1.796603721 \\
\hline
\end{tabular}


Continuação

\begin{tabular}{|c|c|c|c|c|c|c|c|c|c|c|}
\hline ID & $\mathbf{X}$ & $\mathbf{Y}$ & $\begin{array}{c}\mathbf{Z} \\
(\mathbf{m})\end{array}$ & $\begin{array}{c}\text { N.E. } \\
(\mathbf{m})\end{array}$ & $\begin{array}{c}\mathbf{N} . \mathbf{D} . \\
(\mathbf{m})\end{array}$ & $\begin{array}{c}\mathbf{Q} / \mathbf{s} \\
\left(\mathbf{m}^{2} / \mathbf{d}\right)\end{array}$ & $\begin{array}{c}\text { log Q/s } \\
\left(\mathbf{m}^{\mathbf{2} / \mathbf{d})}\right.\end{array}$ & $\begin{array}{c}\mathbf{K} \\
(\mathbf{m} / \mathbf{d})\end{array}$ & $\begin{array}{c}\text { log K} \\
(\mathbf{m} / \mathbf{d})\end{array}$ & $\begin{array}{c}\text { log K (m/d) calculado } \\
\text { por regressão linear }\end{array}$ \\
\hline 261 & 7529770 & 696030 & - & 18.2 & 30.5 & 4.944 & 0.69407846 & - & - & -1.637431153 \\
\hline 262 & 7525920 & 701990 & - & 40.11 & 55.23 & 7.392 & 0.86876196 & - & - & -1.43561931 \\
\hline 263 & 7533750 & 698330 & - & 27.26 & 42.51 & 23.568 & 1.37232273 & - & - & -0.853855551 \\
\hline 264 & 7523730 & 703050 & - & 35 & 86 & 3.768 & 0.57611089 & - & - & -1.773719084 \\
\hline 265 & 7525850 & 701280 & - & 21 & 36 & 1.128 & 0.0523091 & - & - & -2.378867297 \\
\hline 266 & 7525360 & 702360 & - & 20 & 54 & 9 & 0.95424251 & - & - & -1.336863629 \\
\hline 267 & 7527870 & 700670 & - & 45 & 60 & 7.992 & 0.90265548 & - & - & -1.396462129 \\
\hline 268 & 7531420 & 699660 & - & 10 & 38.2 & 3.984 & 0.60031933 & - & - & -1.745751078 \\
\hline 269 & 7528960 & 699340 & - & 18 & 36 & 12.792 & 1.10693845 & - & - & -1.160454008 \\
\hline 270 & 7532590 & 697210 & - & 12.1 & 34.68 & 2.04 & 0.30963017 & - & - & -2.081584268 \\
\hline 271 & 7525130 & 696160 & - & 30.12 & 34.38 & 4.968 & 0.69618159 & - & - & -1.635001412 \\
\hline 272 & 7528350 & 696530 & - & 16.52 & 24.65 & 6.48 & 0.81157501 & - & - & -1.501687396 \\
\hline 273 & 7528240 & 699500 & - & 23 & 48.2 & 0.984 & -0.0070049 & - & - & -2.447392763 \\
\hline 274 & 7528270 & 699420 & - & 51 & 62 & 6.504 & 0.81318053 & - & - & -1.499832531 \\
\hline 275 & 7523530 & 703050 & - & 32.1 & 66 & 4.896 & 0.68984141 & - & - & -1.64232622 \\
\hline 276 & 7525430 & 702320 & - & 18.05 & 39.1 & 3.144 & 0.49748254 & - & - & -1.864558425 \\
\hline 277 & 7526160 & 702060 & - & 32 & 57.45 & 4.8 & 0.68124124 & - & - & -1.652261998 \\
\hline 278 & 7534280 & 699080 & - & 38 & 63.1 & 1.944 & 0.28869626 & - & - & -2.10576921 \\
\hline 279 & 7530540 & 700320 & - & 30 & 51.25 & 1.776 & 0.24944296 & - & - & -2.151118547 \\
\hline 280 & 7527110 & 696260 & - & 34 & 58 & 0.456 & -0.3410352 & - & - & -2.833297917 \\
\hline
\end{tabular}


Continuação

\begin{tabular}{|c|c|c|c|c|c|c|c|c|c|c|}
\hline ID & $\mathbf{X}$ & $\mathbf{Y}$ & $\begin{array}{c}\mathbf{Z} \\
(\mathbf{m})\end{array}$ & $\begin{array}{c}\text { N.E. } \\
(\mathbf{m})\end{array}$ & $\begin{array}{c}\mathbf{N} . \mathbf{D} . \\
(\mathbf{m})\end{array}$ & $\begin{array}{c}\mathbf{Q} / \mathbf{s} \\
\left(\mathbf{m}^{2} / \mathbf{d}\right)\end{array}$ & $\begin{array}{c}\text { log Q/s } \\
\left(\mathbf{m}^{\mathbf{2} / \mathbf{d})}\right.\end{array}$ & $\begin{array}{c}\mathbf{K} \\
(\mathbf{m} / \mathbf{d})\end{array}$ & $\begin{array}{c}\text { log K} \\
(\mathbf{m} / \mathbf{d})\end{array}$ & $\begin{array}{c}\text { log K (m/d) calculado } \\
\text { por regressão linear }\end{array}$ \\
\hline 281 & 7528620 & 696390 & - & 13 & 22 & 15.888 & 1.20106923 & - & - & -1.051704717 \\
\hline 282 & 7528670 & 700170 & - & 22.5 & 65.3 & 2.904 & 0.46299661 & - & - & -1.904400014 \\
\hline 283 & 7522670 & 697830 & - & 25 & 16 & 12.096 & 1.08264178 & - & - & -1.188523954 \\
\hline 284 & 7531780 & 699560 & - & 36.15 & 56.1 & 3.504 & 0.5445641 & - & - & -1.810165098 \\
\hline 285 & 7530410 & 700040 & - & 15 & 28 & 6.384 & 0.80509288 & - & - & -1.509176198 \\
\hline 286 & 7532470 & 702480 & - & 14 & 29.5 & 12.984 & 1.11340851 & - & - & -1.152979152 \\
\hline 287 & 7523650 & 703440 & - & 16.3 & 46.5 & 6.312 & 0.80016699 & - & - & -1.514867076 \\
\hline 288 & 7527570 & 701480 & - & 24.45 & 51 & 3 & 0.47712125 & - & - & -1.888081814 \\
\hline 289 & 7531500 & 704350 & - & 23.51 & 42.1 & 4.872 & 0.68770728 & - & - & -1.64479178 \\
\hline 290 & 7534440 & 699160 & - & 30 & 68 & 28.8 & 1.45939249 & - & - & -0.753263859 \\
\hline 291 & 7526260 & 695980 & - & 16.29 & 40.51 & 8.832 & 0.94605906 & - & - & -1.346317968 \\
\hline 292 & 7529020 & 698770 & - & 48.7 & 85.7 & 8.832 & 0.94605906 & - & - & -1.346317968 \\
\hline 293 & 7529470 & 698040 & - & 40.1 & 80.16 & 13.704 & 1.13684735 & - & - & -1.125900257 \\
\hline 294 & 7530200 & 701150 & - & 32.75 & 66.2 & 3.192 & 0.50406288 & - & - & -1.856956152 \\
\hline 295 & 7530380 & 702800 & - & 28.5 & 51.15 & 1.488 & 0.17260293 & - & - & -2.239891834 \\
\hline 296 & 7530130 & 698110 & - & 36.85 & 76.28 & 5.448 & 0.7362371 & - & - & -1.58872528 \\
\hline 297 & 7532750 & 698250 & - & 34.32 & 42.64 & 4.656 & 0.66801297 & - & - & -1.667544614 \\
\hline 298 & 7529650 & 700060 & - & 19 & 38 & 2.184 & 0.33925263 & - & - & -2.047361432 \\
\hline 299 & 7530860 & 701560 & - & 21 & 39 & 1.584 & 0.19975518 & - & - & -2.208522844 \\
\hline 300 & 7428430 & 698820 & - & 38.15 & 115 & 19.92 & 1.29928933 & - & - & -0.938231032 \\
\hline
\end{tabular}


Continuação

\begin{tabular}{|c|c|c|c|c|c|c|c|c|c|c|}
\hline ID & $\mathbf{X}$ & $\mathbf{Y}$ & $\begin{array}{c}\mathbf{Z} \\
(\mathbf{m})\end{array}$ & $\begin{array}{c}\text { N.E. } \\
(\mathbf{m})\end{array}$ & $\begin{array}{c}\mathbf{N} . \mathbf{D} . \\
(\mathbf{m})\end{array}$ & $\begin{array}{c}\mathbf{Q} / \mathbf{s} \\
\left(\mathbf{m}^{2} / \mathbf{d}\right)\end{array}$ & $\begin{array}{c}\text { log Q/s } \\
\left(\mathbf{m}^{\mathbf{2} / \mathbf{d})}\right.\end{array}$ & $\begin{array}{c}\mathbf{K} \\
(\mathbf{m} / \mathbf{d})\end{array}$ & $\begin{array}{c}\text { log K} \\
(\mathbf{m} / \mathbf{d})\end{array}$ & $\begin{array}{c}\text { log K (m/d) calculado } \\
\text { por regressão linear }\end{array}$ \\
\hline 301 & 7527980 & 700650 & - & 40.25 & 49.67 & 3.888 & 0.58972626 & - & - & -1.757989256 \\
\hline 302 & 7533580 & 698350 & - & 45.6 & 55.1 & 1.584 & 0.19975518 & - & - & -2.208522844 \\
\hline 303 & 7523310 & 703570 & - & 56 & 92 & 6.744 & 0.82891756 & - & - & -1.481651541 \\
\hline 304 & 7531980 & 693390 & - & 17.42 & 32.68 & 5.808 & 0.76402661 & - & - & -1.55662006 \\
\hline 305 & 7530260 & 696790 & - & 4 & 6.5 & 4.896 & 0.68984141 & - & - & -1.64232622 \\
\hline 306 & 7526560 & 701020 & - & 20 & 29.5 & 1.44 & 0.15836249 & - & - & -2.256343813 \\
\hline 307 & 7531140 & 703520 & - & 19.5 & 30 & 95.28 & 1.97900175 & - & - & -0.15295928 \\
\hline 308 & 7533720 & 695280 & - & 41.35 & 59.26 & 12.096 & 1.08264178 & - & - & -1.188523954 \\
\hline 309 & 7531380 & 703370 & - & 28.12 & 43.1 & 87.648 & 1.94274201 & - & - & -0.194850155 \\
\hline 310 & 7530390 & 703360 & - & 28.44 & 44.56 & 2.64 & 0.42160393 & - & - & -1.952220983 \\
\hline 311 & 7527290 & 700780 & - & 48.4 & 62.46 & 0.6 & -0.2218487 & - & - & -2.69560186 \\
\hline 312 & 7533190 & 699120 & - & 34.4 & 37.75 & 4.272 & 0.63063124 & - & - & -1.710731724 \\
\hline 313 & 7532310 & 695890 & - & 38.1 & 52.25 & 1.224 & 0.08778142 & - & - & -2.337886128 \\
\hline 314 & 7530210 & 696230 & - & 26.6 & 50.7 & 15 & 1.17609126 & - & - & -1.080561768 \\
\hline 315 & 7530230 & 696270 & - & 26.3 & 50.15 & 2.88 & 0.45939249 & - & - & -1.908563859 \\
\hline 316 & 7525100 & 701970 & - & 25.1 & 85.56 & 14.64 & 1.16554108 & - & - & -1.092750394 \\
\hline 317 & 7524990 & 702450 & - & 44.18 & 86.59 & 7.632 & 0.88263836 & - & - & -1.419587901 \\
\hline 318 & 7523500 & 697550 & - & 32.8 & 54.1 & 12.624 & 1.10119699 & - & - & -1.167087122 \\
\hline 319 & 7530600 & 699990 & - & 25.1 & 39.51 & 6.288 & 0.79851253 & - & - & -1.516778471 \\
\hline 320 & 7531670 & 704000 & - & 17.56 & 29.8 & 1.896 & 0.27783833 & - & - & -2.118313374 \\
\hline
\end{tabular}


Continuação

\begin{tabular}{|c|c|c|c|c|c|c|c|c|c|c|}
\hline ID & $x$ & $\mathbf{Y}$ & $\begin{array}{c}Z \\
(m)\end{array}$ & $\begin{array}{l}\text { N.E. } \\
(\mathrm{m})\end{array}$ & $\begin{array}{l}\text { N.D. } \\
(\mathrm{m})\end{array}$ & $\begin{array}{c}Q / s \\
\left(m^{2} / d\right)\end{array}$ & $\begin{array}{l}\log Q / s \\
\left(\mathrm{~m}^{2} / \mathrm{d}\right) \\
\end{array}$ & $\begin{array}{c}K \\
(\mathrm{~m} / \mathrm{d}) \\
\end{array}$ & $\begin{array}{l}\log K \\
(\mathrm{~m} / \mathrm{d})\end{array}$ & $\begin{array}{l}\log K(\mathrm{~m} / \mathrm{d}) \text { calculado } \\
\text { por regressão linear }\end{array}$ \\
\hline 321 & 7531040 & 697360 & - & 23 & 34.5 & 10.992 & 1.04107672 & - & - & -1.236544066 \\
\hline 322 & 7531610 & 703650 & - & 88.3 & 91.32 & 2.424 & 0.38453262 & - & - & -1.995049469 \\
\hline 323 & 7528770 & 700540 & - & 20.84 & 29.76 & 2.088 & 0.31973049 & - & - & -2.06991536 \\
\hline 324 & 7526970 & 696040 & - & 37 & 38.15 & 3.864 & 0.58703712 & - & - & -1.761096018 \\
\hline 325 & 7535590 & 699580 & - & 27.8 & 64.1 & 8.568 & 0.93287946 & - & - & -1.361544362 \\
\hline 326 & 7528580 & 695490 & - & 18.4 & 38.07 & 2.04 & 0.30963017 & - & - & -2.081584268 \\
\hline 327 & 7530160 & 696590 & - & 22 & 41 & 4.464 & 0.64972419 & - & - & -1.688673648 \\
\hline 328 & 7530540 & 700000 & - & 21.07 & 44.23 & 1.344 & 0.12839927 & - & - & -2.290960325 \\
\hline 329 & 7536090 & 699720 & - & 45.5 & 63.08 & 5.76 & 0.76042248 & - & - & -1.560783905 \\
\hline 330 & 7533930 & 695800 & - & 42.11 & 85 & 2.664 & 0.42553422 & - & - & -1.947680315 \\
\hline 331 & 7526260 & 695970 & - & 62.27 & 88.49 & 3.072 & 0.48742121 & - & - & -1.876182275 \\
\hline 332 & 7529450 & 699780 & - & 18.45 & 25.36 & 6.624 & 0.82112032 & - & - & -1.49065969 \\
\hline 333 & 7531540 & 699540 & - & 25.8 & 29.6 & 5.04 & 0.70243054 & - & - & -1.627782001 \\
\hline 334 & 7532860 & 698850 & - & 25.1 & 51.8 & 28.08 & 1.4483971 & - & - & -0.765966826 \\
\hline 335 & 7525050 & 703470 & - & 27.7 & 78.53 & 0.096 & -1.0177288 & - & - & -3.615082044 \\
\hline 336 & 7529720 & 701140 & - & 33.12 & 48.39 & 3.36 & 0.52633928 & - & - & -1.831220233 \\
\hline 337 & 7528010 & 696370 & - & 37.33 & 81.5 & 6.84 & 0.8350561 & - & - & -1.474559686 \\
\hline 338 & 7530290 & 699130 & - & 8.6 & 25.79 & 14.616 & 1.16482853 & - & - & -1.093573594 \\
\hline 339 & 7529660 & 700070 & - & 20 & 38.6 & 10.008 & 1.0003473 & - & - & -1.283598768 \\
\hline 340 & 7528350 & 697670 & - & 30 & 76 & 3.984 & 0.60031933 & - & - & -1.745751078 \\
\hline 341 & 7533810 & 698060 & - & 28.07 & 51.57 & 3.888 & 0.58972626 & - & - & -1.757989256 \\
\hline 342 & 7530360 & 696760 & - & 5.1 & 15.8 & 38.088 & 1.58078817 & - & - & -0.613015429 \\
\hline 343 & 7529690 & 698960 & - & 31 & 76 & 7.392 & 0.86876196 & - & - & -1.43561931 \\
\hline
\end{tabular}


